CARLA IVONNE LA FUENTE ARIAS

EFEITO COMBINADO DO ULTRASSOM E DO PULSO DE VÁCUO SOBRE A CINÉTICA DE SECAGEM DA BANANA VERDE (Musa cavendishii) 

CARLA IVONNE LA FUENTE ARIAS

\section{EFEITO COMBINADO DO ULTRASSOM E DO PULSO DE VÁCUO SOBRE A CINÉTICA DE SECAGEM DA BANANA VERDE (Musa cavendishii)}

Tese apresentada à Escola Politécnica da Universidade de São Paulo para obtenção do título de Doutor em Ciências.

São Paulo 

CARLA IVONNE LA FUENTE ARIAS

\section{EFEITO COMBINADO DO ULTRASSOM E DO PULSO DE VÁCUO SOBRE A CINÉTICA DE SECAGEM DA BANANA VERDE (Musa cavendishii)}

Tese apresentada à Escola Politécnica da Universidade de São Paulo para obtenção do título de Doutor em Ciências.

Área de concetração:

Engenharia Química

Orientadora:

Profa. Dra. Carmen Cecilia Tadini

\section{São Paulo}


Este exemplar foi revisado e corrigido em relação à versão original, sob responsabilidade única do autor e com a anuência de seu orientador.

São Paulo, de de

Assinatura do autor:

Assinatura do orientador:

La Fuente Arias, Carla Ivonne

EFEITO COMBINADO DO ULTRASSOM E DO PULSO DE VÁCUO

SOBRE A CINÉTICA DE SECAGEM DA BANANA VERDE (Musa Cavendishii)

/ C. I. La Fuente Arias -- versão corr. -- São Paulo, 2017.

$141 \mathrm{p}$.

Tese (Doutorado) - Escola Politécnica da Universidade de São Paulo. Departamento de Engenharia Química.

1.Secagem 2.Banana verde 3.Ultrassom 4.Pulso de vácuo 5.Amido Resistente I.Universidade de São Paulo. Escola Politécnica. Departamento de Engenharia Química II.t. 



\section{Dedicatória}

Dedico o presente trabalho aos meus pais Ricardo e Lia, por compartilhar comigo o mesmo sonho há muitos anos e por me apoiarem em ir buscá-10, mesmo que isso represente a distância. 



\section{Agradecimentos}

Á professora Carmen pela oportunidade e pela confiança depositada no início, e principalmente pela orientação ao longo de toda esta jornada.

À FAPESP pelo apoio financeiro na adquisição do secador de bandejas através dos processos 2011/22398-0 e 2013/07914-8. À CAPES pela bolsa outorgada. Ao FoRC pelo apoio financeiro para a realização desta pesquisa.

À minha banca de qualificação, professores Pedro de Alcântara Pessoa Filho, Pedro Esteves Duarte Augusto e Antônio Carlos Silva Costa Teixeira pelos comentários e sugestões, que ajudaram na conclusão deste trabalho.

Aos funcionários da LABMAQ, Luciana, Cássio, Fábio e Eduardo pelo suporte constante com o secador.

Ao Alan e toda a equipe de Jaguaré Bananas no CEAGESP pelo fornecimento constante da matéria-prima.

Ao Renato do Laboratório de Tecnologias Aplicadas (LCT) do Departamento de Engenharia de Minas e de Petróleo da Escola Politécnica da USP pela ajuda com as micrografias no microscópio eletrônico de varredura (MEV).

À Bianca, pela ajuda com as análises no Calorímetro Diferencial de Varredura (DSC).

À Aline do Laboratório de Química, Bioquímica e Biologia Molecular de Alimentos do Departamento de Alimentos e Nutrição da Faculdade de Ciências Farmacêuticas da USP pela ajuda na determinação do conteúdo de amido resistente.

Ao professor Jorge, funcionários e amigos do LEA pela força e pelos gratos momentos ao longo deste tempo. Às amizades que ficarão para sempre.

Ao professor Dewton de Moraes Vasconcelos do Instituto de Medicina Tropical da USP por ser meu exemplo a seguir, pelas dicas no trabalho, por ser um ótimo médico e um excelente ser humano.

Aos amigos que São Paulo me deu, que por muito tempo, foram a minha família. Aos meus coleguinhas do boxe pelas longas horas de desestresse.

Aos meus pais, à minha irmã e ao meu cunhado pelo apoio e incentivo constante. Em especial, à minha sobrinha que com sua inocência e doçura foi uma das minhas maiores motivações.

Ao meu colega, amigo, parceiro e esposo Rafael pelo amor, companheirismo, por compartilhar minhas alegrias e por secar minhas lágrimas. Porque o melhor presente que a USP me deu, é a oportunidade de te encontrar na vida.

A Deus pelas bênçãos sempre e sobretudo pela oportunidade de estar aqui cumprindo mais uma meta. 



\section{RESUMO}

Neste trabalho, estudou-se o impacto de dois pré-tratamentos: ultrassom, pulso de vácuo e a combinação de ultrassom seguido de pulso de vácuo, sobre a cinética de secagem da banana verde a (50 e 60) ${ }^{\circ} \mathrm{C}$. Na secagem a $50{ }^{\circ} \mathrm{C}$ constatou-se que, a aplicação de uma única técnica foi mais favorável que a combinação dos pré-tratamentos (20 min de ultrassom, seguido de 60 min de pulso de vácuo), sendo que os melhores resultados foram obtidos com 20 min de ultrassom na potência volumetrica ultrassônica de $(9,38 \pm 0,60) \mathrm{W} / \mathrm{L}$. Os valores da difusividade efetiva da água, da primeira e segunda fases de taxa decrecente foram de $(7,03 \pm$ $0,09$ e $3,84 \pm 0,09) \times 10^{-9} \mathrm{~m}^{2} / \mathrm{s}$ para $(12,10 \pm 0,47$ e $6,84 \pm 0,28) \times 10^{-9} \mathrm{~m}^{2} / \mathrm{s}$, respectivamente, com a aplicação do ultrassom por $20 \mathrm{~min}$. Na secagem a $60{ }^{\circ} \mathrm{C}$, para a primeira fase de taxa decrescente, o pré-tratamento de 25 min de ultrassom resultou mais favorável. Já para a segunda fase de taxa decrescente o pré-tratamento com 25 min de ultrassom e a técnica combinada (25 min de ultrassom, seguido de 60 min de pulso de vácuo) foram os mais eficientes. Desta forma, a hipótese inicial de que micro-canais gerados pelo ultrassom e o gradiente de pressão nos pulsos de vácuo promoveriam maior migração de umidade não foi comprovada. A $60{ }^{\circ} \mathrm{C}$, o aumento dos valores de difusividade efetiva de água, em relação aos ensaios sem prétratamento, foram menores se comparados aos aumentos obtidos nos ensaios a $50{ }^{\circ} \mathrm{C}$. Consequentemente, a $60{ }^{\circ} \mathrm{C}$, o efeito da temperatura prevaleceu, e os efeitos causados pelos pré-tratamentos foram menos evidentes em relação aos ensaios a $50{ }^{\circ} \mathrm{C}$. O modelo de Midilli resultou no melhor modelo para o ajuste dos dados experimentais de secagem com $r^{2} \geq 0,999$, $\mathrm{RMSE} \leq 0,0119$ e $\chi^{2} \leq 0,00012$. O processo aplicando $20 \mathrm{~min}$ de ultrassom na potência volumétrica ultrassônica de $(9,38 \pm 0,60) \mathrm{W} / \mathrm{L}$ e temperatura de secagem de $50{ }^{\circ} \mathrm{C}$ diminuiu 30 min o tempo de secagem. A economia do custo de energia sob essas condição iria de (1,12 para 1,05) $\mathrm{R} \$ / \mathrm{kg}$ de matéria-prima processada. Embora, uma redução da quantidade de energia necessária para a gelatinização foi observada, devido a aplicação do ultrassom por 20 min e secagem a $50{ }^{\circ} \mathrm{C}$, não foi observada redução significativa do teor de amido resistente, assim, a principal característica da farinha de banana verde, por causa de seu efeito positivo sobre a saúde humana, foi preservada. Constatou-se que, aplicação de 20 min de ultrassom $(9,38 \pm$ 0,60) W/L em rodelas imersas em água (hidratadas) ou embaladas a vácuo (não hidratadas) não influenciou significativamente os valores de difusividade efetiva da água, o conteúdo de $A R$, nem a formação dos micro-canais. Os efeitos do ultrassom foram evidentes independentemente do ganho de água, acontecido devido à imersão das rodelas de banana verde em água.

Palavras chaves: secagem, banana verde, ultrassom, pulso de vácuo, amido resistente. 



\begin{abstract}
In this work, the impact of two pre-treatments: ultrasound, pulsed-vacuum and the combination of ultrasound followed by pulsed-vacuum, on the drying kinetics of unripe banana at (50 and 60) ${ }^{\circ} \mathrm{C}$ were studied. For air-drying at $50{ }^{\circ} \mathrm{C}$, the application of a single technique was more favorable for water migration than the combination of pre-treatments (20 min of ultrasound, followed by 60 min of pulsed-vacuum); the best results were observed with ultrasound for 20 min at ultrasonic volumetric power of $(9.38 \pm 0.60) \mathrm{W} / \mathrm{L}$. For this condition, the values of effective water diffusivity for the first and second phases of decreasing rate were $(7.03 \pm 0.09$ and $3.84 \pm 0.09) \times 10^{-9} \mathrm{~m}^{2} / \mathrm{s}$ to $(12.10 \pm 0.47$ and $6.84 \pm 0.28) \times 10^{-9} \mathrm{~m}^{2} / \mathrm{s}$, respectively. At 60 ${ }^{\circ} \mathrm{C}$, for the first phase of decreasing rate, $25 \mathrm{~min}$ of ultrasound resulted more favorable, whereas, for the second phase of decreasing rate, ultrasound for $25 \mathrm{~min}$ and the combined technique (25 min ultrasound, followed by $60 \mathrm{~min}$ pulsed-vacuum) resulted favorable. Thus, the initial hypothesis that micro-channels from ultrasound pre-treatment and pressure gradient from pulsed-vacuum pre-treatment would help moisture migration was not observed. At $60{ }^{\circ} \mathrm{C}$, the increase of the values of effective water diffusivity were lower than those obtained at $50{ }^{\circ} \mathrm{C}$. Consequently, at $60{ }^{\circ} \mathrm{C}$, the effect of temperature prevailed, and the effects caused by pretreatments were less evident with respect to the assays at $50{ }^{\circ} \mathrm{C}$. The Midilli model was the best model for adjusting the experimental drying data with $r^{2} \geq 0.999$, RMSE $\leq 0.0119$ and $\chi^{2} \leq 0.00012$.
\end{abstract}

The process applying 20 min of ultrasound at ultrasonic volumetric power of $(9.38 \pm 0.60) \mathrm{W} / \mathrm{L}$ and air-drying at $50{ }^{\circ} \mathrm{C}$ saved $30 \mathrm{~min}$ of air-drying time. The economy of energy cost under these conditions would represent a value from (1.12 to 1.05$) \mathrm{R} \$ / \mathrm{kg}$ of processed raw material.

Although a reduction in the amount of energy required for gelatinization was observed due to the application of ultrasound for $20 \mathrm{~min}$ and air-drying temperature at $50{ }^{\circ} \mathrm{C}$, no significant reduction of resistant starch content was observed; thus, the main characteristic of unripe banana flour, because of its positive effect on human health, was preserved. It was verified that the application of $20 \mathrm{~min}$ of ultrasound $(9.38 \pm 0.60) \mathrm{W} / \mathrm{L}$ in unripe banana slices, immersed in water (hydrated) or vacuum-packed (non-hydrated), did not influence significantly the values of effective water diffusivity, resistant starch content and the formation of micro-channels. The effects of ultrasound were evident independent of water gain, which occurs due to the immersion of unripe banana slices into water.

Keywords: air-drying, unripe banana, ultrasound, pulsed-vacuum, resistant starch. 



\section{LISTA DE FIGURAS}

Figura 3.1 - Produção brasileira de banana por região geográfica em 2013 ........................... 28

Figura 3.2 - Evolução da coloração da casca da banana ........................................................ 30

Figura 3.3 - Grânulos de amido de banana Nanica verde ........................................................ 31

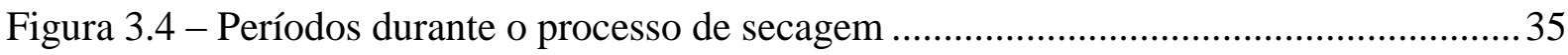

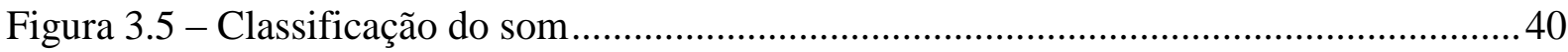

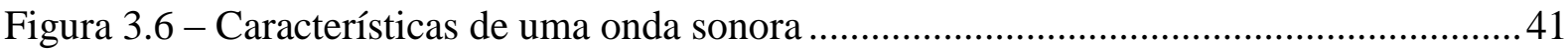

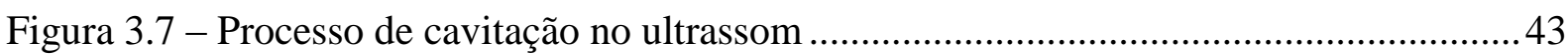

Figura 4.1 - Procedimento para determinação da firmeza na banana in natura ......................50

Figura 4.2 - Preparo do banho para determinação da potência volumétrica ultrassônica (W/L)

Figura 4.3 - Descrição gráfica da amostragem durante a aplicação de pulsos de vácuo em rodelas de banana verde. 54

Figura 4.4 - Sistema de aquisição de imagens composto por um estereomicroscópio (LEICA, modelo S6D, Alemanha) acoplado a uma câmara digital (LEICA, modelo MC 170 HD,

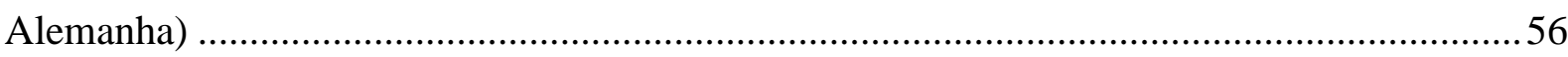

Figura 4.5 - Diagrama esquemático do procedimento realizado na estufa convectiva ............57

Figura 4.6 - Secador de bandejas (LABMAQ, modelo LM.ES-20, Brasil).............................59

Figura 4.7 - Diagrama esquemático do secador de bandejas (LABMAQ, modelo LM.ES-20,

Brasil)

Figura 4.8 - Configuração inicial das bandejas no secador (LABMAQ, modelo LM.ES-20, Brasil)

Figura 4.9 - Configuração final das bandejas no secador (LABMAQ, modelo LM.ES-20, Brasil)

Figura 4.10 - Diagrama esquemático do procedimento realizado no secador de bandejas (LABMAQ, modelo LM.ES-20, Brasil).

Figura 4.11 - Fotos do procedimento experimental realizado no secador de bandejas (LABMAQ, modelo LM.ES-20, Brasil) 65

Figura 4.12 - Rodelas de banana verde embaladas a vácuo. 68

Figura 4.13 - Procedimento de obtenção da farinha da banana verde 71 
Figura 5.1- Ganho de água $(G A)$ de rodelas de banana verde submetidas ao pré-tratamento de ultrassom a duas diferentes potências volumétricas ultrassônicas, em função do tempo de imersão

Figura 5.2-Conteúdo de umidade de rodelas de banana verde submetidas ao pré-tratamento de pulsos de vácuo a pressão de 0,5 bar

Figura 5.3- Rodelas de banana verde não pré-tratadas submetidas ao pré-tratamento de pulsos de vácuo a pressão de 0,5 bar. 80

Figura 5.4- Rodelas de banana verde pré-tratadas com 20 min de ultrassom de potência igual a 9,38 W/L, e submetidas a pulsos de vácuo a pressão de 0,5 bar. 81

Figura 5.5-Rodelas de banana verde pré-tratadas com 25 min de ultrassom de potência igual a 9,38 W/L, e submetidas a pulsos de vácuo a pressão de 0,5 bar. 82

Figura 5.6 - Curvas de secagem a $(50$ e 60$){ }^{\circ} \mathrm{C}$, obtidas no processo de secagem, para rodelas de banana verde, imersas por 20 min no banho ultrassônico de potência volumétrica 9,38 W/L

Figura 5.7 - Curvas de secagem a $(50$ e 60$){ }^{\circ} \mathrm{C}$, obtidas no processo de secagem, para rodelas de banana verde, imersas por 25 min no banho ultrassônico de potência volumétrica 9,38 W/L

Figura 5.8 - Taxas de secagem a $50{ }^{\circ} \mathrm{C}$, obtidas no processo de secagem, para rodelas de banana verde, imersas por (20 e 25) min no banho de ultrassônico de potência volumétrica 9,38 W/L

Figura 5.9- Taxas de secagem a $60^{\circ} \mathrm{C}$, obtidas no processo de secagem, para rodelas de banana verde, imersas por (20 e 25) min no banho de ultrassônico de potência volumétrica 9,38 W/L

Figura 5.10 - Exemplo de curva de secagem a $60{ }^{\circ} \mathrm{C}$ linearizada utilizada no cálculo da difusividade

Figura 5.11 - Curvas de secagem a $(50$ e 60$){ }^{\circ} \mathrm{C}$, obtidas no processo de secagem, para rodelas de banana verde, submetidas a um pulso de vácuo de 0,5 bar por $60 \mathrm{~min}$ 91 Figura 5.12 - Taxas de secagem a $(50$ e 60$){ }^{\circ} \mathrm{C}$, obtidas no processo de secagem, para rodelas de banana verde, submetidas a um pulso de vácuo de 0,5 bar por $60 \mathrm{~min}$ 92 Figura 5.13- Curvas de secagem a $50{ }^{\circ} \mathrm{C}$, obtidas no processo de secagem, para rodelas de banana verde pré-tratadas por 20 min no banho de ultrassônico de potência volumétrica 9,38 W/L e pulso de vácuo de 0,5 bar por $60 \mathrm{~min}$ 94 
Figura 5.14 - Curvas de secagem a $60{ }^{\circ} \mathrm{C}$, obtidas no processo de secagem, para rodelas de banana verde pré-tratadas por 25 min no banho de ultrassônico de potência volumétrica 9,38 W/L e pulso de vácuo de 0,5 bar por $60 \mathrm{~min}$

Figura 5.15 - Taxas de secagem a $50{ }^{\circ} \mathrm{C}$, obtidas no processo de secagem, para rodelas de banana verde, pré-tratadas por 20 min no banho de ultrassônico de potência volumétrica 9,38 W/L e pulso de vácuo de 0,5 bar por $60 \mathrm{~min}$

Figura 5.16 - Taxa de secagem a $60{ }^{\circ} \mathrm{C}$, obtidas no processo de secagem, para rodelas de banana verde, pré-tratadas por 25 min no banho de ultrassônico de potência volumétrica 9,38 W/L e pulso de vácuo de 0,5 bar por $60 \mathrm{~min}$

Figura 5.17 - Curvas de secagem a $50{ }^{\circ} \mathrm{C}$, obtidas no processo de secagem, para rodelas de banana verde, não pré-tratadas e pré-tratadas, cujos dados foram ajustados ao modelo de Newton 98

Figura 5.18 - Curvas de secagem a $60{ }^{\circ} \mathrm{C}$, obtidas no processo de secagem, para rodelas de banana verde, não pré-tratadas e pré-tratadas, cujos dados foram ajustados ao modelo de Newton 98

Figura 5.19 - Curvas de secagem a $50{ }^{\circ} \mathrm{C}$, obtidas no processo de secagem, para rodelas de banana verde, não pré-tratadas e pré-tratadas, cujos dados foram ajustados ao modelo de Page

Figura 5.20 - Curvas de secagem a $60{ }^{\circ} \mathrm{C}$, obtidas no processo de secagem, para rodelas de banana verde, não pré-tratadas e pré-tratadas, cujos dados foram ajustados ao modelo de Page

Figura 5.21 - Curvas de secagem a $50{ }^{\circ} \mathrm{C}$, obtidas no processo de secagem, para rodelas de banana verde, não pré-tratadas e pré-tratadas, cujos dados foram ajustados ao modelo de Henderson \& Pabis 100

Figura 5.22 - Curvas de secagem a $60{ }^{\circ} \mathrm{C}$, obtidas no processo de secagem, para rodelas de banana verde, não pré-tratadas e pré-tratadas, cujos dados foram ajustados ao modelo de Henderson \& Pabis 100

Figura 5.23 - Curvas de secagem a $50{ }^{\circ} \mathrm{C}$, obtidas no processo de secagem, para rodelas de banana verde, não pré-tratadas e pré-tratadas, cujos dados foram ajustados ao modelo Difusional 101

Figura 5.24 - Curvas de secagem a $60{ }^{\circ} \mathrm{C}$, obtidas no processo de secagem, para rodelas de banana verde, não pré-tratadas e pré-tratadas, cujos dados foram ajustados ao modelo Difusional 101 
Figura 5.25 - Curvas de secagem a $50{ }^{\circ} \mathrm{C}$, obtidas no processo de secagem, para rodelas de banana verde, não pré-tratadas e pré-tratadas, cujos dados foram ajustados ao modelo Logaritmico

Figura 5.26 - - Curvas de secagem a $60{ }^{\circ} \mathrm{C}$, obtidas no processo de secagem, para rodelas de banana verde, não pré-tratadas e pré-tratadas, cujos dados foram ajustados ao modelo Logaritmico 102

Figura 5.27 - Curvas de secagem a $50{ }^{\circ} \mathrm{C}$, obtidas no processo de secagem, para rodelas de banana verde, não pré-tratadas e pré-tratadas, cujos dados foram ajustados ao modelo de Midilli

Figura 5.28 - Curvas de secagem a $60{ }^{\circ} \mathrm{C}$, obtidas no processo de secagem, para rodelas de banana verde, não pré-tratadas e pré-tratadas, cujos dados foram ajustados ao modelo de Midilli

Figura 5.29 - Curvas de secagem a $50{ }^{\circ} \mathrm{C}$, obtidas para rodelas de banana verde embaladas a vácuo ou não submetidas ao pré-tratamento com ultrassom por 20 min a $P_{\mathrm{us}}=9,38 \mathrm{~W} / \mathrm{L} \ldots 110$ Figura 5.30 - Imagens obtidas para rodelas de banana verde embaladas a vácuo ou não, submetidas ao pré-tratamento com ultrassom por $20 \mathrm{~min}$ a $P_{\mathrm{us}}=9,38 \mathrm{~W} / \mathrm{L}$ em relação as rodelas não pré-tratadas

Figura 5.31 - Imagens obtidas para rodelas de banana verde embaladas a vácuo ou não submetidas ao pré-tratamento com ultrassom por 20 min a $P_{\text {us }}=9,38 \mathrm{~W} / \mathrm{L}$ e secas a $50{ }^{\circ} \mathrm{C}$ em relação as rodelas não pré-tratadas 114 Figura 5.32 - Solubilidade a $(25,40,50$ e 60$){ }^{\circ} \mathrm{C}$ para farinha de banana verde produzida de rodelas de banana verde embaladas a vácuo ou não submetidas ao pré-tratamento com ultrassom por $20 \mathrm{~min}$ a $P_{\mathrm{us}}=9,38 \mathrm{~W} / \mathrm{L}$ e secas a $50{ }^{\circ} \mathrm{C}$ em relação a rodelas não pré-tratadas.

Figura 5.33 - Imagens obtidas dos grânulos de amido de FBV produzida a partir de rodelas de banana verde embaladas a vácuo ou não submetidas ao pré-tratamento com ultrassom por 20 min a $P_{\text {us }}=9,38 \mathrm{~W} / \mathrm{L}$ e secas a $50{ }^{\circ} \mathrm{C}$, em relação aos grânulos de amido de $\mathrm{FBV}$ produzida a partir de rodelas não pré-tratadas. 


\section{LISTA DE TABELAS}

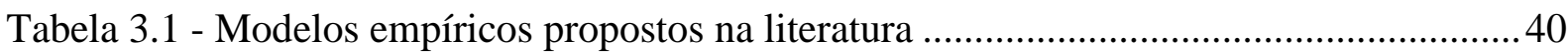

Tabela 4.1 - Tempo de imersão de ultrassom aplicado as rodelas de banana verde ................53

Tabela 4.2 - Tempos de pulso de vácuo aplicados em rodelas de banana verde .....................55

Tabela 4.3 - Ensaios de secagem realizados em estufa convectiva com rodelas de banana verde

Tabela 4.4 - Ensaios de secagem realizados em secador de bandejas (LABMAQ, modelo

LM.ES-20, Brasil) com as rodelas de banana verde.

Tabela 4.5 - Processos de secagem selecionados para a produção de farinha de banana verde

Tabela 5.1 - Caracterização da matéria-prima nos períodos de Maio/Junho 2015 e Fevereiro/Março 2016

Tabela 5.2 - Ganho de água $(G A)$ de rodelas de banana verde submetidas ao pré-tratamento com ultrassom às duas diferentes potências volumétricas ultrassônicas 75

Tabela 5.3 - Efeito estimado e $p$-valor para o ganho de água $(G A)$ 78

Tabela 5.4 - Conteúdo de umidade de rodelas de banana verde submetidas ao pré-tratamento de pulsos de vácuo a pressão de 0,5 bar

Tabela 5.5 - Difusividade efetiva da água $\left(D_{e f}\right)$ obtida nos processos de secagem em estufa, a (50 e 60$){ }^{\circ} \mathrm{C}$, de rodelas de banana verde pré-tratadas com ultrassom de potência volumétrica ultrassônica igual a $9,38 \mathrm{~W} / \mathrm{L}$

Tabela 5.6 - Difusividade efetivada água $\left(D_{e f}\right)$ obtidas nos processos de secagem em estufa, a $(50$ e 60$){ }^{\circ} \mathrm{C}$, de rodelas de banana verde pré-tratadas com ultrassom de potência volumétrica ultrassônica igual a 25,63 W/L 85

Tabela $5.7-D_{e f}$ a (50 e 60) ${ }^{\circ} \mathrm{C}$, obtida nos processos de secagem em secador de bandejas, para rodelas de banana verde, imersas por (20 e 25) min no banho de ultrassônico de potência volumétrica $9,38 \mathrm{~W} / \mathrm{L}$

Tabela $5.8 D_{e f}$ a (50 e 60) ${ }^{\circ} \mathrm{C}$, obtida no processo de secagem em secador de bandejas para rodelas de banana verde submetidas a um pulso de vácuo de 0,5 bar por $60 \mathrm{~min}$

Tabela $5.9-D_{e f}$ a $(50$ e 60$){ }^{\circ} \mathrm{C}$, obtidas no processo de secagem em secador de bandejas, para rodelas de banana verde, pré-tratadas por (20 e 25) min no banho de ultrassônico de potência volumétrica 9,38 W/L, e pulso de vácuo de 0,5 bar por $60 \mathrm{~min}$. 96 Tabela 5.10 - Constantes e coeficientes obtidos do ajuste dos dados experimentais aos modelos Newton, Page, Henderson \& Pabis, Logaritmico e Midilli de rodelas de banana verde não pré- 
tratadas e pré-tratadas (Ultrassom ou Ultrassom + 60 min de Púlso de vácuo) secas a (50 e 60) ${ }^{\circ} \mathrm{C}$

Tabela 5.11 - Redução do teor de umidade inicial obtida nos ensaios de secagem a $(50-60){ }^{\circ} \mathrm{C}$ segundo o modelo de Midilli

Tabela 5.12 - Tempo experimental total de processamento obtido no secador de bandejas (LABMAQ, modelo LS.20, Brasil) 108

Tabela 5.13 - Ganho de água $(G A)$ e difusividade efetiva da água $\left(D_{e f}\right)$ de rodelas de banana verde embaladas a vácuo ou não submetidas ao pré-tratamento com ultrassom por $20 \mathrm{~min}$ a $P_{\text {us }}$ $=9,38 \mathrm{~W} / \mathrm{L}$ e secas a $50{ }^{\circ} \mathrm{C}$.

Tabela 5.14 - Conteúdo de umidade $\left(X_{f}\right)$, atividade de água $\left(a_{w}\right)$, temperatura de gelatinização $\left(T_{p}\right)$, entalpia de gelatinização $(\Delta H)$ e conteúdo de amido resistente $(A R)$ da farinha de banana verde produzida de rodelas de banana verde sem pré-tratamento, pré-tratadas com ultrassom (US) e com a técnica combinada de ultrassom e pulsos de vácuo (US+ PV) 116

Tabela 5.15 - Conteúdo de umidade $\left(X_{f}\right)$, atividade de água $\left(a_{w}\right)$, temperatura de gelatinização $\left(T_{p}\right)$, entalpia de gelatinização $(\Delta H)$ e conteúdo de amido resistente $(A R)$ para farinha de banana verde, produzida de rodelas de banana verde embaladas a vácuo ou não submetidas ao prétratamento com ultrassom por $20 \mathrm{~min}$ a $P_{\text {us }}=9,38 \mathrm{~W} / \mathrm{L}$ e secas a $50{ }^{\circ} \mathrm{C}$. 118 


\section{LISTA DE SÍMBOLOS}

a constante dos modelos de Henderson \& Pabis, Logaritmico e Midilli (-)

$a_{w} \quad$ atividade de água (-)

A amplitude (nm)

AR amido resistente (g/100 g b.s.)

$b \quad$ constante do modelo de Midilli ( $1 / \mathrm{min})$

c constante do modelo logaritmico (-)

$C_{p} \quad$ calor especifico a pressão constante $(\mathrm{J} / \mathrm{g} \mathrm{K})$

$D_{e f} \quad$ difussividade efetiva da água $\left(\mathrm{m}^{2} / \mathrm{s}\right)$

$f \quad$ frequência $(\mathrm{kHz})$

$F_{o} \quad$ número de Fourier (-)

GA ganho de água $\left(\mathrm{g} \mathrm{H}_{2} \mathrm{O} / 100 \mathrm{~g}\right)$

$k \quad$ constante de primeira ordem dos modelos semi-empíricos (1/min)

$L \quad$ semi-espessura da amostra (m)

$m \quad$ massa $(\mathrm{g})$

$M R \quad$ razão do conteúdo de umidade (-)

$n \quad$ constante do modelo de Page e Midilli (-)

$p \quad$ probabilidade de significância estatística

$p_{\text {abs }} \quad$ pressão absoluta $(\mathrm{kPa})$

$P_{\mathrm{us}} \quad$ potência volumétrica ultrassônica $(\mathrm{W} / \mathrm{L})$

$r^{2} \quad$ coeficiente de correlação

$S \quad$ solubilidade $(\mathrm{g} / 100 \mathrm{~g})$

$t \quad$ tempo (min ou s)

$T$ temperatura $\left({ }^{\circ} \mathrm{C}\right)$

UR umidade relativa (\%)

$x \quad$ conteúdo de umidade em base úmida $\left(\mathrm{g} \mathrm{H}_{2} \mathrm{O} / \mathrm{g}\right.$ b.u. $)$

$X \quad$ conteúdo de umidade em base seca $\left(\mathrm{g} \mathrm{H}_{2} \mathrm{O} / \mathrm{g}\right.$ b.s. $)$

$V \quad$ volume (L) 


\section{Subscritos}

$\begin{array}{ll}0 & \text { inicial } \\ e & \text { equilibrio } \\ f & \text { farinha } \\ p & \text { pico } \\ \text { US } & \text { ultrassom }\end{array}$

\section{Letras gregas}

$\Delta H \quad$ entalpia de gelatinização $(\mathrm{J} / \mathrm{g})$

$\lambda \quad$ comprimento de onda (nm)

$\mathrm{T}$ período (min) 


\section{SUMÁRIO}

1. INTRODUÇÃ

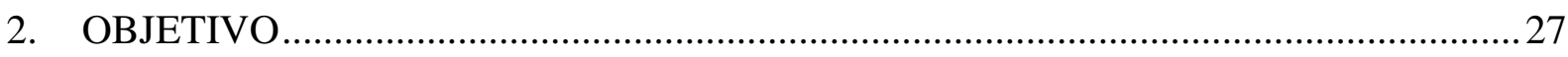

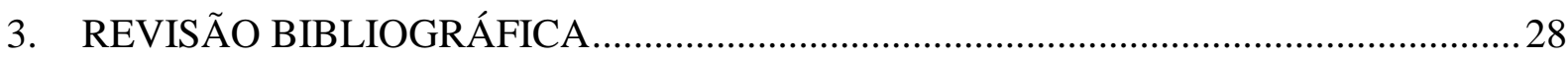

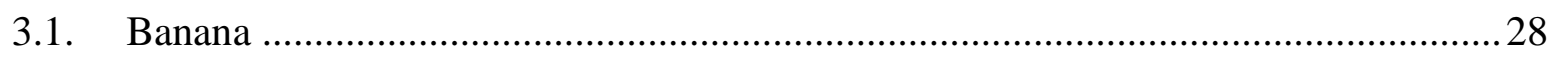

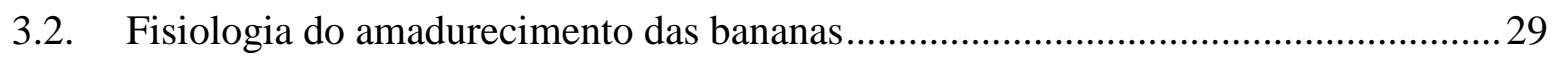

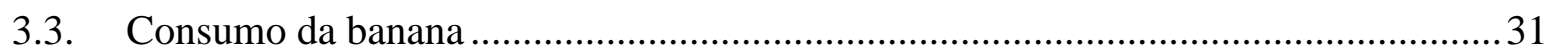

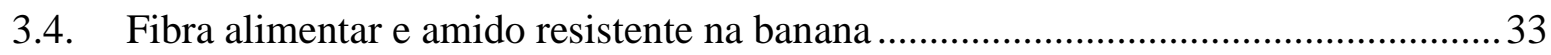

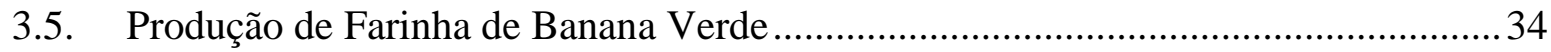

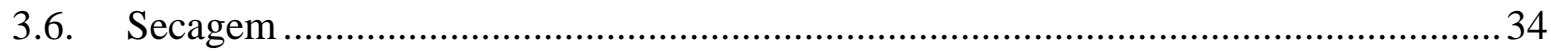

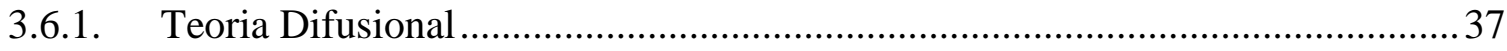

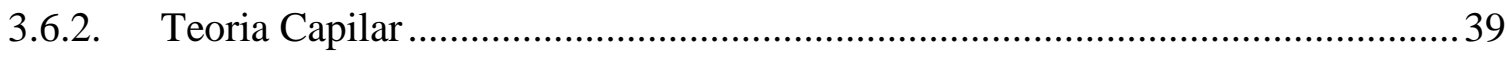

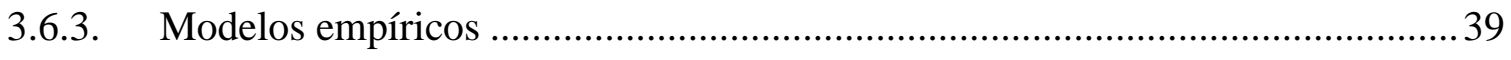

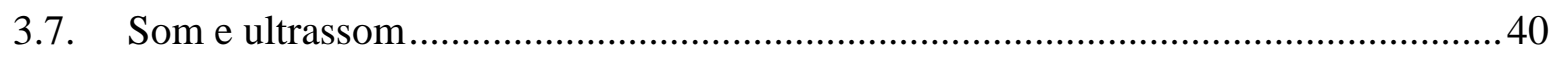

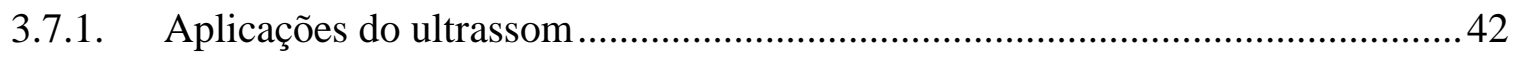

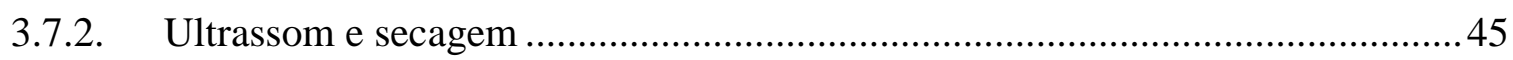

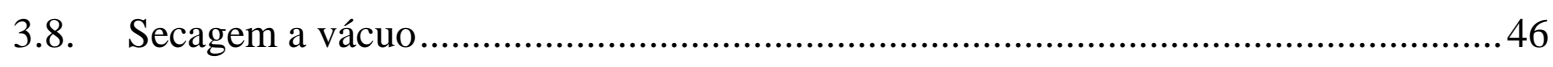

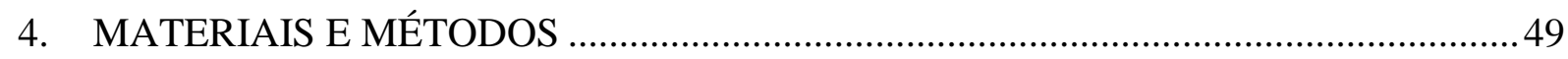

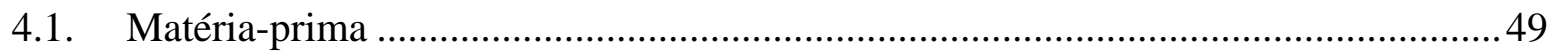

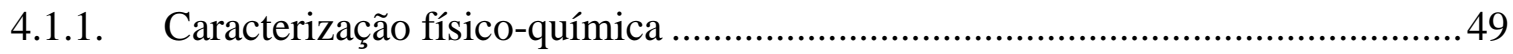

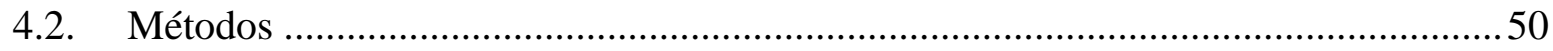

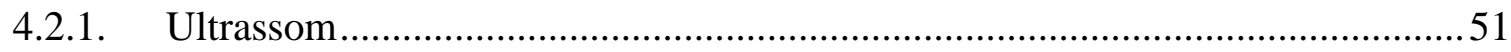

4.2.2. Aplicação de pulso de vácuo combinado com ultrassom ...................................54

4.2.3. Ensaios preliminares de secagem em estufa convectiva ..................................57

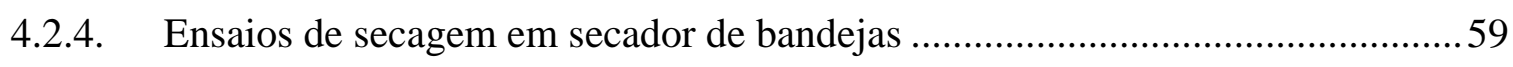

4.2.5. Caracterização da Farinha de Banana Verde .................................................... 70

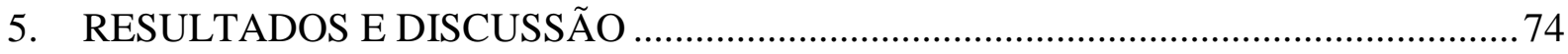




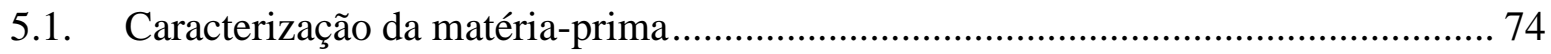

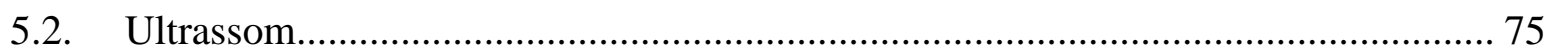

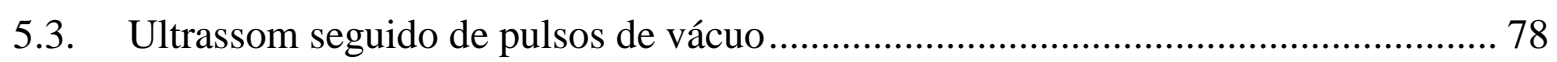

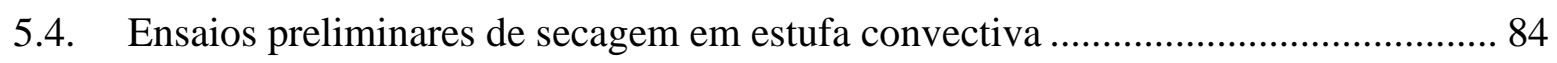

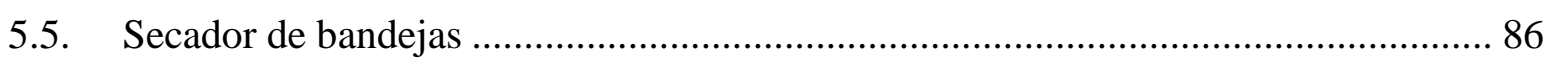

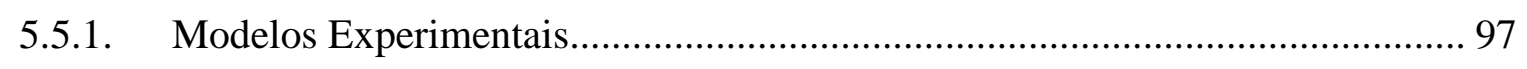

5.5.2. Redução do teor de umidade inicial ........................................................... 107

5.5.3. Tempo experimental total de processo..................................................... 108

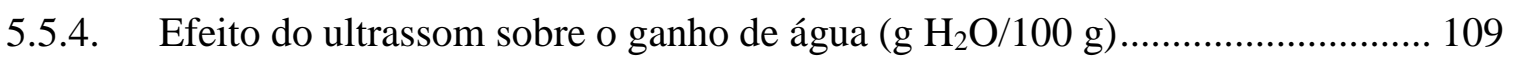

5.6. Caracterização da Farinha de Banana Verde (FBV) ............................................ 115

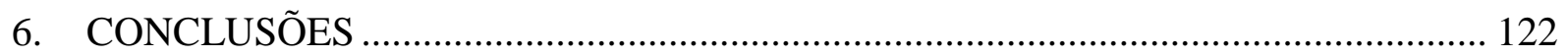

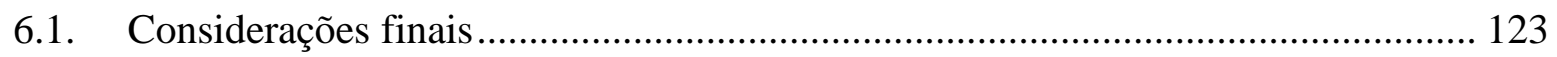

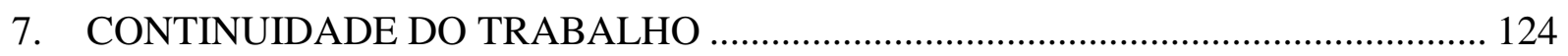

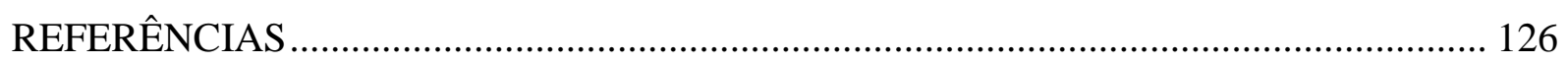

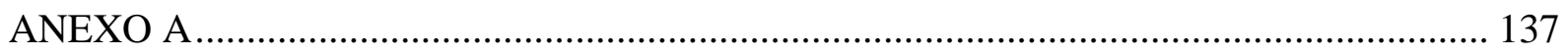

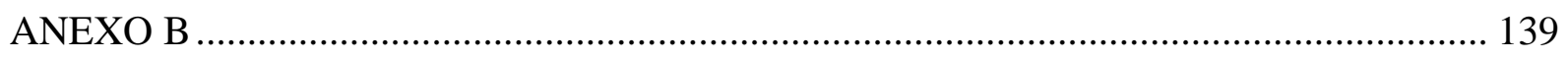




\section{INTRODUÇÃO}

A banana assume um lugar de destaque na produção mundial de bens agrícolas, marcadamente entre os países localizados nos trópicos. A Índia lidera o ranking dos produtores, com um volume de aproximadamente 29 milhões de toneladas da fruta em 2014. Em quarto lugar encontra-se o Brasil, com cerca de sete milhões de toneladas. A banana é um alimento sempre presente na dieta dos brasileiros, sendo a segunda fruta mais produzida no Brasil, atrás apenas da laranja (FAO, 2014). Em contrapartida, o acúmulo de perdas na cadeia produtiva da banana é de até $40 \%$ (CAVALLI, 2015). As principais causas dessas perdas são as técnicas inadequadas de colheita e de pós-colheita, e os sistemas de transporte e armazenamento, que comprometem a qualidade do produto. Falhas na distribuição e a dificuldade na colocação do produto no mercado também podem ser apontadas como causas das perdas.

A banana, quando verde, apresenta elevado conteúdo de amido resistente. Diversos estudos sugerem que o consumo deste produto traz benefícios à saúde humana, associados à presença do amido resistente $(A R)$ com concentrações que variam de (47 a 57) g/100 g (FUENTES-ZARAGOZA et al., 2010). A importância da digestão e da absorção incompleta do amido no intestino delgado, assim como das frações de amido não digeríveis, denominado amido resistente, têm sido alvo de grande interesse, haja vista a sua importância nos benefícios relacionados à saúde (POLESI, 2011). Suas propriedades podem contribuir de forma significativa na prevenção e no tratamento de doenças crônicas não-transmissíveis (DCNT) como a diabetes, as doenças cardiovasculares, a síndrome do colón irritável, a obesidade, além de proporcionar saciedade e de promover redução do colesterol (MENEZES, 2008).

Portanto, uma interessante alternativa para o aproveitamento da banana verde é a produção de farinha. Assim, a produção da farinha de banana verde (FBV) promove o consumo de alimentos com propriedades nutricionais importantes e reduz as perdas pós-colheita da fruta. A farinha é produzida comumente pela técnica de secagem. Tribess (2009) estudou o processo de secagem da banana verde (Musa cavendishii) para a obtenção da FBV. As condições estudadas foram de $(52,55$ e 58$){ }^{\circ} \mathrm{C}$ e com as velocidades do ar de secagem de $(0,6 ; 1,0$ e 1,4$)$ $\mathrm{m} / \mathrm{s}$. O conteúdo de $A R$ foi influenciada significativamente pela temperatura e velocidade de secagem. No entanto, nas condições estudadas o conteúdo médio de amido resistente de 51 $\mathrm{g} / 100 \mathrm{~g}$. 
A técnica de secagem convencional é o método mais antigo empregado industrialmente para processar alimentos. A principal vantagem da secagem convectiva é que ela fornece produtos desidratados com uma vida de prateleira relativamente prolongada. Contudo, um dos problemas de usar apenas a secagem convencional é que o produto final - devido ao longo tempo do processo em temperaturas médias ou elevadas - tem as características de cor, de aroma, de textura e, ainda, nutricionais, diminuídas (KIM; TOLEDO, 1987). Alem disso, a secagem convectiva pode ser considerada como um dos processos que consomem mais energia.

Recentes investigações concentraram-se nas formas de economizar energia minimizando as alterações das propriedades físico-químicas dos alimentos (WITROWARAJCHERT et al., 2014). O desenvolvimento de novas tecnologias de processamento de alimentos ou "emerging technologies" atende às necessidades específicas dos consumidores para a procura de alimentos seguros, saudáveis e, minimamente processados. Estes processos inovadores também são amigáveis para o meio ambiente, devido às baixas exigências de consumo de energia e a redução do uso de água, superando, assim, algumas limitações dos processamentos atuais de alimentos. Processos a Alta Pressão Hidrostática (HHP), Campos Elétricos Pulsados (FIPs), Plasma a Frio (CP) e Ultrassom (US) são exemplos dessas novas tecnologias, que podem ser escaladas em nível industrial (KNORR et al., 2011).

Por outro lado, a aplicação de pré-tratamentos ao processo de secagem convectiva ganhou muita importância e tem sido alvo de várias pesquisas. Pré-tratamentos podem ser usados para reduzir o teor de água inicial do fruto ou para modificar a estrutura do tecido das frutas, de maneira a tornar mais rápida a secagem convectiva (FERNANDES et al., 2006). Dentre os pré-tratamentos destaca-se o ultrassom, que pode ser empregado como uma tecnologia moderna capaz de melhorar as condições de processamento de muitos produtos, atendendo, assim, às novas tendências do mercado. Essa técnica pode ser realizada, ainda, em temperatura ambiente, o que reduz a probabilidade de degradação do alimento (SILVA, 2012). De acordo com Fuentes-Blanco et al. (2006), o uso do ultrassom poderia acelerar as taxas de secagem das frutas devido ao processo de formação de micro-canais durante a aplicação dessa técnica.

De outro ponto de vista, segundo Ito et al. (2007), a aplicação de um pulso de vácuo no início do processo de secagem, retira parte do ar presente no interior dos poros do alimento. A recuperação da pressão do sistema provoca uma rápida alteração na estrutura do alimento e gera consequências nas propriedades de transporte da estrutura. 


\section{OBJETIVO}

O objetivo geral desta pesquisa foi avaliar o impacto de pré-tratamentos ao processo de secagem convectiva da banana (Musa acuminata subgrupo Cavendishii) da variedade Nanicão para a obtenção da farinha de banana verde.

Para atingir o objetivo, as seguintes etapas do trabalho foram propostas:

$\checkmark$ Estudar os efeitos do tempo e da potência volumétrica do ultrassom como prétratamento sobre as propriedades de transporte na secagem.

$\checkmark$ Estudar o efeito de um pulso inicial de vácuo como pré-tratamento sobre as propriedades de transporte na secagem.

$\checkmark$ Estudar a combinação dos pré-tratamentos: ultrassom e pulso de vácuo, sobre as propriedades de transporte na secagem.

$\checkmark$ Estudar as características da farinha de banana verde produzida sob diferentes condições e avaliar o impacto dos pré-tratamentos aplicados. 


\section{REVISÃO BIBLIOGRÁFICA}

\subsection{Banana}

As bananas são provavelmente oriundas do quente e úmido sudeste asiático, de onde provêm os mais antigos registros de seu cultivo e as mais antigas lendas construídas ao seu redor. Para muitos, a antiguidade e a origem asiática da banana são fatos incontestáveis (SILVA, 2001).

Ao que tudo indica, antes da chegada dos europeus à América existiam algumas espécies de bananeiras nativas. Seus frutos, todavia, não eram consumidos crus, necessitando, assim, de um preparo ou de um cozimento prévio, e não constituíam a parte principal da dieta das populações autóctones. Presume-se que foi apenas a partir do século XV que a banana, o seu cultivo e os seus usos foram introduzidos no continente americano. Atualmente, no Brasil, encontram-se bananas em qualquer parte, destacando-se as regiões Nordeste e Sudeste como as maiores produtoras nacionais da fruta (SILVA, 2001). Na Figura 3.1 é apresentada a distribuição da produção de bananas por região do Brasil no ano de 2013, a partir de dados do Instituto Brasileiro de Geografia e Estatística (IBGE, 2013).

Figura 3.1 - Produção brasileira de banana por região geográfica em 2013

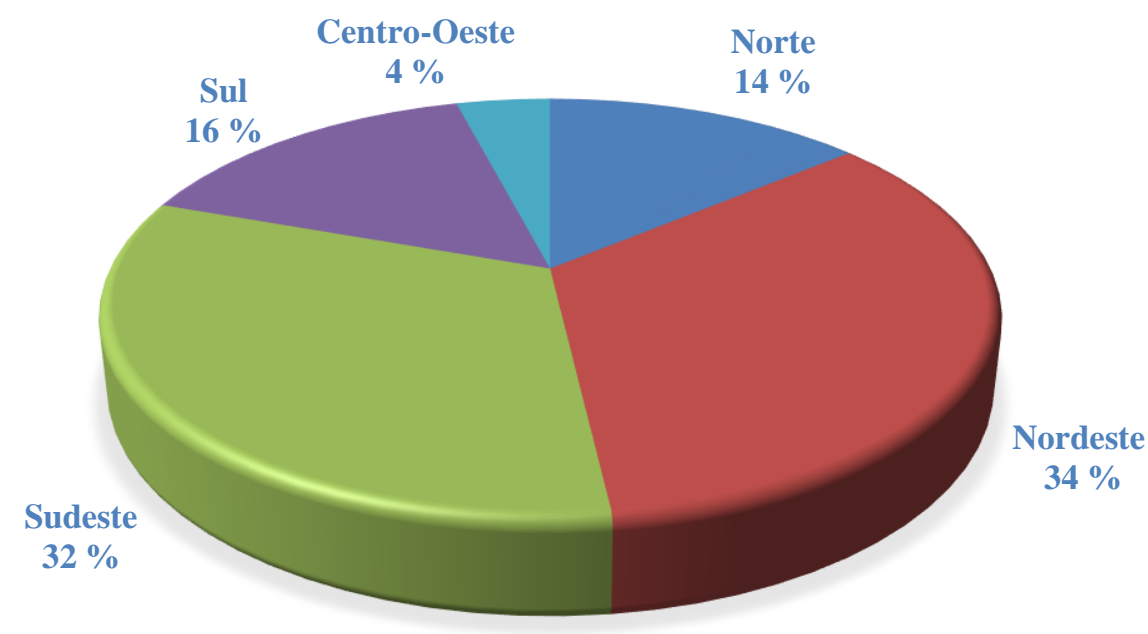

Fonte: IBGE - Produção de bananas por região do Brasil, 2013. 
As variedades mais difundidas no Brasil são: Prata, Pacovan, Prata Anã, Maçã, Thap Maeo, Terra e D’Angola, do grupo AAB, utilizadas unicamente para o mercado interno, representando aproximadamente $60 \%$ da área cultivada no Brasil. As variedades Nanica e Nanicão (AAA), também conhecidas como banana d'água, são de elevada importância econômica no Brasil - por conta de sua alta produtividade, são destinadas à exportação - e apresentam frutos delgados, longos, encurvados, de cor amarelo-esverdeada ao amadurecer e uma polpa muito doce (MEDINA; PEREIRA, 2004). Em menor escala, são plantadas: Ouro AA, Figo Cinza e Figo Vermelho ABB, Caru Verde e Caru Roxa AAA (SILVA; SANTOSSEREJO; CORDEIRO, 2006). Do total de bananas produzidas no país, aproximadamente 40 $\%$ são perdidas somente na fase pós-colheita. As principais causas são: o manuseio excessivo e o uso de embalagens não adequadas como as caixas de madeira que além de causar sérios problemas de contaminação dos frutos ocasionam injurias mecânicas e são pouco econômicas. O transporte dos frutos também é inadequado: o uso de caminhões com sistema de refrigeração no transporte de banana ainda é muito pequeno, assim como o inadequado sistema de refrigeração nos supermercados, o segmento que mais exige qualidade de fruto (CAVALLI, 2015).

\subsection{Fisiologia do amadurecimento das bananas}

A banana é uma fruta de padrão respiratório climatérico, caracterizada pelo aumento da taxa respiratória e da produção do etileno durante esse período. Pode, então, ser colhida antes do seu completo amadurecimento. É na fase do climatério, que se iniciam as principais alterações sensoriais da fruta, tais como pigmentação amarela da casca, amaciamento da polpa e alterações de sabor e aroma, que se tornam característicos da fruta madura (MEDINA; PEREIRA, 2004).

Com o amadurecimento ocorre a hidrólise do amido e o consequente acúmulo de açúcares solúveis, a redução da adstringência e o amaciamento da polpa. Paralelamente, na casca, se observa a aparição da cor amarela (Figura 3.2), originada pela degradação da clorofila (pigmento que confere a cor verde) e a síntese de pigmentos carotenóides. A cor da casca é um bom indicativo do grau de amadurecimento da banana e é o seu principal critério para a colheita, aliado à idade do cacho (MEDINA; PEREIRA, 2004). 
Figura 3.2 - Evolução da coloração da casca da banana

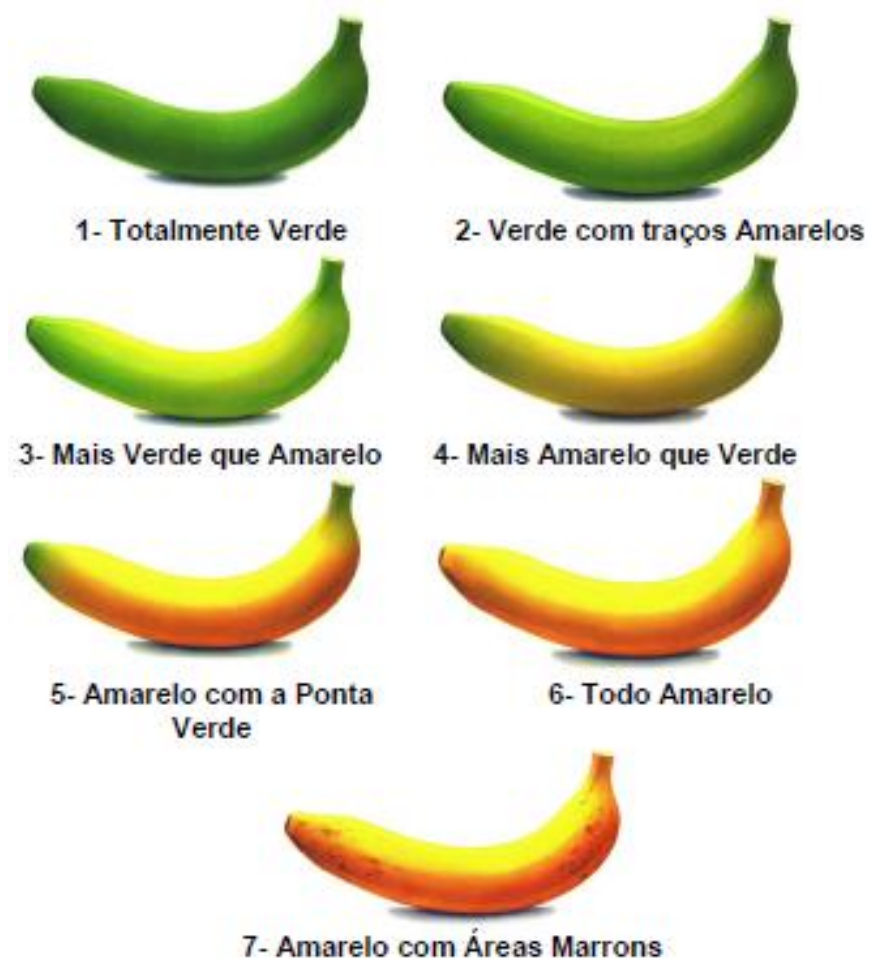

Fonte: Adaptado de Ormenese (2010).

Os sete estágios de maturação da banana, mostrados na Figura 3.2 são descritos como: 1. fruto totalmente verde; 2 . fruto verde com traços amarelos; 3 . fruto mais verde que amarelo; 4. fruto mais amarelo que verde; 5. fruto amarelo com pontas verdes; 6. fruto totalmente amarelo e 7. fruto amarelo com manchas marrons.

Lii, Chang e Young (1982), ao investigarem as mudanças que ocorrem durante o amadurecimento de bananas, encontraram, à medida que a maturação evoluiu, a diminuição do teor de amido e o aumento dos teores de açúcares redutores e de sacarose. Os autores verificaram também que houve um pequeno aumento na temperatura de gelatinização do amido com o processo de maturação. Ditchfield e Tadini (2002) avaliaram bananas da variedade Nanicão em sete diferentes estágios através dos seguintes parâmetros: pH, sólidos solúveis ( ${ }^{\circ}$ Brix), firmeza em texturômetro TA-XT2i e acidez titulável expressa em porcentagem de ácido málico. Por meio de análises estatísticas, as autoras concluíram que o melhor parâmetro para determinar o estágio de maturação da banana foi a firmeza, que teve um valor médio de 25,66 $\mathrm{N}$ no estágio 1; no estágio 2 igual a 13,75 N e no estágio 3 igual a $5,28 \mathrm{~N}$, mantendo a tendência de queda até atingir valor de 1,53 $\mathrm{N}$ no estágio 7 . A relação ${ }^{\circ}$ Brix/acidez também forneceu um bom parâmetro para o estágio de maturação, enquanto que, o pH e a acidez titulável não foram 
considerados adequados, uma vez que apresentaram valores semelhantes nos estágios inicial e final de maturação. Os sólidos solúveis se mantiveram praticamente constantes após o estágio 3 de maturação.

Lii, Chang e Young (1982) verificaram que o formato dos grânulos de amido das diferentes variedades da banana são oval ou elíptico medindo de (6 a 80) $\mu \mathrm{m}$. Peroni et al. (2010) também verificaram que, nos primeiros estágios de maturação, o grânulo de amido da banana Nanicão apresenta superfície lisa e formato oval ou elíptico (Figura 3.3).

Figura 3.3 - Grânulos de amido de banana Nanica verde
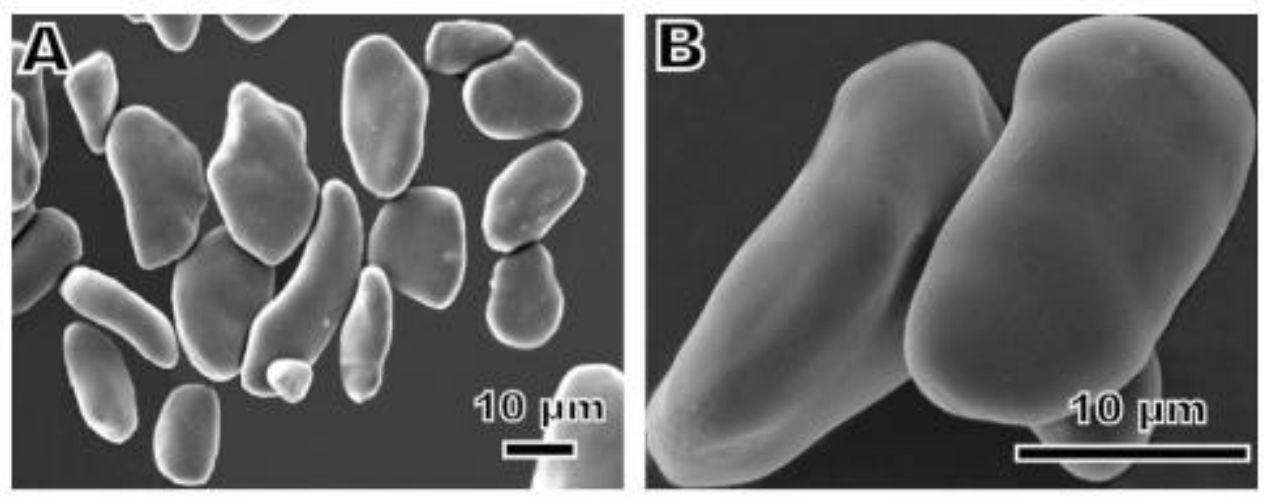

Fonte: Peroni et al. (2010).

\subsection{Consumo da banana}

Dentro do setor alimentício, além do consumo in natura, a banana possui uma demanda voltada para o processamento industrial. Relativamente poucos produtores se dedicam às atividades de beneficiamento da fruta; em geral, esta etapa fica a cargo de terceiros. No entanto, alguns produtos derivados da banana podem ser facilmente convertidos em produtos de maior valor agregado. Uma importante vantagem no processamento de derivados está na redução das dificuldades logísticas (incluindo nelas o transporte e armazenamento), uma vez que, os processos de industrialização reduzem o peso e volume dos alimentos, além de torná-los menos perecíveis e mais lucrativos (SEBRAE, 2008). Dentre estes produtos, destacam-se: 


\section{- Banana passa}

Geralmente feito a partir da variedade Prata, este produto é um dos mais tradicionais. O processo é simples, executado por equipamentos de desidratação de frutas - há modelos que utilizam energia elétrica e, outros, energia solar. Em geral, não são usados aditivos ou conservantes, o que encurta a sua validade. As bananas podem ser desidratadas inteiras, em pedaços ou rodelas até chegar na umidade final de (20 a 25) g/100 g b.u.

\section{- Banana chips}

Novidade do norte do país, as bananas chips rapidamente ganharam mercado, inclusive no Sudeste. Aproveitando-se das características da produção local, as mais antigas fabricantes fazem uso da variedade Pacovan. Há marcas que trabalham com chips adocicados ou salgados.

\section{- Doces e geleia de banana}

A partir de processos de industrialização razoavelmente simples, as bananas que se soltam das pencas e que, geralmente, são descartadas no momento da colheita podem ser transformadas em doces ou em geleias. As variedades mais utilizadas são a Prata para as bananadas e a Nanica para os doces em compota. Há boas perspectivas de mercado para estes produtos, uma vez que a larga aceitação da fruta se transfere para os seus derivados.

\section{- Farinha de banana verde}

Com a maioria das bananas verdes pode se produzir uma farinha extremamente nutritiva, com potencial uso em formulações alimentícias (SILVA, 2001). Pode ser usada como ingrediente na produção de outros alimentos como pães, barras de cereais, biscoitos e sopas desidratadas (MENEZES, 2008). Os principais compostos da farinha de banana verde são a água e o amido resistente, com concentrações que variam entre (40 e 59) g/100 g b.s. (TRIBESS et al., 2009). 


\subsection{Fibra alimentar e amido resistente na banana}

Na definição proposta pela FAO/WHO (2006), as fibras alimentares são carboidratos com grau de polimerização igual ou superior a 3, não digeridos e nem absorvidos pelo intestino delgado. Originalmente, as subclasses das fibras alimentares incluem celulose, hemicelulose, pectinas e ligninas. Outra maneira de descrever as subclasses é pela diferenciação entre a fibra solúvel e a insolúvel. A descoberta de uma fração do amido, na análise de determinação de fibra alimentar, despertou um grande interesse no amido (BERRY, 1986).

O amido é o polissacarídeo de armazenamento mais abundante nos vegetais e é formado por dois polímeros: a amilose e a amilopectina. Segundo Fuentes-Zaragoza et al. (2010), o amido divide-se em rapidamente digerível, lentamente digerível e amido resistente $(A R)$. Por sua vez, o $A R$ é constituído por quatro tipos: o tipo 1 representa o grânulo de amido fisicamente inacessível, na matriz do alimento; o tipo 2 refere-se aos grânulos de amido nativo encontrados no interior da célula vegetal, apresentando lenta digestibilidade devido às características intrínsecas da estrutura cristalina; o tipo 3 consiste em polímeros de amido retrogradado (principalmente de amilose), produzidos quando o amido é resfriado após a sua gelatinização, e um quarto tipo de $A R$ tem sido evidenciado quando o amido sofre modificações em sua estrutura química. A banana verde é considerada um produto rico em amido resistente tipo 2 .

Entre as propriedades mais importantes, com influência no seu valor nutricional, estão a taxa e a extensão da digestão ao longo do trato gastrointestinal e o metabolismo dos monômeros absorvidos (CUMMING et al., 1987). O AR proporciona um aumento moderado de glicose e insulina plasmática após uma refeição e permite a entrada lenta de glicose na corrente sanguínea. Essa absorção lenta dos açúcares diminui o risco de se adquirir doenças tais como a obesidade, o diabetes e as demais doenças cardiovasculares. Como o $A R$ é pouco absorvido no intestino delgado, parte dele servirá como substrato de fermentação para a microflora colônica, funcionando como fibra alimentar e prebiótico (MENEZES, 2008).

Santos (2010) estudou o efeito in vivo da adição de FBV em barras energéticas; as amostras consistiam em dois tipos de barras de cereais: uma delas elaborada com FBV e a outra sem o ingrediente. Foi possível concluir que a adição de FBV nas barras de cereais aumentou o conteúdo de carboidratos não disponíveis, resultando em um produto de alta fermentabilidade no intestino e de baixa resposta glicêmica. 


\subsection{Produção de Farinha de Banana Verde}

A FBV é obtida comumente pela secagem convectiva da banana verde. Após a desidratação da fruta, as rodelas ou fatias são moídas e a farinha é obtida. Durante o processo de secagem, o produto sofre alterações na sua estrutura, devido as altas temperaturas do processo. Uma dessas alterações é a gelatinização do amido em temperaturas $>67{ }^{\circ} \mathrm{C}$, que tem como consequência a redução do amido resistente. Tribess et al. (2009) desenvolveram um procedimento para obtenção do produto a partir da secagem de banana verde (Musa acuminata AAA var. Nanicão). O processo de secagem foi conduzido em escalas de laboratório e piloto, nas condições de temperatura de $(52,55$ e 58$){ }^{\circ} \mathrm{C}$ e de velocidade do ar de secagem de $(0,6,1,0$ e 1,4$) \mathrm{m} / \mathrm{s}$. Realizou-se a caracterização físico-química, térmica, viscoamilográfica e reológica da farinha de banana verde produzida. Verificou-se que as bananas mantiveram as características referentes ao primeiro estágio de maturação por 16 dias após a colheita, com o conteúdo de amido resistente pouco alterado neste período. Na secagem das rodelas de banana verde observou-se a presença de duas fases de secagem em velocidade decrescente. O conteúdo de $A R$ foi influenciada significativamente pela temperatura e velocidade de secagem. Desta forma, as farinhas produzidas apresentaram teor de amido resistente na faixa de (40 - 59) g/100 g b.s. As análises térmicas apresentaram temperaturas de pico de gelatinização de $(67,9 \pm 0,3)$ ${ }^{\circ} \mathrm{C} \mathrm{a}(68,6 \pm 0,3){ }^{\circ} \mathrm{C}$.

\subsection{Secagem}

Uma das primeiras regras de processamento de alimentos é a de converter alimentos perecíveis - tais como frutas - em produtos estáveis que podem ser armazenados por longos períodos de tempo, reduzindo, dessa forma, as suas perdas. Vários processos tecnológicos têm sido explorados em escala industrial com o fim de preservar alimentos perecíveis, tais como o enlatamento, congelamento e a desidratação, sendo esta última a mais antiga (LIMA; NEBRA; QUEIROZ, 2000).

A secagem de sólidos é uma das mais antigas e usuais operações unitárias encontradas nos mais diversos processos usados nas indústrias agrícolas, químicas, alimentícias, farmacêuticas, de papel, celulose, mineral e polímeros. Segundo Mujumdar (2006) é também uma das operações mais complexas e menos compreendidas, devido à dificuldade da descrição matemática dos fenômenos envolvidos, da transferência simultânea de calor e massa no sólido. 
A secagem tem como finalidade eliminar um líquido volátil, contido em um corpo não volátil, por meio da evaporação. Durante a secagem, é necessário um fornecimento de calor para evaporar a umidade do material, e também deve haver um sorvedor de umidade para remover o vapor de água formado a partir da superfície do material seco. Esse processo de fornecimento de calor, da fonte quente para o material úmido, promoverá a evaporação da água do material. Em seguida, a transferência de massa arrastará o vapor formado. O movimento de água, do interior do material até a superfície é analisado pelos mecanismos de transferência de massa, os quais indicarão a dificuldade de secagem dos materiais (PARK et al., 2007).

A evolução das transferências simultâneas de calor e de massa no decorrer da operação de secagem faz com que esta seja dividida, esquematicamente, em períodos, mostrados na Figura 3.4.

Figura 3.4 - Períodos durante o processo de secagem

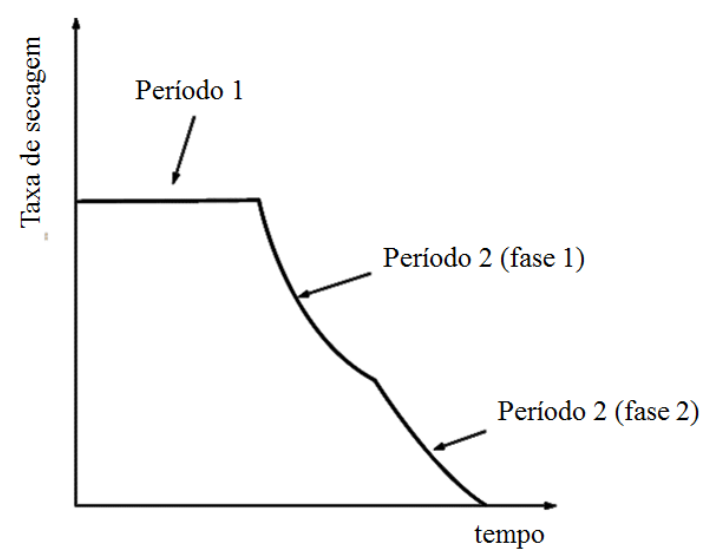

Fonte: Adaptado de Mujundar (2006).

Park et al. (2007) descreveram os períodos no processo da secagem:

Período 0: de indução ou o período de entrar em regime operacional. No começo, o produto é geralmente mais frio do que o ar, a pressão parcial de vapor da água na superfície do produto é débil e, por consequência, a transferência de massa e a taxa de secagem também são débeis. A duração deste período é insignificante em relação ao período total de secagem, e não é visível na Figura 3.4. 
Período 1: consiste no período de taxa constante de secagem. Durante este período, assim como no anterior, a quantidade de água disponível dentro do produto é bem grande. A água evapora como água livre. A pressão de vapor de água na superfície é constante e é igual à pressão de vapor de água pura à temperatura do produto. Este período continua enquanto a migração de água do interior até a superfície do produto for o suficiente para acompanhar a perda por evaporação de água na superfície. É bom ressaltar que, para os materiais biológicos, é difícil a existência deste período.

Período 2: Consiste no período de taxa decrescente de secagem. A taxa de secagem diminui desde o momento em que a água começa a ser deficiente na superfície. Apesar de alguns autores definirem o valor do teor de água do produto no ponto de transição entre os períodos 1 e 2 como conteúdo crítico de água, seria conveniente denominar esse ponto como o de inflexão. Essa transição é frequentemente pouco nítida e o teor de água, nesse ponto, varia de acordo com a natureza do material, a sua espessura e a velocidade de secagem.

O período 2 é quase sempre o único observado para a secagem de produtos agrícolas e alimentícios. A complexidade dos fenômenos, colocados em jogo, durante a secagem, conduz os pesquisadores a propor numerosas teorias e múltiplas fórmulas empíricas para predizer a taxa de secagem neste período. Ele ainda é subdividido em duas fases, como observado na Figura 3.4. Entretanto, é bem difícil indicar com clareza as divisões nas curvas experimentais de secagem (BROD, 2003). Duas fases de taxa descrente são comumente observadas na secagem de produtos higroscópicos, que incluem as frutas e os vegetais (SCHÖSSLER; JÄGER; KNORR, 2012a). Nos estudos de secagem da banana verde realizados por Tribess (2009) e por Zabalaga (2016), as autoras observaram que o mecanismo de retirada de umidade acontece no período decrescente e, ainda, verificaram duas fases dentro desse período.

A migração interna de água, no decorrer do período de taxa decrescente, determina a cinética de secagem. De acordo com Park (1987), as teorias para se explicar o comportamento da água podem ser resumidas em duas: a teoria difusional e a teoria capilar. 


\subsubsection{Teoria Difusional}

Esta teoria se apoia exclusivamente sobre a Lei de Fick, que expressa que o fluxo de massa é proporcional ao gradiente da concentração de água. Utilizando a Lei de Fick na equação do balanço de massa de água no interior do produto, tem-se a eq. (1):

$$
\frac{\partial X}{\partial t}=\nabla\left(D_{e f} \cdot \nabla X\right)
$$

Em que:

$D_{e f}=$ difusividade efetiva da água $\left(\mathrm{m}^{2} / \mathrm{s}\right) ;$

$X=$ conteúdo de umidade (b.s.);

$t=$ tempo $(\mathrm{s})$.

Como a difusividade da água varia conforme mudam as condições de secagem (a temperatura e velocidade do ar), ela não é intrínseca ao material; portanto, convenciona-se chamar de difusividade efetiva $\left(D_{e f}\right)$. Crank (1975) apresentou um grande número de soluções da equação da difusão para diferentes condições iniciais e de contorno. Entretanto, essas soluções se aplicam aos sólidos de formas geométricas simples - corpos semi-infinitos, placas, cilindros e esferas. As hipóteses para a solução da equação são:

1. A difusividade da água é constante. A secagem se faz de maneira isotérmica e a difusividade é independente do teor de água;

2. O produto é homogêneo. Apresenta geometria regular simples e simétrica: em geral, os autores fazem relação a uma esfera ou placa plana. A dimensão característica $(L=x$ e/ou r) é adotada considerando o mesmo volume para o produto e a geometria adotada;

3. As dimensões do produto permanecem constantes ao longo do tempo, o que não ocorre com os produtos biológicos, pois os mesmos encolhem durante a secagem. O movimento de água resulta de um gradiente dentro da partícula, onde é assumido um perfil linear de concentração de umidade do material;

4. A superfície do produto se põe imediatamente em equilíbrio com o ar de secagem;

5. O conteúdo de umidade do material tende para a umidade de equilíbrio. 
Considerando o material, na forma de uma placa plana de espessura $2 L$, de difusão unidirecional, e as seguintes condições de contorno:

○ Umidade inicial uniforme: $X(z, t)=X(z, 0)=X_{0}$

○ Simetria: $\partial X /\left.\partial z\right|_{z=0}=0$

○ Umidade de equilíbrio na superfície: $X_{(z, t)}=X_{(L, t)}=X_{e}$

A eq. (2) é a resolução proposta (ANTONIO, 2006; BROD,2003; PARK et al., 2001, entre outros):

$$
\frac{X-X_{e}}{X_{0}-X_{e}}=\frac{8}{\pi^{2}} \sum_{i=0}^{\infty} \frac{1}{(2 i+1)^{2}} \cdot \exp \left[-(2 i+1)^{2} \cdot \pi^{2} \cdot \frac{D_{e f}}{4 L^{2}} \cdot t\right]
$$

Em que:

$X=$ conteúdo de umidade ao longo do tempo (b.s.);

$X_{e}=$ conteúdo de umidade no equilíbrio (b.s.);

$X_{0}=$ conteúdo de umidade inicial (b.s.);

$D_{e f}=$ difusividade efetiva da água $\left(\mathrm{m}^{2} / \mathrm{s}\right)$

$L=$ semi-espessura da amostra (m);

$t=$ tempo $(\mathrm{s})$

$i=$ número de termos da série.

Comumente, a relação entre as umidades é expressa como a razão do conteúdo de umidade (MR) de acordo com a eq. (3)

$$
M R=\frac{X-X_{e}}{X_{0}-X_{e}}
$$

Para tempos longos de secagem, a eq. (2) pode ser simplificada e truncada para o primeiro termo da equação $(i=0)$, tornando-se a eq. 4 :

$$
M R=\frac{8}{\pi^{2}} \cdot \exp \left[-\pi^{2} \cdot \frac{D_{e f}}{4 L^{2}} \cdot t\right]
$$


Nestas condições, a difusividade efetiva da água poderia ser determinada aplicando o método das tangentes (KARATHANOS, VILLALOBOS e SARAVACOS et al., 1990; SCHÖSSLER et al., 2012a). A curva experimental de secagem é comparada com a teórica, obtida do número de Fourier $\left(F_{o}\right)$. Para uma placa infinita, o número de Fourier está dado por:

$$
F_{o}=\frac{D_{e f}}{L^{2}} \cdot t
$$

A tangente da curva experimental $(\mathrm{d} M R / \mathrm{d} t)_{\exp }$ e da curva teórica $\left(\mathrm{d} M R / \mathrm{d} F_{o}\right)_{\text {teo }}$ são estimadas pelos segmentos retos de $\ln (M R)$ vs. $t$ e $\ln (M R)$ vs $F_{o}$. Esta metodologia foi aplicada para a determinação da difusividade efetiva da água de alimentos como a maçã e o pimentão (SCHÖSSLER et al., 2012a), amido gelatinizado (KARATHANOS et al., 1990) e a banana verde (TRIBESS, 2009), entre outros.

\subsubsection{Teoria Capilar}

Daudin apud Brod (2003) expõe, detalhadamente, a teoria do movimento capilar da água líquida dentro de sistemas simples, constituídos por capilares dentro de sistemas complexos, tal como os corpos porosos. O princípio é o seguinte: para um tubo capilar isolado, a pressão de sucção e então ascensão da água dentro do capilar é proporcional à tensão superficial de água e, inversamente, proporcional ao seu raio. Admitindo-se que a tensão capilar é fortemente associada ao teor de água, o autor, estabeleceu uma lei geral na qual a força matriz é o gradiente do teor de água. De acordo com BROD (2003), a migração capilar em produtos vegetais tem pouca influência. No entanto, não se pode esquecer que esta teoria fornece ferramentas poderosíssimas para fundamentar as equações fenomenológicas de transferência simultânea de calor e de massa.

\subsubsection{Modelos empíricos}

Em algumas situações, a aplicação da teoria difusional ou capilar não é adequada para ajustar a cinética de secagem, devido ao efeito das resistências interna e externa sobre o material. Nestes casos, modelos empíricos podem ser aplicados para ajustar os dados experimentais. Consequentemente, os modelos serão válidos somente no domínio da pesquisa experimental, na qual foram estabelecidos (BROD, 2003). Na literatura, vários modelos empíricos são propostos e, na Tabela 3.1, alguns dos mais empregados na secagem de frutas e verduras, são apresentados. 
Tabela 3.1 - Modelos empíricos propostos na literatura

\begin{tabular}{llc}
\hline Modelo & \multicolumn{1}{c}{ Equação } & Referência \\
\hline Newton & $\mathrm{MR}=\exp (-k t)$ & O' CALLAGHAN et al. (1971) \\
Page & $\mathrm{MR}=\exp \left(-k t^{n}\right)$ & ZHANG e LITCHFIELD (1991) \\
Henderson \& Pabis & $\mathrm{MR}=a \exp (-k t)$ & HENDERSON \& PABIS (1961) \\
Logaritmico & $\mathrm{MR}=a \exp (-k t)+c$ & YALDIZ et al. (2001) \\
Midilli & $\mathrm{MR}=a \exp \left(-k t^{n}\right)+b t$ & MIDILLI et al. (2002)
\end{tabular}

\subsection{Som e ultrassom}

O som é uma onda mecânica que se propaga longitudinalmente em meios materiais. A velocidade do som varia de acordo com a densidade do meio em que este se propaga (HUGH; FREEDMAN, 2009). Ainda, segundo os autores, as ondas sonoras classificam-se em três tipos, como apresentados na Figura 3.5.

Figura 3.5 - Classificação do som

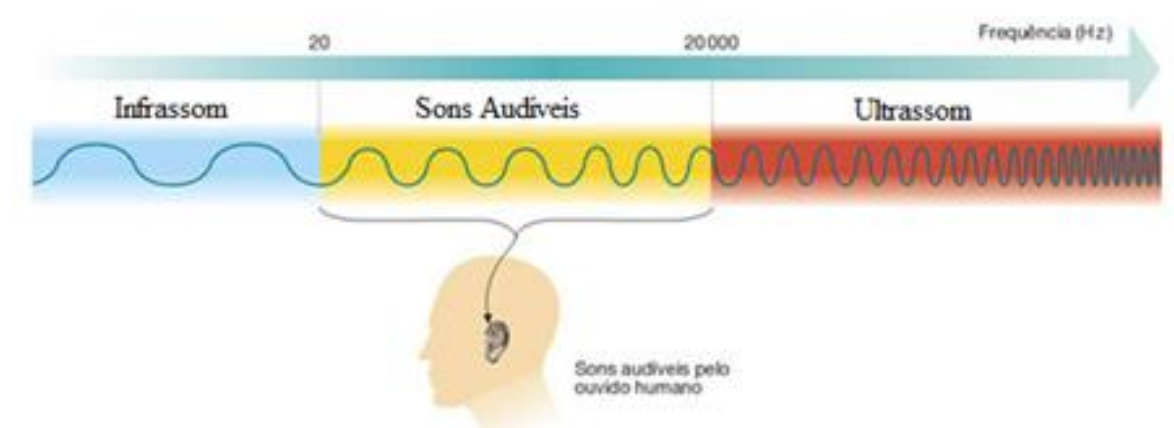

Fonte: Adaptado de Machado (2016).

- Infrassom: Ondas mecânicas com frequências inferiores a $20 \mathrm{~Hz}$. Nessa frequência, o som não é audível pelo ouvido humano.

- Som: ondas mecânicas produzidas por uma fonte nas frequências audíveis pelo ouvido humano, que variam entre $20 \mathrm{~Hz}$ e $20.000 \mathrm{~Hz}$.

- Ultrassom: são ondas mecânicas com frequências superiores a $20.000 \mathrm{~Hz}$, e também não são audíveis pelo ouvido humano. 
Numa posição fixa no meio, as ondas sonoras se comportam de forma sinusoidal em relação ao tempo, como mostrado na Figura 3.6.

Figura 3.6 - Características de uma onda sonora

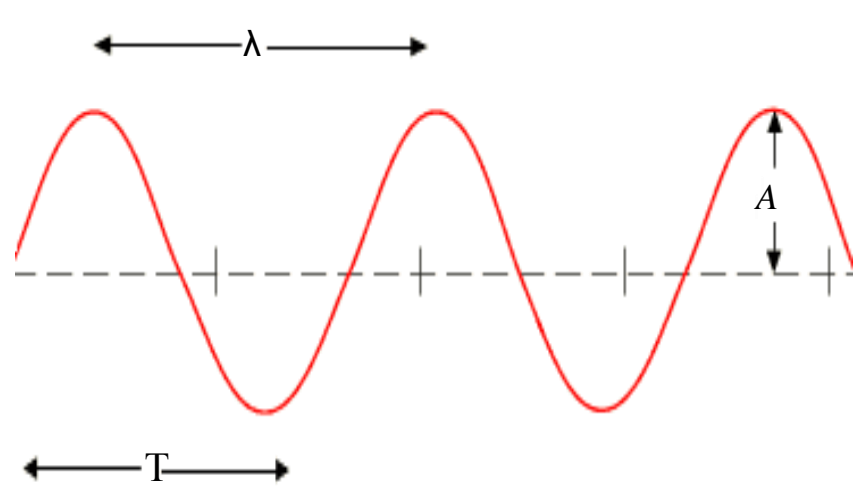

Fonte: Adaptado de Hugh e Freedman (2009).

De acordo com McClements (1995) as ondas sonoras apresentam as seguintes características: frequência $(f)$, que corresponde ao número de vibrações por segundo, medida em hertz. Período (T), que é o tempo de um ciclo completo de uma oscilação de onda. Amplitude $(A)$, que é a medida da extensão de uma perturbação durante um ciclo da onda e o comprimento de onda $(\lambda)$, que é a distância entre o pico de uma onda e o da seguinte.

A ideia de utilizar o eco das ondas sonoras como forma de detecção de objetos (ecolocalização) data do início do século XX, após estudos com golfinhos e morcegos. Após a I Guerra Mundial, este princípio passou a ser utilizado em instrumentos de navegação em águas profundas, originando o SONAR (Sound Navigation and Ranging) em 1917. Em 1941, esse princípio foi aplicado na navegação aérea com ondas de radiofrequência, as quais originaram o RADAR (Radio Detection and Ranging). Somente após a II Guerra Mundial cresceu o interesse do uso de ecos de ondas de som na medicina. Os médicos Douglas Howry e D. Ronderic Bliss foram pioneiros ao realizar estudos com o ultrassom. Em 1949, desenvolveram o primeiro sistema com objetivo médico e, em 1950, captaram a primeira imagem médica por ultrassom (LINS, 2013). 


\subsubsection{Aplicações do ultrassom}

Ao longo dos últimos anos, tem havido um crescente interesse do consumidor em relação a alimentos funcionais que, além da função básica de fornecer nutrientes, diminuem o risco de doenças e, assim, promover a saúde. Em vista disso, é de suma importância aplicar métodos de processamento que preservem, não apenas o valor nutricional e sensorial, mas, também, a bioatividade de alguns dos seus compostos (SORIA; VILLAMIEL, 2010). A aplicação de calor é a técnica mais comum para o processamento de alimentos, devido à sua capacidade de eliminar micro-organismos e inativar enzimas. No entanto, o processamento com calor sob certas condições pode alterar as propriedades físicas e químicas, que prejudicam as propriedades organolépticas e reduzem o conteúdo ou a biodisponibilidade de alguns nutrientes. Portanto, a indústria de alimentos está constantemente à procura de novas tecnologias emergentes de processamento, não só para obter alimentos de alta qualidade, mas também alimentos funcionais (ASHOKKUMAR et al., 2008). Entre estas tecnologias emergentes, durante os últimos anos, destaca-se o ultrassom.

O ultrassom é classificado de acordo com a intensidade das ondas. Recentemente, algumas das aplicações do ultrassom na tecnologia de alimentos envolvem análises não destrutivas, importantes na avaliação da qualidade dos produtos; pois fornecem informações sobre as propriedades físico-químicas como a firmeza, maturação, o teor de açúcares e a acidez. Tais aplicações utilizam alta frequência $(100 \mathrm{kHz}$ até $1 \mathrm{MHz})$ e baixa intensidade de potência (tipicamente $<1 \mathrm{~W} / \mathrm{cm}^{2}$ ). Por outro lado, encontram-se as aplicações de baixa frequência (16 até 1000$) \mathrm{kHz}$ e alta intensidade de potência entre (10 e 1000) W/ $\mathrm{cm}^{2}$ empregadas para alterar, seja física ou quimicamente, as propriedades dos alimentos (BERMÚDEZ-AGUIRRE et al., 2011; McCLEMENTS, 1995).

Nos meios líquidos, o efeito de ultrassom mais conhecido é o da cavitação. Quando uma onda sonora intensa passa através de um líquido, cria regiões de compressão (pressão positiva) e de rarefação (pressão negativa). Se a pressão negativa durante a rarefação é alta o suficiente, uma cavidade ou bolha pode formar-se no líquido a partir de núcleos de gases existentes no interior do fluído. Estas bolhas, distribuídas por todo o líquido, crescem até chegar num tamanho crítico, no qual se tornam instáveis e colapsam (MASON et al., 2005). A implosão de bolhas na cavitação leva a acúmulos de energia em zonas quentes, gerando temperaturas extremas $(5000 \mathrm{~K})$ e pressões de 1000 atm que produzem, por sua vez, altas energias de cisalhamento e turbulência na zona da cavitação. Outro fenômeno resultante da variação do tamanho da bolha e subsequente colapso é o desenvolvimento de fortes correntes (ou micro- 
streaming) que alteram as características do meio (SORIA; VILLAMIEL, 2010). O processo da cavitação é apresentado esquematicamente na Figura 3.7.

Figura 3.7 - Processo de cavitação no ultrassom

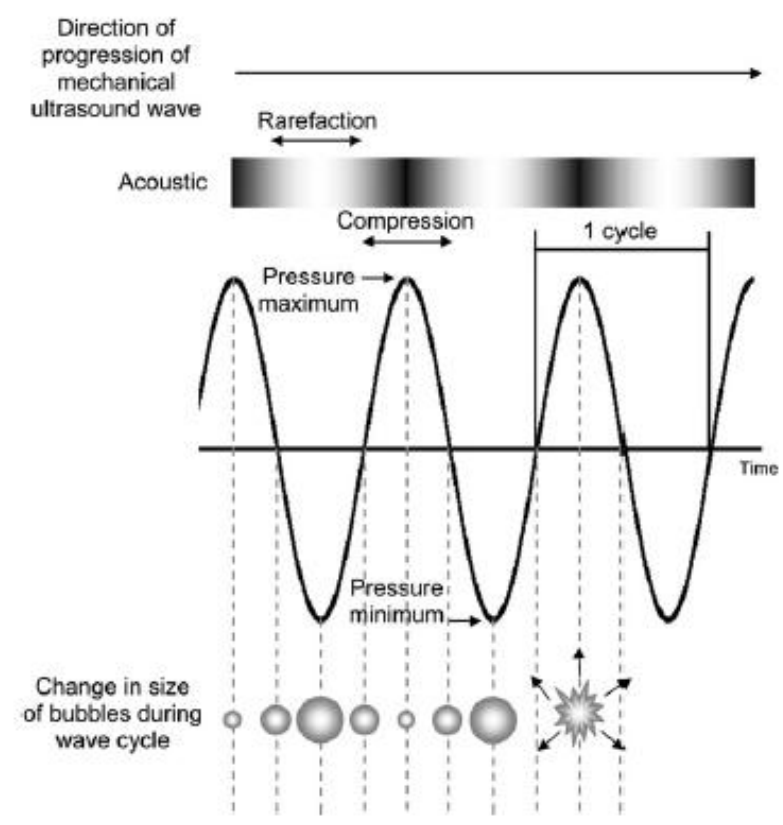

Fonte: Soria e Villamiel (2010)

São muitas as aplicações do ultrassom. Entre as mais destacadas encontram-se:

Inativação microbiológica. A interação entre a energia ultrassônica e os micro-organismos é complexa. O ultrassom em combinação com a temperatura (termocavitação) podem inativar bactérias com a finalidade de garantir a inocuidade do alimento (KENTISH; FENG, 2014).

Inativação enzimática. Para alimentos líquidos, o ultrassom pode ser aplicado como uma alternativa para o processamento térmico, com a finalidade de inativar enzimas, minimizando, desta maneira, a degradação da qualidade do produto, causada pelo calor (KENTISH; FENG, 2014).

Congelamento. $\mathrm{O}$ ultrassom pode promover a nucleação do gelo durante o congelamento. A distribuição do tamanho de cristal pode ser controlada, minimizando, assim, a destruição celular (ZHENG; SUN 2006). 
Emulsificação/homogeneização. Para criar uma emulsão de dois líquidos imiscíveis, tratados com ultrassom, num deles deve acontecer a cavitação. Durante a cavitação, as bolhas podem entrar em colapso perto da interface dos dois líquidos e o resultado do choque é uma mistura eficiente. Consequentemente, emulsões altamente estáveis podem ser obtidas com relativa baixa potência ultrassônica (SORIA; VILLAMIEL, 2010).

Alterações na viscosidade e textura. Dependendo da intensidade do ultrassom, a viscosidade de alimentos pode aumentar ou diminuir, e o efeito pode ser reversível ou permanente. A cavitação provoca forças de cisalhamento, o que, no caso de fluidos tixotrópicos, provoca uma diminuição reversível da viscosidade. Se a energia suficiente é aplicada, o peso molecular pode ser alterado, dando origem a uma diminuição irreversível da viscosidade (SESHADRI et al., 2003).

Qualquer sistema de aplicação de ultrassom deve ser capaz de produzir um campo ultrassônico estável e confiável. Normalmente o sistema ultrassônico está composto de três elementos básicos (CARCEL et al., 2014): a Fonte de energia é qualquer tipo de energia que possa ser convertida em energia ultrassônica. No entanto, a mais empregada é a energia elétrica. O Transdutor converte a energia fornecida em energia ultrassônica. Existem muitos tipos de transdutores, a característica de cada um depende da fonte de energia e o meio onde será aplicado e para cada aplicação específica. Em aplicações ultrassônicas de alta potência, normalmente, são empregados os transdutores piezoelétricos. Finalmente, o Meio de aplicação, um dos principais problemas nas aplicações de ultrassom é o de atingir um bom acoplamento entre o sistema que gera as ondas e meio a ser tratado. A diferença da impedância entre o sistema e o meio, dificulta a transmissão das ondas e ocasiona reflexão. Esta que, inclusive, pode causar dano ao sistema. Portanto, quanto maior for a diferença na impedância, menor será a eficiência de transmissão do ultrassom.

Ao operar em condições idênticas, o mesmo sistema ultrassônico produz um efeito acústico diferente, dependendo das propriedades do meio como a: viscosidade, densidade ou tensão superficial. A frequência das ondas está ligada à vibração produzida pelo ultrassom nas interfaces, cujos efeitos se tornam mais acentuados à medida que a frequência aplicada aumenta. Além disso, não somente as propriedades físicas têm uma influência significativa no campo ultrassônico aplicado, mas também o nível de agitação do meio (CÁRCEL et al., 2014). De acordo com Cárcel et al. (2003), quando a água é fortemente agitada, a pressão acústica medida é significativamente reduzida. As turbulências produzidas pela agitação perturbam o campo ultrassônico, que, por sua vez, reduz a energia ultrassônica efetiva aplicada e, portanto, a sua capacidade de afetar o processo de transferência de massa. 
Tal como foi comentado previamente, o ultrassom podem ser utilizado para melhorar vários processos de transferência de massa. Entre estes se destaca o da secagem, o foco do presente trabalho.

\subsubsection{Ultrassom e secagem}

Segundo Fuente-Blanco et al. (2006), as ondas ultrassônicas podem causar uma série de compressões e expansões, de uma maneira bem similar quando as esponjas são espremidas e liberadas repetidamente. As forças envolvidas por esse mecanismo podem ser mais elevadas do que a tensão superficial que mantém a umidade dentro do material, criando, assim, canais microscópicos que podem remover a umidade mais facilmente.

Segundo Miano et al. (2016), a melhoria da transferência de massa pelo ultrassom pode ser dividida em efeitos diretos e indiretos: os indiretos estão relacionados com a formação dos micro-canais no produto, devido às tensões mecânicas associadas à transmissão das ondas. E os efeitos diretos estão relacionados com o 'efeito esponja', produzido pelas ondas ultrassônicas, que viajam através do produto. Além disso, o 'efeito esponja' ajuda a manter os micro-canais desobstruídos, para o movimento de umidade, promovendo, dessa maneira, a sua migração no sólido. De acordo com as características do meio a ser tratado, a tecnologia do ultrassom pode ser aplicada de duas formas durante o processo da secagem:

Tratamento em meio gasoso. A aplicação do ultrassom de alta potência em meio gasoso, com a finalidade de melhorar o processo da secagem, é mais difícil quando comparado com a aplicação em meio líquido - devido aos gases terem uma maior capacidade de atenuação das ondas ultrassônicas e absorverem mais a energia. No entanto, sistemas com estas características conseguiram uma redução do tempo da secagem entre (30 e 75) \%, e valores no aumento da difusividade efetiva da água de $400 \%$, dependendo do produto (CARCEL et al., 2014).

Tratamento em meio líquido. Comumente aplicada como pré-tratamento ao processo da secagem. Os dois possíveis sistemas são probes ou banhos. Atualmente, banhos ultrassônicos são disponíveis no mercado em escala laboratorial e industrial, de diferentes tamanhos, potências e frequências. $\mathrm{O}$ aumento no valor da difusividade efetiva da água vai depender da intensidade de potência $\left(\mathrm{W} / \mathrm{cm}^{2}\right)$ aplicada. 
O efeito do pré-tratamento com ultrassom é principalmente advertido durante o processo da secagem, no qual é observado um aumento na difusividade efetiva da água. Além disso, em processos com valores altos de difusividade efetiva, tempos de secagem menores são relatados (RODRIGUES; FERNANDES, 2008).

Aumento na difusividade efetiva da água foi observado na secagem convectiva de vários tipos de frutas e vegetais. No caso da banana, Fernandes e Rodrigues (2007) estudaram a aplicação de ultrassom como pré-tratamento na secagem convectiva de banana madura (Musa ssp. var. Nanica). Os tempos de banho ultrassônico estudados foram de (10, 20 e 30) min. Após a aplicação do ultrassom, as bananas foram submetidas à secagem convectiva a temperatura de $60{ }^{\circ} \mathrm{C}$ e $16 \%$ UR. Segundo os autores, amostras com tempo de imersão de 20 min apresentaram maiores valores de difusividade efetiva da água. No entanto, o tempo de imersão de 30 min não se mostrou mais benéfico para o processo de secagem. Provavelmente porque tempos muito altos de ultrassom, ocasionam mudanças muito drásticas na estrutura da fruta. Observou-se uma redução do tempo total de processamento de 10,3\%. Segundo os autores, as amostras precisaram de um menor tempo para atingir a umidade de equilíbrio e para remover $95 \%$ do conteúdo de água inicial. Consequentemente, a eficiência do processo de secagem aumentou.

Azoubel et al. (2010) secaram fatias de banana (21 ${ }^{\circ}$ Brix) (cv. Pacovan) pré-tratadas em banho ultrassônico, com tempos de imersão de (10, 20 e 30) min. Após a aplicação do ultrassom, as fatias de banana foram submetidas à secagem convectiva a $70{ }^{\circ} \mathrm{C}$ e velocidade do ar de $3 \mathrm{~m} / \mathrm{s}$. As amostras que foram imersas por tempos maiores no banho de ultrassom (30 min) apresentaram difusividade efetiva da água mais elevada, em comparação às fatias sem prétratamento.

\subsection{Secagem a vácuo}

A principal aplicação da secagem a vácuo é a desidratação de alimentos muito sensíveis ao calor, como sucos de frutas, tomate concentrado e extratos de café. Os produtos assim tratados se expandem ao se aplicar vácuo na câmara, pela liberação de gases e vapores. Essa estrutura porosa favorece a secagem e a sua posterior reidratação (PUHL; NITZKE, 2014). 
Os processos a vácuo oferece uma vantagem única. Sob vácuo, a evaporação da água ocorre em temperaturas mais brandas, tornando o processo mais eficaz. Desta forma, este tipo processamento permite a obtenção de produtos de alta qualidade, mantendo as suas características (PUHL; NITZKE, 2014).

Segundo Sokhansanj e Jayas (2006), a técnica de secagem a vácuo consiste em secar o produto utilizando a combinação de aquecimento e vácuo. A transferência de calor se dá por condução e radiação, ou seja: o calor é transportado da placa de aquecimento para a bandeja, contendo o alimento por condução, sendo que, o alimento também é submetido à transferência de calor por radiação, proveniente das paredes da câmara. Assimilar essa distinção é essencial para compreender as vantagens e limitações da secagem à vácuo, bem como para selecionar um secador à vácuo que, de forma eficiente e econômica, atinge aos objetivos do processo (PUHL; NITZKE, 2014).

Com a diminuição da pressão do sistema, na secagem à vácuo, o ponto de ebulição da água é reduzido para abaixo de $100{ }^{\circ} \mathrm{C}$. A redução da pressão do sistema e a temperatura de secagem a serem empregadas dependem da sensibilidade do material. A secagem à vácuo é um método intermediário entre a secagem convencional e a liofilização, pois permite trabalhar em pressões baixas e em temperaturas moderadas (PORCIUNCULA, 2014).

O vácuo causa a expansão do ar e do vapor de água presentes no alimento, dando origem a uma estrutura fofa e inflada. Essa estrutura expandida resulta em uma alta razão área/volume, que resulta em altas taxas de secagem (JAYA; DAS, 2003).

Uma das aplicações mais importantes do vácuo é a sua combinação com a desidratação osmótica, já que foi observada uma maior perda de água e ganho de solutos. Segundo Fito (1994), a principal diferença entre a desidratação osmótica à vácuo e a desidratação em pressão normal se deve à transferência de matéria por um mecanismo hidrodinâmico como consequência da mudança de pressão ocorrida no sistema. E que se traduz em um aumento da superfície de contato sólido-líquido nos poros do produto. Não obstante, o maior incoveniente da desidratação osmótica à vácuo é o elevado custo do equipamento requerido, para poder se trabalhar em baixas pressões. 
$\mathrm{Na}$ literatura, existem diversos estudos sobre a aplicação de secagem à vácuo para diferentes frutas, como a maçã, o pêssego e a manga (BOIRA et al., 2007; ITO et al., 2007; MERLIN, 2007). Com relação à banana (SOUSA, 2002; SOUSA et al., 2003 entre outros), na maioria dos estudos, o vácuo está associado à desidratação osmótica. Porciuncula (2010) estudou a secagem da banana (var. Prata) por ciclos de aquecimento-pulso de vácuo (1,5 kPa), nos quais as amostras foram colocadas em uma câmara selada e aquecida até $60{ }^{\circ} \mathrm{C}$. Atingida a temperatura, foi aplicado vácuo durante 5 min. Após esse período, a pressão do sistema foi restabelecida e as amostras foram aquecidas novamente para a aplicação de um novo ciclo de vácuo. No total, 12 ciclos foram aplicados. O tempo total deste processo foi menor comparado com a secagem convectiva. Ainda não foram relatados, na literatura, estudos sobre a secagem convectiva da banana verde, assistida com pulsos de vácuo inicial e à baixa temperatura. 


\section{MATERIAIS E MÉTODOS}

\subsection{Matéria-prima}

Bananas verdes (Musa acuminata subgrupo Cavendishii) da variedade Nanicão, com estágio de maturação 1, não submetidas ao processo de maturação com etileno em câmara controlada, e provenientes da região do Vale da Ribeira (SP) foram coletadas semanalmente da Companhia de Entrepostos e Armazéns Gerais de São Paulo (CEAGESP), caracterizadas e processadas imediatamente.

\subsubsection{Caracterização físico-química}

As bananas foram caracterizadas em função dos seguintes parâmetros: teor de sólidos solúveis, firmeza e teor de umidade. A caracterização foi feita em toda a matéria-prima antes da realização dos experimentos, para certificar que os frutos se encontravam no primeiro estágio de maturação.

\section{- Teor de sólidos solúveis}

A determinação de sólidos solúveis foi realizada por medida direta em um refratômetro de bancada (CARL-ZEISS JENA, modelo 711849, Alemanha), em duplicata, à temperatura ambiente. Pedaços de banana foram ralados e, logo, dispostos em tecido estéril e de textura porosa e macerados até a obtenção de gotas de suco. Os dados foram corrigidos e apresentados a $20^{\circ} \mathrm{C}$, segundo Zenebon et al. (2008).

\section{- Firmeza}

A firmeza da banana in natura foi determinada em triplicata, em um texturômetro (SMS, modelo XT2i Plus, Inglaterra), por meio do teste de penetração com um probe de aço de $6 \mathrm{~mm}$ de diâmetro, a uma velocidade de penetração de $1,0 \mathrm{~mm} / \mathrm{s}$, de acordo com a metodologia proposta por Ditchfield e Tadini (2002). Em cada banana foi medida a penetração em três pontos: no início, no meio e no final do fruto, como mostrado na Figura 4.1. A média das três determinações da força máxima da curva força-deformação foi considerada como a firmeza, expressa em Newton $(\mathrm{N})$. 
Figura 4.1 - Procedimento para determinação da firmeza na banana in natura

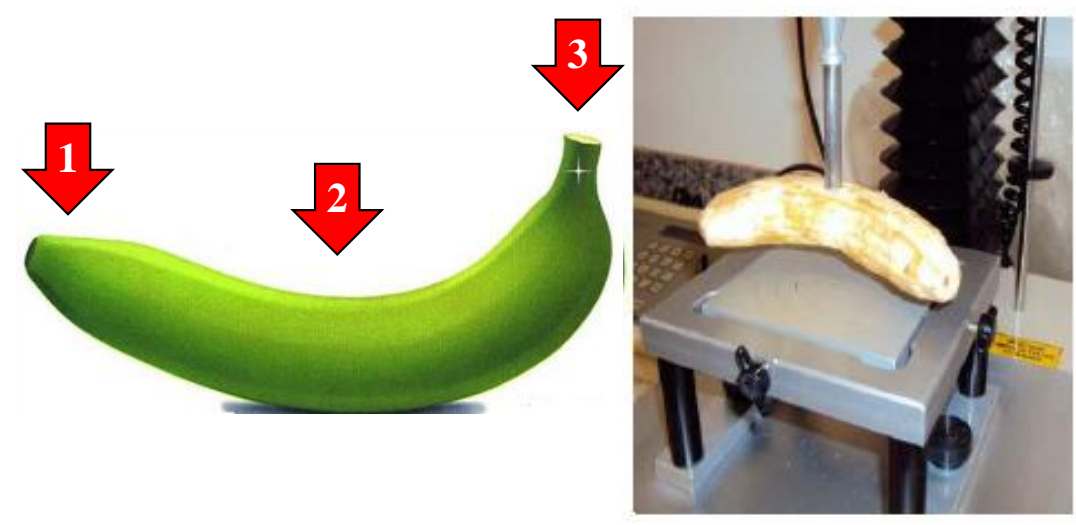

Fonte: Adaptado de Rayo (2013).

\section{- Umidade}

A determinação da umidade da banana foi realizada em triplicata em estufa (MARCONI, modelo MA030, Brasil), a $70{ }^{\circ} \mathrm{C}$ sob vácuo de $\leq 20 \mathrm{kPa}$ até peso constante, de acordo com a metodologia proposta por Zenebon et al. (2008).

\subsection{Métodos}

A presente pesquisa foi conduzida em quatro etapas. Na primeira etapa, o estudo dos pré-tratamentos: ultrassom e pulsos de vácuo, foram realizados. $\mathrm{Na}$ segunda etapa, após a primeira aproximação com o mecanismo de ação dos pré-tratamentos, foram realizados alguns ensaios de pré-tratamento de ultrassom seguido de secagem convectiva, considerados ensaios preliminares. Estes ensaios foram conduzidos em estufa convectiva, em que o único parâmetro do processo da secagem controlado foi a temperatura. Na terceira etapa do trabalho foram conduzidos ensaios de secagem no secador de bandejas (LABMAQ, modelo LM.ES-20, Brasil). Os experimentos realizados foram: ultrassom seguido de secagem convectiva; pulso de vácuo seguido de secagem convectiva e finalmente, ultrassom seguido pulso de vácuo e secagem convectiva. Na quarta e última etapa foi caracterizada a farinha de banana verde produzida sob algumas das condições de secagem descritas na terceira etapa. 


\subsubsection{Ultrassom}

Os ensaios com ultrassom foram realizados em dois equipamentos: um banho ultrassônico (UNIQUE, modelo USC-1850, Brasil) de $25 \times 10 \times 10 \mathrm{~cm}^{3}$, potência nominal 154 W e frequência de $25 \mathrm{kHz}$, do Laboratório de Engenharia de Alimentos (LEA); e o segundo foi o banho ultrassônico (FISHER SCIENTIFIC, modelo FS 110, USA) de $31 \times 15 \times 31 \mathrm{~cm}^{3}, 135$ W de potência nominal e $42 \mathrm{kHz}$ de frequência, do Laboratório de Simulação e Controle de Processos (LSCP), ambos do Departamento de Engenharia Química da Universidade de São Paulo (USP).

\section{- Determinação da Potência volumétrica ultrassônica (W/L)}

Como os efeitos do ultrassom estão diretamente relacionados ao campo de aplicação, a sua caracterização é fundamental. Usualmente a potência ultrassônica é expressa como o consumo energético do gerador. No entanto, essa informação é incompleta porque o campo ultrassônico efetivo, aplicado às amostras, depende de outros parâmetros como a eficiência do transdutor em converter a energia elétrica em energia ultrassônica, as dimensões do banho e as características do fluido (viscosidade, tensão superficial, impedância, pressão de vapor, etc.), tal como exposto previamente. Um dos parâmetros para adequadamente caracterizar um campo ultrassônico é a potência volumétrica ultrassônica, visto que esta expressa a quantidade de energia real fornecida ao material (CÁRCEL et al., 2014).

A potência volumétrica ultrassônica (W/L) foi determinada segundo a metodologia proposta por Cárcel et al. (2007), em quintuplicata. As quatro paredes do banho ultrassônico foram isoladas com isopor, para minimizar a transferência de calor através das paredes. A fim de evitar que as ondas ultrassônicas voltem ao transdutor, e para garantir a perfeita absorção na água, o equipamento foi inclinado $30^{\circ}$ e as paredes e o fundo do banho foram cobertas com papel alumínio, como mostrado na Figura 4.2 (KIKUCHI; UCHIDA, 2011; VINATORU, 2015). O equipamento foi preenchido com $2 \mathrm{~L}$ de água destilada à temperatura de $26{ }^{\circ} \mathrm{C} \mathrm{e}, \operatorname{logo}$ em seguida, ligado por 5 min, enquanto que a temperatura da água foi registrada em tempo real por um termopar calibrado e com ajuda do software LabVIEW 2010 (National Instruments, USA). O aquecimento da água é o resultado da energia liberada pelas ondas do ultrassom e a potência volumétrica ultrassônica foi calculada de acordo a eq. (6). 


$$
P_{\mathrm{us}}=m C_{p} \frac{d T}{d t} \frac{1}{V}
$$

Em que:

$P_{\text {us }}=$ potência volumétrica ultrassônica $(\mathrm{W} / \mathrm{L})$;

$m=\operatorname{massa}(\mathrm{g})$

$C_{p}=$ capacidade calorífica $(\mathrm{J} / \mathrm{g} \mathrm{K})$;

$T=$ temperatura $\left({ }^{\circ} \mathrm{C}\right)$;

$t=$ tempo (s);

$V=$ volume $(\mathrm{L})$.

Figura 4.2 - Preparo do banho para determinação da potência volumétrica ultrassônica (W/L)

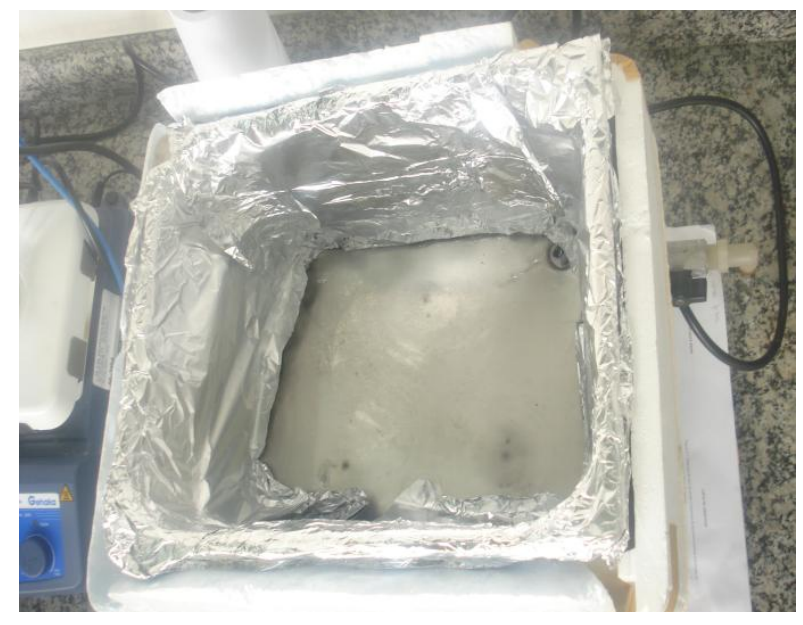

Fonte: O próprio autor.

\section{- Aplicação do ultrassom}

As bananas foram lavadas, descascadas manualmente e, logo em seguida, cortadas em rodelas de $5 \mathrm{~mm}$ de espessura com a ajuda de um cortador de frios (ECO, Brasil). Aproximadamente $500 \mathrm{~g}$ de rodelas de banana verde in natura foram colocadas em uma sacola de tecido perfurado e, logo em seguida, imersas no banho ultrassônico. A relação mássica entre a água destilada e a fruta se manteve em 4:1, em temperatura ambiente para todos os ensaios. Após o pré-tratamento, as amostras foram retiradas do banho, o excesso de água foi removido e, a seguir, estas foram submetidas à secagem convectiva em dois equipamentos: estufa (NOVA 
ÉTICA, modelo 410/4, Brasil) e no secador de bandejas (LABMAQ, modelo LM.ES-20, Brasil), a temperatura de secagem de $(50$ ou 60$){ }^{\circ} \mathrm{C}$.

$\mathrm{Na}$ Tabela 4.1 o resumo dos ensaios realizados com ultrassom prévios a secagem em estufa convectiva (NOVA ÉTICA, modelo 410/4, Brasil) ou no secador de bandejas (LABMAQ, modelo LM.ES-20, Brasil), em função do tempo, da potência nominal e frequência do ultrassom, é apresentado, sendo cada condição realizada em duplicata.

Tabela 4.1 - Tempo de imersão de ultrassom aplicado as rodelas de banana verde

\begin{tabular}{ccc}
\hline \multirow{2}{*}{$\mathrm{P}(\mathrm{W}) \times \mathrm{f}(\mathrm{kHz})$} & \multicolumn{2}{c}{ Tempo de ultrassom (min) } \\
\cline { 2 - 3 } & Estufa convectiva & Secador de bandejas \\
\hline & 0 & 0 \\
$154 \times 25$ & 15 & 20 \\
& 20 & 25 \\
& 25 & \\
$135 \times 42$ & 0 & \\
& 20 & \\
& 25 & \\
\end{tabular}

Fonte: O próprio autor.

Para todos os ensaios foi determinado o ganho de água $(G A)$ durante o pré-tratamento segundo a eq.(7)

$$
G A=\frac{m_{\mathrm{us}} x_{\mathrm{us}}-m_{0} x_{0}}{m_{0}} \times 100
$$

Em que:

$m_{0}=$ massa antes do pré-tratamento de ultrassom $(\mathrm{g})$

$m_{\mathrm{us}}=$ massa após pré-tratamento de ultrassom $(\mathrm{g})$;

$x_{0}=$ conteúdo de umidade inicial (b.u.);

$x_{\text {us }}=$ conteúdo de umidade após o pré-tratamento de ultrassom (b.u.). 
A determinação da umidade das rodelas de banana foi realizada em triplicata, em estufa (MARCONI, modelo MA030, Brasil) a $70{ }^{\circ} \mathrm{C}$, sob vácuo de $\leq 20 \mathrm{kPa}$ até peso constante, de acordo com a metodologia proposta por Zenebon et al. (2008).

\subsubsection{Aplicação de pulso de vácuo combinado com ultrassom}

Os ensaios de pulso de vácuo foram realizados no secador (LABMAQ, modelo LM.ES20, Brasil). A fim de compreender melhor o comportamento das rodelas de banana verde frente a esse pré-tratamento, foram realizados alguns ensaios preliminares. Pressões de $(0,1$ até 0,4$)$ bar e tempos de aplicação de (10 até 50) min em intervalos de 10 min foram testadas. No entanto, após a aplicação do pré-tratamento nestas condições, não foram observadas mudanças na aparência física e nem no peso total das rodelas. Consequentemente, decidiu-se por aplicar a máxima pressão de vácuo do equipamento, igual a 0,5 bar $\left(p_{\text {abs }}=51,325 \mathrm{kPa}\right)$ por tempos iguais e maiores a 60 min. Foram aplicados três pulsos de vácuo, o primeiro com duração de 60 min. Após esse tempo, três rodelas de banana foram coletadas do secador para a determinação do conteúdo de umidade. Um novo pulso de $30 \mathrm{~min}$ foi aplicado (totalizando 90 min), e o conteúdo de umidade de três rodelas de banana, após esta etapa, também foi determinado. Um último pulso de $30 \mathrm{~min}$ (totalizando $120 \mathrm{~min}$ ) foi aplicado e também foi feita a determinação do teor de umidade de três rodelas no final desta etapa. Os ensaios foram realizados, em triplicata, à temperatura ambiente. Na Figura 4.3 é apresentado um esquema da amostragem para melhor compreensão. As condições estudadas estão apresentadas na Tabela 4.2 .

Figura 4.3 - Descrição gráfica da amostragem durante a aplicação de pulsos de vácuo em rodelas de banana verde

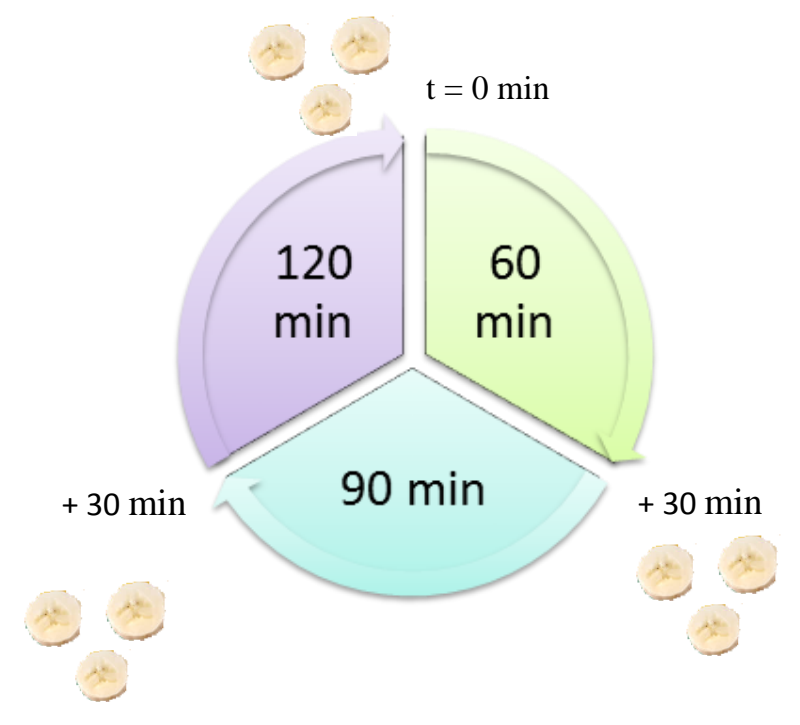

Fonte: O próprio autor. 
Tabela 4.2 - Tempos de pulso de vácuo aplicados em rodelas de banana verde

\begin{tabular}{lcc}
\hline Ensaio & $t$ ultrassom (min) & $t$ vácuo (min) \\
\hline Vácuo & 0 & 60 \\
& & 90 \\
Ultrassom (154 W x $25 \mathrm{kHz})$ seguido de pulso de vácuo & 20 & 120 \\
\hline & & 60 \\
\hline Ultrassom $(154 \mathrm{~W}$ x $25 \mathrm{kHz})$ seguido de pulso de vácuo & 25 & 90 \\
& & 60 \\
\hline
\end{tabular}

Fonte: O próprio autor.

O conteúdo de umidade, após os pulsos de vácuo, foi avaliado para rodelas de banana verde sem o pré-tratamento de ultrassom (in natura) e as amostras submetidas previamente ao banho ultrassônico (154 W x $25 \mathrm{kHz}$ ) por (20 e 25) min. A determinação da umidade da banana foi realizada em triplicata, em estufa (MARCONI, modelo MA030, Brasil), a $70{ }^{\circ} \mathrm{C}$ sob vácuo de $\leq 20 \mathrm{kPa}$ até peso constante, de acordo com a metodologia proposta por Zenebon et al. (2008).

\section{- Morfologia}

As rodelas de banana foram analizadas imediatamente após o pré-tratamento, e sem algum tipo de preparo, por um sistema de aquisição de imagens, mostrado na Figura 4.4. O sistema é composto por um estereomicroscópio (LEICA, modelo S6D, Alemanha) acoplado a uma câmara digital (LEICA, modelo MC 170 HD, Alemanha). As imagens foram coletadas num computador portátil e processadas através do software LAS V 4.5 (LEICA Micro Systems Applications, Suíça). Cinco estágios foram fotografados: rodelas de banana verde in natura; rodelas após a aplicação do ultrassom $(20$ ou 25) min; rodelas após a aplicação do primeiro pulso de $60 \mathrm{~min}$; do segundo pulso de 90 min e finalmente após o último pulso de $120 \mathrm{~min}$. As imagens foram capturadas a 40x de ampliação. 
Figura 4.4 - Sistema de aquisição de imagens composto por um estereomicroscópio (LEICA, modelo S6D, Alemanha) acoplado a uma câmara digital (LEICA, modelo MC 170 HD, Alemanha)

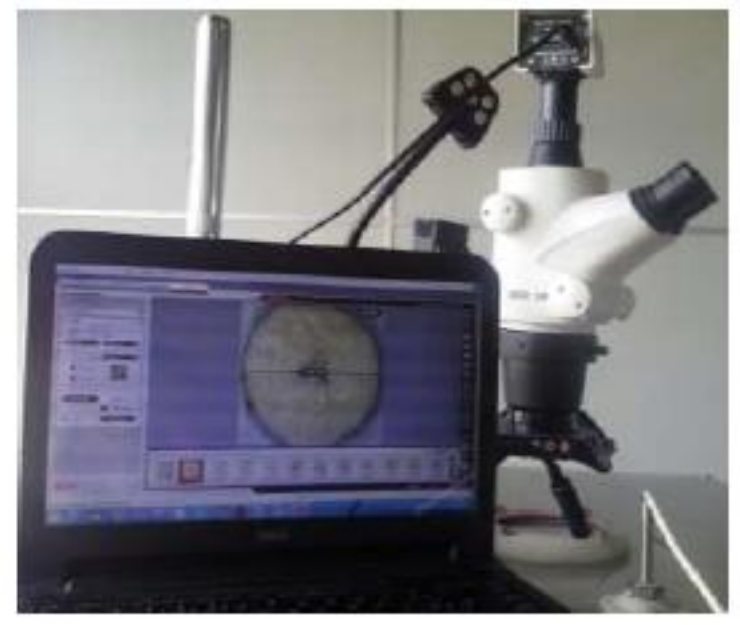

Fonte: Adapatado de Zabalaga (2016).

\section{- Análise estatística}

A interação das variáveis: tempo e potência volumétrica ultrassônica sobre o ganho de água; e o conteúdo de umidade após cada aplicação de pulso de vácuo foi avaliado estatisticamente por meio da Análise da Variância (ANOVA) multifatorial, aplicando o teste de Tukey, para o nível de confiança de $5 \%$, com o auxílio do software Statgraphics Centurion XV (StatPoint, Inc., USA). 


\subsubsection{Ensaios preliminares de secagem em estufa convectiva}

Os ensaios de secagem foram realizados em estufa convectiva (NOVA ÉTICA, modelo 410/4, Brasil), em duas condições de temperatura, (50 e 60) ${ }^{\circ} \mathrm{C}$, e velocidade do ar no centro da estufa de $1 \mathrm{~m} / \mathrm{s}$, não se teve controle da umidade relativa ao longo do processo. $\mathrm{O}$ diagrama esquemático do procedimento está apresentado na Figura 4.5.

Figura 4.5 - Diagrama esquemático do procedimento realizado na estufa convectiva

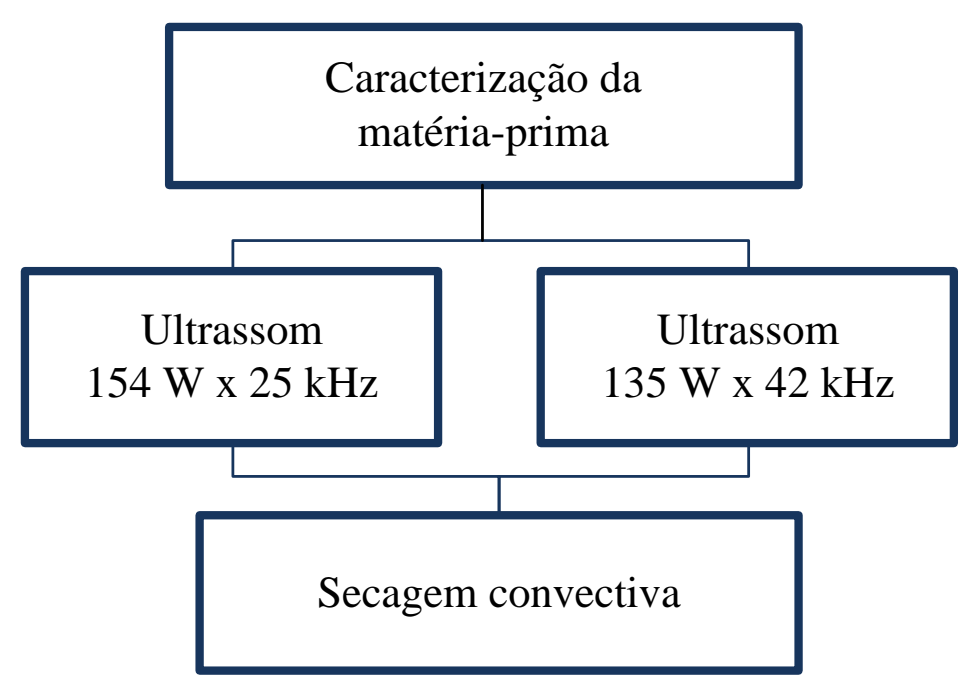

Fonte: O próprio autor.

Foi feito o acompanhamento da perda de massa no decorrer do processo, para a obtenção das curvas de secagem. Durante os primeiros $120 \mathrm{~min}$, as amostras foram pesadas em uma balança analítica (BEL ENGINEERING, modelo S3102, Brasil) em intervalos de 15 min. Nos $240 \mathrm{~min}$ seguintes, os intervalos foram de $30 \mathrm{~min}$ até atingir-se o equilíbrio (360 min, aproximadamente). Os ensaios foram conduzidos em duplicata. Na Tabela 4.3 consta um resumo das condições estudadas em função do tempo, potência nominal e frequência do ultrassom; assim como a temperatura de secagem. 
Tabela 4.3 - Ensaios de secagem realizados em estufa convectiva com rodelas de banana verde

\begin{tabular}{ccc}
\hline Tempo ultrassom (min) & $P(\mathrm{~W}) \times f(\mathrm{kHz})$ & Temp. secagem $\left({ }^{\circ} \mathrm{C}\right)$ \\
\hline- & - & 60 \\
\hline 10 & - & 50 \\
10 & $154 \times 25$ & 60 \\
15 & 50 \\
15 & 60 \\
20 & 50 \\
20 & 60 \\
25 & & 50 \\
25 & & 60 \\
20 & & 50 \\
20 & $135 \times 42$ & 60 \\
25 & & 50 \\
25 & & 60 \\
\hline
\end{tabular}

Fonte: O próprio autor.

A razão do conteúdo de umidade $(M R)$ foi expressa de acordo com a eq. (3), com algumas considerações. O valor da umidade inicial considerado foi o valor após o prétratamento com ultrassom, de maneira que, a relação $M R$ inicialmente se manteve sempre unitária. Os valores da umidade de equilíbrio $\left(X_{e}\right)$ foram obtidos por Zabalaga et al. (2016) a 30 $\%$ de UR e nas temperaturas de $50{ }^{\circ} \mathrm{C}=0,044 \mathrm{~g} \mathrm{H}_{2} \mathrm{O} / \mathrm{g}$ b.s. e $60{ }^{\circ} \mathrm{C}=0,047 \mathrm{~g} \mathrm{H}_{2} \mathrm{O} / \mathrm{g}$ b.s. A determinação da difusividade efetiva da água foi realizada empregando a eq. (2), considerando os primeiros cinco termos da equação com o auxílio do software Statgraphics Centurion XV (StatPoint, Inc., USA).

\section{- Análises estatísticas}

A interação das variáveis: tempo de imersão no ultrassom e temperatura de secagem sobre a difusividade efetiva da água foi avaliada estatisticamente por meio da Análise da Variância (ANOVA) multifatorial, aplicando-se o teste de Tukey, para o nível de confiança de $5 \%$, com o auxílio do software Statgraphics Centurion XV (StatPoint, Inc., USA). 


\subsubsection{Ensaios de secagem em secador de bandejas}

O secador de bandejas (LABMAQ, modelo LM.ES-20, Brasil) é um protótipo que foi desenvolvido especificamente para a secagem da banana verde. É um secador cujo mecanismo de transferência de calor é a convecção, mediante o aquecimento do ar.

Figura 4.6 - Secador de bandejas (LABMAQ, modelo LM.ES-20, Brasil)
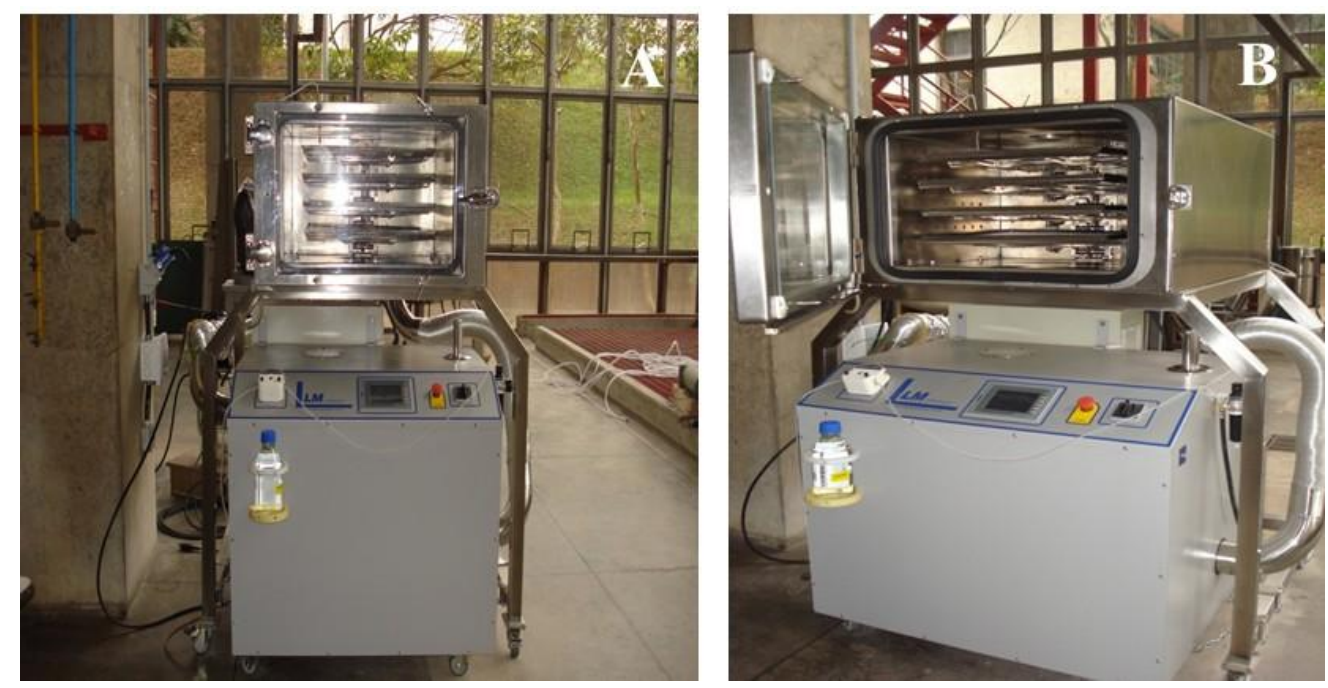

(A) vista frontal e (B) vista lateral. Fonte: O próprio autor.

Como mostrado na Figura 4.6 o equipamento é composto por dois módulos. O primeiro é a câmara de secagem, com capacidade de 4 kg, distribuída em quatro bandejas. Em cada uma delas está acoplada uma célula de carga, para acompanhamento em tempo real da perda de massa ao longo da secagem (coleta de dados a cada minuto). Na parte superior da câmara de secagem há um visor de quartzo para acoplamento de um microscópio, para as medidas de encolhimento do material. Ainda, na parte superior da câmara, tem-se um sensor de temperatura (PT 100). Na parte inferior-posterior, há dois dutos para circulação do ar na câmara de secagem: um para a entrada do ar e o outro para sua saída. Ainda, no mesmo local, há uma válvula solenoide cuja função é a de retirar o ar da câmara e controlar o vácuo.

O segundo módulo é o responsável pelo comando e controle do equipamento, sendo composto principalmente por: 
- Dois ventiladores de vazão $24,6 \mathrm{~m}^{3} / \mathrm{s}$, que permitem uma velocidade de até $5 \mathrm{~m} / \mathrm{s}$ do ar entre as bandejas centrais.

- Uma resistência de 3500 W.

- Uma unidade de refrigeração de $186 \mathrm{~W}$ para a retirada e o controle da umidade no processo.

- Uma bomba de vácuo com a capacidade nominal de 0,6 bar absoluto.

- Um sistema de atomização composto por uma bomba peristáltica e um bico atomizador, para a introdução e o controle da umidade no sistema.

- Um sensor de temperatura (PT 100) e um termo-higrômetro, para controle e indicação de temperatura e umidade.

- Um sistema de automação composto principalmente por fontes, relés, inversores de frequência, dissipadores e disjuntores.

A Figura 4.7 representa o diagrama esquemático do equipamento em função do seus componentes.

Figura 4.7 - Diagrama esquemático do secador de bandejas (LABMAQ, modelo LM.ES-20, Brasil)

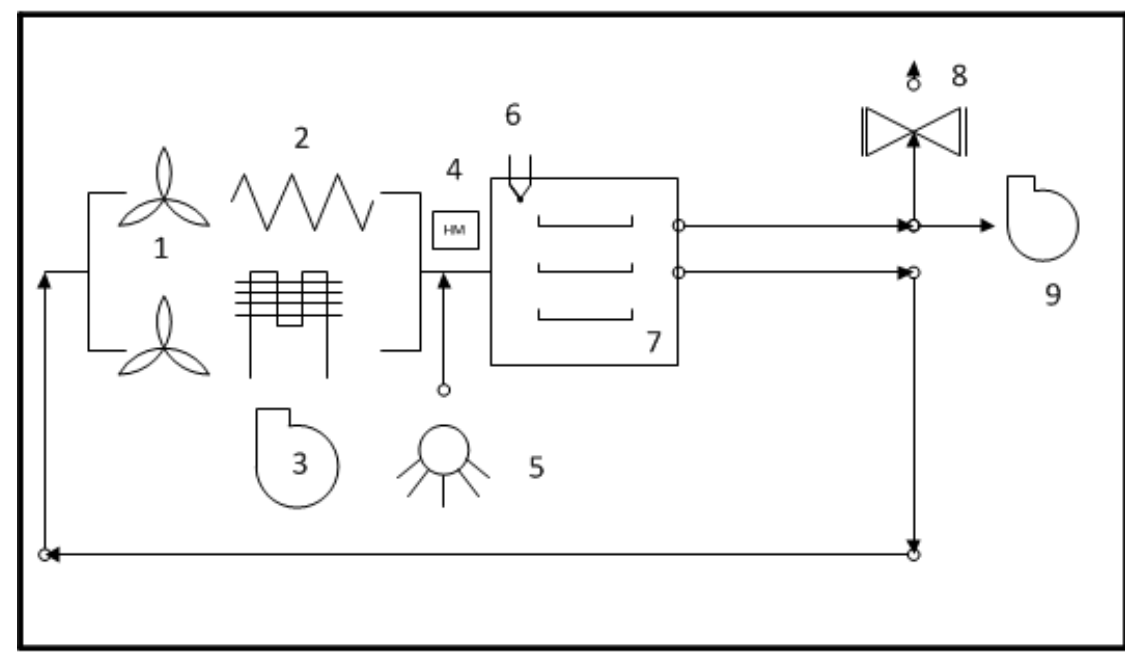

(1) ventiladores, (2) resistência, (3) unidade de refrigeração, (4) termohigrômetro, (5) atomizador, (6) sensor de temperatura (PT 100), (7) câmara de secagem, (8) válvula solenoide para retirada do ar e (9) bomba de vácuo.

Fonte: O próprio autor. 


\section{- Calibração e validação do secador de bandejas}

Uma das etapas mais desafiadoras deste projeto foi a calibração e validação do secador, realizadas após a instalação do equipamento e de maneira a garantir o bom funcionamento do equipamento. Em todos os ensaios foi empregada batata como matéria prima, sendo a escolha da matéria-prima pelo fato de que a batata apresenta o mesmo tipo de amido resistente da banana, e a acessibilidade desta matéria prima é facilitada. As validações foram realizadas para a temperatura, velocidade do ar e célula de carga, como descritas a seguir, operando em temperaturas na faixa de $(50-60){ }^{\circ} \mathrm{C}$, umidades relativas entre $(10-20) \%$ e velocidade de ar fixa em $4 \mathrm{~m} / \mathrm{s}$.

Verificação da temperatura. A distribuição de temperaturas em cada bandeja da câmara foi realizada com a ajuda de termopares, como mostrado na Figura 4.8. Os termopares foram previamente calibrados com termômetro de mercúrio de referência; a leitura das temperaturas foi feita através do software LabVIEW 2010 (National Instruments, USA).

Figura 4.8 - Configuração inicial das bandejas no secador (LABMAQ, modelo LM.ES-20, Brasil)

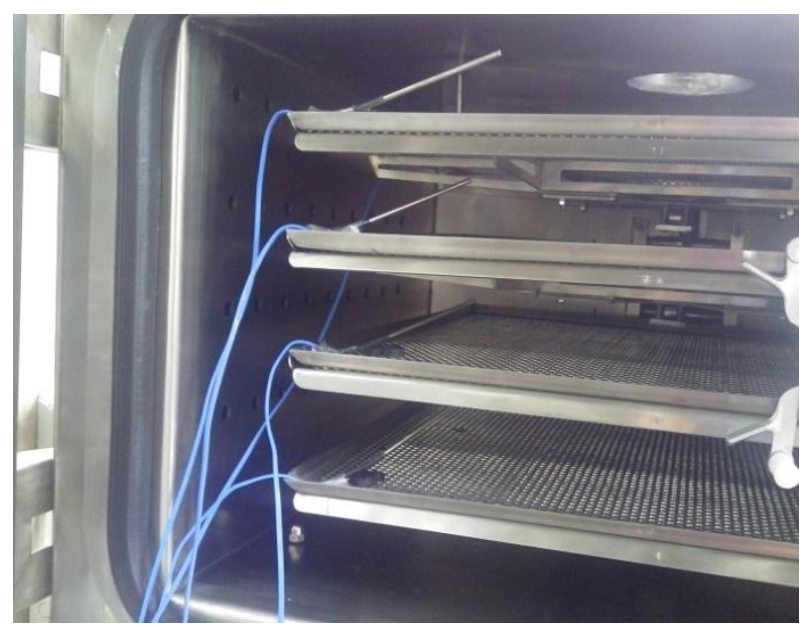

Fonte: O próprio autor.

Verificação da velocidade do ar. Realizada nos mesmos pontos que as da temperatura (Figura 4.8), com anemômetro de bancada. 
Verificação das células de carga. Ensaios de secagem foram conduzidos. Ao longo do processo, o peso das fatias de batata foi registrado em balança analítica (METTLER INSTRUMENTS, modelo PE11, Suiça) e comparado com o peso registrado pela célula de carga do equipamento. Na configuração inicial do secador, como apresentada na Figura 4.8, cada bandeja foi suportada na parte central, com esta configuração, foi observado um erro percentual $>20 \%$ entre o peso real (registrado na balança analítica) e o registrado pela célula de carga. Outro fato que foi evidenciado foi as oscilações no peso das fatias de batata durante o processo de secagem, o que impossibilitou a coleta de dados para a construção da curva de secagem. Nesta etapa do projeto resolveu-se que o equipamento retornaria para o fabricante para a modificação da estrutura das bandejas e para a calibração da célula de carga. Na configuração final, apresentada na Figura 4.9, se observa que as bandejas foram reforçadas com um chapa de inox, diminuindo, assim, a oscilação. Com a nova configuração, observou-se erro percentual < $10 \%$ entre o peso real das fatias de batata (registrado na balança analítica) e o peso registrado pela célula de carga do equipamento.

Figura 4.9 - Configuração final das bandejas no secador (LABMAQ, modelo LM.ES-20, Brasil)

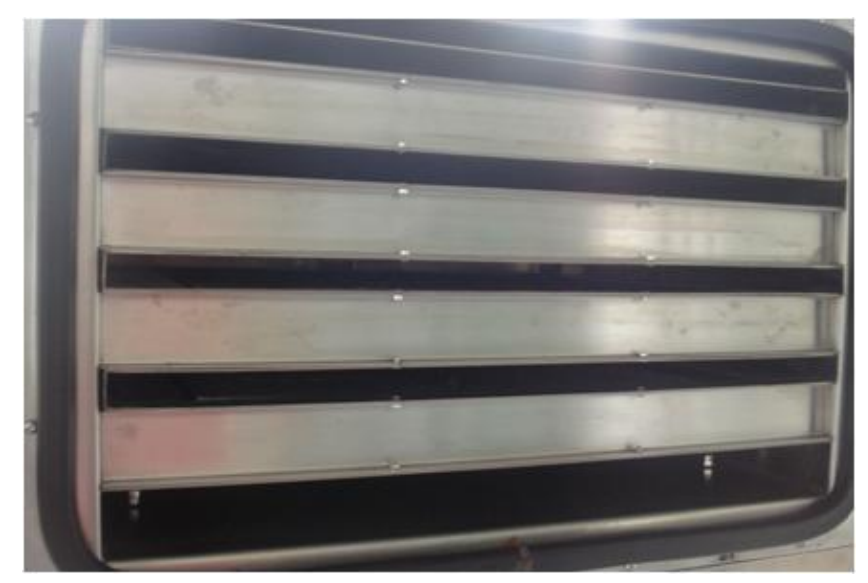

Fonte: O próprio autor.

$\mathrm{Na}$ Figura 4.10, o diagrama geral do procedimento realizado neste equipamento é apresentado. Três tipos de ensaios foram conduzidos. Primeiramente, ensaios de pré-tratamento de ultrassom seguido de secagem convectiva. A escolha das condições testadas foi baseada nos resultados obtidos da segunda etapa do trabalho; as combinações, que resultaram em maior difusividade efetiva da água, foram novamente reproduzidas neste equipamento. O segundo tipo de ensaios conduzidos foram ensaios de pré-tratamento pulso de vácuo seguidos de 
secagem convectiva. O tempo de pulso de vácuo aplicado foi escolhido baseado nos resultados obtidos na primeira etapa do ttrabalho. Finalmente, ensaios combinados de pré-tratamento de ultrassom, seguido de pulsos de vácuo e secagem convectiva foram conduzidos.

Figura 4.10 - Diagrama esquemático do procedimento realizado no secador de bandejas (LABMAQ, modelo LM.ES-20, Brasil)

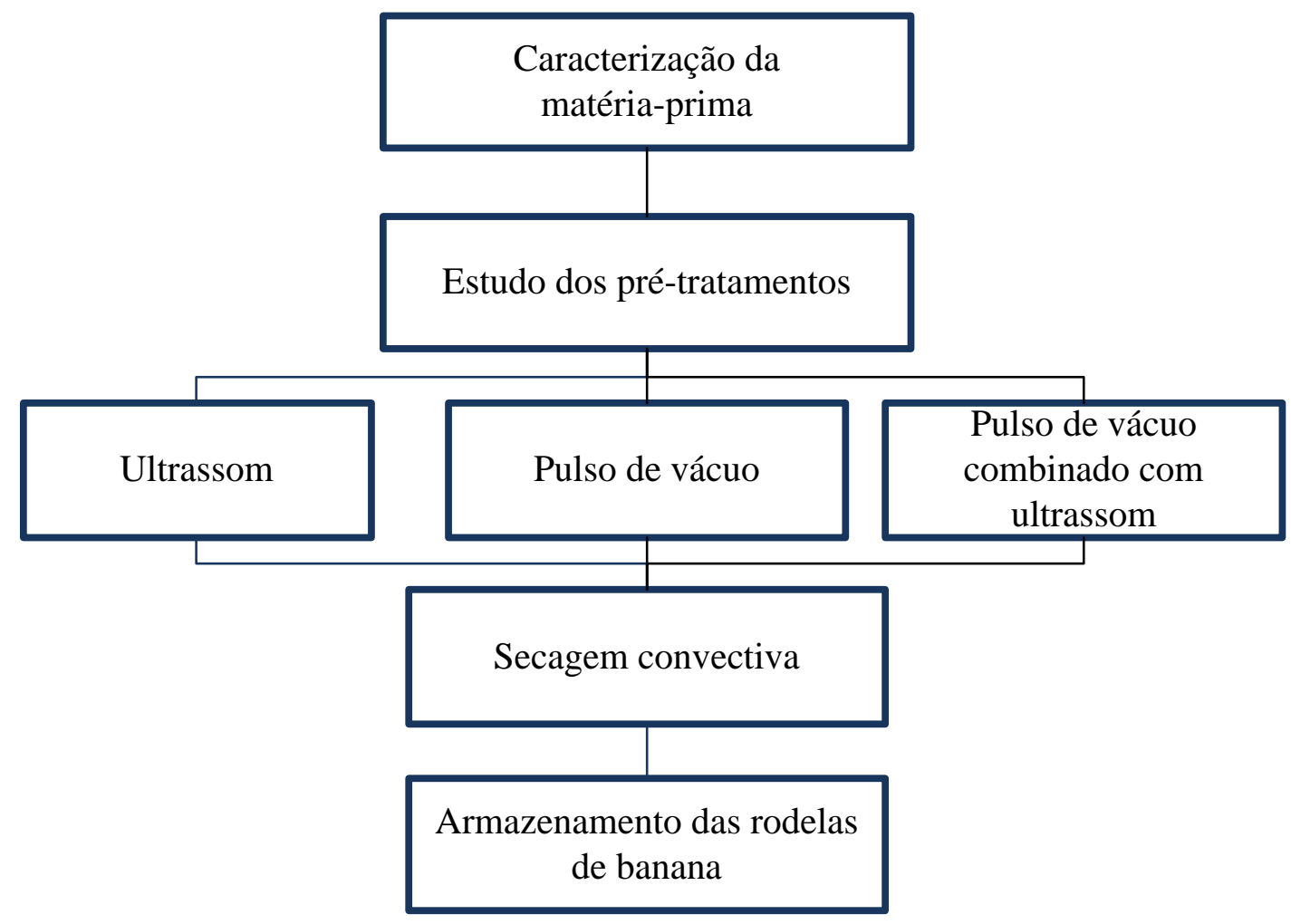

Fonte: O próprio autor.

Os ensaios realizados com pré-tratamento ultrassom seguido de secagem convectiva foram conduzidos para as rodelas de banana verde pré-tratadas com ultrassom (154 W x 25 $\mathrm{kHz}$ ) por (20 e 25) min. Os parâmetros da secagem, empregados nos ensaios, foram: $50{ }^{\circ} \mathrm{C}, 4$ $\mathrm{m} / \mathrm{s}$ e $10 \% \mathrm{UR}$; e $60{ }^{\circ} \mathrm{C}, 4 \mathrm{~m} / \mathrm{s}$ e $10 \%$ UR por $490 \mathrm{~min}$.

Nos ensaios realizados com pré-tratmento de pulso de vácuo seguido de secagem convectiva foi empregada uma pressão de 0,5 bar por $60 \mathrm{~min}$. As condições de secagem testadas para estes ensaios foram: $50{ }^{\circ} \mathrm{C}, 4 \mathrm{~m} / \mathrm{s}$ e $10 \% \mathrm{UR}$; e $60{ }^{\circ} \mathrm{C}, 4 \mathrm{~m} / \mathrm{s}$ e $10 \%$ UR por $490 \mathrm{~min}$. 
Finalmente, foram testadas duas condições combinando os dois pré-tratamentos. Primeiramente, amostras submetidas a 20 min de ultrassom (154 W x $25 \mathrm{kHz}$ ), seguido de um pulso de vácuo $(0,5$ bar $)$ de 60 min e secagem convectiva a $50{ }^{\circ} \mathrm{C}, 4 \mathrm{~m} / \mathrm{s}$ e $10 \%$ UR. Na segunda condição, amostras foram submetidas a 25 min de ultrassom ( $154 \mathrm{~W}$ x $25 \mathrm{kHz}$ ), seguido de um pulso de vácuo $\left(0,5\right.$ bar) por 60 min e secagem convectiva a $60{ }^{\circ} \mathrm{C}, 4 \mathrm{~m} / \mathrm{s}$ e $10 \%$ UR. Os experimentos de secagem foram conduzidos em dois períodos distintos: entre Maio/Junho 2015 e Fevereiro/Março 2016. Na Tabela 4.4 consta o resumo das condições estudadas, todas realizadas em duplicata, e na Figura 4.11 fotos do procedimento experimental são mostradas.

Tabela 4.4 - Ensaios de secagem realizados em secador de bandejas (LABMAQ, modelo LM.ES-20, Brasil) com as rodelas de banana verde

Tempo ultrassom (min) Tempo vácuo (min) Temp. secagem $\left({ }^{\circ} \mathrm{C}\right)$

\begin{tabular}{ccc}
\hline- & - & 60 \\
- & - & 50 \\
\hline 20 & - & 60 \\
20 & - & 50 \\
25 & - & 60 \\
25 & - & 50 \\
\hline- & 60 & 60 \\
- & 60 & 50 \\
\hline 20 & 60 & 50 \\
25 & 60 & 60
\end{tabular}

Fonte: O próprio autor. 
Figura 4.11 - Fotos do procedimento experimental realizado no secador de bandejas (LABMAQ, modelo LM.ES-20, Brasil)
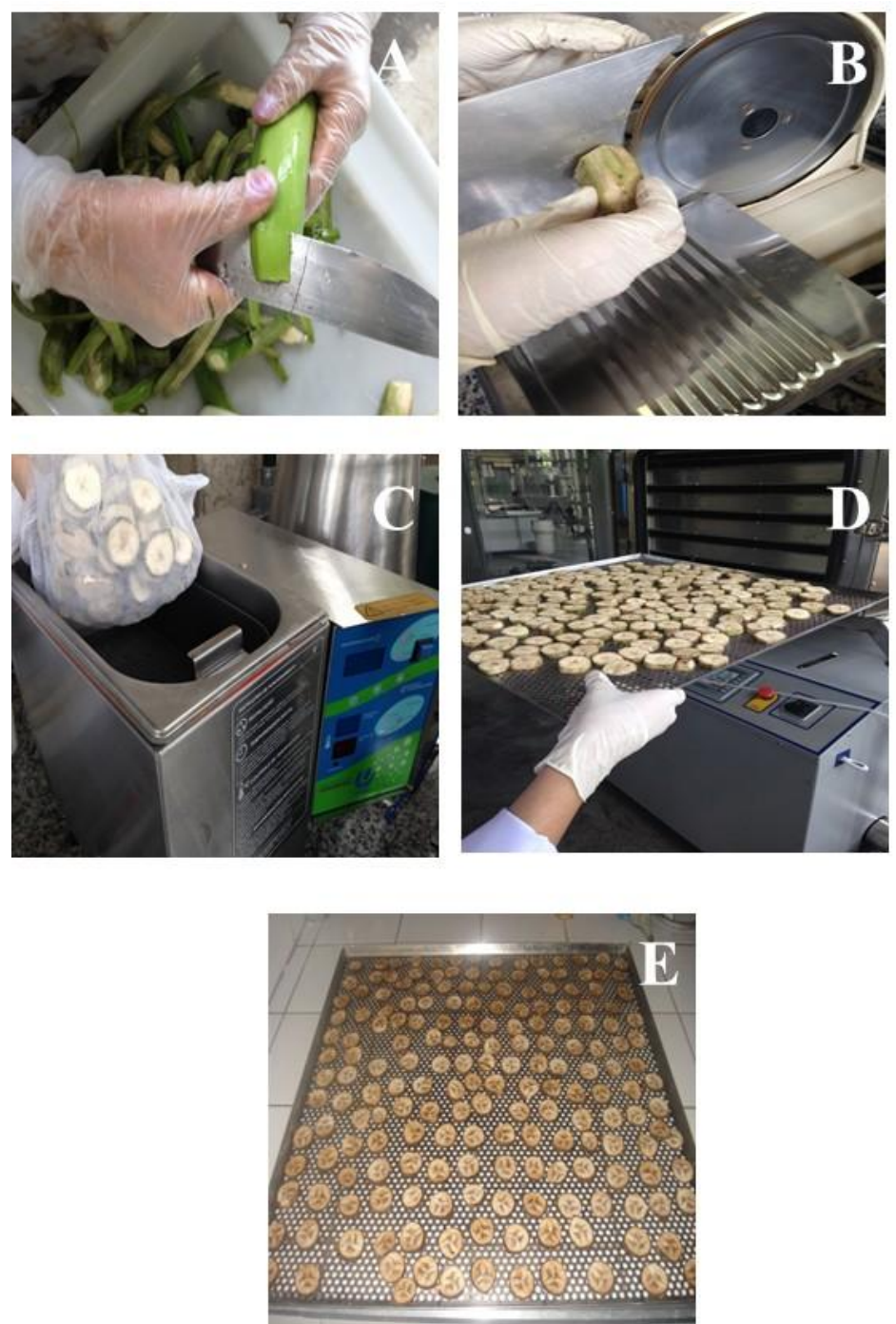

(A) bananas descascadas; (B) bananas sendo cortadas em rodelas de $5 \mathrm{~mm}$ de espessura, com a ajuda do cortador de aço; (C) rodelas de banana sendo colocadas no banho ultrassônico; (D) rodelas de banana na entrada do secador convectivo; (E) rodelas de banana no final do processo de secagem. Fonte: O próprio autor.

A razão do conteúdo de umidade ( $M R$ ) foi expressa de acordo com a eq.(3), em que os valores de $X_{e}$ empregados a $10 \% \mathrm{UR}$ e $50{ }^{\circ} \mathrm{C}$ foram: $=0,015 \mathrm{~g} \mathrm{H}_{2} \mathrm{O} / \mathrm{g}$ b.s. e a $10 \% \mathrm{UR}$ e 60 ${ }^{\circ} \mathrm{C}=0,017 \mathrm{~g} \mathrm{H}_{2} \mathrm{O} / \mathrm{g}$ b.s. (ZABALAGA et al., 2016). 
Para estes ensaios a difusividade efetiva da água foi calculada pelo método das tangentes. Na eq. (4) foram aplicados os logaritmos, de maneira que:

$$
\begin{gathered}
\ln (M R)=\ln \left[\frac{8}{\pi^{2}} \cdot \exp \left(-\pi^{2} \cdot \frac{D_{e f}}{4 L^{2}} \cdot t\right)\right] \\
\ln (M R)=\ln \frac{8}{\pi^{2}}+\left(-\pi^{2} \cdot \frac{D_{e f}}{4 L^{2}} \cdot t\right)
\end{gathered}
$$

Diferenciando a equação:

$$
\frac{d \ln (M R)}{d t}=-\pi^{2} \cdot \frac{D_{f f}}{4 L^{2}}
$$

Para a curva teórica:

$$
\begin{array}{r}
\ln (M R)=\ln \left[\frac{8}{\pi^{2}} \cdot \exp \left(-\frac{\pi^{2}}{4} \cdot F_{o}\right)\right] \\
\ln (M R)=\ln \frac{8}{\pi^{2}}+\left(-\frac{\pi^{2}}{4} \cdot F_{o}\right)
\end{array}
$$

Diferenciando a equação:

$$
\frac{d \ln (M R)}{d F_{o}}=-\frac{\pi^{2}}{4}
$$

Finalmente, a difusividade foi calculada:

$$
D_{e f f}=\frac{d \ln (M R) / d t}{d \ln (M R) / d F_{o}} \cdot L^{2}
$$

A taxa de secagem $d X / d t\left(\mathrm{~g} \mathrm{H}_{2} \mathrm{O} / \mathrm{g} \cdot \min\right.$ b.s.) foi calculada para todos os ensaios e foi plotada em função de $X\left(\mathrm{~g} \mathrm{H}_{2} \mathrm{O} / \mathrm{g}\right.$ b.s.). 


\subsubsection{Modelos empíricos}

Os dados experimentais foram ajustados a cinco modelos empíricos, apresentados na Tabela 3.1. O coeficiente de correlação $\left(r^{2}\right)$ foi um dos primeiros critérios para a seleção do melhor modelo. Adicionalmente, foi calculado o erro quadrático médio (RMSE) e o chiquadrado $\left(\chi^{2}\right)$ para determinar a qualidade do ajuste. De acordo as seguintes equações:

$$
\begin{aligned}
R M S E & =\left[\frac{1}{N} \sum_{i=0}^{N}\left(M R_{\text {modeloi }}-M R_{\text {expi }}\right)^{2}\right]^{1 / 2} \\
\chi^{2} & =\frac{\sum_{i=0}^{N}\left(M R_{\text {modeloi }}-M R_{\text {expi }}\right)^{2}}{N-n}
\end{aligned}
$$

Em que:

$M R_{\text {model }, i}=$ relação de umidades predita pelo modelo;

$M R_{\text {exp }, i}=$ relação de umidades experimental;

$N=$ número de observações;

$n=$ número de constantes.

\subsubsection{Redução do teor de umidade inicial}

Empregando um dos modelos experimentais foi determinada a redução do teor de umidade em relação ao seu teor inicial, para rodelas de banana verde não pré-tratadas e prétratadas com: ultrassom (20 ou 25) min, ultrassom (20 ou 25) min, seguido de 60 min de púlso de vácuo e secagem na temperatura de $(50$ e 60$){ }^{\circ} \mathrm{C}$. O tempo de secagem considerado para a calcular dita redução foi diferentes para cada temperatura de secagem.

\subsubsection{Tempo total experimental do processo}

De acordo com Cardoso e Pena (2014), a farinha de banana verde apresenta estabilidade microbiológica com atividade de água $<0,6$. Segundo, as curvas de desorção a (50 e 60) ${ }^{\circ} \mathrm{C}$ para banana verde corresponde a um teor de umidade de equilibro próximo a $0,15 \mathrm{~g} \mathrm{H}_{2} \mathrm{O} / \mathrm{g}$ b.s. (ZABALAGA et al., 2016). Novos ensaios, com tempos de imersão de (20 e 25) min no banho ultrassônico de $154 \mathrm{~W}$ x $25 \mathrm{kHz}$ e secagem convectiva a (50 e 60) ${ }^{\circ} \mathrm{C}$ no secador de bandejas (LABMAQ, modelo LS.20, Brasil) foram conduzidos, para determinar o tempo em que estas condições de estabilidade fossem atingidas. Nos primeiros $270 \mathrm{~min}$ de secagem, o processo aconteceu sem interrupção. Após esse tempo, rodelas de bananas verde foram coletadas do 
secador a cada 30 min para a determinação da atividade de água $\left(a_{w}\right)$ e do teor de umidade. A $a_{w}$ das rodelas de banana verde foi determinada por leitura direta à temperatura de $25{ }^{\circ} \mathrm{C}$ no equipamento Vapor Sorption Analyzer (DECAGON, modelo Aqualab-VSA, USA). A determinação da umidade foi realizada, em estufa (MARCONI, modelo MA030, Brasil), a 70 ${ }^{\circ} \mathrm{C}$ sob vácuo de $\leq 20 \mathrm{kPa}$ até peso constante, de acordo com a metodologia proposta por Zenebon et al. (2008). Todas as determinações foram realizas em triplicata.

\subsubsection{Efeito do ultrassom sobre o ganho de água $\left(\mathrm{g} \mathrm{H}_{2} \mathrm{O} / 100 \mathrm{~g}\right)$}

Para compreender melhor como o ultrassom influencia o $G A$ e, posteriormente, as propriedades de transporte durante a secagem, aplicou-se dois pré-tratamentos diferentes, conforme a seguinte descrição:

Pré-tratamento 1. Rodelas de banana verde foram colocadas em uma sacola de tecido perfurado e, logo em seguida, imersas em água, no banho ultrassônico (154 W x $25 \mathrm{kHz}$ ) por $20 \mathrm{~min}$, como descrito em 4.2.1 (hidratadas).

Pré-tratamento 2. Com a finalidade de tratar as rodelas de banana verde com ultrassom por 20 min sem hidratação, foram embaladas previamente em embaladora a vácuo (SELOVAC, modelo 200S, Brasil), em sacolas de plástico de polipropileno (REGISTRON, Brasil) (não hidratadas). As rodelas de banana verde embaladas foram imersas até o fundo do banho ultrassônico (154 W x $25 \mathrm{kHz}$ ) de modo a receber, com maior intensidade, as ondas ultrassônicas. No banho foi mantido o nível de água mínimo requerido pelo fabricante. $\mathrm{Na}$ Figura 4.14, apresenta-se as imagens das rodelas de banana verde após a embalagem a vácuo.

Figura 4.12 - Rodelas de banana verde embaladas a vácuo

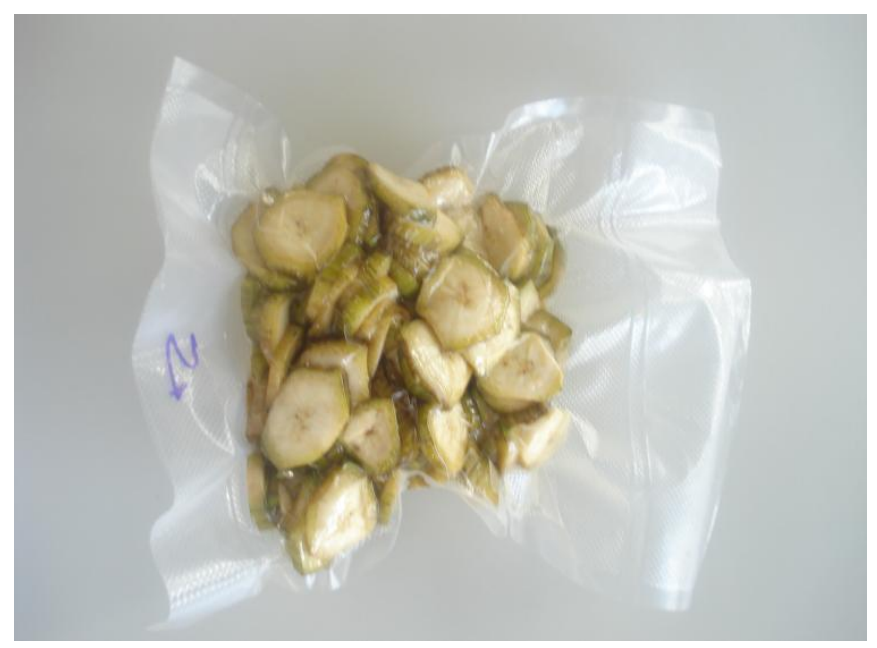

Fonte: O próprio autor 
Para todos os ensaios, foi determinado o ganho de água $(G A)$ durante o pré-tratamento segundo a eq. (7). Depois do pré-tratamento, as rodelas de banana verde foram secas a $50{ }^{\circ} \mathrm{C}$, $4 \mathrm{~m} / \mathrm{s}$ e $10 \%$ UR, por $360 \mathrm{~min}$. A difusividade efetiva da água foi determinada também pelo método das tangentes, como descrito previamente empregando a eq. (14).

\section{- Morfologia}

As mudanças estruturais nas rodelas de banana verde foram avaliadas ao longo do processo. Foram micro fotografadas três amostras: a banana in natura, as rodelas de banana verde após o pré-tratamento com ultrassom de 20 min (embaladas a vácuo e imersas em água). Estas rodelas, devido ao elevado conteúdo de água, foram previamente liofilizadas em liofilizador (LABCONCO, modelo Free Zone 4.5, USA) e armazenadas sob refrigeração até a análise. Rodelas após a secagem a $50{ }^{\circ} \mathrm{C}, 4 \mathrm{~m} / \mathrm{s}$ e $10 \%$ UR (não pré-tratadas, embaladas a vácuo e imersas em água) também foram fotografadas. O equipamento empregado foi o microscópio eletrônico de varredura (MEV) (FEI, modelo Quanta 600FEG, Holanda) instalado no Laboratório de Caracterização Tecnológica (LCT) no Departamento de Engenharia de Minas e de Petróleo da Escola Politécnica da USP, São Paulo. As amostras foram colocadas em um suporte metálico (stub), apropriado para a análise no $\mathrm{MEV}$, e preparadas para metalização com platina (BAL-TEC, modelo MED020, Suíça). As imagens foram capturadas a 300x e 600x.

\section{- Análise estatística}

A interação das variáveis sobre o ganho de água e a difusividade efetiva da água foi avaliada estatisticamente, por meio da Análise da Variância (ANOVA) multifatorial, aplicando o teste de Tukey para o nível de confiança de $5 \%$, com o auxílio do software Statgraphics Centurion XV (StatPoint, Inc., USA). 


\subsubsection{Caracterização da Farinha de Banana Verde}

Foram selecionadas algumas das condições de secagem estudadas na terceira etapa do trabalho para a produção da farinha de banana verde. Um dos critérios para a seleção foi o do valor obtido de difusividade efetiva de água. Embora os ensaios combinados de ultrassom seguido de pulso de vácuo não tenham aumentado os valores de difusividade efetiva da água, em relação aos ensaios sem pré-tratamento, as farinhas foram produzidas, pois representam uma parte interessante do estudo. Na Tabela 4.5 apresentam-se as condições de secagem selecionadas para a produção da farinha de banana verde. Ainda foram produzidas farinhas com as rodelas de banana verde pré-tratadas com ultrassom por $20 \mathrm{~min}$, imersas em água (hidratadas) e aquelas embaladas a vácuo (não hidratadas). Na Figura 4.13 fotos do procedimentos experimental são mostradas.

Tabela 4.5 - Processos de secagem selecionados para a produção de farinha de banana verde

\begin{tabular}{ccc}
\hline Ultrassom (min) & Pulso de vácuo $(\min )$ & Temp. secagem $\left({ }^{\circ} \mathrm{C}\right)$ \\
\hline- & - & 50 \\
- & - & 60 \\
20 & - & 50 \\
25 & - & 60 \\
20 & 60 & 50 \\
25 & 60 & 60
\end{tabular}

Fonte: O próprio autor. 
Figura 4.13 - Procedimento de obtenção da farinha da banana verde
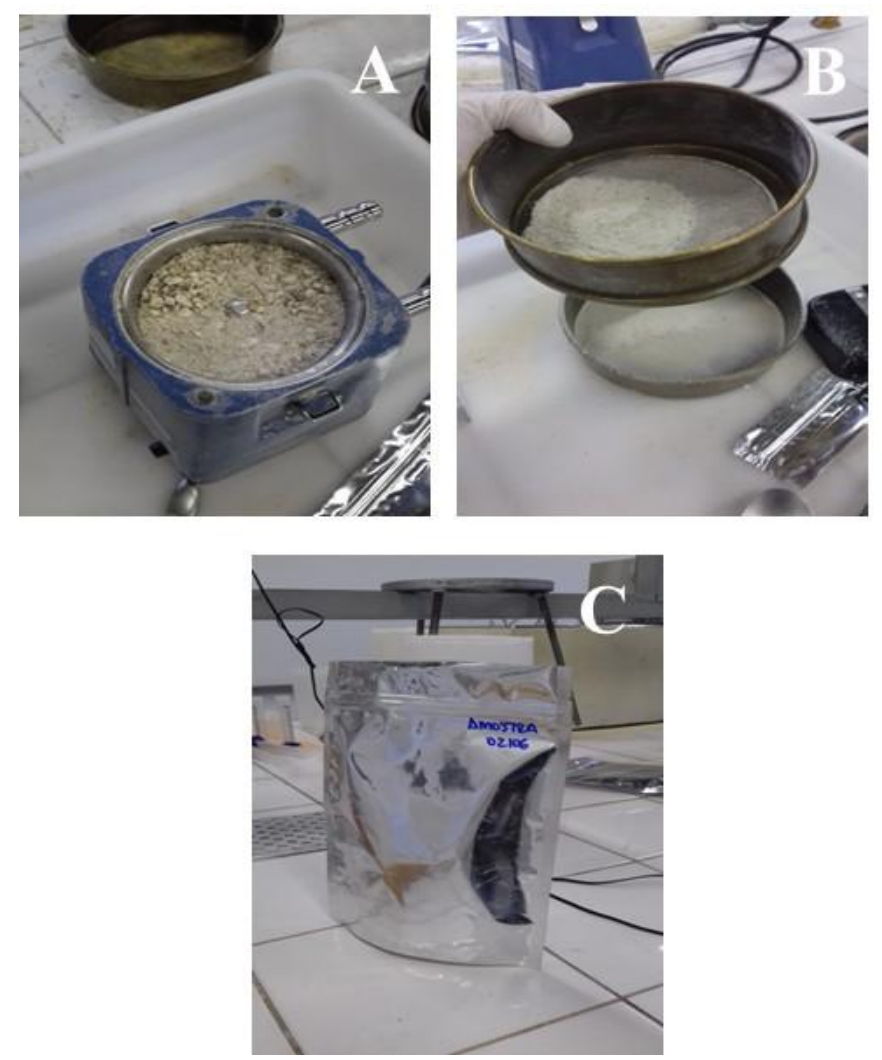

(A) rodelas de banana verde moídas em moinho de laboratório (IKA, modelo A10, USA), (B) farinha peneirada até $250 \mu \mathrm{m}$ e $(\mathrm{C})$ farinha armazenada. Fonte: O próprio autor.

As farinhas produzidas foram armazenadas em sacolas plásticas de alumínio zip lock (AGACE, Brasil), segundo as informações fornecidas pelo fabricante, a permeabilidade ao oxigênio $\left(\mathrm{O}_{2}\right)$, determinada pelo método ASTM D 3985 a $25^{\circ} \mathrm{C}$, é de $(100-120) \mathrm{g} / \mathrm{m}^{2}$ dia e a permeabilidade ao vapor de água, determinada pelo método ASTM F $124938^{\circ} \mathrm{C}-90 \%$ UR é de $\left(10,0\right.$ - 12,0) $\mathrm{cm}^{3} / \mathrm{m}^{2}$ dia. As sacolas plásticas contendo as farinhas foram armazenadas em dessecador e dispostas em sala climatizada a $21^{\circ} \mathrm{C}$, até o momento das posteriores análises.

As farinhas foram caracterizadas quanto a: 


\section{- Umidade}

A determinação da umidade da farinha foi realizada em triplicata, em estufa (MARCONI, modelo MA030, Brasil) a $70{ }^{\circ} \mathrm{C}$ sob vácuo de $\leq 20 \mathrm{kPa}$ até peso constante, de acordo com a metodologia proposta por Zenebon et al. (2008).

\section{- Atividade de água $\left(a_{w}\right)$}

A atividade de água das farinhas foi determinada em triplicata, por leitura direta, à temperatura de $25^{\circ} \mathrm{C}$ no equipamento Vapor Sorption Analyzer (DECAGON, modelo AqualabVSA, USA).

\section{- Conteúdo de Amido Resistente (AR)}

Foi determinado em triplicata pelo Laboratório de Química, Bioquímica e Biologia Molecular de Alimentos do Departamento de Alimentos e Nutrição da Faculdade de Ciências Farmacêuticas da USP (São Paulo), segundo a metodologia 2002.002 da AOAC (McCLEARY; MONAGHAM, 2002).

\section{- Temperatura $\left(T_{p}\right)$ e Entalpia $(\Delta H)$ de Gelatinização}

A temperatura e entalpia de gelatinização do amido foram determinadas em triplicata, em um Calorímetro Diferencial de Varredura (TA Instruments, model Q Serie, USA), previamente calibrado com cadinho vazio, padrão de zafira e padrão de indio. Foram pesados $2 \mathrm{mg}$ da amostra, em cadinho de alumínio, e então adicionados $7 \mu \mathrm{L}$ de água deionizada. $\mathrm{O}$ cadinho foi selado hermeticamente e mantido por uma hora para umectação, antes da realização da análise. Transcorrido o tempo de umectação, foi submetido a um programa de aquecimento em um intervalo de $(20$ a 100$){ }^{\circ} \mathrm{C}$, a uma velocidade de aquecimento de $10^{\circ} \mathrm{C} / \mathrm{min}$. Como referência, foi utilizado um cadinho vazio. A temperatura do pico foi considerada como a temperatura de gelatinização $\left(T_{p}\right)$. A entalpia e temperatura de gelatinização foram obtidas do programa da TA instruments. 
- Solubilidade $(S)$

Amostras de 0,1 $\mathrm{g}$ de farinha de banana verde foram adicionadas a $10 \mathrm{~mL}$ de água destilada em um tubo de centrífuga e então colocados em banho termostatizado (MARCONI, modelo MA-184, Brasil) com agitação a (25, 40, 50 ou 60) ${ }^{\circ} \mathrm{C}$ por $30 \mathrm{~min}$. Logo, em seguida, as amostras foram centrifugadas em centrífuga (TOMINGA WORKS LTD, modelo TD-65, Japão) a $3000 \mathrm{rpm}$, por $15 \mathrm{~min}$. O sobrenadante foi separado por micropipeta de $5 \mathrm{~mL}$ (LABMATE pro, modelo HTL, Brasil) e seco em estufa (MARCONI, modelo MA030, Brasil) a $105^{\circ} \mathrm{C}$, sob vácuo $(\leq 20 \mathrm{kPa})$, até peso constante. A solubilidade foi determinada em triplicata e calculada a partir da eq. (17) (IZIDORO et al., 2011; ORMENENSE, 2010):

$$
S=\frac{\text { massa do sobrenadante seco }}{\text { massa da amostra }} \times 100
$$

\section{- Morfologia}

A morfologia das farinhas produzidas com as rodelas de banana verde, pré-tratadas com ultrassom por $20 \mathrm{~min}$, imersas em água (hidratas) e as embaladas a vácuo (não hidratas) foi avaliada através do microscópio eletrônico de varredura - MEV (FEI, modelo Quanta 600FEG, Holanda), instalado no Laboratório de Caracterização Tecnológica (LCT) no Departamento de Engenharia de Minas e de Petróleo da Escola Politécnica da USP, São Paulo. As farinhas foram colocadas em suporte metálico(stub), apropriado para a análise no MEV, e preparadas para a metalização com platina (BAL-TEC, modelo MED020, Suíça). As imagens foram capturadas a 2500x e 5000x.

\section{- Análise estatística}

As características físico-químicas de cada farinha foram avaliadas estatisticamente por meio da Análise da Variância (ANOVA) multifatorial, aplicando o teste de Tukey, para o nível de confiança de $5 \%$, com o auxílio do software Statgraphics Centurion XV (StatPoint, Inc., USA). 


\section{RESULTADOS E DISCUSSÃO}

\subsection{Caracterização da matéria-prima}

Na Tabela 5.1 estão apresentados os resultados do teor de umidade, sólidos solúveis e firmeza da matéria-prima, para os ensaios realizados em Maio/Junho 2015 e Fevereiro/Março 2016.

Tabela 5.1 - Caracterização da matéria-prima nos períodos de Maio/Junho 2015 e Fevereiro/Março 2016

\begin{tabular}{lccc}
\hline \multicolumn{1}{c}{ Característica } & Maio/Junho 2015 & Fevereiro/Março 2016 & Dados da literatura $^{\mathrm{a}}$ \\
\hline Teor de umidade ( $\mathrm{g} \mathrm{H}_{2} \mathrm{O} / 100 \mathrm{~g}$ b.u.) & $72,02 \pm 0,46$ & $75,33 \pm 1,35$ & $70,2 \pm 0,5$ \\
Sólidos solúveis ( $\left.{ }^{\circ} \mathrm{Brix}\right)$ & $2,0 \pm 0,7$ & $2,1 \pm 0,2$ & $2,1 \pm 0,6$ \\
Firmeza $(\mathrm{N})$ & $32,8 \pm 4,1$ & $33,8 \pm 4,2$ & $31,5 \pm 1,5$ \\
\hline
\end{tabular}

${ }^{\text {a }}$ Tribess (2009). Fonte: O próprio autor.

Segundo Ditchfield e Tadini (2002), o melhor parâmetro para determinar o estágio de maturação do fruto é a sua firmeza. As autoras relataram um valor médio de 25,6 N para banana verde no estágio 1 de maturação. Rayo (2013), por sua vez, relatou um valor médio de 30,8 N também para a banana no estágio 1 de maturação. Como se pode observar na Tabela 5.1, os valores obtidos neste trabalho são próximos aos citados na literatura; confirmando, que a banana encontrava-se no primeiro estágio de maturação. Um fenômeno interessante para observar na Tabela 5.1 é a diferença no conteúdo de umidade entre os frutos de Maio/Junho 2015 e Fevereiro/Março 2016. As bananas colhidas no verão (Fevereiro/Março 2016) apresentaram um valor de teor de umidade de $3 \mathrm{~g} \mathrm{H}_{2} \mathrm{O} / 100 \mathrm{~g}$ maior se comparado com as bananas colhidas em Maio/Junho 2015. No entanto, os valores de firmeza, o principal parâmetro para determinar o estágio de maturação foram similares. Tribess (2009) também comparou as propriedades físico-químicas da banana verde em dois períodos diferentes (Maio e Julho). A autora observou conteúdo similar de sólidos solúveis, enquanto que o $\mathrm{pH}$, a acidez e firmeza apresentaram ligeiras diferenças entre os dois períodos analisados. 


\subsection{Ultrassom}

A potência volumétrica ultrassônica do banho de $154 \mathrm{~W}$ x $25 \mathrm{kHz}$ foi de $(9,38 \pm 0,60)$ W/L; e a do banho de $135 \mathrm{~W}$ x $42 \mathrm{kHz}$ foi de $(25,63 \pm 1,24) \mathrm{W} / \mathrm{L}$. Os valores citados correspondem à média de cinco determinações. Observa-se que a maior frequência maior valor de potência volumétrica ultrassônica foi determinado. Como foi exposto anteriormente, cada sistema ultrassônico apresenta as suas próprias características. No entanto, valores similares de potência volumétrica ultrassônica foram citados na literatura em condições próximas. Lima e Fernandes (2014) obtiveram valores de $(9$ - 18) W/L de potência volumétrica ultrassônica, dependendo do meio a ser tratado, de um banho operando a frequência de $25 \mathrm{kHz}$ e $220 \mathrm{~W}$ de potência nominal. Kek et al. (2013) obtiveram um valor de potência volumétrica ultrassônica próximo a $9 \mathrm{~W} / \mathrm{L}$ de um banho operando a $25 \mathrm{kHz}$ e $100 \mathrm{~W}$ de potência nominal. Por outro lado, Patero e Augusto (2015), de um banho de 40 kHz e 135 W de potência nominal e Yildirim et al. (2011), de um banho de $40 \mathrm{kHz}$ e $100 \mathrm{~W}$, obtiveram parâmetros muito próximos a um dos banhos utilizados neste trabalho, com valores de potência volumétrica ultrassônica de (26 e 25) W/L, respectivamente. Todos os resultados obtidos neste trabalho estão apresentados em função da potência volumétrica ultrassônica. Na Tabela 5.2, é apresentado o ganho de água (GA) para as amostras de banana verde submetidas ao pré-tratamento de ultrassom.

\begin{tabular}{|c|c|c|}
\hline \multirow{2}{*}{$\begin{array}{l}\text { Tempo de ultrassom } \\
\text { (min) }\end{array}$} & \multicolumn{2}{|c|}{$G A\left(\mathrm{~g} \mathrm{H}_{2} \mathrm{O} / 100 \mathrm{~g}\right)$} \\
\hline & $9,38 \mathrm{~W} / \mathrm{L}$ & $25,63 \mathrm{~W} / \mathrm{L}$ \\
\hline 0 & $0,0 \pm 0,00^{\mathrm{a}}$ & $0,0 \pm 0,00^{\mathrm{a}}$ \\
\hline 10 & $6,17 \pm 0,39^{b}$ & - \\
\hline 15 & $6,29 \pm 0,54^{b}$ & - \\
\hline 20 & $6,39 \pm 0,26^{b}$ & $5,35 \pm 0,48^{\mathrm{b}}$ \\
\hline 25 & $7,53 \pm 0,26^{\mathrm{c}}$ & $5,53 \pm 0,44^{\mathrm{b}}$ \\
\hline DMS & 0,75 & 0,60 \\
\hline
\end{tabular}

$\overline{\text { Letras diferentes na mesma coluna indicam diferença }}$ significativa entre os tratamentos $(p<0,05)$. DMS: diferença mínima significativa pelo teste de Tukey. Fonte: O próprio autor. 
Como se observa na Tabela 5.2, na potência de 9,38 W/L houve diferença estatística no $G A$ para as rodelas submetidas ao banho ultrassônico por $(10,15$ e 20$)$ min se comparadas às rodelas não pré-tratadas e às imersas por 25 min no ultrassom. Nos ensaios conduzidos na potência volumétrica ultrassônica de 25,63 W/L, houve uma diferença estatística para as amostras pré-tratadas por (20 e 25) min no ultrassom em relação às amostras não pré-tratadas. No estudo realizado por Fernandes et al. (2007), as rodelas de banana, imersas por 20 min no banho ultrassônico de $4870 \mathrm{~W} / \mathrm{m}^{2}$ x $25 \mathrm{kHz}$, apresentaram $G A$ superior às imersas por (10 e 30) min, sendo o valor alcançado de 11,1 $\mathrm{g} \mathrm{H}_{2} \mathrm{O} / 100 \mathrm{~g}$. Azoubel et al. (2010) observaram um GA de 3,47 $\mathrm{g} \mathrm{H}_{2} \mathrm{O} / 100 \mathrm{~g}$ para amostras imersas por $20 \mathrm{~min}$, a $220 \mathrm{~W}$ x $25 \mathrm{kHz}$; verificaram, ainda, acréscimo no ganho de água em função do tempo de imersão, o mesmo comportamento observado nos resultados obtidos neste trabalho.

Na Figura 5.1 é mostrada a média do $G A$ nos ensaios conduzidos no ultrassom de $(9,38$ e 25,63) W/L. Além de observar o aumento no $G A$ em relação ao tempo de imersão, também é possível verificar que as rodelas de banana verde pré-tratadas a 9,38 W/L de potência volumétrica ultrassônica apresentaram maior $G A$ se comparadas com as rodelas pré-tratadas no ultrassom de 25,63 W/L. Segundo os resultados obtidos neste trabalho, a menor frequência (25 $\mathrm{kHz}$ ) porém a maior potência nominal $(154 \mathrm{~W})$ favoreceram o $G A$ nas rodelas de banana verde. Um fator a considerar é o menor volume útil, no banho de $220 \mathrm{~W}$ x $25 \mathrm{kHz}$, disponível para transmissão das ondas ultrassônicas, que poderia ter beneficiado as condições dos ensaios, diminuindo a atenuação, resultando, assim, em maiores valores do GA. Kek et al. (2013) estudaram a aplicação de ultrassom em fatias de goiaba por tempos de imersão na faixa de (20 a 60) min, na frequência constante de $25 \mathrm{kHz}$ e nas potências volumétricas ultrassônicas de (9 e 15) W/L. Os autores observaram que, com o aumento da potência volumétrica ultrassônica, o $G A$ das amostras de goiaba aumentou, tendência contrária à observada neste trabalho para rodelas de banana verde. No entanto, é importante destacar que, no presente estudo, foram empregados dois banhos ultrassônicos com frequência, volume útil e potência nominal diferentes, enquanto que, no trabalho desenvolvido pelos autores empregou-se um único banho com frequência constante e potência variável. Cumpre ressaltar que a comparação dos resultados obtidos neste trabalho com os da literatura é difícil devido às diferentes nomenclaturas empregadas para fazer referência à potência ultrassônica: potência nominal (W) ou intensidade de potência $\left(\mathrm{W} / \mathrm{m}^{2}\right)$ ou, como apresentada no presente trabalho, potência volumétrica ultrassônica (W/L). 
Figura 5.1- Ganho de água $(G A)$ de rodelas de banana verde submetidas ao pré-tratamento de ultrassom a duas diferentes potências volumétricas ultrassônicas, em função do tempo de imersão

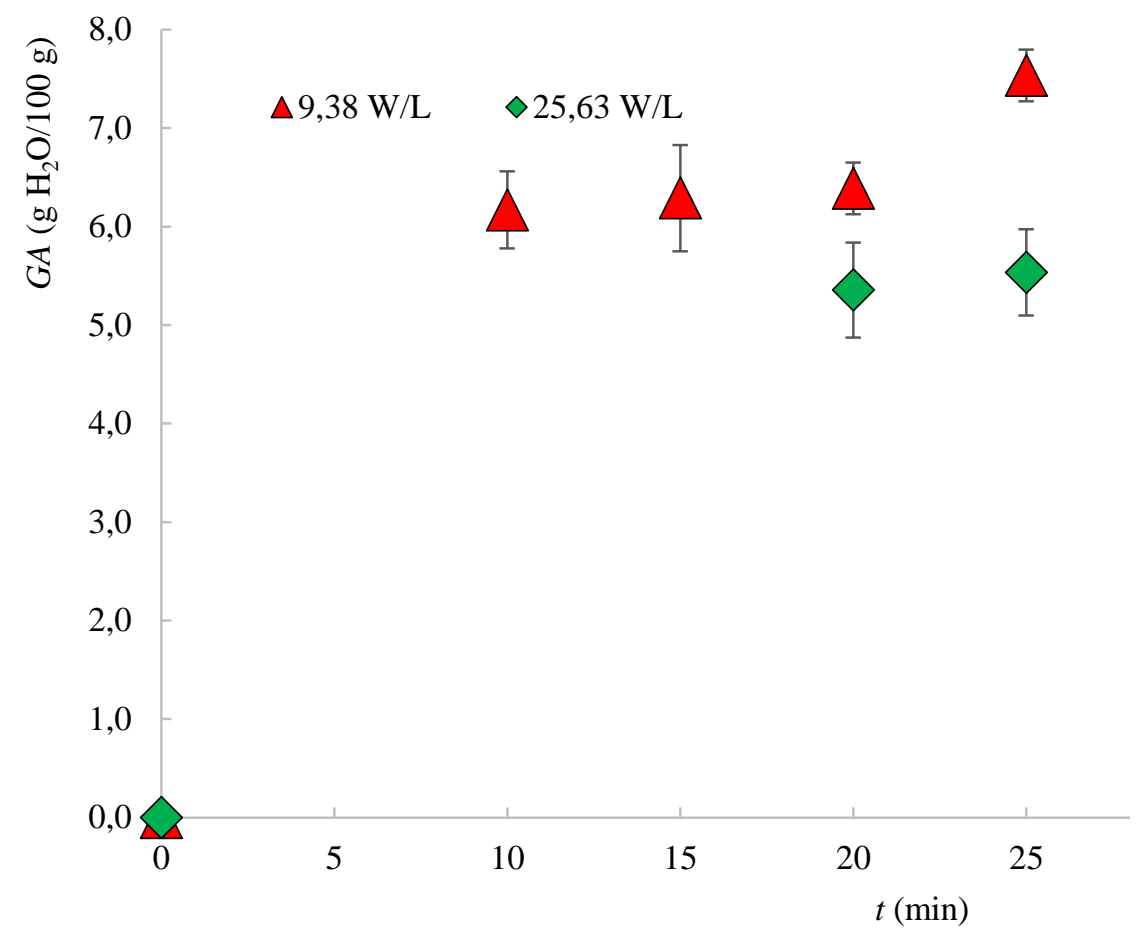

Fonte: O próprio autor.

A análise estatística dos resultados obtidos com o tempo de imersão de $(0,20$ e 25) min, nas potências volumétricas ultrassônicas de $(9,38$ e 25,63) W/L, demostrou que as variáveis tempo e potência volumétrica do ultrassom, assim como a interação das duas variáveis foram estatisticamente significativas sobre o $G A(p<0,05)$. A Tabela 5.3 apresenta os valores do efeito estimado de cada variável. Esses valores indicam o quanto as variáveis exercem influência sobre a resposta. Desta forma, quanto maior for o seu valor, maior será a sua influência sobre a resposta. Um efeito positivo sobre a resposta indica que, ao passar de um valor mínimo a um valor máximo da variável, o valor da resposta aumenta. Observa-se que o tempo foi a variável que mais influenciou o $G A$ e que a potência foi inversamente proporcional ao $G A$. 
Tabela 5.3 - Efeito estimado e $p$-valor para o ganho de água $(G A)$

\begin{tabular}{lcccc}
\hline Variáveis & Efeito & Erro padrão & $t$ cal & $p$ - valor \\
\hline Média & 3,49 & 0,12 & 29,08 & \\
Tempo & 6,68 & 0,30 & 22,26 & 0,000 \\
Potência volumétrica ultrassônica & $-0,80$ & 0,25 & 3,20 & 0,007 \\
Tempo x Potência volumétrica ultrassônica & $-0,93$ & 0,30 & 3,10 & 0,007 \\
\hline
\end{tabular}

Fonte: O próprio autor.

\subsection{Ultrassom seguido de pulsos de vácuo}

Na Tabela 5.4, os resultados do conteúdo de umidade após os pulsos de vácuo de 0,5 bar $\left(p_{\text {abs }}=51,325 \mathrm{kPa}\right.$ ) para as rodelas de banana verde sem ultrassom (in natura) e imersas previamente no banho ultrassônico de potência volumétrica ultrassônica de 9,38 W/L por (20 e 25) min, são apresentados.

Tabela 5.4 - Conteúdo de umidade de rodelas de banana verde submetidas ao pré-tratamento de pulsos de vácuo a pressão de 0,5 bar

\begin{tabular}{|c|c|c|c|c|c|c|}
\hline \multirow{3}{*}{ Pré-tratamento } & \multicolumn{5}{|c|}{ Conteúdo de umidade ( $\mathrm{g} \mathrm{H}_{2} \mathrm{O} / \mathrm{g}$ b.s.) } & \multirow[b]{3}{*}{ DMS } \\
\hline & \multirow[t]{2}{*}{ Inicial } & \multirow[t]{2}{*}{ Ultrassom } & \multicolumn{3}{|c|}{ Pulsos de vácuo (min) } & \\
\hline & & & 60 & 90 & 120 & \\
\hline Sem ultrassom & $2,92 \pm 0,03^{\mathrm{aA}}$ & - & $2,91 \pm 0,13^{\mathrm{aA}}$ & $2,66 \pm 0,10^{\mathrm{aA}}$ & $2,89 \pm 0,10^{\mathrm{aA}}$ & 0,39 \\
\hline 20 min de ultrassom & $2,77 \pm 0,23^{\mathrm{aA}}$ & $2,93 \pm 0,07^{\mathrm{aA}}$ & $2,72 \pm 0,11^{\mathrm{aA}}$ & $2,82 \pm 0,15^{\mathrm{aA}}$ & $2,80 \pm 0,14^{\mathrm{aA}}$ & 0,27 \\
\hline 25 min de ultrassom & $2,75 \pm 0,2^{\mathrm{aA}}$ & $3,23 \pm 0,29^{\mathrm{aC}}$ & $3,07 \pm 0,17^{\mathrm{aBC}}$ & $3,15 \pm 0,30^{\mathrm{aBC}}$ & $2,97 \pm 0,30^{\mathrm{aA}}$ & 0,25 \\
\hline DMS & 0,75 & 0,90 & 0,57 & 0,80 & 0,81 & \\
\hline
\end{tabular}

Letras diferentes na mesma coluna (minúsculas) e na mesma linha (maiuscúlas) indicam diferença significativa entre os tratamentos $(p<0,05)$. DMS: diferença mínima significativa pelo teste de Tukey. Fonte: O próprio autor.

A análise estatística revelou que o conteúdo de umidade das rodelas de banana verde no início do processo foi estatisticamente igual. Nas rodelas pré-tratadas com ultrassom por (20 e 25) min houve o acréscimo no conteúdo de umidade como consequência do $G A$, discutido previamente. No entanto, a aplicação de pulsos de vácuo não causou a remoção da umidade, tal como era esperado. $\mathrm{O}$ mesmo comportamento se observou para as rodelas de banana verde que não foram pré-tratadas, como pode ser melhor visualizado na Figura 5.2. 
Figura 5.2- Conteúdo de umidade de rodelas de banana verde submetidas ao pré-tratamento de pulsos de vácuo a pressão de 0,5 bar

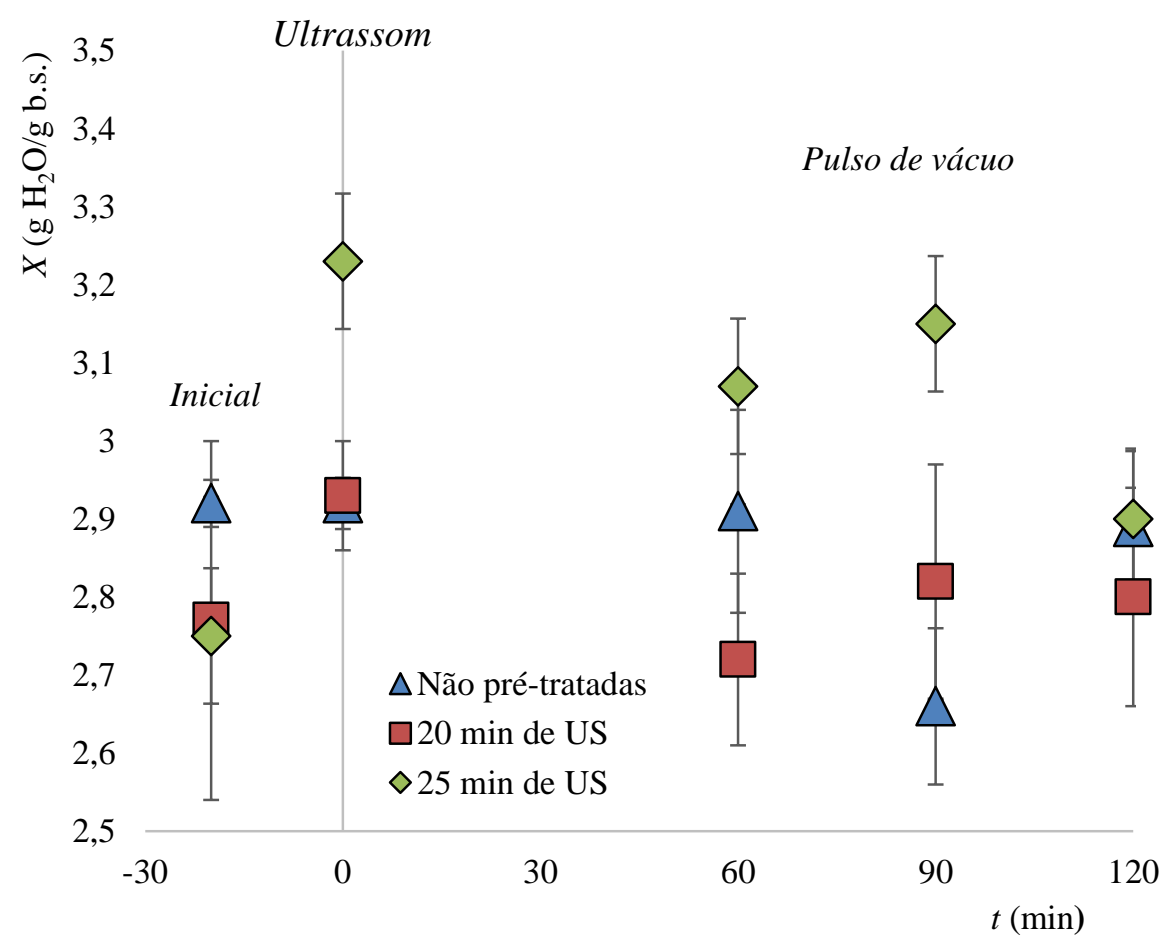

Fonte: O próprio autor.

As taxas de redução do conteúdo de umidade após 120 min de pulso de vácuo foram calculadas. Os valores obtidos foram de $-(0,25 ; 1,08$ e 2,75$) \times 10^{-4} \mathrm{~g} \mathrm{H}_{2} \mathrm{O} / \mathrm{g} \cdot \min$ b.s. para as rodelas de banana verde sem ultrassom (in natura) e as rodelas de (20 e 25) min de ultrassom, respectivamente. Demostra-se novamente que, no caso das rodelas in natura, os pulsos de vácuo tiveram efeito mínimo sobre a redução do conteúdo de água. No caso das rodelas pré-tratadas por (20 e 25) min, embora haja redução de umidade, não foi significativo sobre os valores absolutos do conteúdo de umidade (Tabela 5.4). 
Nas Figuras 5.3 a 5.5, as imagens obtidas com estereomicroscópio a 40x de rodelas de banana verde, após a aplicação do ultrassom e dos pulsos de vácuo, podem ser observadas.

Figura 5.3- Rodelas de banana verde não pré-tratadas submetidas ao prétratamento de pulsos de vácuo a pressão de 0,5 bar
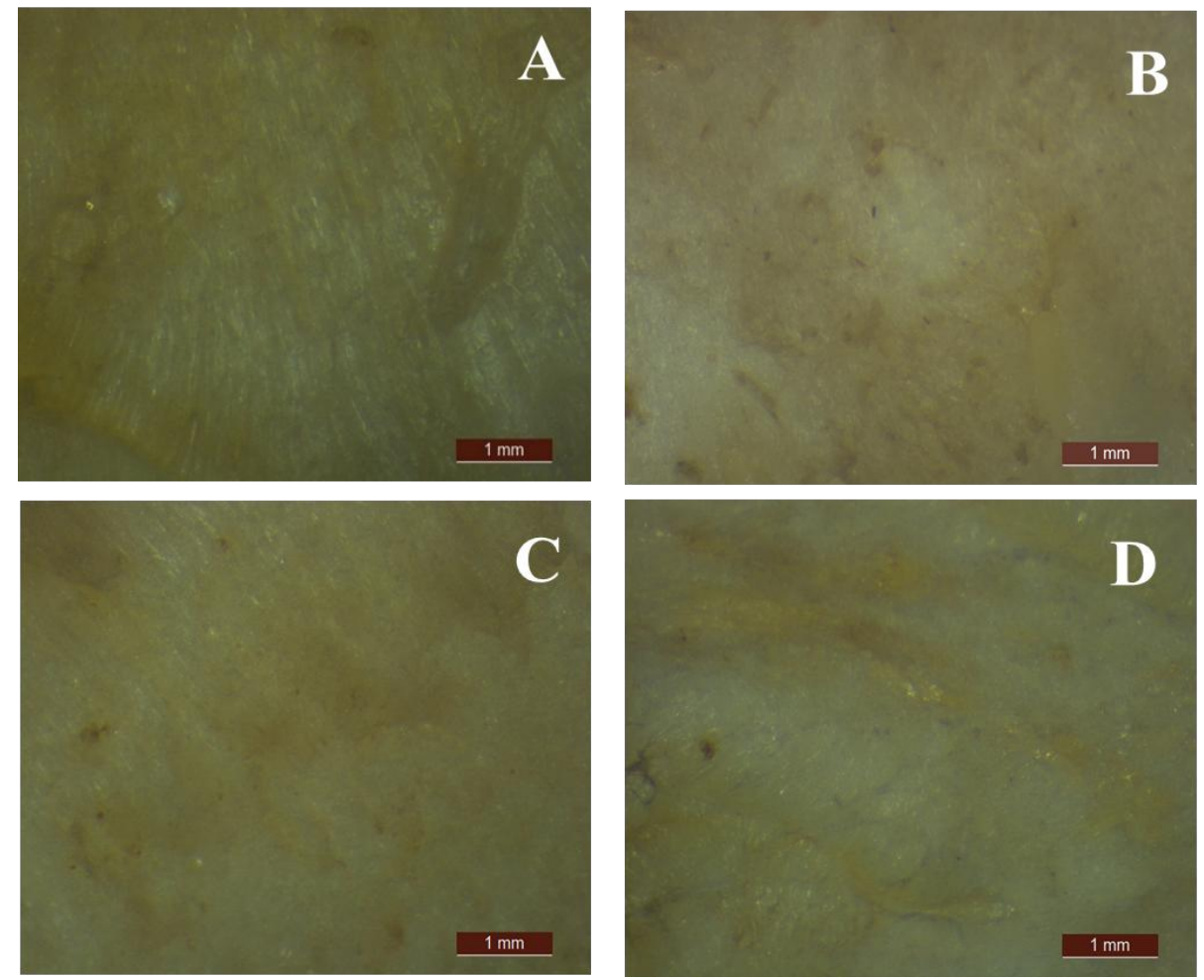

(A) rodelas de banana verde in natura, (B) rodelas de banana verde após 60 min de pulso de vácuo, (C) rodelas de banana verde após 90 min de pulso de vácuo, (D) rodelas de banana verde após 120 min de pulso de vácuo. Fonte: O próprio autor.

Diferente da Figura 5.3, na qual visualmente não se observam diferenças entre a banana verde in natura e as submetidas aos pulsos de vácuo, na Figura 5.4 se observa que, após a aplicação de 20 min de ultrassom (Figura 5.4B), uma fina camada de água superficial, com formas características de dutos, pode ser identificada como os micro-canais causados pelo ultrassom. Com a aplicação de (60, 90 e 120) min de pulsos de vácuo (Figura 5.4C, 5.4D e 5.4E), a camada superficial de água quase desaparece em sua totalidade. Pouca diferença observou-se entre as rodelas de banana verde submetidas a diferentes tempos de pulsos de vácuo. 
Figura 5.4- Rodelas de banana verde pré-tratadas com 20 min de ultrassom de potência igual a 9,38 W/L, e submetidas a pulsos de vácuo a pressão de 0,5 bar
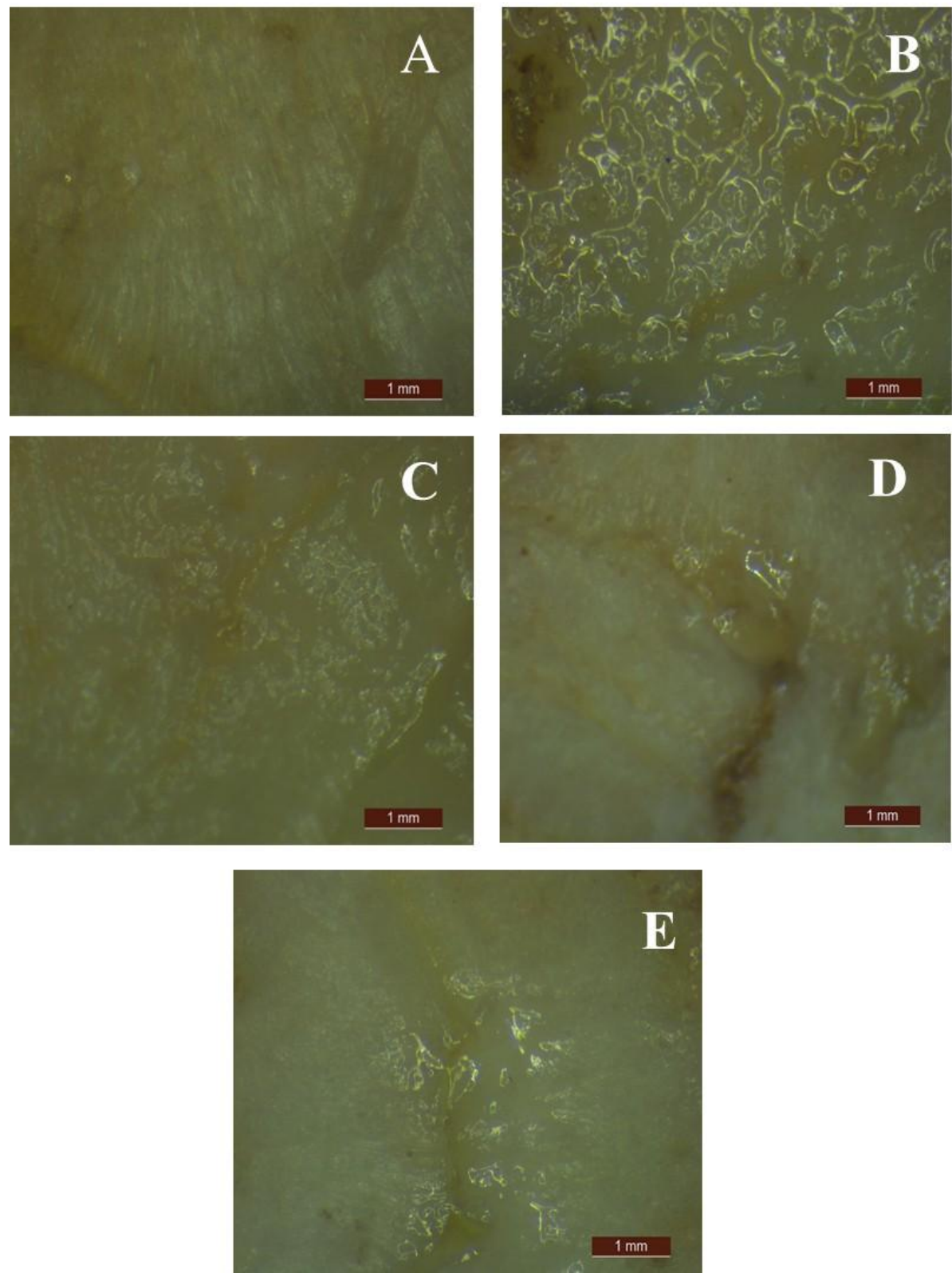

(A) rodelas de banana verde in natura, (B) rodelas de banana verde após 20 min de ultrassom, (C) rodelas de banana verde após 60 min de pulsos de vácuo, (D) rodelas de banana verde após 90 min de pulso de vácuo, (E) rodelas de banana verde após 120 min de pulso de vácuo. Fonte: O próprio autor. 
Na Figura 5.5B, após 25 min de ultrassom, observa-se os espaços intercelulares com morfologia típica de dutos, podendo ser os micro-canais relacionados ao pré-tratamento de ultrassom. Com a aplicação de (60, 90 e 120) min de pulsos de vácuo (Figura 5.5C, 5.5D e 5.5E) a água superficial desaparece. Maiores mudanças a 40x não foram observadas, tal como no caso das amostras pré-tratadas por 20 min no ultrassom (Figura 5.4).

Figura 5.5- Rodelas de banana verde pré-tratadas com 25 min de ultrassom de potência igual a 9,38 W/L, e submetidas a pulsos de vácuo a pressão de 0,5 bar
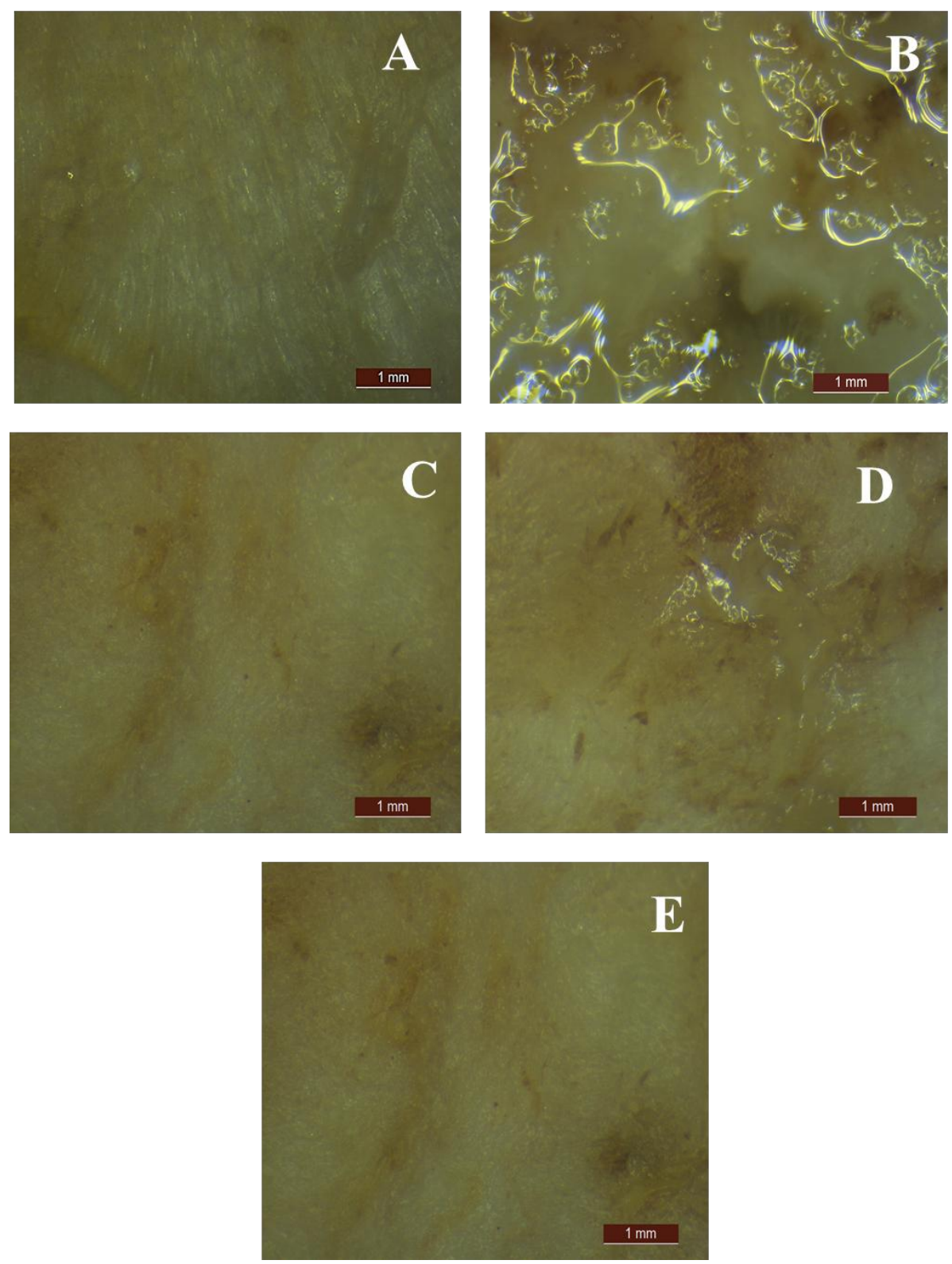

(A) rodelas de banana verde in natura, (B) rodelas de banana verde após 25 min de ultrassom, (C) rodelas de banana verde após 60 min de pulsos de vácuo, (D) rodelas de banana verde após 90 min de pulso de vácuo, (E) rodelas de banana verde após 120 min de pulso de vácuo. Fonte: O próprio autor. 
Diferenças no conteúdo de umidade e na estrutura das rodelas de banana verde não prétratadas (in natura) e as imersas no ultrassom por (20 e 25) min, após a aplicação dos pulsos de vácuo, eram esperadas. Isto porque a hipótese inicial - que os micro-canais gerados pelo ultrassom (FUENTES-BLANCO et al., 2006; PATERO et al., 2015, entre outros) e o posterior gradiente de pressão provocado pela aplicação dos pulsos de vácuo (FITO, 1994), facilitariam a saída de água - não foi comprovada, ou seja: a combinação das duas técnicas, nestas condições, não favoreceu a taxa de remoção de umidade. Este fato poderia ter acontecido possivelmente devido ao colapso da estrutura da fruta (micro-canais formados no ultrassom) após a aplicação dos 60 min de pulso de vácuo. No entanto, este fenômeno não foi visualizado a 40x nas Figuras 5.3 a 5.5.

Na literatura foram relatados estudos para analize da morfologias em frutas através de microscopia ótica, em que, as amostras eram previamente fixadas com corante para melhor visualização (FERNANDES et al., 2009; PERONI-OKITA et al., 2013, entre outros). Entretanto, nenhuma destas metodologias foi aplicada neste trabalho fato que também poderia ter dificultado a visualização da mudança da estrutura após os pulsos de vácuo, nas rodelas de banana verde.

Na sequência do trabalho, ainda foi avaliado o impacto da combinação do ultrassom com pulso de vácuo sobre a cinética de secagem de rodelas de banana verde. Como o tempo de pulso de vácuo não influenciou significativamente a remoção de água, para os posteriores ensaios foi considerado unicamente $60 \mathrm{~min}$ de pulso de vácuo. 


\subsection{Ensaios preliminares de secagem em estufa convectiva}

$\mathrm{Na}$ Tabela 5.5 são apresentados os valores da difusividade efetiva da água $\left(D_{e f}\right)$, calculados para rodelas de banana verde pré-tratadas por $(10,15,20$ e 25$)$ min no banho de potência volumétrica ultrassônica igual a 9,38 W/L. Os valores de $D_{e f}$ foram determinados utilizando a eq. (2), na qual os primeiros cinco termos da série de Fourier foram considerados. Os coeficientes de regressão do ajuste do modelo também são apresentados. O tempo total de secagem para os ensaios foi de $360 \mathrm{~min}$, e as amostras apresentaram conteúdo de umidade final em torno de $0,05 \mathrm{~g} \mathrm{H}_{2} \mathrm{O} / \mathrm{g}$ b.s.

Tabela 5.5 - Difusividade efetiva da água $\left(D_{e f}\right)$ obtida nos processos de secagem em estufa, a $(50$ e 60$){ }^{\circ} \mathrm{C}$, de rodelas de banana verde pré-tratadas com ultrassom de potência volumétrica ultrassônica igual a 9,38 W/L

\begin{tabular}{ccccc}
\hline \multirow{2}{*}{ Tempo de ultrassom (min) } & \multicolumn{4}{c}{$D_{\text {ef } \times 10^{-10}\left(\mathrm{~m}^{2} / \mathrm{s}\right)}$} \\
\cline { 2 - 5 } & Temp. 50 ${ }^{\circ} \mathrm{C}$ & $r^{2}$ & Temp. $60^{\circ} \mathrm{C}$ & $r^{2}$ \\
\hline 0 & $1,25 \pm 0,01^{\mathrm{aA}}$ & 94,08 & $1,39 \pm 0,27^{\mathrm{aB}}$ & 95,13 \\
10 & $1,17 \pm 0,00^{\mathrm{aA}}$ & 93,73 & $1,48 \pm 0,17^{\mathrm{aB}}$ & 95,74 \\
15 & $1,19 \pm 0,02^{\mathrm{aA}}$ & 92,46 & $1,37 \pm 0,19^{\mathrm{aB}}$ & 97,01 \\
20 & $1,31 \pm 0,06^{\mathrm{aA}}$ & 93,13 & $1,40 \pm 0,09^{\mathrm{aB}}$ & 95,15 \\
25 & $1,20 \pm 0,07^{\mathrm{aA}}$ & 93,03 & $1,58 \pm 0,40^{\mathrm{aB}}$ & 98,85 \\
DMS & 0,36 & & 0,36 & \\
\hline
\end{tabular}

Letras diferentes na mesma coluna (minúscula) ou linha (maiúscula) indicam diferença significativa entre os tratamentos $(p<0,05)$. DMS: diferença mínima significativa pelo teste de Tukey Fonte: O próprio autor.

Na temperatura de secagem de $50{ }^{\circ} \mathrm{C}$ o maior valor de $D_{e f}$ foi obtido para as rodelas de banana verde pré-tratadas com 20 min de ultrassom, enquanto que à temperatura de secagem de $60{ }^{\circ} \mathrm{C}$, a maior difusividade efetiva da água obtida foi para as rodelas de banana verde prétratadas com 25 min de ultrassom. A difusividade efetiva da água obtida nos ensaios a $60{ }^{\circ} \mathrm{C}$ foi superior se comparada com as dos ensaios à $50^{\circ} \mathrm{C}$, para cada tempo de pré-tratamento, como esperado. A análise estatística revelou que o tempo do ultrassom, nas condições estudadas, não influenciou significativamente a difusividade efetiva; no entanto, a temperatura de secagem, sim. Embora não tenham sido encontradas diferenças estatísticas, comparando as rodelas de banana verde pré-tratadas com 20 min de ultrassom e secas a $50{ }^{\circ} \mathrm{C}$ em relação às rodelas não pré-tratadas, foi observado aumento na difusividade efetiva da água de $4,8 \%$. No caso dos ensaios conduzidos a $60{ }^{\circ} \mathrm{C}$, o aumento da difusividade efetiva da água nas rodelas de banana 
verde pré-tratadas com 25 min de ultrassom em relação às rodelas não pré-tratadas foi de 13,67 $\%$. As curvas de secagem correspondentes a estes ensaios estão apresentadas no ANEXO A.

Na Tabela 5.6, os valores de difusividade efetiva da água $\left(D_{e f}\right)$ calculados para os ensaios conduzidos com pré-tratamento de (20 e 25) min no banho de potência volumétrica ultrassônica igual a $25,63 \mathrm{~W} / \mathrm{L}$ e temperatura de secagem de $(50$ e 60$){ }^{\circ} \mathrm{C}$, assim como os coeficientes de regressão do modelo estão apresentados.

Tabela 5.6 - Difusividade efetivada água $\left(D_{e f}\right)$ obtidas nos processos de secagem em estufa, a (50 e 60) ${ }^{\circ} \mathrm{C}$, de rodelas de banana verde pré-tratadas com ultrassom de potência volumétrica ultrassônica igual a 25,63 W/L

\begin{tabular}{ccccc}
\hline \multirow{2}{*}{ Tempo de ultrassom (min) } & \multicolumn{4}{c}{$D_{\text {ef }} \times 10^{-10}\left(\mathrm{~m}^{2} / \mathrm{s}\right)$} \\
\cline { 2 - 5 } & Temp. $50^{\circ} \mathrm{C}$ & $r^{2}$ & Temp. $60{ }^{\circ} \mathrm{C}$ & $r^{2}$ \\
\hline 0 & $1,25 \pm 0,01^{\mathrm{aA}}$ & 94,08 & $1,39 \pm 0,27^{\mathrm{aB}}$ & 95,13 \\
20 & $0,77 \pm 0,04^{\mathrm{bA}}$ & 91,73 & $1,23 \pm 0,01^{\mathrm{bB}}$ & 95,33 \\
25 & $0,84 \pm 0,04^{\mathrm{bA}}$ & 92,66 & $1,23 \pm 0,01^{\mathrm{bB}}$ & 94,96 \\
DMS & 0,26 & & 0,26 &
\end{tabular}

Letras diferentes na mesma coluna (minúscula) ou linha (maiúscula) indicam diferença significativa entre os tratamentos $(p<0,05)$. DMS: diferença mínima significativa pelo teste de Tukey Fonte: O próprio autor.

Observa-se que, os valores da difusividade da água efetiva foram significativamente menores, nas duas temperaturas, para as rodelas de banana verde submetidas ao pré-tratamento de ultrassom por (20 e 25) min, em comparação às rodelas não pré-tratadas. A análise estatística revelou que a temperatura de secagem influenciou significativamente a difusividade efetiva da água, como foi observado anteriormente (Tabela 5.5). As curvas de secagem para estes ensaios estão apresentadas no ANEXO B. Como observado nas curvas de secagem dos ANEXOS A e $\mathrm{B}$, a relação de umidades $(M R)$, no inicio do processo é igual a unidade, isto porque como foi relatado previamente, na eq. (3), o valor considerado para a umidade inicial $\left(X_{0}\right)$ foi após o prétratamento com ultrassom.

Pelos coeficientes de regressão obtidos (Tabelas 5.5 e 5.6) verifica-se que, o emprego da eq. (2) não foi o melhor modelo para a determinação da difusividade efetiva da água. Contudo, como foi descrito anteriormente, estes ensaios foram conduzidos como uma primeira abordagem, cujo objetivo principal foi o de definir algumas condições para os ensaios no secador de bandejas (LABMAQ, modelo LM.ES-20, Brasil). Assim, segundo os resultados observados, os ensaios com pré-tratamento de $(20$ e 25$)$ min na potência volumétrica ultrassônica de 9,38 W/L, nas duas temperaturas de secagem, foram definidos para a sequência do trabalho. 


\subsection{Secador de bandejas}

Nas Figuras 5.6 e 5.7 são apresentadas as curvas de secagem a $(50 \text { e } 60)^{\circ} \mathrm{C}$ conduzidas no secador de bandejas para as rodelas de banana verde imersas por (20 e 25) min no ultrassom de potência volumétrica ultrassônica de 9,38 W/L. Nas Figuras 5.8 e 5.9 são mostradas as taxas de secagem obtidas nestes processos nas duas temperaturas. Observa-se que as rodelas submetidas aos pré-tratamentos de ultrassom iniciaram o processo de secagem com $M R$ (relação de umidades) maior que a unidade, devido ao ganho de água, resultado do pré-tratamento com ultrassom. Nestes ensaios, o valor de $X_{0}$ considerado foi o inicial (banana in natura) por considerar-se uma melhor forma de descrever o fenômeno envolvendo o ultrassom. Na Figura 5.6, é possível observar que o pré-tratamento de 20 min de ultrassom foi o mais favorável sobre a secagem quando a temperatura foi de $50{ }^{\circ} \mathrm{C}$. Na Figura 5.7, vê-se que o pré-tratamento de 25 min de ultrassom não foi muito vantajoso em comparação aos ensaios sem pré-tratamento, nas duas temperaturas. Assim, é possível verificar que, o efeito do ultrassom por 20 min é mais visível quando a temperatura de secagem foi de $50{ }^{\circ} \mathrm{C}$.

Figura 5.6 - Curvas de secagem a $(50$ e 60$){ }^{\circ} \mathrm{C}$, obtidas no processo de secagem, para rodelas de banana verde, imersas por $20 \mathrm{~min}$ no banho ultrassônico de potência volumétrica 9,38 W/L

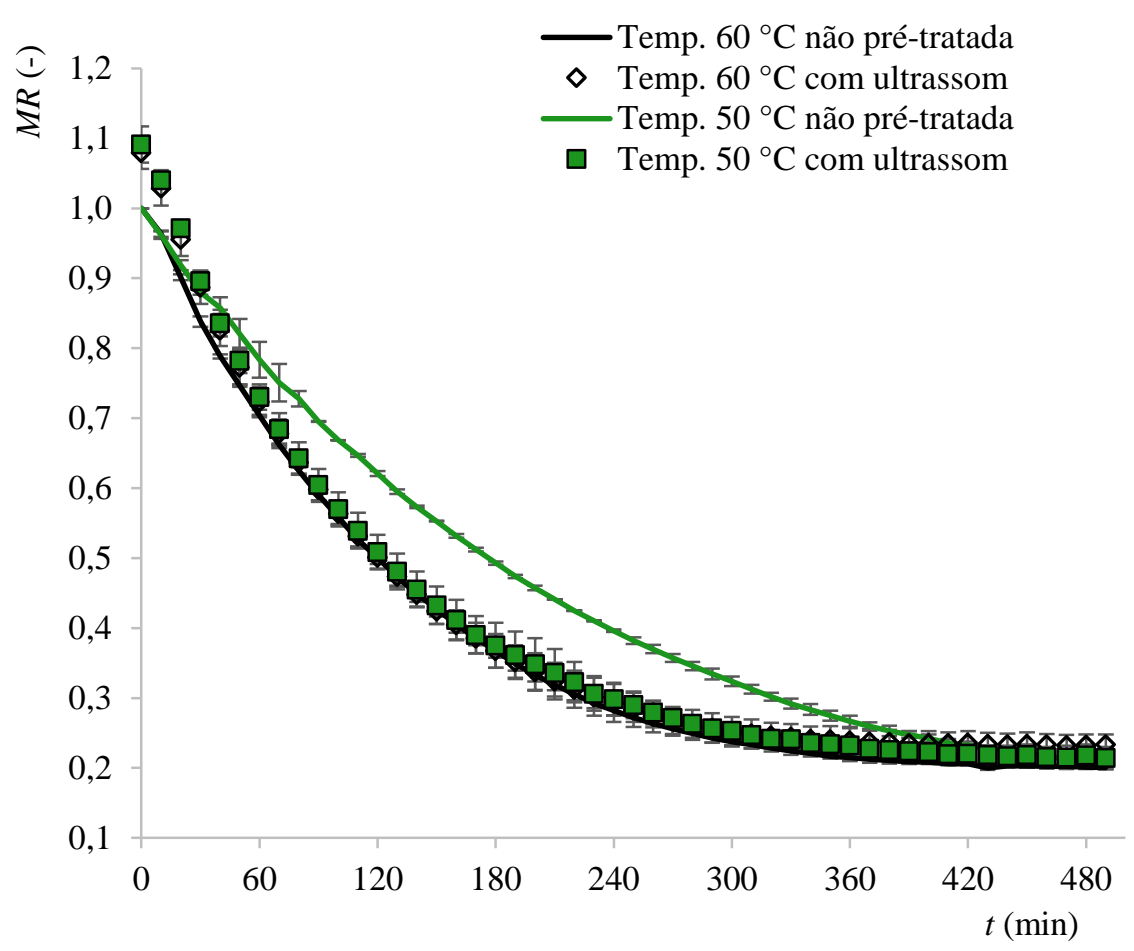

Fonte: O próprio autor. 
Figura 5.7 - Curvas de secagem a $(50$ e 60$){ }^{\circ} \mathrm{C}$, obtidas no processo de secagem, para rodelas de banana verde, imersas por 25 min no banho ultrassônico de potência volumétrica 9,38 W/L

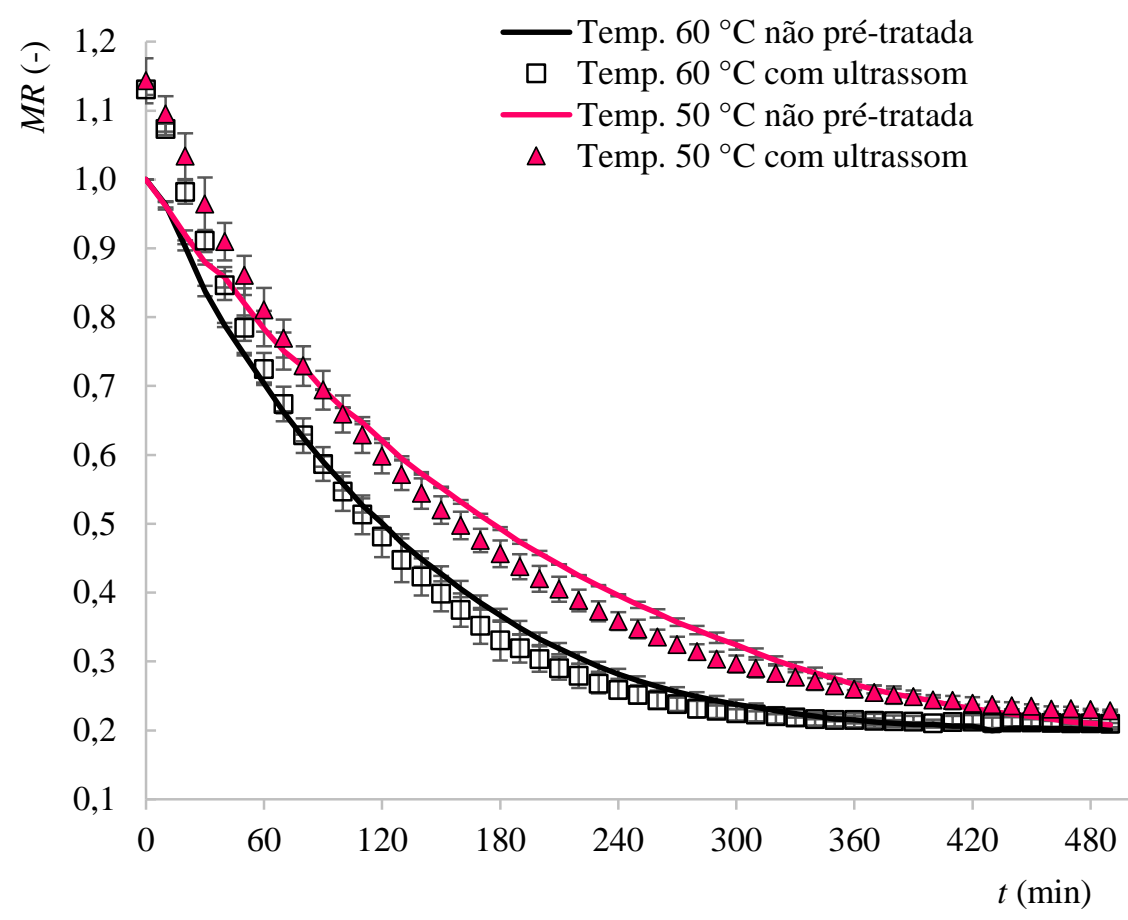

Fonte: O próprio autor.

Figura 5.8 - Taxas de secagem a $50{ }^{\circ} \mathrm{C}$, obtidas no processo de secagem, para rodelas de banana verde, imersas por (20 e 25) min no banho de ultrassônico de potência volumétrica $9,38 \mathrm{~W} / \mathrm{L}$

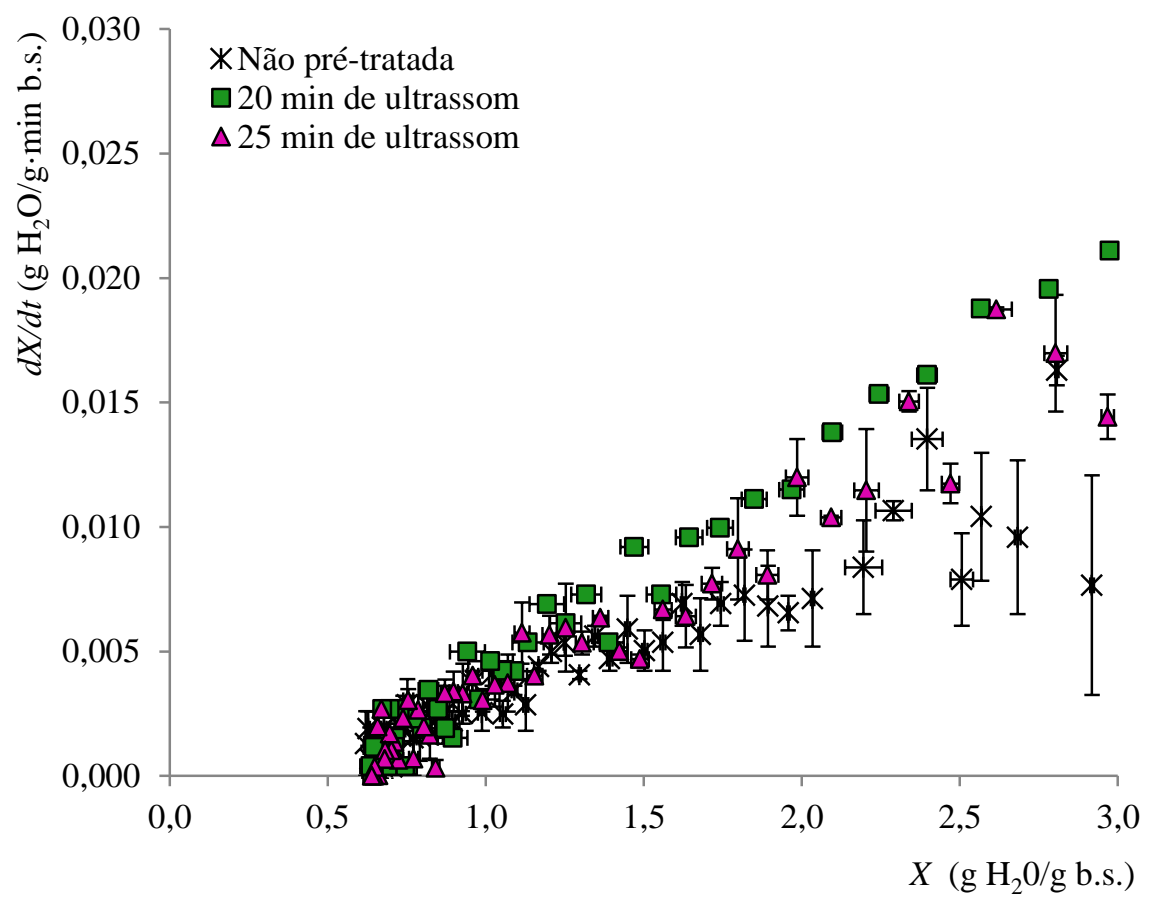

Fonte: O próprio autor. 
Figura 5.9 - Taxas de secagem a $60{ }^{\circ} \mathrm{C}$, obtidas no processo de secagem, para rodelas de banana verde, imersas por (20 e 25) min no banho de ultrassônico de potência volumétrica $9,38 \mathrm{~W} / \mathrm{L}$

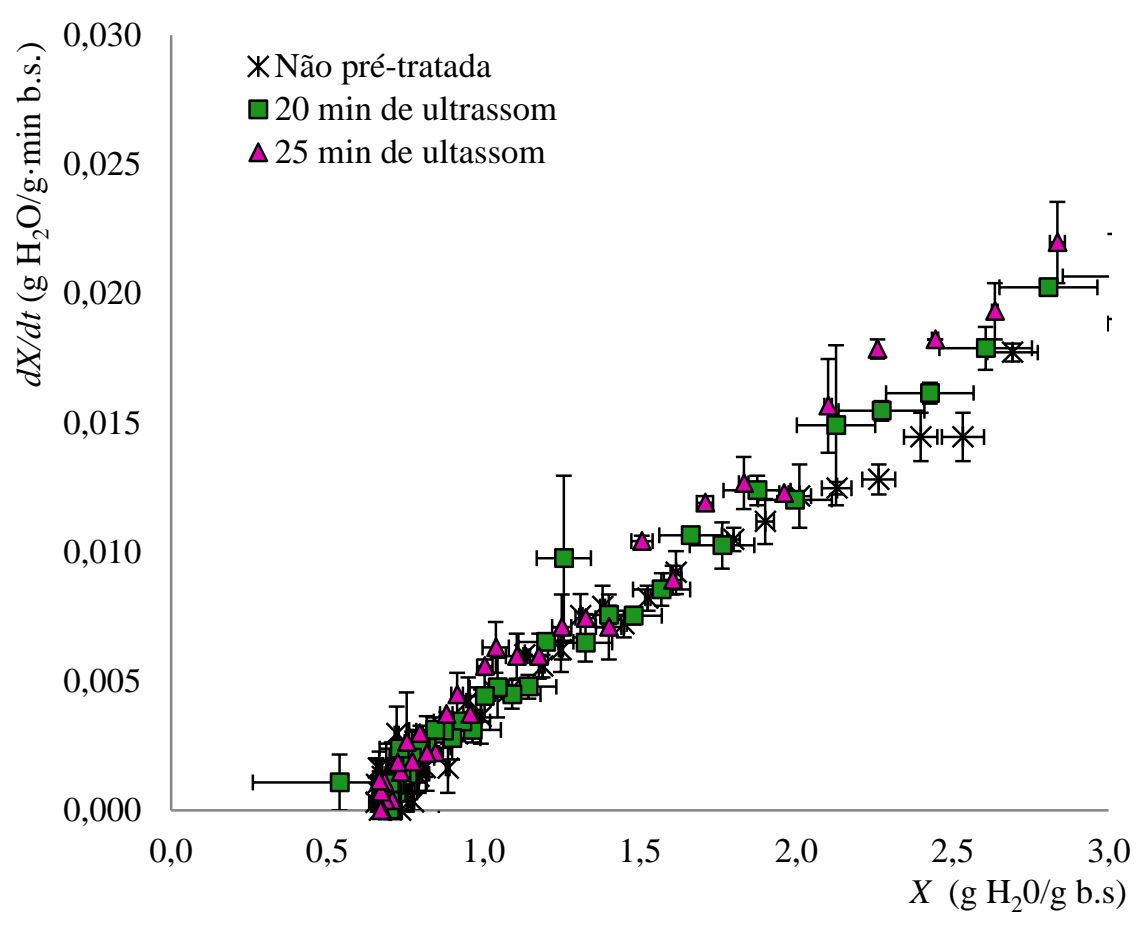

Fonte: O próprio autor.

Na Figura 5.8 é possível verificar que, o pré-tratamento com 20 min de ultrassom favoreceu a taxa de secagem a $50{ }^{\circ} \mathrm{C}$, como já foi observado na Figura 5.6. Apesar das rodelas de banana verde apresentarem maior conteúdo de umidade devido ao ganho de água no prétratamento, as taxas se mantiveram superiores ao longo do processo. Por outro lado, a $60{ }^{\circ} \mathrm{C}$ (Figura 5.9), as taxas obtidas para os ensaios das rodelas de banana verde não pré-tratada e com pré-tratamento de ultrassom por (20 e 25) min foram muito próximas. Mostra-se, novamente, que a $60{ }^{\circ} \mathrm{C}$ a aplicação do pré-tratamento com ultrassom não se mostrou muito favorável. De fato, segundo Ricce et al. (2016) o emprego de temperaturas mais altas de secagem se sobrepõe aos efeitos do pré-tratamento com ultrassom.

A difusividade efetiva da água foi calculada pelo método das tangentes, segundo a eq. (14), em que, $D_{e f}$ é a relação entre a linearização da curva experimental (eq. 10) e a linearização da curva teórica (eq. 13). O coeficiente de regressão lineal $\left(r^{2}\right)$ para todos os ensaios foi $\geq 0,98$. Na Figura 5.10 apresenta-se, como exemplo, uma curva experimental linearizada de secagem a $60{ }^{\circ} \mathrm{C}$, de rodelas de banana verde não pré-tratadas, em que, é possível observar três períodos durante a secagem, duas fases no período de taxa decrescente de secagem e um último período, 
quando o equilibro foi atingido. Tribess (2009) e Zabalaga (2016) também observaram duas fases na taxa decrescente da secagem de banana verde.

Figura 5.10 - Exemplo de curva de secagem a $60{ }^{\circ} \mathrm{C}$ linearizada utilizada no cálculo da difusividade

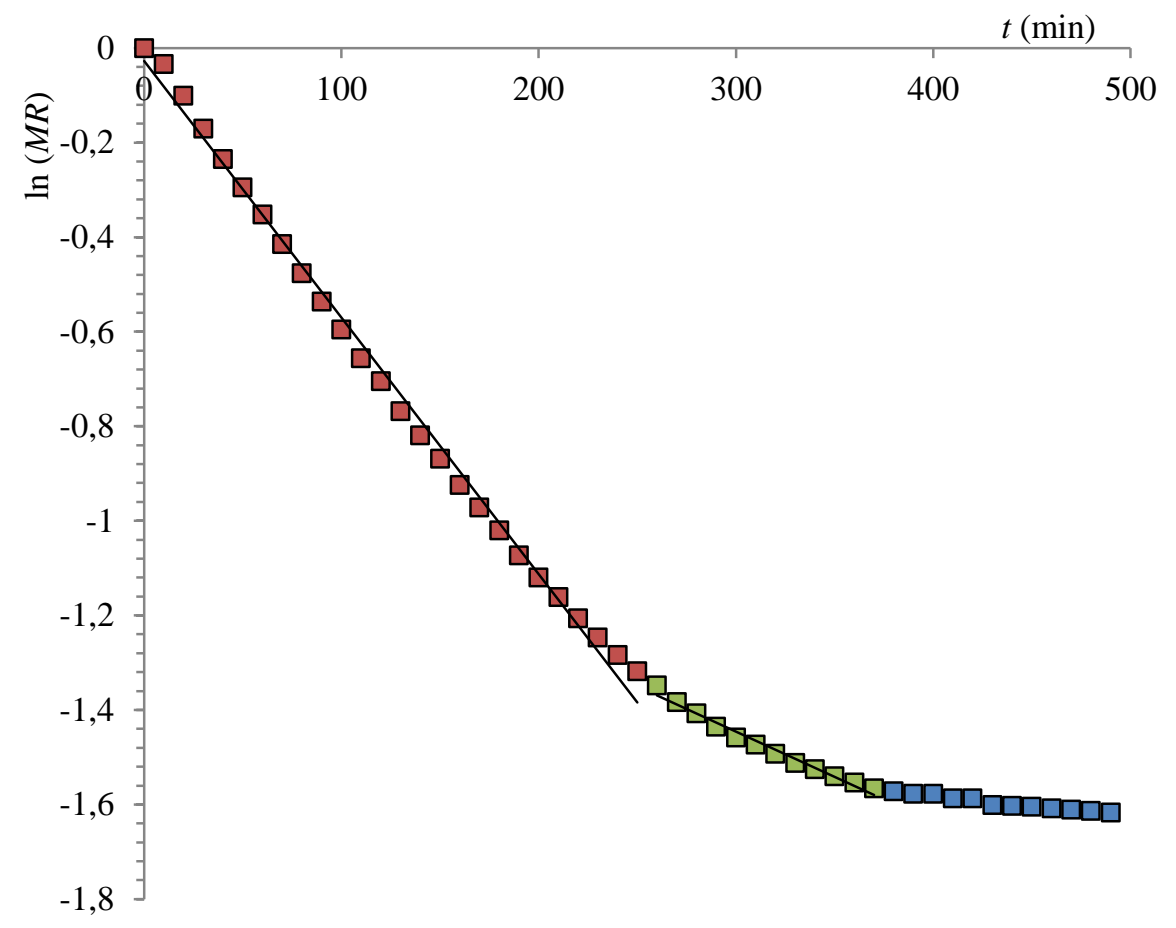

Fonte: O próprio autor.

$\mathrm{Na}$ Tabela 5.7, a difusividade efetiva da água $\left(D_{e f}\right)$ calculada para cada ensaio é apresentada. A análise estatística foi conduzida separadamente para a primeira e segunda fase de velocidade decrescente.

Tabela 5.7 $-D_{e f}$ a $(50$ e 60$){ }^{\circ} \mathrm{C}$, obtida nos processos de secagem em secador de bandejas, para rodelas de banana verde, imersas por (20 e 25) min no banho de ultrassônico de potência volumétrica $9,38 \mathrm{~W} / \mathrm{L}$

\begin{tabular}{lccccc}
\hline \multirow{2}{*}{ Pré-tratamento } & $t(\min )$ & \multicolumn{2}{c}{$1^{\circ} D_{e f} \times 10^{-9}\left(\mathrm{~m}^{2} / \mathrm{s}\right)$} & \multicolumn{2}{c}{$2^{\circ} D_{e f} \times 10^{-9}\left(\mathrm{~m}^{2} / \mathrm{s}\right)$} \\
\cline { 2 - 5 } & & $50^{\circ} \mathrm{C}$ & $60^{\circ} \mathrm{C}$ & $50^{\circ} \mathrm{C}$ & $60^{\circ} \mathrm{C}$ \\
\hline Não pré-tratada & - & $7,03 \pm 0,09^{\mathrm{aA}}$ & $9,93 \pm 0,19^{\mathrm{aB}}$ & $3,84 \pm 0,09^{\mathrm{aA}}$ & $3,65 \pm 0,01^{\mathrm{aA}}$ \\
Ultrassom & 20 & $12,18 \pm 0,47^{\mathrm{bA}}$ & $11,4 \pm 0,19^{\mathrm{bB}}$ & $6,84 \pm 0,28^{\mathrm{bA}}$ & $5,71 \pm 0,09^{\mathrm{bA}}$ \\
Ultrassom & 25 & $8,62 \pm 0,00^{\mathrm{cA}}$ & $12,5 \pm 0,47^{\mathrm{cB}}$ & $3,28 \pm 0.09^{\mathrm{aA}}$ & $5,06 \pm 0,19^{\mathrm{aA}}$ \\
DMS & & 0,59 & 0,59 & 0,48 & 0,48 \\
\hline
\end{tabular}

Letras diferentes na mesma coluna (minúscula) ou linha (maiúscula) indicam diferença significativa entre os tratamentos $(p<0,05)$. DMS: diferença mínima significativa pelo teste de Tukey. Fonte: O próprio autor. 
Na primeira fase de taxa decrescente, na temperatura de secagem de $50{ }^{\circ} \mathrm{C}$, observa-se que o pré-tratamento por $20 \mathrm{~min}$ no ultrassom resultou em valor de difusividade efetiva da água significativamente superior. No caso da secagem a $60{ }^{\circ} \mathrm{C}$, o pré-tratamento de $25 \mathrm{~min}$ foi significativamente superior. A temperatura de secagem foi significativa para a primeira difusividade efetiva da água, como observado nos ensaios realizados em estufa convectiva (Tabelas 5.5 e 5.6). Segundo Demirel e Turhan (2003), na primeira fase de velocidade decrescente, o material apresenta a superfície parcialmente úmida e a resistência interna à difusão governa o processo. No entanto, a velocidade do ar na superfície tem incidência na taxa de secagem, dependendo das condições do processo. Segundo Zabalaga (2016) a maior parte de retirada de água acontece nesta fase.

Na segunda fase de taxa decrescente, a superfície do produto apresenta-se totalmente seca e a resistência interna à difusão controla sozinha a secagem do material (DEMIREL; TURHAN, 2003). Nesta fase observa-se que, a temperatura de secagem não foi significativa, e o pré-tratamento com ultrassom, por $20 \mathrm{~min}$, mostrou-se significativamente superior nas duas temperaturas. Schössler et al. (2012a) estudaram a secagem assistida com ultrassom para fatias de pimentão e observaram aumento no valor da difusividade efetiva da água na segunda fase da taxa decrescente, e atribuíram esse efeito benéfico às mudanças na estrutura e ao 'efeito esponja' do ultrassom, observado quando a quantidade de água disponível é menor. ANOVA acusou que, para a primeira e segunda difusividade efetiva de água, nas duas temperaturas, a interação das variáveis (tempo de ultrassom e temperatura de secagem) foi significativa. Assim, a incidência do pré-tratamento de ultrassom, nas propriedades de transporte, durante a secagem não pode ser analisado isoladamente sem considerar a temperatura de secagem.

Quando o pré-tratamento de ultrassom foi aplicado por $20 \mathrm{~min}$ e secagem a $50{ }^{\circ} \mathrm{C}$, o aumento da difusividade efetiva da água, em relação às amostras não pré-tratadas, foi de $(72,1$ e 78,1$) \%$, na primeira e segunda fases de taxa decrescente, respectivamente. No caso das amostras pré-tratadas por $25 \mathrm{~min}$ e secas a $60^{\circ} \mathrm{C}$ o aumento foi de $(25,8$ e 38,6$) \%$, na primeira e segunda fases de taxa decrescente, respectivamente. A mesma tendência foi observada nas amostras secas em estufa (Tabela 5.5), porém o aumento nos valores de difusividade efetiva da água foi menor para esses ensaios.Vale destacar que, nos ensaios conduzidos no secador de bandejas, os parâmetros envolvidos no processo (temperatura, velocidade de ar e umidade) foram rigorosamente controlados, enquanto que, nos ensaios na estufa convectiva, o único parâmetro controlado foi a temperatura. 
Karim et al. (2005) estudaram a secagem de banana madura a $0,7 \mathrm{~m} / \mathrm{s}$ e $60{ }^{\circ} \mathrm{C}$, e o valor da $D_{\text {ef }}$ obtido foi de $2,41 \times 10^{-10} \mathrm{~m}^{2} / \mathrm{s}$. Tribess (2009) observou, a $55^{\circ} \mathrm{C}$ e $1,4 \mathrm{~m} / \mathrm{s}$, dois valores de difusividade efetiva: $(1,27$ e 2,50$) \times 10^{-11} \mathrm{~m}^{2} / \mathrm{s}$ para a primeira e segunda fase do período decrescente, respectivamente. Zabalaga (2016) também estudou a secagem de banana verde (Musa Cavendishii) a $60{ }^{\circ} \mathrm{C}$ e $4 \mathrm{~m} / \mathrm{s}$, sendo as $D_{\text {ef }}$ relatadas de $(3,28$ e 1,77$) \times 10^{-10} \mathrm{~m}^{2} / \mathrm{s}$, na primeira e segunda fases do período decrescente, respectivamente. Nos estudos realizados, aplicando a técnica de ultrassom como pré-tratamento, os valores da $D_{\text {ef }}$ relatados por Azoubel et al. (2010), a partir da imersão de banana madura (cv. Pacovan) por 20 min em ultrassom e seca a $50{ }^{\circ} \mathrm{C}$ e $3,0 \mathrm{~m} / \mathrm{s}$, foi de $9,26 \times 10^{-10} \mathrm{~m}^{2} / \mathrm{s}$. Fernandes et al. (2007), com a imersão da banana madura (Musa ssp.) por $20 \mathrm{~min}$ em ultrassom e seca a $60{ }^{\circ} \mathrm{C}$, relataram um valor de $1,46 \times 10^{-9}$ $\mathrm{m}^{2} / \mathrm{s}$. Cabe lembrar que, a difusividade não é uma propriedade intrínseca ao material e depende das condições de secagem (temperatura e velocidade do ar), o que tornam difíceis as comparações entre os diferentes trabalhos na literatura com o presente trabalho.

Nas Figuras 5.11 e 5.12, as curvas de secagem a $(50$ e 60$){ }^{\circ} \mathrm{C}$ e as respectivas taxas de secagem obtidas para as rodelas de banana verde, pré-tratadas com pulso de vácuo por $60 \mathrm{~min}$ a $0,5 \operatorname{bar}\left(p_{\text {abs }}=51,325 \mathrm{kPa}\right)$, são apresentadas.

Figura 5.11 - Curvas de secagem a $(50$ e 60$){ }^{\circ} \mathrm{C}$, obtidas no processo de secagem, para rodelas de banana verde, submetidas a um pulso de vácuo de 0,5 bar por $60 \mathrm{~min}$

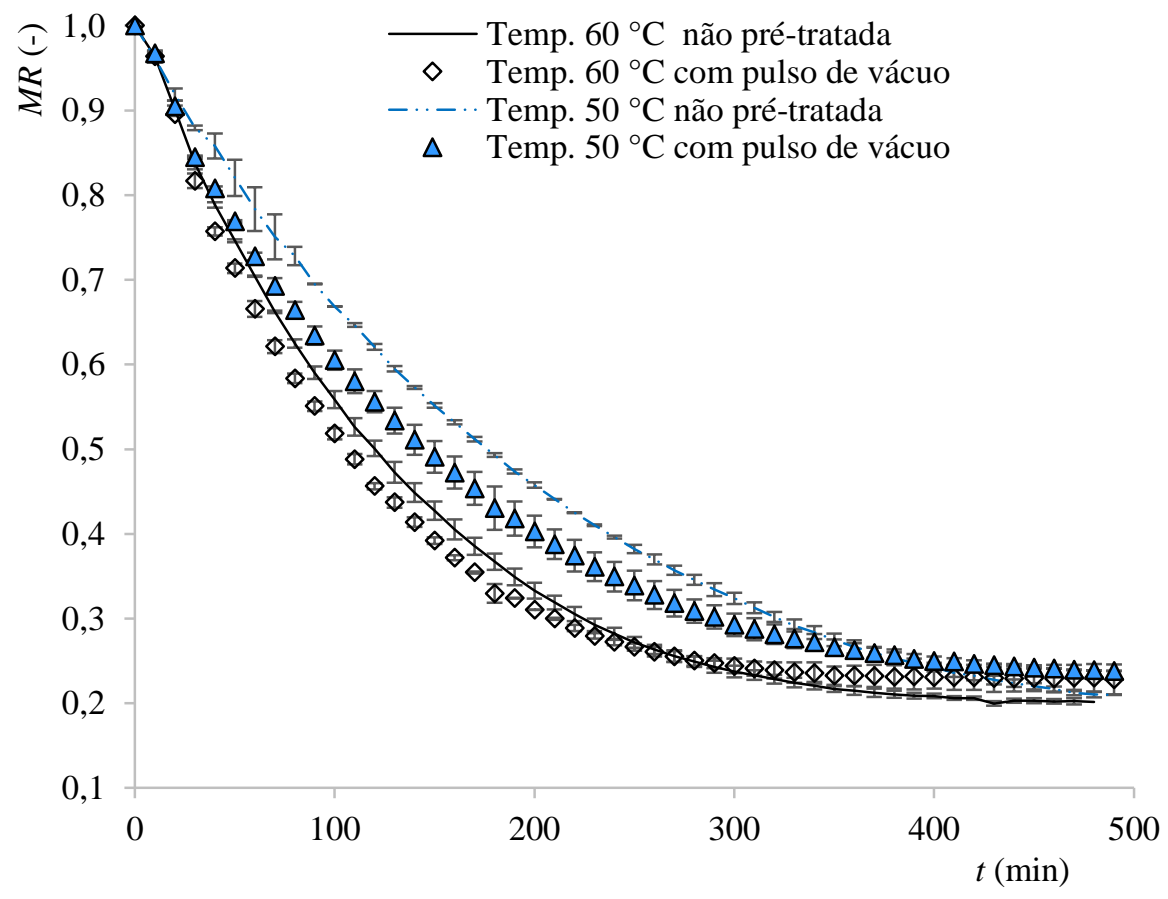

Fonte: O próprio autor. 
Figura 5.12 - Taxas de secagem a $(50$ e 60$){ }^{\circ} \mathrm{C}$, obtidas no processo de secagem, para rodelas de banana verde, submetidas a um pulso de vácuo de 0,5 bar por 60 min

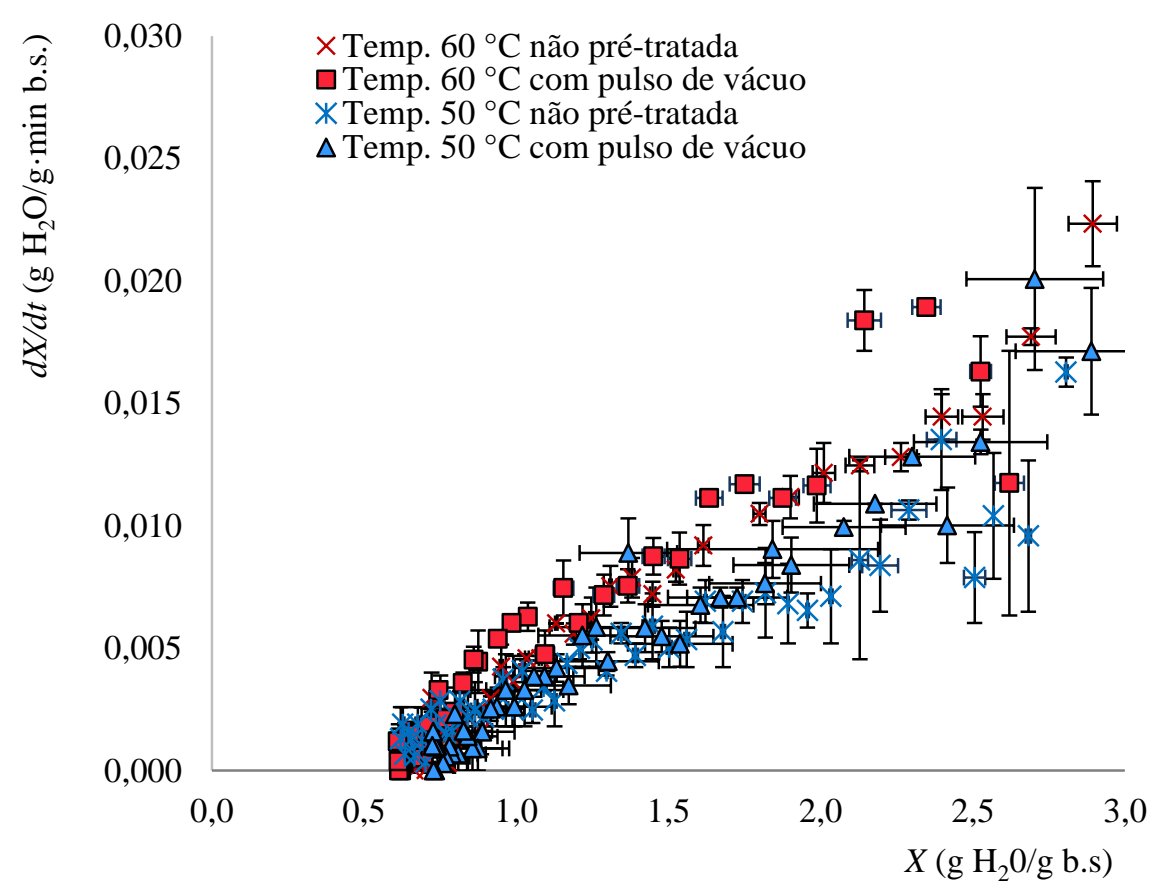

Fonte: O próprio autor.

Na Figura 5.11 observa-se que, o pulso de vácuo favoreceu minimamente a taxa de remoção de água para os ensaios a $(50$ e 60$){ }^{\circ} \mathrm{C}$, sendo que, a $60{ }^{\circ} \mathrm{C}$ o efeito é menos evidente. Ao comparar as curvas de secagem obtidas a $50{ }^{\circ} \mathrm{C}$ das rodelas de banana verde pré-tratadas com 20 min de ultrassom (Figura 5.6), observa-se que, a eficiência de secagem foi mais vantajosa com a utilização do ultrassom. Ainda, comparando as duas figuras, é possível observar que menor tempo foi necessário para atingir as condições de equilíbrio para as rodelas pré-tratadas com ultrassom. No caso dos ensaios a $60{ }^{\circ} \mathrm{C}$, nenhum dos pré-tratamentos: ultrassom (Figuras 5.6 e 5.7), ou pulso de vácuo por 60 min (Figura 5.11), mostraram-se mais vantajosos para a eficiência de secagem em relação ao ensaio de rodelas não pré-tratadas. Ainda na Figura 5.11, observa-se que, as rodelas submetidas ao pré-tratamento iniciaram o processo de secagem com $M R$ próximos à unidade, como discutido previamente (Tabela 5.4), o pulso de vácuo inicial não influenciou significativamente o conteúdo de umidade. Na Figura 5.12 podese observar que, as taxas de secagem a $60{ }^{\circ} \mathrm{C}$ são maiores que as taxas a $50{ }^{\circ} \mathrm{C}$, como era esperado, pelo efeito da temperatura. Na Tabela 5.8, são apresentados os valores de difusividade efetiva da água obtidos para estes ensaios, também determinados pelo método das tangentes. A análise estatística foi conduzida separadamente para cada fase de taxa decrescente. 
Tabela 5.8 $D_{e f}$ a $(50$ e 60$){ }^{\circ} \mathrm{C}$, obtida no processo de secagem em secador de bandejas para rodelas de banana verde submetidas a um pulso de vácuo de 0,5 bar por 60 min

\begin{tabular}{lccccc}
\hline \multirow{2}{*}{ Pré-tratamento } & $t(\min )$ & \multicolumn{2}{c}{$1^{\circ} D_{e f} \times 10^{-9}\left(\mathrm{~m}^{2} / \mathrm{s}\right)$} & \multicolumn{2}{c}{$2^{\circ} D_{e f} \times 10^{-9}\left(\mathrm{~m}^{2} / \mathrm{s}\right)$} \\
\cline { 2 - 6 } & & $50{ }^{\circ} \mathrm{C}$ & $60{ }^{\circ} \mathrm{C}$ & $50{ }^{\circ} \mathrm{C}$ & $60^{\circ} \mathrm{C}$ \\
\hline Não pré-tratada & - & $7,03 \pm 0,09^{\mathrm{aA}}$ & $9,93 \pm 0,19^{\mathrm{aB}}$ & $3,84 \pm 0,09^{\mathrm{aA}}$ & $3,65 \pm 0,01^{\mathrm{aA}}$ \\
Pulso de vácuo & 60 & $8,43 \pm 0,37^{\mathrm{bA}}$ & $11,89 \pm 0,09^{\mathrm{bB}}$ & $4,59 \pm 0,09^{\mathrm{bA}}$ & $5,62 \pm 0,37^{\mathrm{bA}}$ \\
DMS & & 0,60 & 0,60 & 0,56 & 0,56 \\
\hline
\end{tabular}

Letras diferentes na mesma coluna (minúscula) ou linha (maiúscula) indicam diferença significativa entre os tratamentos $(p<0,05)$. DMS: diferença mínima significativa pelo teste de Tukey. Fonte: O próprio autor

$\mathrm{Na}$ primeira fase da taxa decrescente, as variáveis pulso de vácuo e temperatura influenciaram significativamente a difusividade efetiva da água. Na segunda fase de taxa decrescente, somente o pulso de vácuo teve efeito significativo, como aconteceu nos ensaios, empregando o pré-tratamento de ultrassom (Tabela 5.7), nesta fase, a resistência interna é a que governa sozinha a difusão de água nas rodelas de banana verde. A $60{ }^{\circ} \mathrm{C}$, o aumento da $D_{e f \text {, em }}$ relação às rodelas de banana verde não pré-tratadas foi de $(19,83$ e 57,97$) \%$ para as primeira e segunda fases da taxa decrescente, enquanto a $50{ }^{\circ} \mathrm{C}$, o aumento foi de $(19,91$ e 19,53$) \%$, respectivamente. Observa-se que, a $50{ }^{\circ} \mathrm{C}$, o aumento no valor da difusividade efetiva da água foi superior quando o pré-tratamento de ultrassom foi aplicado. A $60{ }^{\circ} \mathrm{C}$ observa-se que, os valores obtidos da difusividade efetiva da água, nas duas fases da taxa decrescente, foram muito próximos aos das rodelas de banana verde pré-tratadas com ultrassom (Tabela 5.7). Não foi possível a comparação dos resultados obtidos neste trabalho com outros estudos, já que a aplicação inicial de pulsos de vácuo a baixas temperaturas não foram relatados ainda na literatura.

Nas Figuras 5.13 e 5.14 as curvas de secagem a $(50$ e 60$){ }^{\circ} \mathrm{C}$, obtidas para rodelas de banana verde pré-tratadas com ultrassom por (20 e 25) min, seguido de pulso de vácuo de 0,5 bar por 60 min, são apresentadas. Nas Figuras 5.15 e 5.16, as suas respetivas taxas estão apresentadas. 
Figura 5.13- Curvas de secagem a $50{ }^{\circ} \mathrm{C}$, obtidas no processo de secagem, para rodelas de banana verde pré-tratadas por 20 min no banho de ultrassônico de potência volumétrica $9,38 \mathrm{~W} / \mathrm{L}$ e pulso de vácuo de 0,5 bar por $60 \mathrm{~min}$

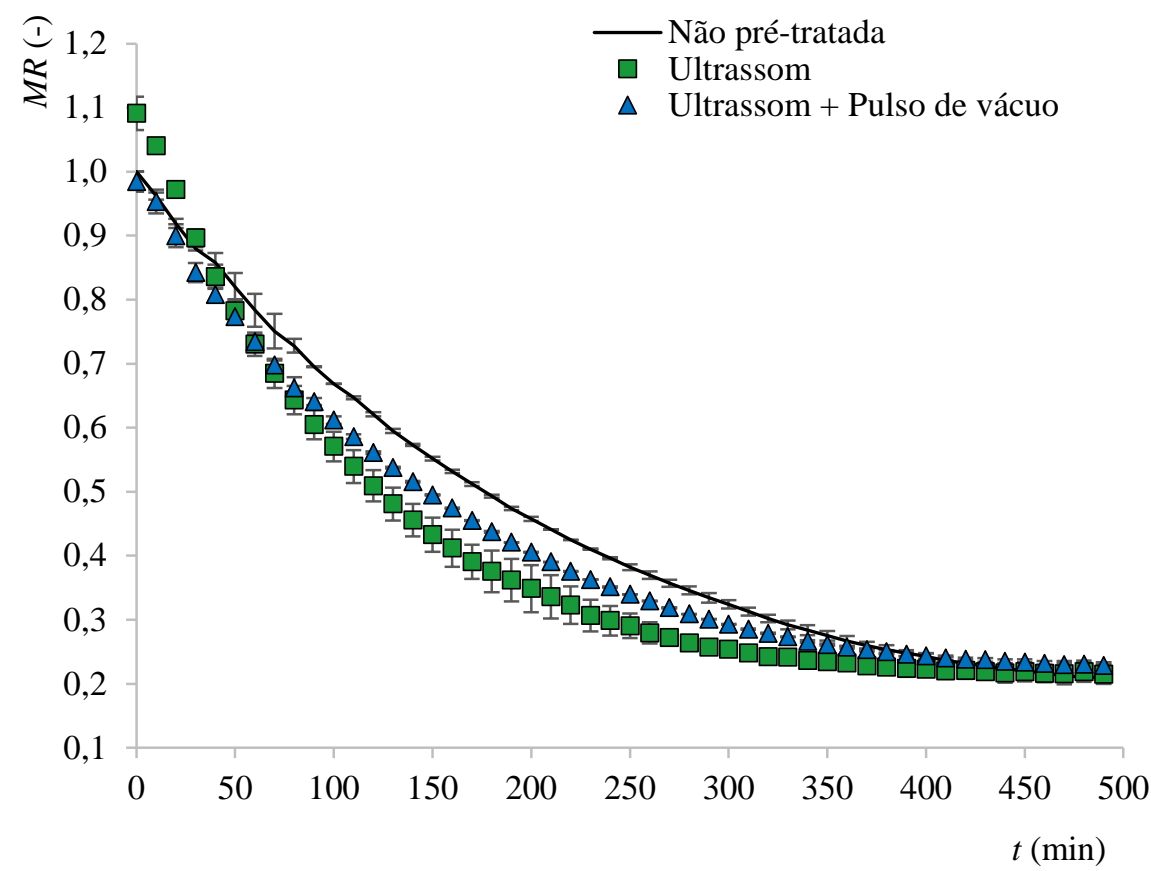

Fonte: O próprio autor.

Figura 5.14 - Curvas de secagem a $60{ }^{\circ} \mathrm{C}$, obtidas no processo de secagem, para rodelas de banana verde pré-tratadas por 25 min no banho de ultrassônico de potência volumétrica $9,38 \mathrm{~W} / \mathrm{L}$ e pulso de vácuo de 0,5 bar por $60 \mathrm{~min}$

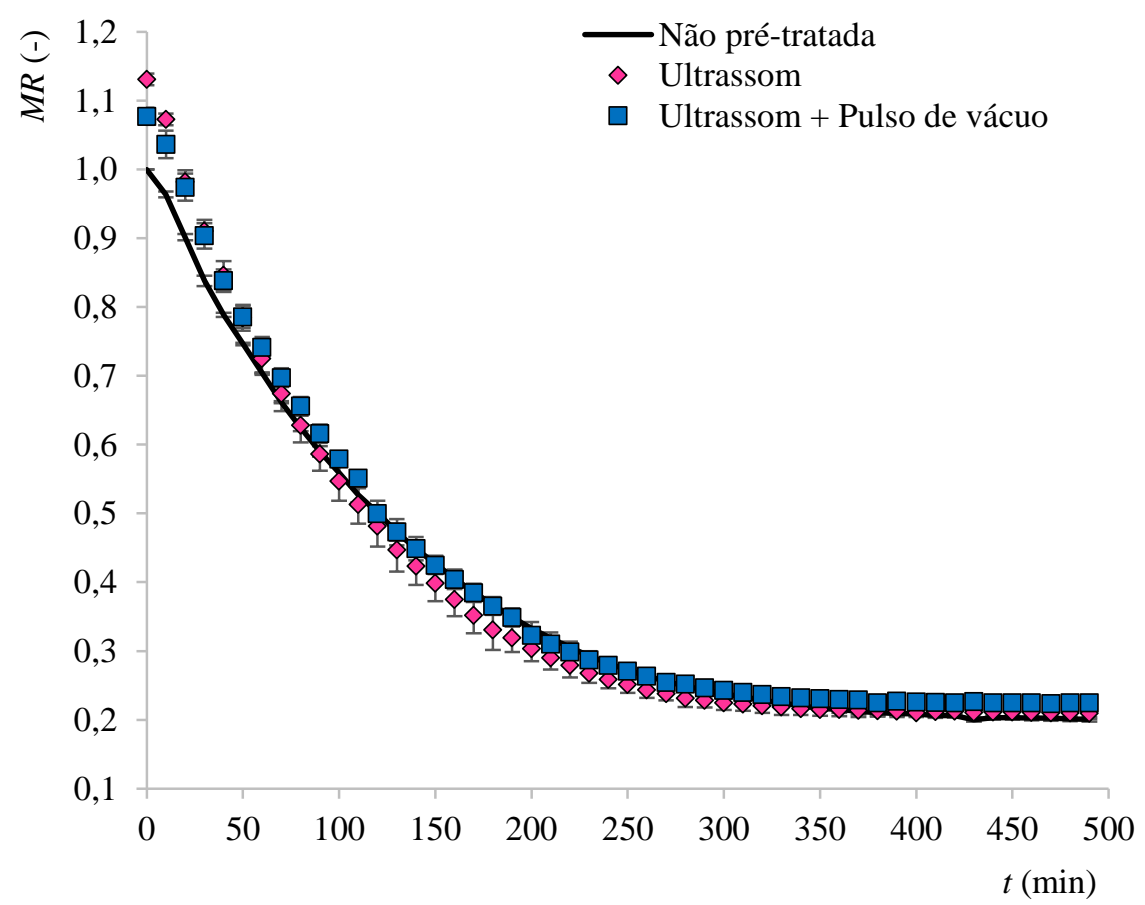

Fonte: O próprio autor. 
Figura 5.15 - Taxas de secagem a $50{ }^{\circ} \mathrm{C}$, obtidas no processo de secagem, para rodelas de banana verde, pré-tratadas por 20 min no banho de ultrassônico de potência volumétrica $9,38 \mathrm{~W} / \mathrm{L}$ e pulso de vácuo de 0,5 bar por $60 \mathrm{~min}$

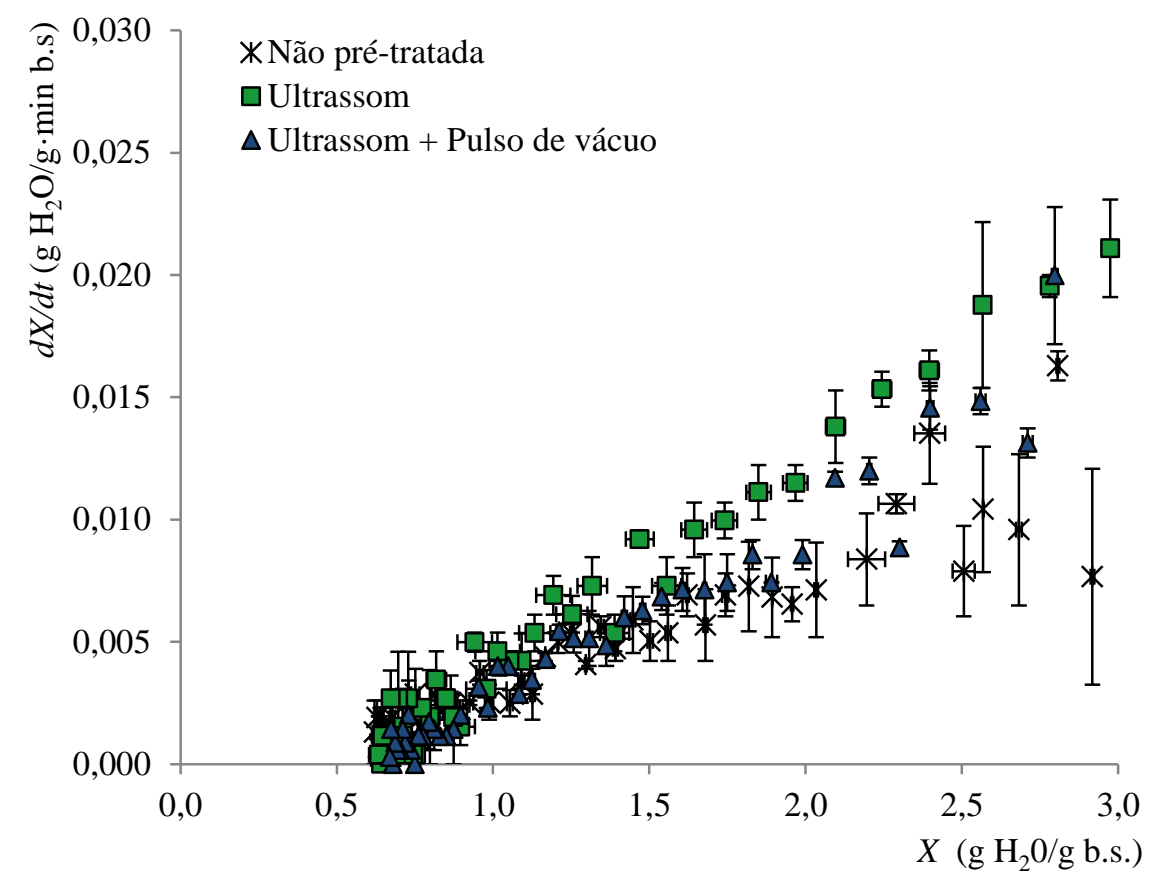

Fonte: O próprio autor.

Figura 5.16 - Taxa de secagem a $60{ }^{\circ} \mathrm{C}$, obtidas no processo de secagem, para rodelas de banana verde, pré-tratadas por 25 min no banho de ultrassônico de potência volumétrica $9,38 \mathrm{~W} / \mathrm{L}$ e pulso de vácuo de 0,5 bar por $60 \mathrm{~min}$

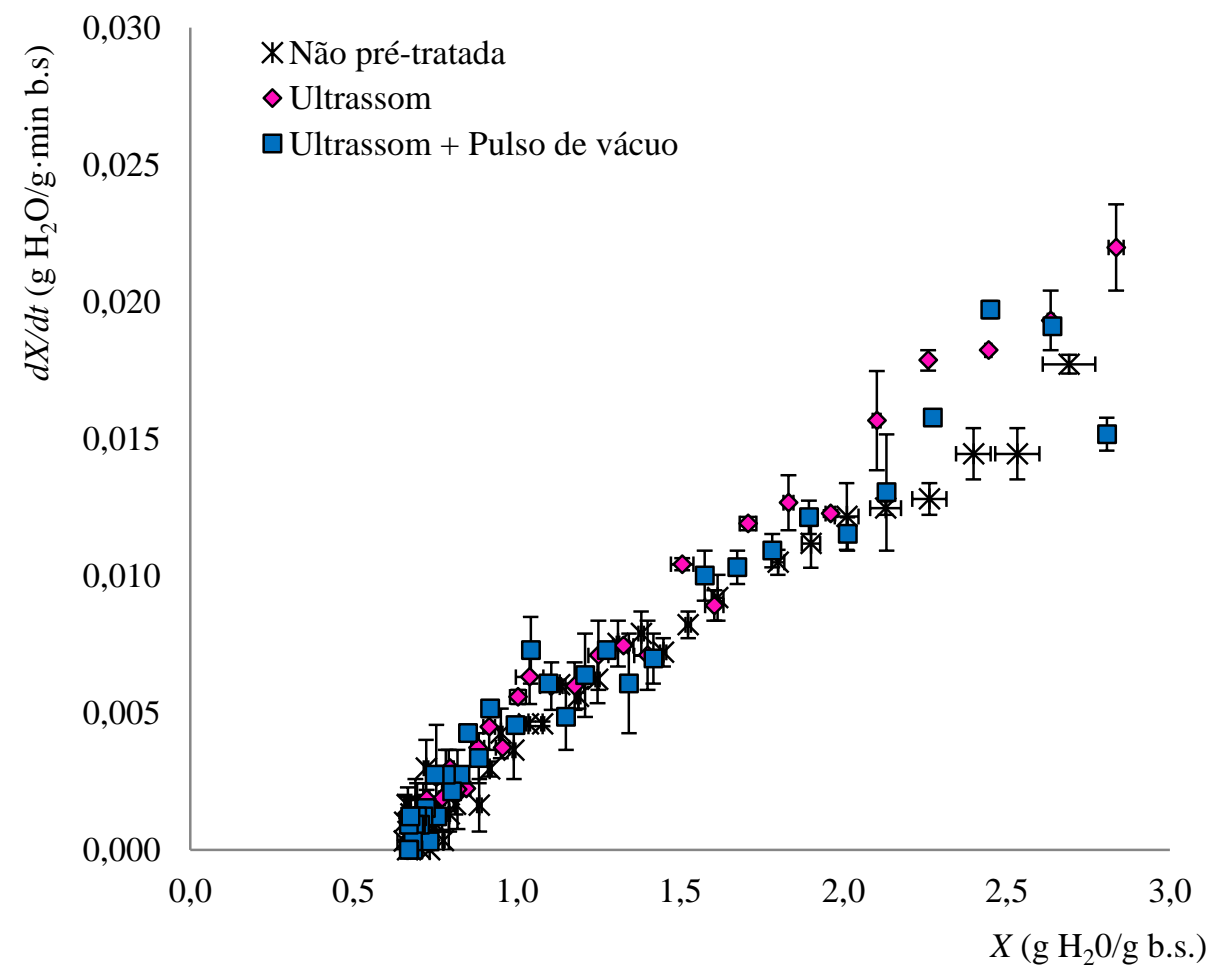

Fonte: O próprio autor. 
No ensaio realizado com pré-tratamento de 20 min de ultrassom seguido de pulso de vácuo de $60 \mathrm{~min}$, à temperatura de secagem $50{ }^{\circ} \mathrm{C}$ (Figuras 5.13 e 5.15), é possível observar que, a combinação das técnicas, resultou em uma maior remoção de água, em relação à secagem das rodelas de banana verde não pré-tratadas. Porém, observa-se que, a aplicação do pulso de vácuo não tornou a remoção de água mais facilitada, em comparação a aplicação de ultrassom sozinho. A temperatura de secagem de $60{ }^{\circ} \mathrm{C}$, não se observam diferenças nas taxas de secagem para as três condições estudadas (Figuras 5.14 e 5.16). Na Tabela 5.9, os valores de difusividade efetiva da água obtidos para estes ensaios, determinados também pelo método das tangentes, são apresentados. A análise estatística foi conduzida separadamente para cada temperatura.

Tabela 5.9 $-D_{e f}$ a $(50$ e 60$){ }^{\circ} \mathrm{C}$, obtidas no processo de secagem em secador de bandejas, para rodelas de banana verde, pré-tratadas por (20 e 25) min no banho de ultrassônico de potência volumétrica $9,38 \mathrm{~W} / \mathrm{L}$, e pulso de vácuo de 0,5 bar por $60 \mathrm{~min}$

\begin{tabular}{|c|c|c|c|c|}
\hline \multirow{2}{*}{ Pré-tratamento } & \multirow{2}{*}{$t(\min )$} & \multirow{2}{*}{$T\left({ }^{\circ} \mathrm{C}\right)$} & \multicolumn{2}{|c|}{$D_{e f} \times 10^{-9}\left(\mathrm{~m}^{2} / \mathrm{s}\right)$} \\
\hline & & & $1^{\circ}$ fase & $2^{\circ}$ fase \\
\hline Não pré-tratada & - & 50 & $7,03 \pm 0,09^{a}$ & $3,84 \pm 0,09^{a}$ \\
\hline Ultrassom & 20 & 50 & $12,18 \pm 0,47^{\mathrm{b}}$ & $6,84 \pm 0,28^{b}$ \\
\hline Ultrassom + Pulso de vácuo & $20+60$ & 50 & $7,78 \pm 0,09^{a}$ & $3,19 \pm 0,00^{\mathrm{a}}$ \\
\hline DMS & & & 1,77 & 1,00 \\
\hline Não pré-tratada & - & 60 & $9,93 \pm 0,19^{a}$ & $3,65 \pm 0,01^{\mathrm{a}}$ \\
\hline Ultrassom & 25 & 60 & $12,46 \pm 0,47^{\mathrm{b}}$ & $5,06 \pm 0,19^{a b}$ \\
\hline Ultrassom + Pulso de vácuo & $25+60$ & 60 & $11,30 \pm 0,47^{\mathrm{ab}}$ & $6,00 \pm 0,38^{\mathrm{b}}$ \\
\hline DMS & & & 2,25 & 1,47 \\
\hline
\end{tabular}

Letras diferentes na mesma coluna indicam diferença significativa entre os tratamentos $(p<0,05)$. DMS: diferença mínima significativa pelo teste de Tukey Fonte: O próprio autor.

A análise estatística revelou que não há diferença estatística entre os valores de difusividade efetiva da água das rodelas de banana verde pré-tratadas com a combinação de ultrassom e pulso de vácuo, e as não pré-tratadas a $50{ }^{\circ} \mathrm{C}$, nas duas fases de taxa decrescente. Observa-se que não houve sinergia dos pré-tratamentos, ultrassom e pulso de vácuo sobre a remoção de água, em relação à aplicação do pré-tratamento de ultrassom sozinho. A $60{ }^{\circ} \mathrm{C}$, é possível observar que, a aplicação de ultrassom sozinho e a combinação das técnicas resultaram estatisticamente iguais. 
Resumindo os resultados obtidos no secador de bandejas até esta fase do trabalho, observa-se que, a temperatura de secagem de $50{ }^{\circ} \mathrm{C}$, o pré-tratamento de 20 min de ultrassom resultou mais favorável para a cinética de secagem das rodelas de banana verde, em relação aos outros pré-tratamentos - 25 min de ultrassom, pulso de vácuo de 60 min e a combinação de 20 min de ultrassom seguido de 60 min de pulso de vácuo. No caso dos ensaios conduzidos a 60 ${ }^{\circ} \mathrm{C}$, os resultados são mais dispersos. Para a primeira fase de taxa decrescente, o pré-tratamento de 25 min de ultrassom foi o mais favorável. Já para a segunda fase de taxa decrescente, o prétratamento de 25 min de ultrassom sozinho e o pré-tratamento combinado ( 25 min de ultrassom, seguido de 60 min de pulso de vácuo) foram favoráveis para promover a remoção da água. No entanto, aumento dos valores de difusividade efetiva de água foram menores se comparados aos obtidos nos ensaios a $50{ }^{\circ} \mathrm{C}$. Consequentemente, pode-se dizer que, a $60{ }^{\circ} \mathrm{C}$, o efeito da temperatura prevalece, e os efeitos causados pelos pré-tratamentos são menos evidentes em relação aos ensaios a $50{ }^{\circ} \mathrm{C}$, como foi observado no trabalho de Ricce et al. (2016).

\subsubsection{Modelos Experimentais}

Nas Figuras 5.17 a 5.28 as curvas de secagem, obtidas para rodelas de banana verde, submetidas ao pré-tratamento combinado e secas em secador de bandejas (Tabela 5.9), cujos dados experimentais foram ajustados aos modelos de Newton, Page, Henderson \& Pabis (Tabela 3.1), ao modelo difusional, considerando os primeiros cinco termos da eq. (2), são apresentadas. No caso do modelo de Midilli, que foi o que apresentou melhores ajustes, os gráficos de paridade, valores preditos vrs experimentais, também são apresentados. 
- Modelo de Newton: $M R=\exp (-k t)$

Figura 5.17 - Curvas de secagem a $50{ }^{\circ} \mathrm{C}$, obtidas no processo de secagem, para rodelas de banana verde, não pré-tratadas e pré-tratadas, cujos dados foram ajustados ao modelo de Newton

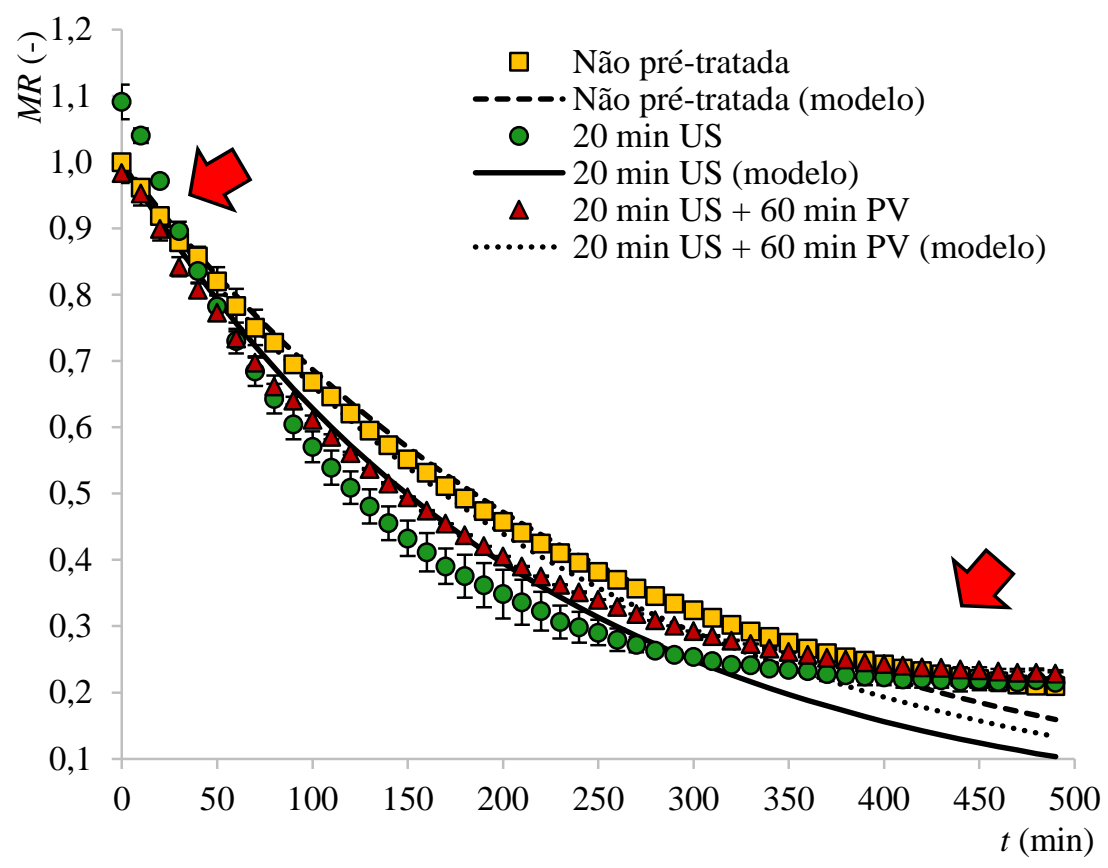

Fonte: O próprio autor.

Figura 5.18 - Curvas de secagem a $60{ }^{\circ} \mathrm{C}$, obtidas no processo de secagem, para rodelas de banana verde, não pré-tratadas e pré-tratadas, cujos dados foram ajustados ao modelo de Newton

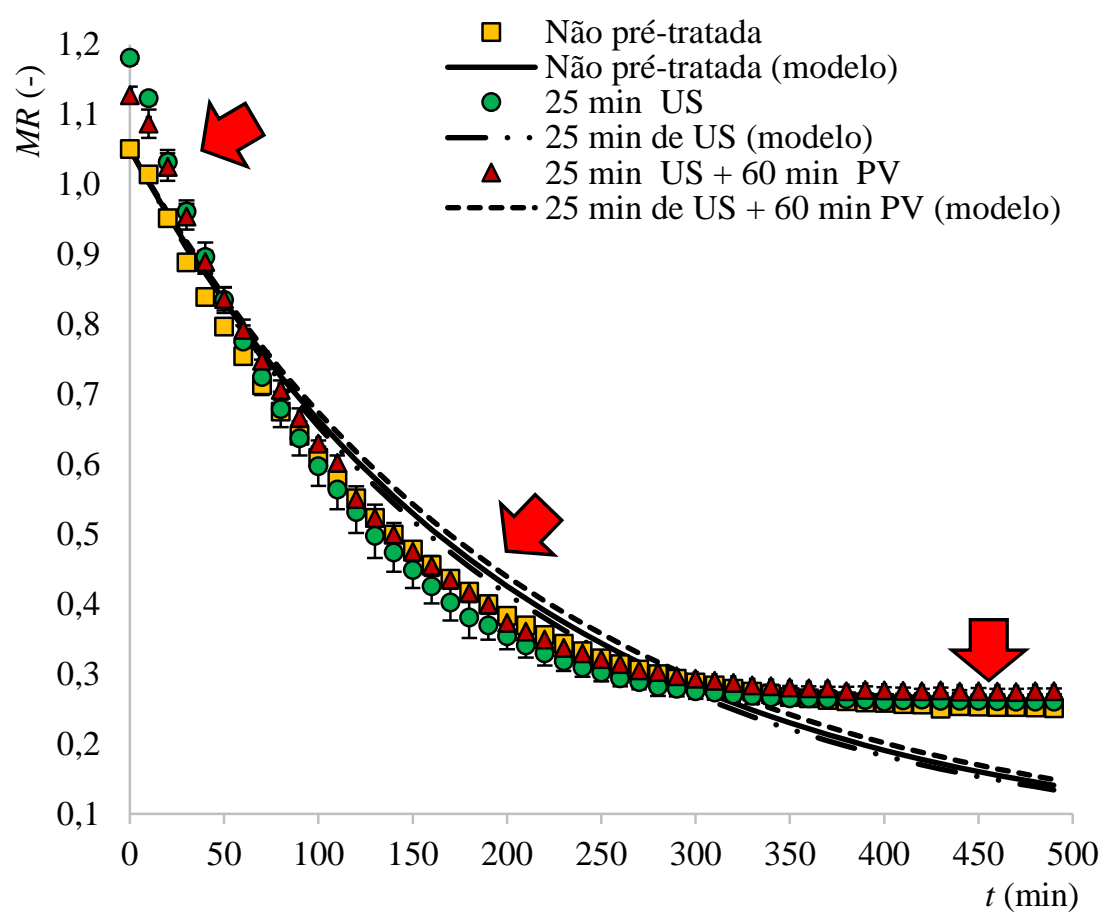

Fonte: O próprio autor. 
- Modelo de Page: $M R=\exp \left(-k t^{n}\right)$

Figura 5.19 - Curvas de secagem a $50{ }^{\circ} \mathrm{C}$, obtidas no processo de secagem, para rodelas de banana verde, não pré-tratadas e pré-tratadas, cujos dados foram ajustados ao modelo de Page

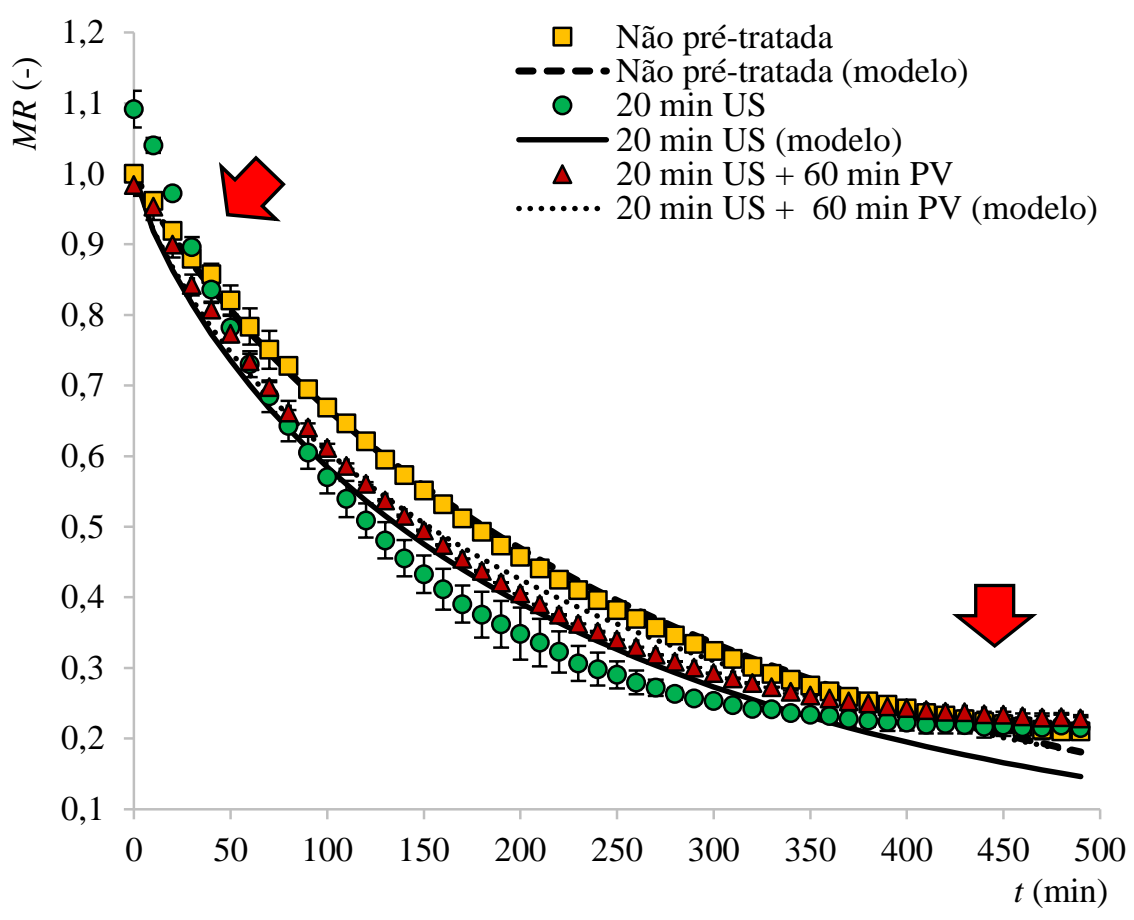

Fonte: O próprio autor.

Figura 5.20 - Curvas de secagem a $60{ }^{\circ} \mathrm{C}$, obtidas no processo de secagem, para rodelas de banana verde, não pré-tratadas e pré-tratadas, cujos dados foram ajustados ao modelo de Page

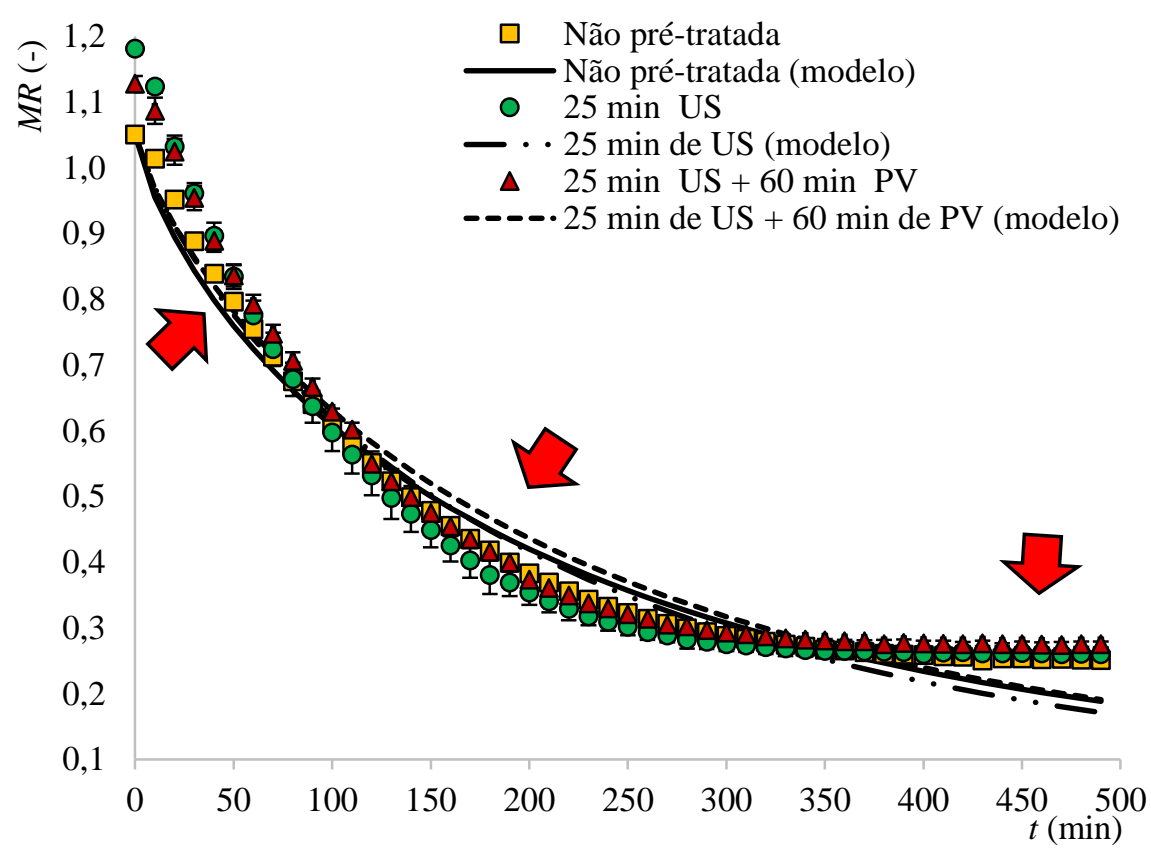

Fonte: O próprio autor. 
- Modelo de Henderson \& Pabis: $M R=a \exp (-k t)$

Figura 5.21 - Curvas de secagem a $50{ }^{\circ} \mathrm{C}$, obtidas no processo de secagem, para rodelas de banana verde, não pré-tratadas e pré-tratadas, cujos dados foram ajustados ao modelo de Henderson \& Pabis

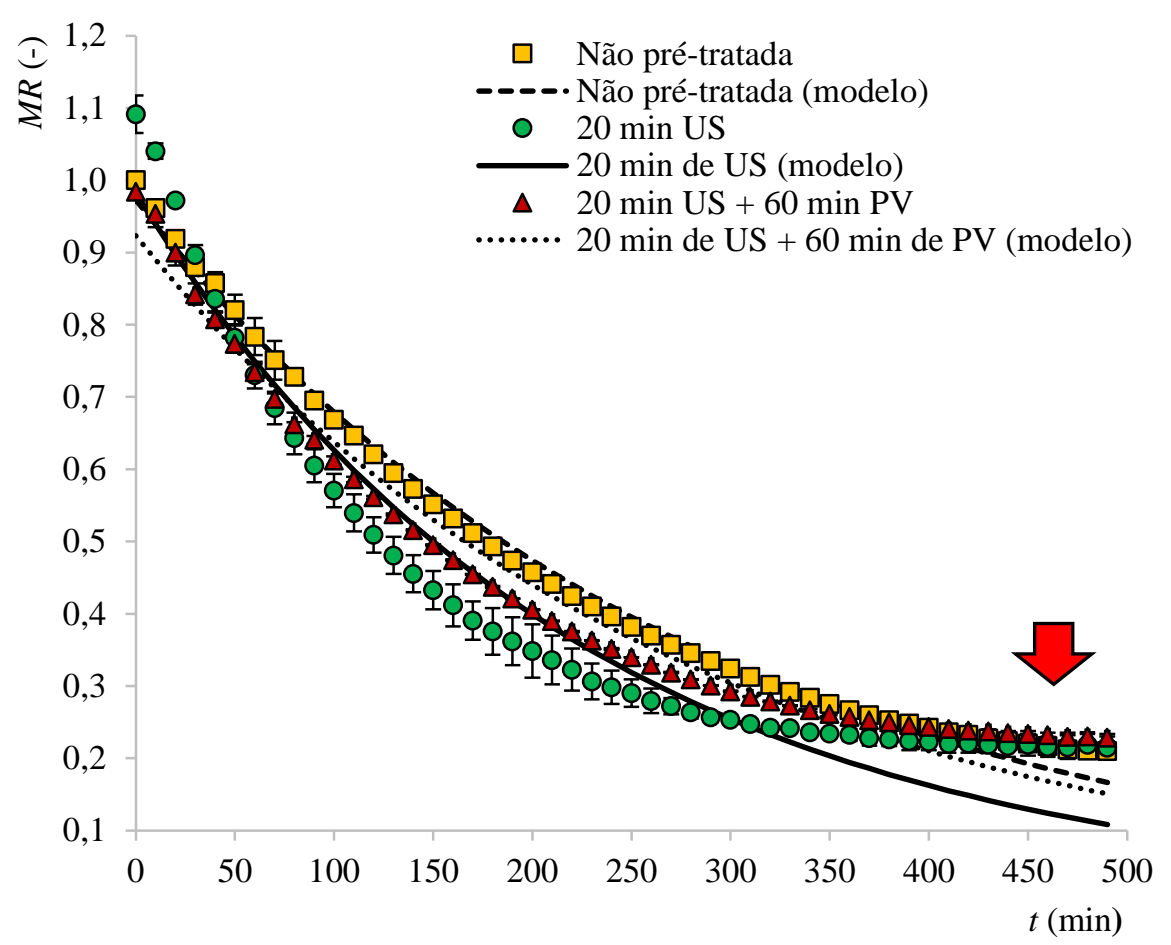

Fonte: O próprio autor.

Figura 5.22 - Curvas de secagem a $60{ }^{\circ} \mathrm{C}$, obtidas no processo de secagem, para rodelas de banana verde, não pré-tratadas e pré-tratadas, cujos dados foram ajustados ao modelo de Henderson \& Pabis

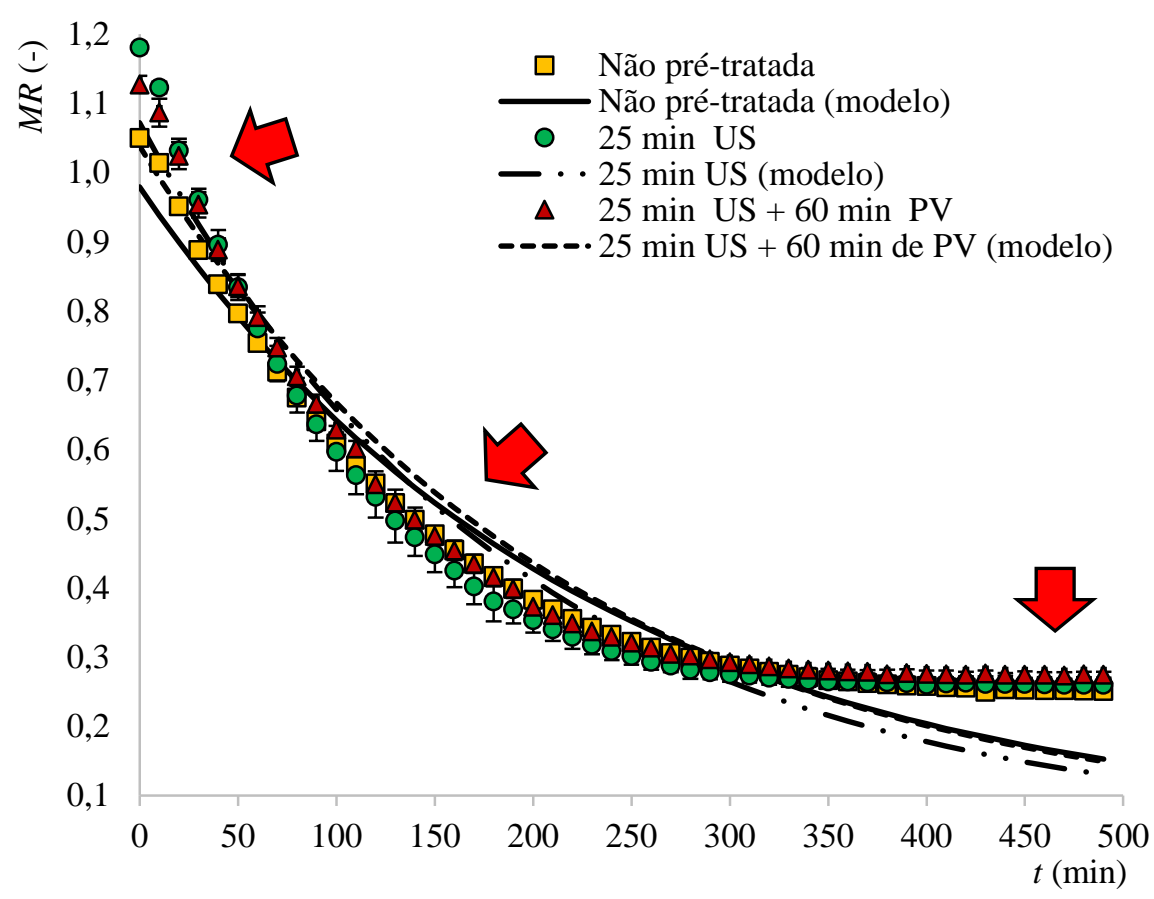

Fonte: O próprio autor. 
- Modelo Difusional: $M R=\frac{8}{\pi^{2}} \sum_{i=0}^{\infty} \frac{1}{(2 i+1)^{2}} \cdot \exp \left[-(2 i+1)^{2} \cdot \pi^{2} \cdot \frac{D_{e f}}{4 L^{2}} \cdot t\right]$

Figura 5.23 - Curvas de secagem a $50{ }^{\circ} \mathrm{C}$, obtidas no processo de secagem, para rodelas de banana verde, não pré-tratadas e pré-tratadas, cujos dados foram ajustados ao modelo Difusional

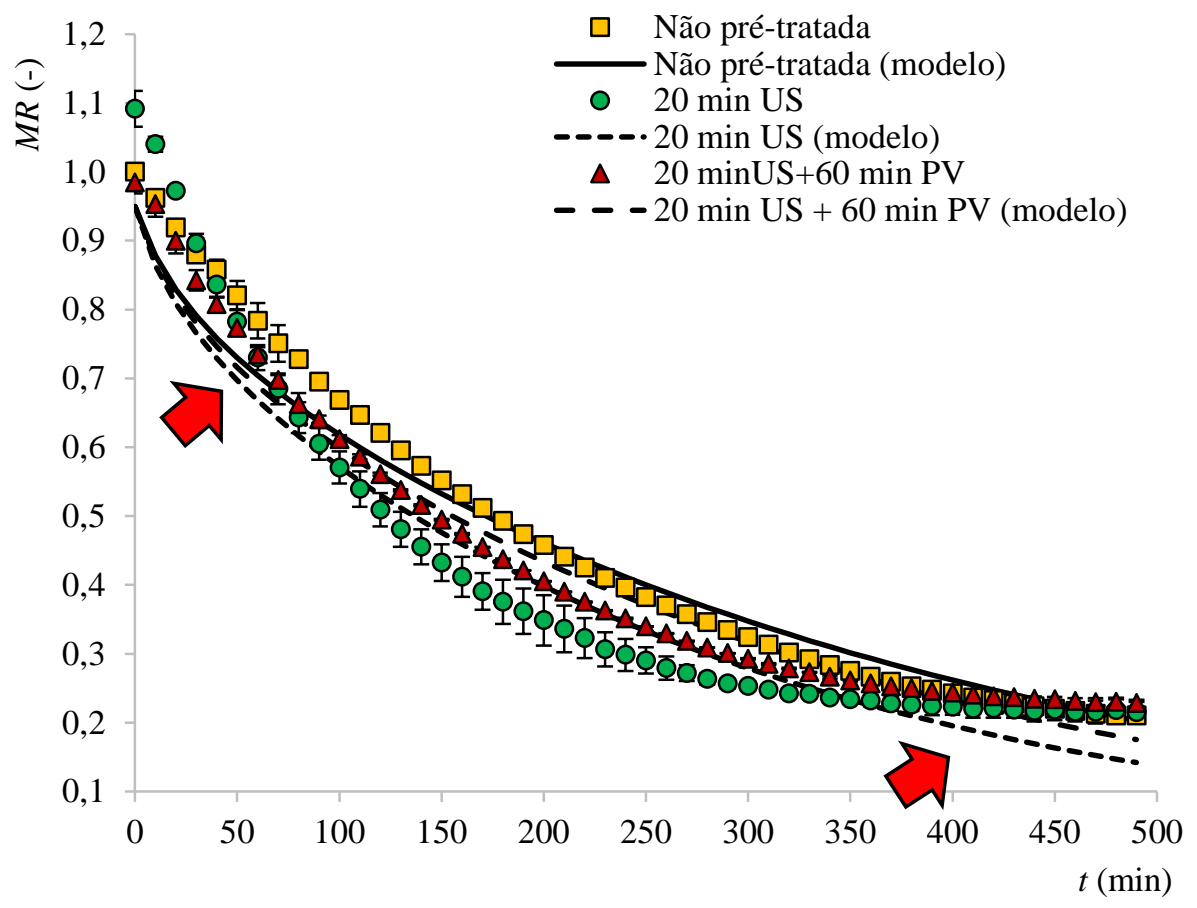

Fonte: O próprio autor.

Figura 5.24 - Curvas de secagem a $60{ }^{\circ} \mathrm{C}$, obtidas no processo de secagem, para rodelas de banana verde, não pré-tratadas e pré-tratadas, cujos dados foram ajustados ao modelo Difusional

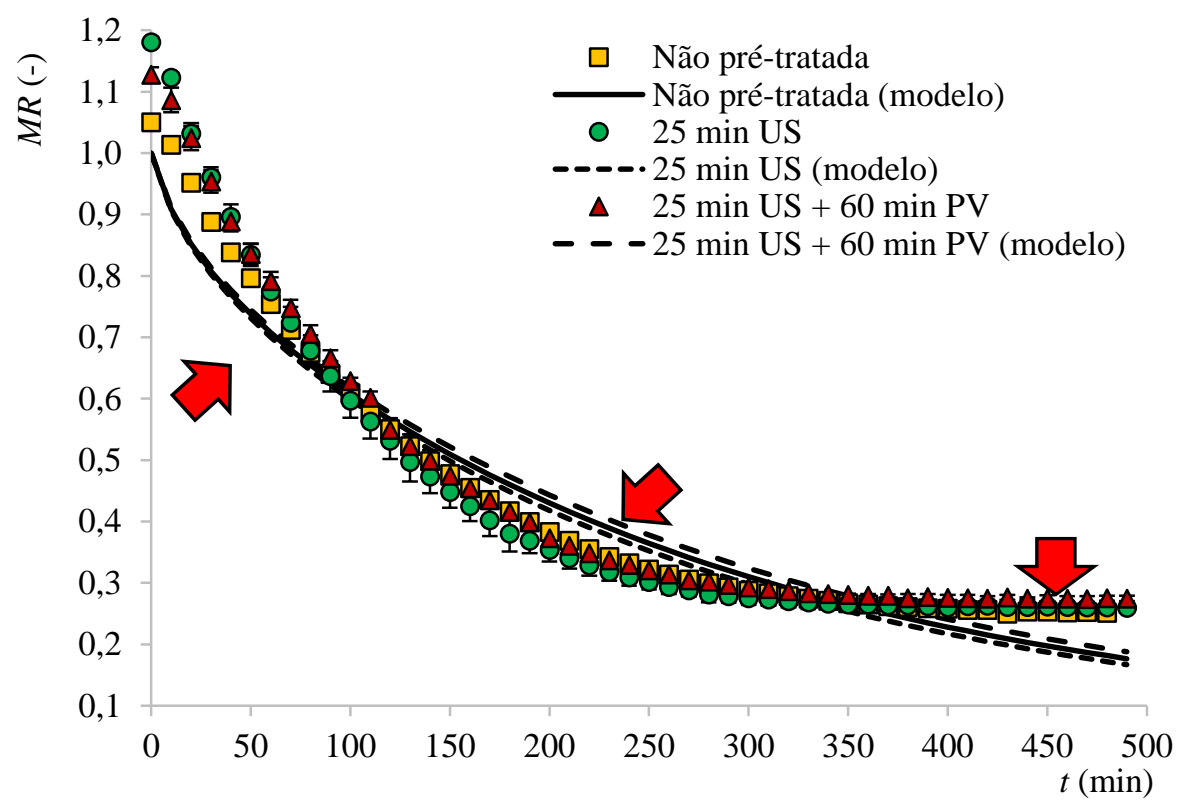

Fonte: O próprio autor. 
- Modelo Logaritmico: $M R=a \exp (-k t)+c$

Figura 5.25 - Curvas de secagem a $50{ }^{\circ} \mathrm{C}$, obtidas no processo de secagem, para rodelas de banana verde, não pré-tratadas e pré-tratadas, cujos dados foram ajustados ao modelo Logaritmico

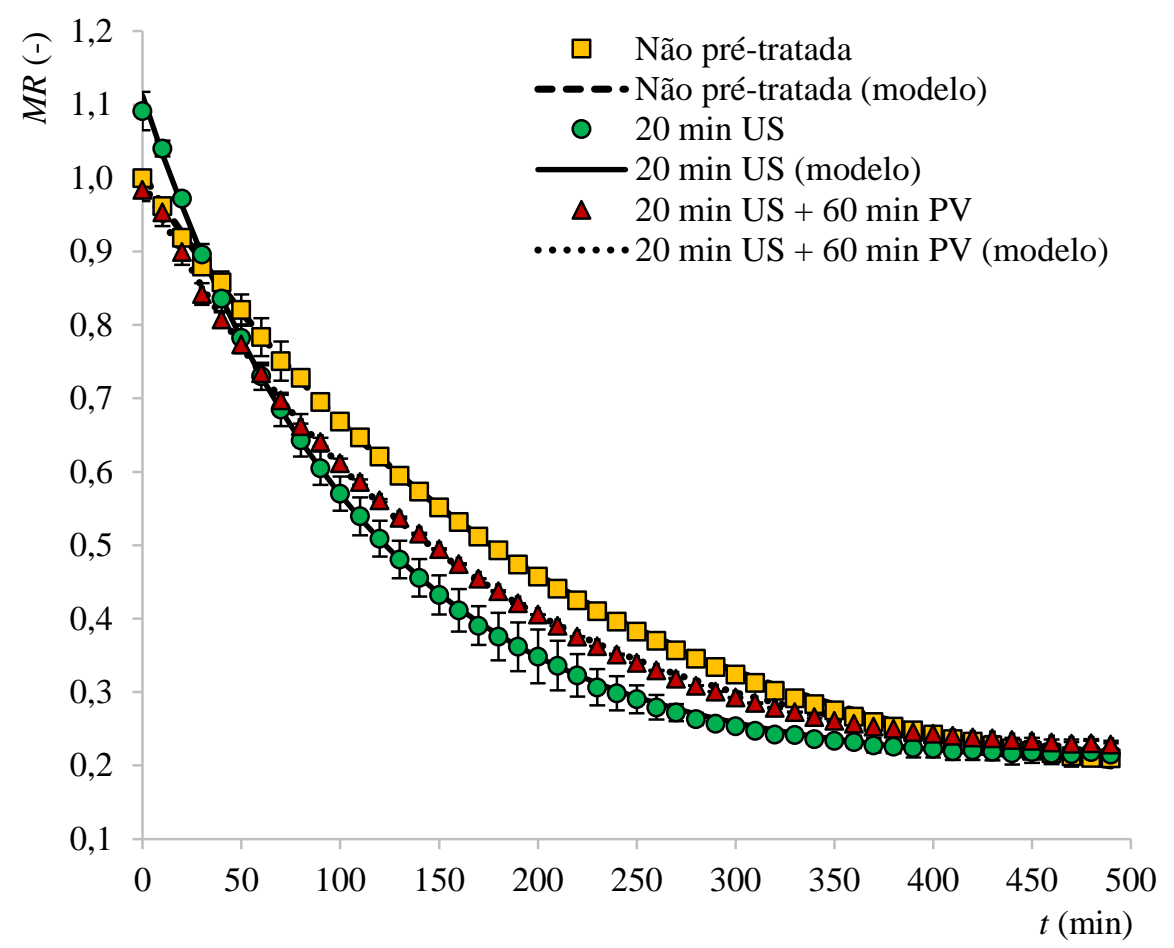

Fonte: O próprio autor.

Figura 5.26 - - Curvas de secagem a $60{ }^{\circ} \mathrm{C}$, obtidas no processo de secagem, para rodelas de banana verde, não pré-tratadas e pré-tratadas, cujos dados foram ajustados ao modelo Logaritmico

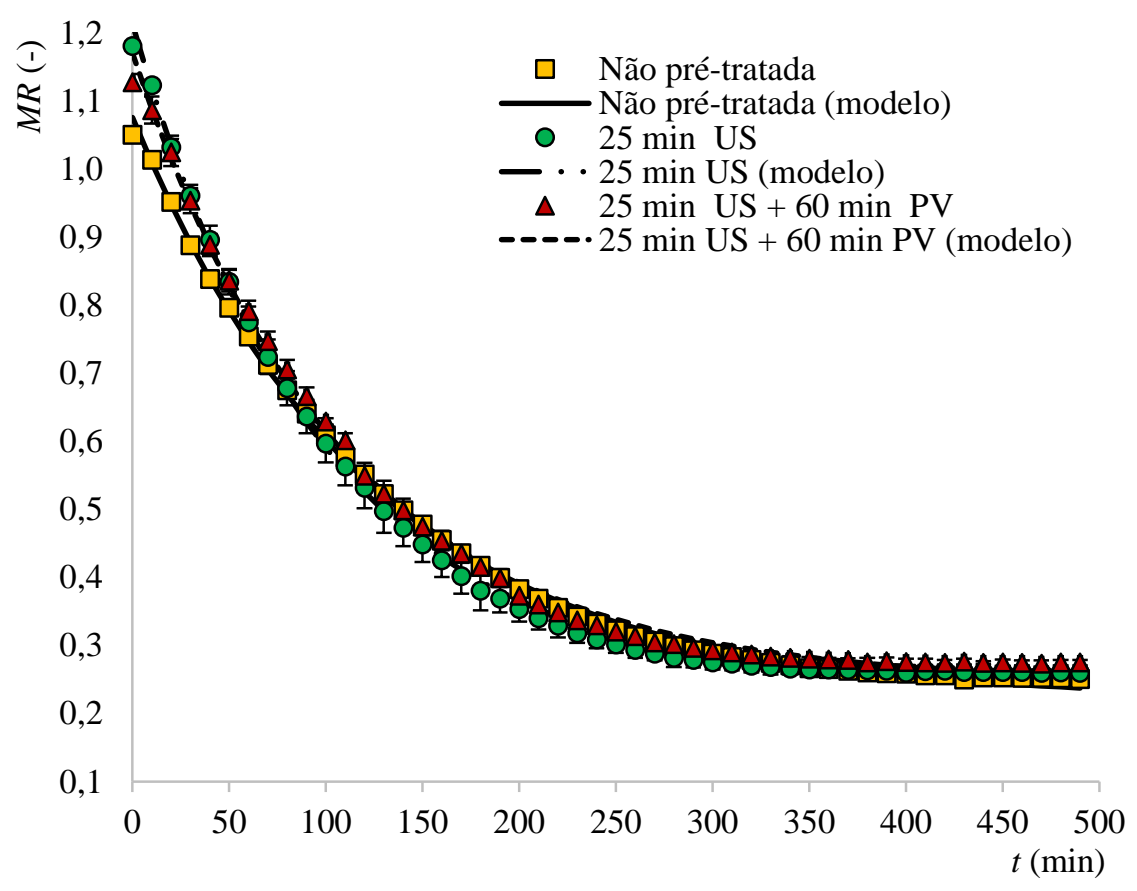

Fonte: O próprio autor. 
- Modelo de Midilli: $M R=a \exp \left(-k t^{n}\right)+b t$

Figura 5.27 - Curvas de secagem a $50{ }^{\circ} \mathrm{C}$, obtidas no processo de secagem, para rodelas de banana verde, não pré-tratadas e pré-tratadas, cujos dados foram ajustados ao modelo de Midilli

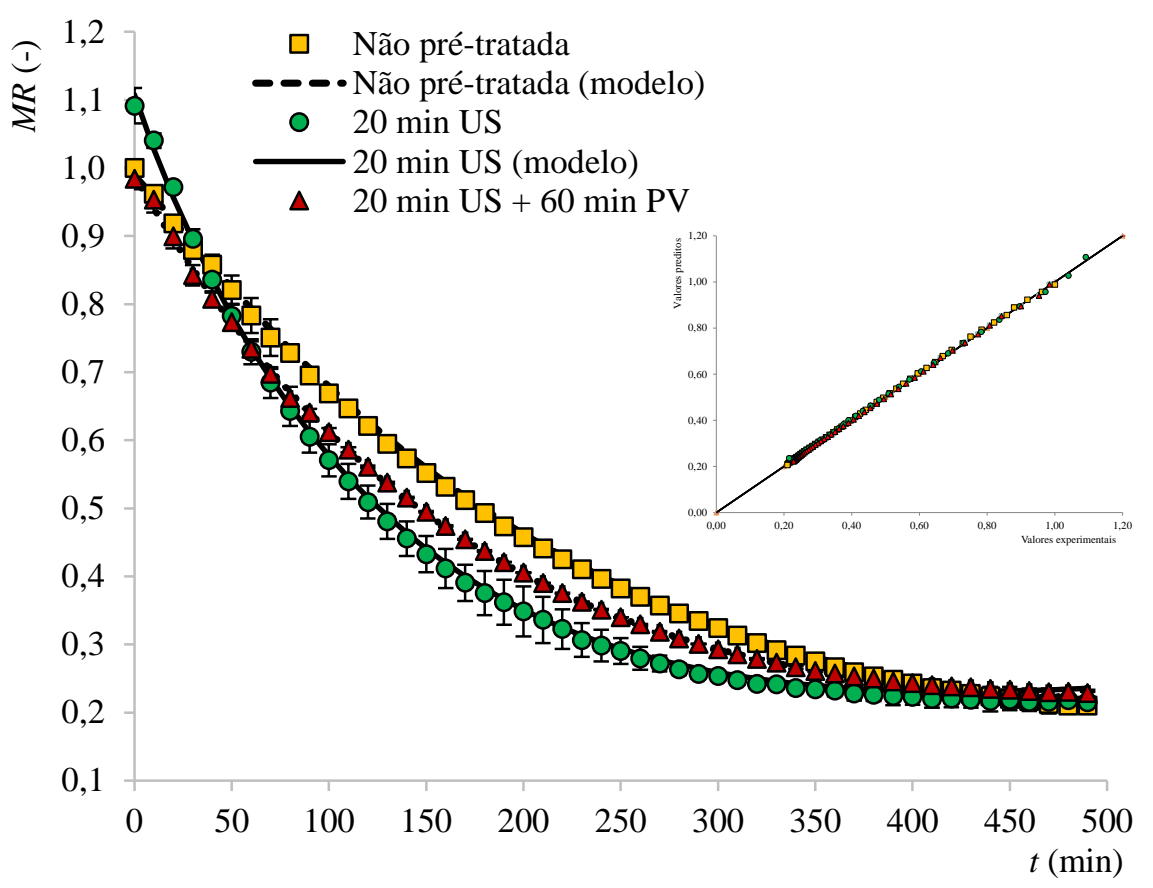

Fonte: O próprio autor.

Figura 5.28 - Curvas de secagem a $60^{\circ} \mathrm{C}$, obtidas no processo de secagem, para rodelas de banana verde, não pré-tratadas e pré-tratadas, cujos dados foram ajustados ao modelo de Midilli

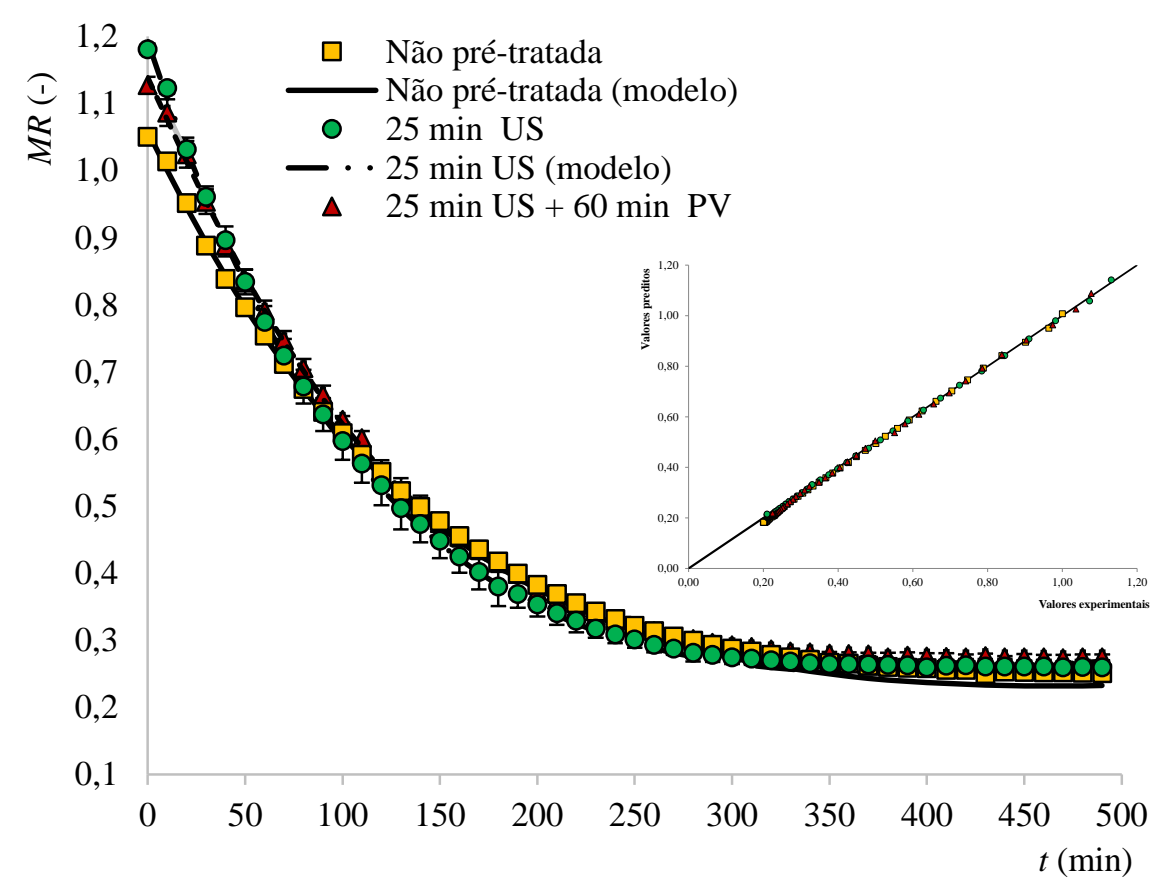

Fonte: O próprio autor. 
Pode-se observar que o ajuste dos dados experimentais aos modelos de Newton, Page, Henderson \& Pabis e Difusional não resultaram adequados para representar as curvas de secagem. A falta de ajuste foi mais visível para os ensaios conduzidos a $60{ }^{\circ} \mathrm{C}$. Nos modelos mais simples, Newton, Page e Henderson \& Pabis o valor inicial de $M R$ - que, após a aplicação do pré-tratamento de ultrassom, é maior que 1 - não foi considerado. Ainda, estes modelos apresentaram falta de ajuste em regiões específicas da curva de secagem, indicadas com as setas em vermelho nas Figuras 5.17 a 5.22. Ricce et al. (2016) também relataram a falta de ajuste dos dados experimentais da secagem de cenoura pré-tratada com 60 min de ultrassom e, secas a 40 ${ }^{\circ} \mathrm{C}$, com os modelos de Newton e Page. Porém, bom ajuste foi observado com o modelo de Henderson \& Pabis. No modelo Difusional, a falta de ajuste foi observada em diferentes etapas da curva de secagem, sendo que $r^{2} \geq 0,910$, RMSE $\leq 0,0750$ e $\chi^{2} \leq 0,00574$. A falta de ajuste empregando este modelo já foi apresentada nas Tabelas 5.5 e 5.6, em que, os valores de $r^{2} \leq 0,966$, mostrando não ser a melhor equação para a determinação da difusividade efetiva da água em rodelas de banana verde.

Na Tabela 5.10 os coeficientes de regressão para todos os modelos empregados, são apresentados. Se observa que, o modelo Logarítmico, com três parâmetros, resultou em bons ajustes, sendo que, $r^{2} \geq 0,997$, RMSE $\leq 0,0144$ e $\chi^{2} \leq 0,00019$. Bons ajustes também foram obtidos empregando o modelo de quatro parâmetros Midilli ( $r^{2} \geq 0,999$, RMSE $\leq 0,0119$ e $\left.\chi^{2} \leq 0,00012\right)$. A través dos parâmetros estatísticos observou-se que houve bons ajustes enpregandos os modelos de três e quatro parâmetros. Na literatura ajustes de dados experimentais empregando o modelo de Midilli e Logaritmico, quando o ultrassom é aplicado como pré-tratamento à secagem de maçã e pimentões (SCHÖSSLER et al., 2012a), e o modelo de Midilli no caso da secagem de batata (SCHÖSSLER et al., 2012b), entre outros. 
Tabela 5.10 - Constantes e coeficientes obtidos do ajuste dos dados experimentais aos modelos Newton, Page, Henderson \& Pabis, Logaritmico e Midilli de rodelas de banana verde não pré-tratadas e pré-tratadas (Ultrassom ou Ultrassom + 60 min de Púlso de vácuo) secas a (50 e 60) ${ }^{\circ} \mathrm{C}$

\begin{tabular}{|c|c|c|c|c|c|c|c|c|c|c|c|}
\hline Pré-tratamento & $t(\min )$ & $T\left({ }^{\circ} \mathrm{C}\right)$ & Modelo & $k(1 / \min )$ & $n(-)$ & $a(-)$ & $b(1 / \mathrm{min})$ & $c(-)$ & $r^{2}$ & RMSE x $10^{-2}$ & $\chi^{2} \times 10^{-3}$ \\
\hline \multirow{5}{*}{ Não pré-tratada } & \multirow{5}{*}{-} & \multirow{5}{*}{50} & Newton & 0,004 & & & & & 0,9931 & 1,92 & 0,38 \\
\hline & & & Page & 0,006 & 0,907 & & & & 0,9977 & 1,12 & 0,13 \\
\hline & & & Henderson \& Pabis & 0,004 & & 0,973 & & \multirow{3}{*}{0,110} & 0,9948 & 1,65 & 0,28 \\
\hline & & & Logarítmico & 0,005 & & 0,895 & & & 0,9997 & 0,46 & 0,02 \\
\hline & & & Midilli & 0,003 & 1,066 & 0,989 & 0,0002 & & 0,9997 & 0,55 & 0,03 \\
\hline \multirow{5}{*}{ Ultrassom } & \multirow{5}{*}{20} & \multirow{5}{*}{50} & Newton & 0,005 & & & & \multirow{5}{*}{0,197} & 0,9399 & 5,88 & 3,60 \\
\hline & & & Page & 0,013 & 0,803 & & & & 0,9635 & 4,59 & 2,19 \\
\hline & & & Henderson \& Pabis & 0,005 & & 0,982 & & & 0,9406 & 5,84 & 3,56 \\
\hline & & & Logarítmico & 0,009 & & 0,915 & & & 0,9995 & 0,49 & 0,02 \\
\hline & & & Midilli & 0,009 & 0,960 & 1,108 & 0,0004 & & 0,9995 & 0,91 & 0,08 \\
\hline \multirow{5}{*}{ Ultrassom + Pulso de vácuo } & \multirow{5}{*}{$20+60$} & \multirow{5}{*}{50} & Newton & 0,004 & & & & & 0,9550 & 4,58 & 2,18 \\
\hline & & & Page & 0,014 & 0,776 & & & & 0,9904 & 2,11 & 0,46 \\
\hline & & & Henderson \& Pabis & 0,004 & & 0,923 & & \multirow{3}{*}{0,184} & 0,9718 & 3,62 & 1,37 \\
\hline & & & Logarítmico & 0,007 & & 0,812 & & & 0,9994 & 0,53 & 2,96 \\
\hline & & & Midilli & 0,005 & 0,996 & 0,989 & 0,0003 & & 0,9997 & 0,39 & 1,64 \\
\hline
\end{tabular}

Fonte: O próprio autor. 
Tabela 5.10 - (Continuação). Constantes e coeficientes obtidos do ajuste dos dados experimentais aos modelos Newton, Page, Henderson \& Pabis, Logaritmico e Midilli de rodelas de banana verde não pré-tratadas e pré-tratadas (Ultrassom ou Ultrassom +60 min de Púlso de vácuo) secas a (50 e 60 ) ${ }^{\circ} \mathrm{C}$

\begin{tabular}{|c|c|c|c|c|c|c|c|c|c|c|c|}
\hline Pré-tratamento & $t(\min )$ & $T\left({ }^{\circ} \mathrm{C}\right)$ & Modelo & $k(1 / \min )$ & $n(-)$ & $a(-)$ & $b(1 / \min )$ & $c(-)$ & $r^{2}$ & RMSE x $10^{-2}$ & $\chi 2 \times 10^{-3}$ \\
\hline \multirow{5}{*}{ Não pré-tratada } & \multirow{5}{*}{-} & \multirow{5}{*}{60} & Newton & 0,005 & & & & \multirow{5}{*}{0,172} & 0,9438 & 5,36 & 2,99 \\
\hline & & & Page & 0,017 & 0,768 & & & & 0,9796 & 3,22 & 1,08 \\
\hline & & & Henderson \& Pabis & 0,005 & & 0,929 & & & 0,9552 & 4,78 & 2,38 \\
\hline & & & Logarítmico & 0,008 & & 0,854 & & & 0,9987 & 0,81 & 0,06 \\
\hline & & & Midilli & 0,006 & 1,026 & 1,008 & 0,0003 & & 0,9998 & 0,13 & 0,017 \\
\hline \multirow{6}{*}{ Ultrassom } & \multirow{6}{*}{25} & \multirow{6}{*}{60} & Newton & & & & & \multirow{6}{*}{0,189} & & & \\
\hline & & & Page & 0,005 & & & & & 0,9242 & 6,91 & 4,97 \\
\hline & & & Henderson \& Pabis & 0,012 & 0,828 & & & & 0,9433 & 5,98 & 3,73 \\
\hline & & & Logarítmico & 0,005 & & 1,022 & & & 0,9240 & 6,91 & 4,97 \\
\hline & & & Midilli & 0,010 & & 0,974 & & & 0,9983 & 1,04 & 0,01 \\
\hline & & & Newton & 0,008 & 1,010 & 1,142 & 0,0004 & & 0,9996 & 0,70 & 0,05 \\
\hline \multirow{5}{*}{ Ultrassom + Pulso de vácuo } & \multirow{5}{*}{$25+60$} & \multirow{5}{*}{60} & Newton & 0,005 & & & & & 0,9316 & 3,72 & 4,17 \\
\hline & & & Page & 0,013 & 0,806 & & & & 0,9534 & 3,46 & 2,84 \\
\hline & & & Henderson \& Pabis & 0,005 & & 0,988 & & \multirow{3}{*}{0,196} & 0,9319 & 3,72 & 4,15 \\
\hline & & & Logarítmico & 0,009 & & 0,924 & & & 0,9968 & 1,44 & 0,19 \\
\hline & & & Midilli & 0,005 & 1,061 & 1,088 & 0,0004 & & 0,9995 & 1,19 & 0,12 \\
\hline
\end{tabular}




\subsubsection{Redução do teor de umidade inicial}

$\mathrm{Na}$ Figura 5.10, observa-se uma curva de secagem a $60{ }^{\circ} \mathrm{C}$, em que, são visíveis duas fases de taxa decrescente de secagem e, ainda, uma terceira etapa no final do processo, na qual o equilíbrio foi atingido, ou seja: as rodelas de banana verde foram secas além do necessário. Baseado nesse critério, para atingir o equilíbrio, foi considerado um tempo de secagem de 360 min, para os ensaios conduzidos a $50{ }^{\circ} \mathrm{C}$ e 300 min para os ensaios a $60{ }^{\circ} \mathrm{C}$ e, empregando o modelo de Midilli foi determinada a redução do teor de umidade respeito ao seu teor inicial. Os valores estão mostrados na Tabela 5.11.

Tabela 5.11 - Redução do teor de umidade inicial obtida nos ensaios de secagem a (50-60) ${ }^{\circ} \mathrm{C}$ segundo o modelo de Midilli

\begin{tabular}{lcccc}
\hline Pré-tratamento & $t(\min )$ & $T\left({ }^{\circ} \mathrm{C}\right)$ & $t$ secagem $(\min )$ & Redução da umidade inicial $(\mathrm{g} / 100 \mathrm{~g})$ \\
\hline Não pré-tratada & - & 50 & 360 & 72,2 \\
Ultrassom & 20 & 50 & & 75,8 \\
Ultrassom + Pulso de vácuo & $20+60$ & 50 & & 73,9 \\
Não pré-tratada & - & 60 & 300 & 77,2 \\
Ultrassom & 25 & 60 & & 78,0 \\
Ultrassom + Pulso de vácuo & $25+60$ & 60 & & 76,5 \\
\hline
\end{tabular}

Fonte: O próprio autor.

Mediante esse critério adotado, a maior redução da umidade foi observada nas rodelas de banana verde pré-tratadas com ultrassom, tanto secas a $50{ }^{\circ} \mathrm{C}$ quanto secas a $60^{\circ} \mathrm{C}$, sendo que a $50{ }^{\circ} \mathrm{C}$ a remoção foi superior. Verifica-se que, de fato, a combinação dos prétratamentos: ultrassom seguido de pulso de vácuo não foi efetiva para a remoção da umidade. Estes resultados complementam a informação dada pelos valores de difusividade efetiva da água (Tabelas 5.7 a 5.9), no qual o pré-tratamento de ultrassom por 20 min e temperatura de secagem $50{ }^{\circ} \mathrm{C}$, mostrou-se claramente favorável para a remoção de água, e a $60{ }^{\circ} \mathrm{C}$ o impacto dos pré-tratamentos não foi nitidamente visível. 


\subsubsection{Tempo experimental total de processo}

Foram conduzidos novos ensaios experimentais para os ensaios em que o prétratamento com ultrassom foi empregado sozinho, com a finalidade de determinar o tempo de secagem experimental em que as condições de estabilidade para a farinha de banana verde, produto final foco deste trabalho, fossem atingidas. Estas condições são: $a_{w}<0,6$ (CARDOSO; PENA, 2014), e umidade de equilíbrio a $\left(50\right.$ e 60) ${ }^{\circ} \mathrm{C}$ inferior a $0,15 \mathrm{~g}$ água/g b.s. (ZABALAGA et al., 2016). Rodelas de banana verde foram coletadas do secador de bandejas (LABMAQ, modelo LS.20, Brasil), a cada 30 min, para a determinação da atividade de água e do conteúdo de umidade. Observa-se, na Tabela 5.12, que, para as rodelas de banana verde pré-tratadas por $20 \mathrm{~min}$ no ultrassom e secas a $50{ }^{\circ} \mathrm{C}$, o tempo total de processo determinado foi menor em comparação ao tempo, das rodelas não pré-tratadas, para atingir as mesmas condições, resultando em $30 \mathrm{~min}$ de economia no tempo de secagem. O tempo de secagem obtido a $60{ }^{\circ} \mathrm{C}$ foi o mesmo para as rodelas não pré-tratadas e as pré-tratadas, não resultando em economia no tempo total de processamento.

Tabela 5.12 - Tempo experimental total de processamento obtido no secador de bandejas (LABMAQ, modelo LS.20, Brasil)

\begin{tabular}{|c|c|c|c|c|c|c|}
\hline \multicolumn{2}{|c|}{ Pré-tratamento } & \multicolumn{2}{|c|}{ Secagem } & \multirow{2}{*}{$t$ total $(\min )$} & \multirow{2}{*}{$a_{w}(-)$} & \multirow{2}{*}{$X$ (g H${ }_{2} \mathrm{O} / g$ b.s. $)$} \\
\hline & $t(\min )$ & $T\left({ }^{\circ} \mathrm{C}\right)$ & $\mathrm{t}(\min )$ & & & \\
\hline Não pré-tratada & - & 50 & 360 & 360 & $0,334 \pm 0,036$ & $0,060 \pm 0,014$ \\
\hline Ultrassom & 20 & 50 & 330 & 350 & $0,318 \pm 0,010$ & $0,048 \pm 0,002$ \\
\hline Não pré-tratada & - & 60 & 300 & 300 & $0,349 \pm 0,017$ & $0,047 \pm 0,002$ \\
\hline Ultrassom & 25 & 60 & 300 & 325 & $0,304 \pm 0,075$ & $0,038 \pm 0,006$ \\
\hline
\end{tabular}

Fonte: O próprio autor.

O secador de bandejas (LABMAQ, modelo LS.20, Brasil) demanda elevado consumo energético, igual a $3500 \mathrm{~W}$ (dados informados pelo fabricante). Em contrapartida, o banho de ultrassom tem, como característica, o baixo consumo energético (KNORR et al., 2011). No caso do banho ultrassônico (UNIQUE, modelo USC-5000A, Brasil) de 21 L (capacidade compatível com a demanda do secador) igual a $1800 \mathrm{~W}$. Assim, considerando $4 \mathrm{~kg}$ de matériaprima processada diariamente, em 20 dias de produção mensal, com um custo da energia para o setor industrial (A4), bandeira azul e posto tarifário fora do ponto igual a $0,214 \mathrm{R} \$ / \mathrm{kWh}$ (Resolução Homologatória $\mathrm{N}^{\circ}$ 2.103/2016 da ANEEL), o processo a $50{ }^{\circ} \mathrm{C}$, sem prétratamento, custaria $1,12 \mathrm{R} \$ / \mathrm{kg}$, e o processo aplicando $20 \mathrm{~min}$ de ultrassom, custaria 1,05 
$\mathrm{R} \$ / \mathrm{kg}$, confirmando, assim, os resultados obtidos previamente e ressaltando fortemente as vantagens do pré-tratamento ao processo de secagem das rodelas de banana verde.

\subsubsection{Efeito do ultrassom sobre o ganho de água $\left(\mathrm{g} \mathrm{H}_{2} \mathrm{O} / 100 \mathrm{~g}\right)$}

Poucos trabalhos investigaram o efeito do ultrassom sobre as alterações microestruturais e a eventual formação de micro-canais, isolado do ganho de água que acontece quando o alimento é imerso em água. Na Tabela 5.13, observa-se que as rodelas de banana verde pré-tratadas com ultrassom embaladas a vácuo (não hidratadas), apresentaram menor $G A$ em comparação às rodelas imersas em água no banho ultrassônico (hidratadas), como esperado. A análise estatística acusou diferença estatística para o $G A(p<0,05)$. Fernandes et al. (2007) e Azoubel et al. (2010), entre outros, relataram que o GA de rodelas de banana madura foi devido ao pré-tratamento com ultrassom. No entanto, como se observa na Tabela 5.13, o GA é consequência da imersão das rodelas em água.

Tabela 5.13 - Ganho de água $(G A)$ e difusividade efetiva da água $\left(D_{e f}\right)$ de rodelas de banana verde embaladas a vácuo ou não submetidas ao prétratamento com ultrassom por $20 \mathrm{~min}$ a $P_{\text {us }}=9,38 \mathrm{~W} / \mathrm{L}$ e secas a $50{ }^{\circ} \mathrm{C}$.

\begin{tabular}{lccc}
\hline \multirow{2}{*}{ Pré-tratamento } & $G A\left(\mathrm{~g} \mathrm{H}_{2} \mathrm{O} / 100 \mathrm{~g}\right)$ & \multicolumn{2}{c}{$D_{\text {ef }} \times 10^{-9}\left(\mathrm{~m}^{2} / \mathrm{s}\right)$} \\
\cline { 3 - 4 } & & $1^{\circ}$ fase & $2^{\circ}$ fase \\
\hline Não pré-tratadas & $0,0^{\mathrm{a}}$ & $10,02 \pm 0,09^{\mathrm{a}}$ & $5,24 \pm 0,18^{\mathrm{a}}$ \\
Imersas em água & $7,60 \pm 0,05^{\mathrm{b}}$ & $10,49 \pm 0,19^{\mathrm{a}}$ & $8,43 \pm 0,37^{\mathrm{b}}$ \\
Embaladas a vácuo & $0,83 \pm 0,03^{\mathrm{c}}$ & $11,70 \pm 0,65^{\mathrm{a}}$ & $8,05 \pm 0,19^{\mathrm{b}}$ \\
DMS & 0,22 & 2,34 & 1,56 \\
\hline
\end{tabular}

Letras diferentes, na mesma coluna, indicam diferença significativa entre os tratamentos $(p<0,05)$. DMS: diferença mínima significativa pelo teste de Tukey. Fonte: O próprio autor.

Ao comparar o valor de $G A$ das rodelas de banana verde pré-tratadas por 20 min na potência volumétrica ultrassônica de 9,38 W/L, apresentado na Tabela 5.2, com aquele apresentado na Tabela 5.13: o segundo é superior, possivelmente devido à sazonalidade da matéria-prima - adquirida em épocas distintas - consequentemente diferenças em teor de umidade e aparência são esperadas. Comparando os resultados de difusividade efetiva da água, em relação aos apresentados na Tabela 5.7, maiores valores também foram obtidos nos ensaios da Tabela 5.13. Segundo a análise estatística, na primeira fase da taxa decrescente de secagem não se observou diferença estatística para os diferentes pré-tratamentos empregados. No entanto, na segunda fase, a difusividade efetiva da água foi significativamente superior para as rodelas de banana verde pré-tratadas com $20 \mathrm{~min}$ de ultrassom $(p<0,05)$. Como foi discutido previamente, na segunda fase de taxa decrescente, a resistência interna do material 
é a que governa sozinha a difusão, aumentos nos valores de difusividade efetiva da água, nesta fase, são atribuídos às mudanças na estrutura e ao 'efeito esponja' causado pelo ultrassom (SCHÖSSLER et al., 2012a). Assim, comparando a ANOVA realizada nos valores de difusividade efetiva da água, obtidos nas Tabelas 5.7 e 5.13, observa-se o mesmo comportamento para ambos ensaios. A aplicação de ultrassom em rodelas imersas em água (hidratadas) ou as embaladas a vácuo (não hidratadas) não influenciou a difusividade efetiva da água.

$\mathrm{Na}$ Figura 5.29, as curvas de secagem a $50{ }^{\circ} \mathrm{C}$, obtidas das rodelas de banana verde não pré-tratadas e pré-tratadas com ultrassom por 20 min imersas em água (hidratadas) e embaladas a vácuo (não hidratadas) no banho ultrassônico, são apresentadas.

Figura 5.29 - Curvas de secagem a $50{ }^{\circ} \mathrm{C}$, obtidas para rodelas de banana verde embaladas a vácuo ou não submetidas ao pré-tratamento com ultrassom por $20 \min$ a $P_{\mathrm{us}}=9,38 \mathrm{~W} / \mathrm{L}$.

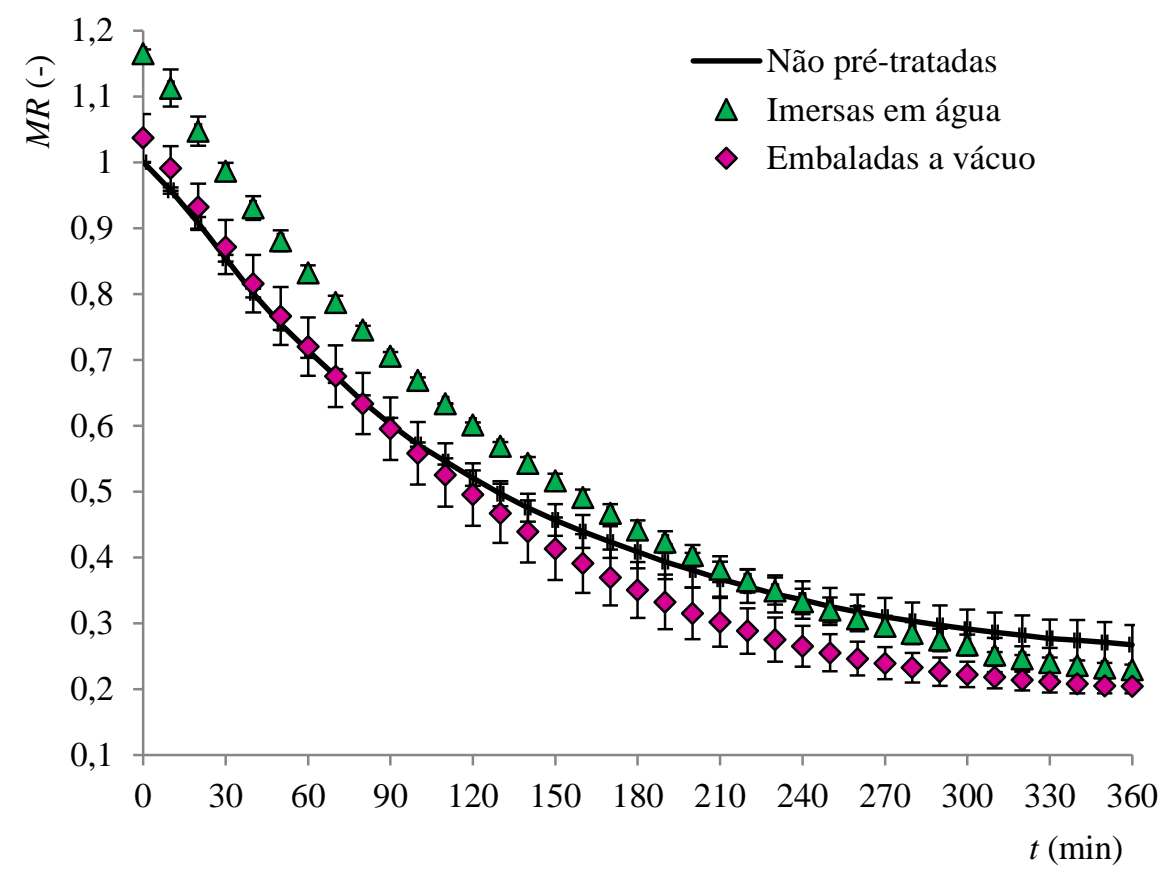

Fonte: O próprio autor. 
Miano et al. (2016) estudaram grãos de sorgo $\left(a_{w}=0,985 \pm 0,003\right)$ embalados a vácuo, pré-tratados com ultrassom por $3 \mathrm{~h}$ (potência volumétrica ultrassônica de $28 \mathrm{~W} / \mathrm{L}$ ). Após o pré-tratamento, os grãos de sorgo foram hidratados a $25{ }^{\circ} \mathrm{C}$, por $2 \mathrm{~h}$. Foi observada uma melhoria no processo de hidratação para os grãos pré-tratados com ultrassom. $\mathrm{O}$ aumento de transferência de massa pelo ultrassom foi devido ao efeito direto ('efeito esponja') e ao efeito indireto (formação de micro-canais); observados independentemente se o pré-tratamento foi acompanhado, ou não, da hidratação. No entanto, no trabalho desenvolvido por Ricce et al. (2016), em fatias de cenoura pré-tratadas por $60 \mathrm{~min}$ com ultrassom e secas a $40{ }^{\circ} \mathrm{C}$, observouse que, nas fatias embaladas a vácuo e pré-tratadas com ultrassom, a taxa de perda de água, durante a secagem, foi menor em comparação à obtida das fatias não pré-tratadas e às obtidas das fatias imersas em água no ultrassom. Neste caso, não só a formação de micro-canais, mas também a hidratação foram os mecanismos que aumentaram a eficiência na secagem. Segundo os resultados obtidos neste trabalho (Tabela 5.13), no caso das rodelas de banana verde, foi observado que o aumento da difusividade efetiva da água foi devido ao efeito do ultrassom, independentemente ou não do ganho de água durante o pré-tratamento, tal como foi observado por Miano et al. (2016) em grãos de sorgo.

Na Figura 5.30 são mostradas as imagens adquiridas no MEV a 300x e 600x, após o pré-tratamento, por $20 \mathrm{~min}$, com ultrassom de potência volumétrica igual a 9,38 W/L em rodelas de banana verde imersas em água (hidratadas) e embaladas a vácuo (não hidratadas). 
Figura 5.30 - Imagens obtidas para rodelas de banana verde embaladas a vácuo ou não, submetidas ao pré-tratamento com ultrassom por $20 \mathrm{~min}$ a $P_{\text {us }}=9,38 \mathrm{~W} / \mathrm{L}$ em relação as rodelas não pré-tratadas
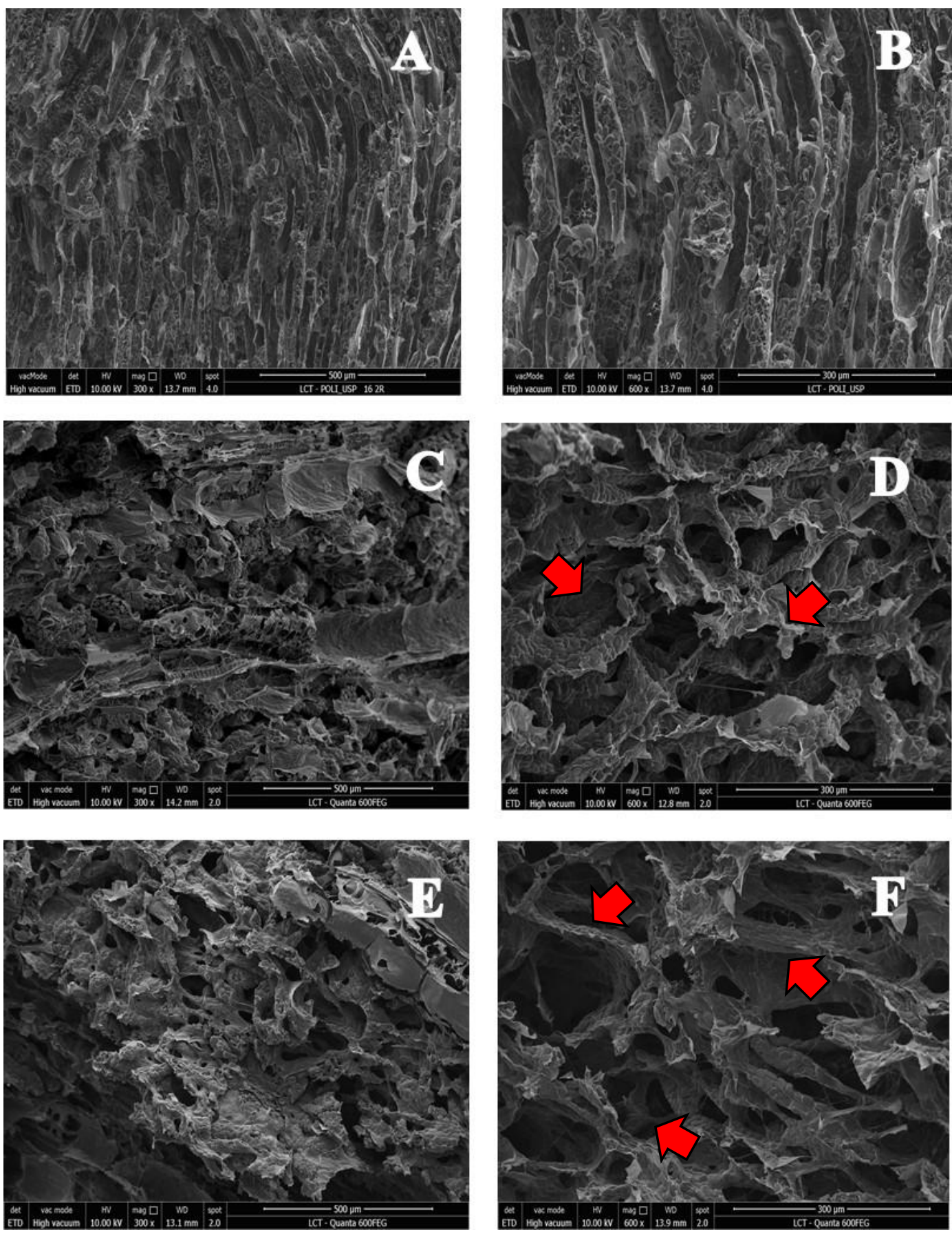

(A) e (B) rodelas de banana verde in natura, (C) e (D) rodelas de banana verde embaladas a vácuo, (E) e $(F)$ rodelas de banana verde imersas em água. Fonte: O próprio autor. 
São fortemente visíveis as diferenças na microestrutura das rodelas de banana verde, devido à aplicação do ultrassom. Na banana verde in natura é possível observar que o amido resistente foi preservado no amiloplasto (Figura 5.30A e 5.30B), com cavidades menores e de alta densidade celular. No caso da banana verde pré-tratada (Figuras 5.30C a 5.30F), é possível verificar que a estrutura apresenta células danificadas, com espaços intercelulares maiores (regiões indicadas com as zetas em vermelho), os quais podem ser relacionados aos microcanais descritos na literatura, quando o ultrassom é aplicado. No entanto, distinguir diferenças na estrutura da banana verde pré-tratada imersa em água (hidratadas) e a embalada a vácuo (não hidratada) não foi possível. Na Figura 5.4, a 40x observou-se que a banana verde, submetida a 20 min de ultrassom, apresentou uma camada de água superficial com dutos; a 300x e 600x, esses dutos foram mais visíveis. A formação de micro-canais devido à aplicação de ultrassom foi também observada em melão (RODRIGUES; FERNANDES, 2008), maracujá (NASCIMENTO et al., 2016), maçã (RODRÍGUES et al., 2014), entre outros.

Na Figura 5.31, as micrografias a 300x e 600x das rodelas de banana verde pré-tratadas por 20 min com ultrassom e secas a $50{ }^{\circ} \mathrm{C}$, são mostradas. As rodelas de banana verde prétratadas (Figuras 5.31C a 5.31F) apresentaram uma estrutura porosa com mais volume livre entre as células (regiões indicadas pelas zetas em vermelho), se comparadas com as rodelas de banana verde não pré-tratadas (Figuras 5.31A e 5.31B). A difusividade efetiva da água nos frutos não só depende da estrutura do tecido, mas também da sua porosidade (RODRIGUES; FERNANDES, 2008). Um aumento na porosidade aumenta os espaços vazios e diminui a resistência à difusão. As paredes celulares atuam como uma membrana semi-permeável, conferindo resistência à difusão da água e de sólidos (RODRIGUES; FERNANDES, 2008). A influência do ultrassom sobre a resistência interna a difusão vem do 'efeito esponja' ou da criação de micro-canais, o que pode facilitar o movimento de soluções dentro do sólido (CÁRCEL et al., 2012). Assim, as rodelas de banana verde pré-tratadas com ultrassom apresentaram estruturas mais porosas e, consequentemente, maiores valores de difusividade efetiva da água foram obtidos (Tabelas 5.5, 5.7 e 5.13). Não foi possível observar diferenças na estrutura das rodelas de banana verde imersas em água (hidratadas) ou embaladas a vácuo (não hidratadas). 
Figura 5.31 - Imagens obtidas para rodelas de banana verde embaladas a vácuo ou não submetidas ao pré-tratamento com ultrassom por $20 \mathrm{~min}$ a $P_{\text {us }}=9,38 \mathrm{~W} / \mathrm{L}$ e secas a $50{ }^{\circ} \mathrm{C}$ em relação as rodelas não pré-tratadas
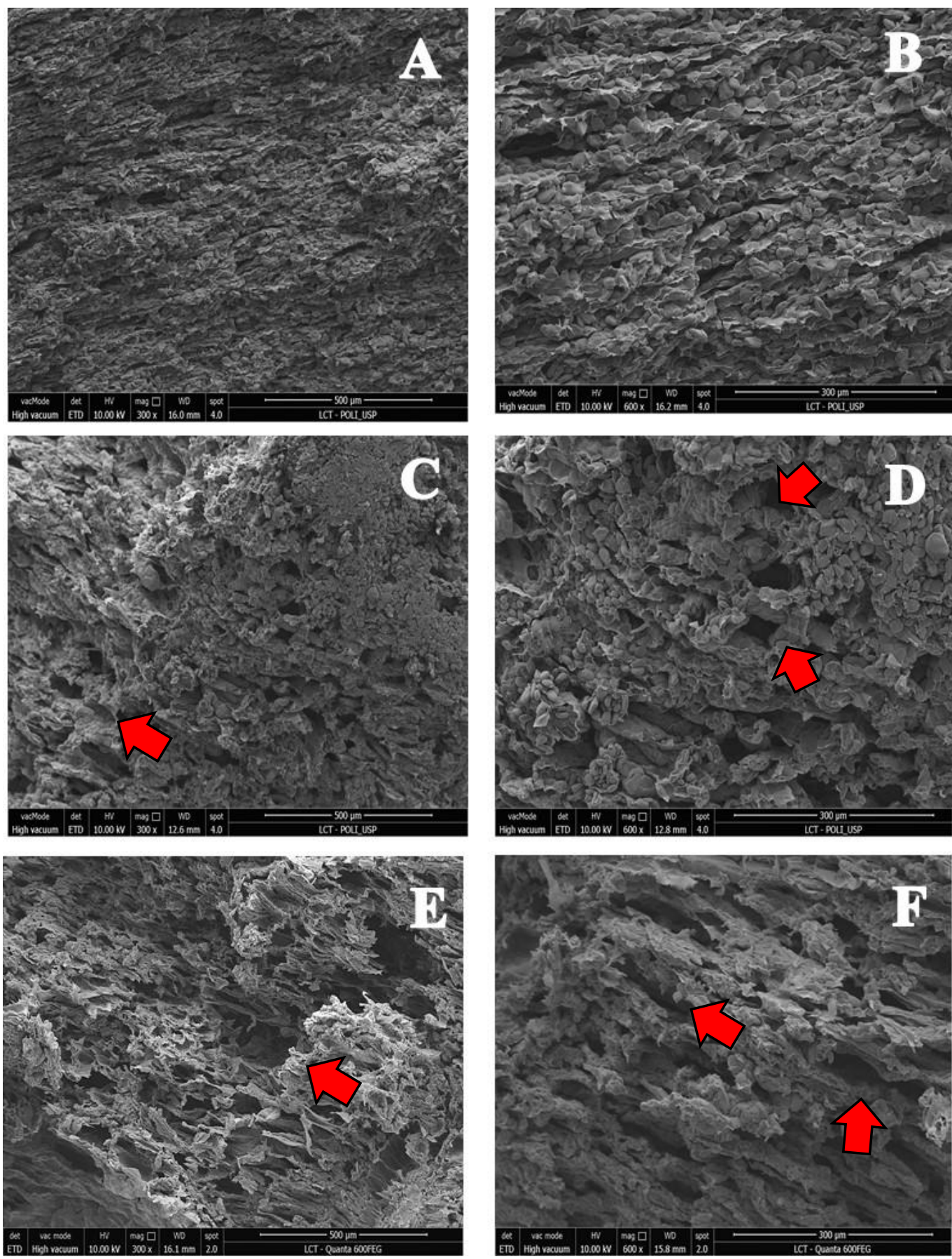

(A) e (B) rodelas de banana verde não pré-tratadas e secas $(C)$ e (D) rodelas de banana verde embaladas a vácuo pré-tratadas com ultrassom e secas, $(E)$ e $(F)$ rodelas de banana verde imersas em água no ultrassom e secas. Fonte: O próprio autor. 


\subsection{Caracterização da Farinha de Banana Verde (FBV)}

Na Tabela 5.14 a caracterização da farinha de banana verde (FBV), produzida a partir das rodelas de banana verde pré-tratadas e secas sob diferentes condições, descritas na Tabela 5.9, são apresentadas. A análise estatística foi conduzida separadamente para os ensaios de secagem a $(50$ e 60$){ }^{\circ} \mathrm{C}$.

O tempo total de secagem para estes ensaios foi de 490 min. Todas as farinhas produzidas sob diferentes condições alcançaram as condições reconhecidas de estabilidade microbiológica: atividade de água <0,6 (CARDOSO; PENA, 2014); e umidade inferior a 0,15 $\mathrm{g} \mathrm{H}_{2} \mathrm{O} / \mathrm{g}$ b.s. (ZABALAGA et al., 2016). No entanto, foram observadas diferenças estatísticas do conteúdo de umidade e da atividade de água, sendo que a FBV produzida de rodelas de banana verde não pré-tratadas apresentou valores superiores nas duas temperaturas de secagem.

A temperatura $\left(T_{p}\right)$ e entalpia $(\Delta H)$ de gelatinização foram obtidas das curvas do DSC. $\mathrm{Na}$ FBV, obtida dos ensaios conduzidos a $50{ }^{\circ} \mathrm{C}$, a $T_{p}$ foi significativamente menor para as rodelas de banana verde pré-tratadas. No entanto, para a secagem a $60{ }^{\circ} \mathrm{C}$, não foram observadas diferenças estatísticas $(p>0,05)$. No caso da $\Delta H$ a $50{ }^{\circ} \mathrm{C}$ também houve diferença estatística entre as amostras não pré-tratadas e pré-tratadas. Já para a secagem a $60{ }^{\circ} \mathrm{C}$, não foram observadas diferenças estatísticas $(p>0,05)$, como aconteceu com a $T_{p}$. O ultrassom reduz a quantidade de energia necessária para a gelatinização do amido devido às diferenças nas forças de ligação da dupla hélice que formam a estrutura da amilopectina, o que resulta em diferentes alinhamentos das ligações de hidrogênio dentro das moléculas de amido; consequentemente, menor valor de temperatura de gelatinização é observado (IZIDORO et al., 2011; JAMBRAK et al., 2010). As temperaturas de gelatinização para as farinhas de banana verde encontram-se na faixa de valores relatados em outros estudos para banana verde (IZIDORO et al., 2011; RAYO et al., 2015; TRIBESS et al., 2009). No entanto, os valores da entalpia de gelatinização foram inferiores em relação aos valores relatados nos estudos citados. 
Tabela 5.14 - Conteúdo de umidade $\left(X_{f}\right)$, atividade de água $\left(a_{w}\right)$, temperatura de gelatinização $\left(T_{p}\right)$, entalpia de gelatinização $(\Delta H)$ e conteúdo de amido resistente $(A R)$ da farinha de banana verde produzida de rodelas de banana verde sem pré-tratamento, pré-tratadas com ultrassom (US) e com a técnica combinada de ultrassom e pulsos de vácuo $(\mathrm{US}+\mathrm{PV})$

\begin{tabular}{|c|c|c|c|c|c|c|c|}
\hline Pré-tratamento & $t(\min )$ & $T\left({ }^{\circ} \mathrm{C}\right)$ & $X_{f}\left(\mathrm{~g} \mathrm{H}_{2} \mathrm{O} / \mathrm{g}\right.$ b.s. $)$ & $a_{w}(-)$ & $T_{p}\left({ }^{\circ} \mathrm{C}\right)$ & $\Delta H(\mathrm{~J} / \mathrm{g})$ & $A R$ (g /100 g b.s.) \\
\hline Não pré-tratadas & - & 50 & $0,037 \pm 0,008^{\mathrm{a}}$ & $0,42 \pm 0,03^{\mathrm{ab}}$ & $76,26 \pm 0,54^{\mathrm{a}}$ & $2,19 \pm 0,07^{\mathrm{ab}}$ & $43,61 \pm 0,58^{a}$ \\
\hline Ultrassom & 20 & 50 & $0,017 \pm 0,008^{\mathrm{b}}$ & $0,35 \pm 0,01^{\mathrm{a}}$ & $74,54 \pm 0,43^{\mathrm{b}}$ & $1,97 \pm 0,13^{\mathrm{a}}$ & $44,27 \pm 1,61^{\mathrm{a}}$ \\
\hline Ultrassom + Pulso de vácuo & $20+60$ & 50 & $0,018 \pm 0,002^{\mathrm{b}}$ & $0,43 \pm 0,02^{\mathrm{b}}$ & $73,65 \pm 0,11^{b}$ & $2,45 \pm 0,08^{b}$ & $42,56 \pm 0,26^{\mathrm{a}}$ \\
\hline DMS & & & 0,02 & 0,07 & 1,68 & 0,39 & 2,49 \\
\hline Não pré-tratadas & - & 60 & $0,045 \pm 0,003^{\mathrm{a}}$ & $0,36 \pm 0,01^{\mathrm{a}}$ & $73,85 \pm 0,71^{\mathrm{a}}$ & $1,92 \pm 0,22^{\mathrm{a}}$ & $43,66 \pm 1,19^{\mathrm{a}}$ \\
\hline Ultrassom & 25 & 60 & $0,011 \pm 0,004^{b}$ & $0,32 \pm 0,01^{\mathrm{b}}$ & $74,54 \pm 0,46^{\mathrm{a}}$ & $2,47 \pm 0,45^{\mathrm{a}}$ & $40,34 \pm 1,16^{\mathrm{ab}}$ \\
\hline Ultrassom + Pulso de vácuo & $25+60$ & 60 & $0,013 \pm 0,005^{\mathrm{b}}$ & $0,35 \pm 0,01^{\mathrm{a}}$ & $73,60 \pm 0,17^{\mathrm{a}}$ & $2,40 \pm 0,85^{\mathrm{a}}$ & $38,92 \pm 1,63^{b}$ \\
\hline DMS & & & 0,01 & 0,01 & 2,07 & 0,40 & 3,36 \\
\hline
\end{tabular}

Letras diferentes na mesma coluna indicam diferença significativa entre os tratamentos $(p<0,05)$. DMS: diferença mínima significativa pelo teste de Tukey. Fonte: O próprio autor. 
O teor encontrado de amido resistente para a matéria-prima foi de $(62,26 \pm 3,84) \mathrm{g} / 100$ g b.s. comparável com os relatados na literatura (RAYO et al., 2015). A análise estatística indicou que o teor de $A R$ da FBV não foi influenciado pelos diferentes pré-tratamentos aplicados nas rodelas de banana verde, na temperatura de secagem a $50{ }^{\circ} \mathrm{C}$. No entanto, a 60 ${ }^{\circ} \mathrm{C}$, a aplicação de pré-tratamentos reduziu significativamente o teor de amido resistente da farinha $(p<0,05)$. O menor teor foi observado para a FBV produzida a partir de rodelas de banana verde pré-tratadas com a combinação de ultrassom e pulsos de vácuo. De acordo com Jambrak et al. (2010) a redução do conteúdo de $A R$ ocorre devido à desorganização parcial da estrutura cristalina dos grânulos de amido, em consequência da aplicação do ultrassom. A cavitação rompe os grânulos de amido, e a difusão de água permite a quebra da estrutura cristalina (JAMBRAK et al., 2010).

A $50{ }^{\circ} \mathrm{C}$, o efeito de $20 \mathrm{~min}$ de ultrassom resultou em menor quantidade de energia necessária para a gelatinização. No entanto, não foi significativo para alterar o conteúdo de $A R$, considerado como o principal atributo da farinha de banana verde. Ainda, valores superiores de difusividade efetiva de água foram relatados (Tabelas 5.7, 5.9 e 5.13), assim como, redução no tempo total de secagem (Tabela 5.12) e menores custo de operação podem ser obtidos com este processo. A $60{ }^{\circ} \mathrm{C}$, a aplicação de pré-tratamentos ( 25 min de ultrassom ou a combinação de 25 min de ultrassom com pulso de vácuo por $60 \mathrm{~min}$ ) reduziu significativamente o teor de $A R$, com aumento pouco visível na difusividade efetiva da água, porém, sem diminuição no tempo de processamento, ou seja: sem economia no processo, mostrando não ser a escolha mais vantajosa na produção de farinha de banana verde.

A Tabela 5.15 apresenta os resultados da caraterização da farinha de banana verde para as rodelas de banana verde não pré-tratadas e pré-tratadas com ultrassom de $P_{\text {us }}=9,38 \mathrm{~W} / \mathrm{L}$ por 20 min imersas em água (hidratadas) ou embaladas a vácuo (não hidratadas) e secas a $50{ }^{\circ} \mathrm{C}$. 
Tabela 5.15 - Conteúdo de umidade $\left(X_{f}\right)$, atividade de água $\left(a_{w}\right)$, temperatura de gelatinização $\left(T_{p}\right)$, entalpia de gelatinização $(\Delta H)$ e conteúdo de amido resistente $(A R)$ para farinha de banana verde, produzida de rodelas de banana verde embaladas a vácuo ou não submetidas ao pré-tratamento com ultrassom por $20 \mathrm{~min}$ a $P_{\text {us }}=9,38 \mathrm{~W} / \mathrm{L}$ e secas a $50{ }^{\circ} \mathrm{C}$.

\begin{tabular}{lccccc}
\hline Pré-tratamento & $\mathrm{X}_{f}\left(\mathrm{~g} \mathrm{H}_{2} \mathrm{O} / \mathrm{g}\right.$ d.b. $)$ & $a_{w}(-)$ & $T_{p}\left({ }^{\circ} \mathrm{C}\right)$ & $\Delta H(\mathrm{~J} / \mathrm{g})$ & $A R(\mathrm{~g} / 100 \mathrm{~g} \mathrm{~b} . \mathrm{s})$. \\
\hline Não pré-tratadas & $0,08 \pm 0,01^{\mathrm{a}}$ & $0,48 \pm 0,09^{\mathrm{a}}$ & $75,39 \pm 0,81^{\mathrm{a}}$ & $2,75 \pm 0,37^{\mathrm{a}}$ & $52,73 \pm 0,31^{\mathrm{a}}$ \\
Embaladas a vácuo & $0,10 \pm 0,01^{\mathrm{a}}$ & $0,54 \pm 0,05^{\mathrm{a}}$ & $74,45 \pm 0,56^{\mathrm{a}}$ & $1,83 \pm 0,22^{\mathrm{ab}}$ & $49,61 \pm 1,22^{\mathrm{a}}$ \\
Imersas em água & $0,08 \pm 0,01^{\mathrm{a}}$ & $0,46 \pm 0,05^{\mathrm{a}}$ & $72,48 \pm 0,29^{\mathrm{b}}$ & $1,59 \pm 0,31^{\mathrm{b}}$ & $50,09 \pm 0,23^{\mathrm{a}}$ \\
DMS & 0,06 & 0,17 & 1,83 & 1,14 & 4,37 \\
\hline
\end{tabular}

Letras diferentes na mesma coluna indicam diferença significativa entre os tratamentos $(p<0,05)$. DMS: diferença mínima significativa pelo teste de Tukey. Fonte: O próprio autor.

Confirma-se o exposto previamente, a secagem a $50{ }^{\circ} \mathrm{C}$ por $360 \mathrm{~min}$ foi suficiente para as rodelas de banana verde atingirem os valores desejados para garantir a estabilidade microbiológica (CARDOSO; PENA, 2014; ZABALAGA et al., 2016). ANOVA revelou que a $T_{p}$ da FBV, produzida de rodelas de banana verde de 20 min de ultrassom imersas em água, foi estatísticamente inferior $(p<0,05)$, assim como a $\Delta H$. A temperatura de gelatinização pode ser usada como medida de estabilidade ou de integridade das regiões cristalinas (MESQUITA et al., 2016). Segundo os resultados mostrados na Tabela 5.15, a FBV produzida a partir de rodelas de banana verde pré-tratadas com ultrassom apresentaram estruturas cristalinas menos estáveis e, por isso menor quantidade de energia foi necessária para a gelatinização, tal como aconteceu nos resultado apresentados na Tabela 5.14.

O teor de amido resistente para a banana verde in natura destes ensaios foi de $(59,55 \pm$ 2,99) g/100 g b.s. valor próximo ao obtido na matéria-prima dos ensaios da Tabela 5.14. ANOVA não revelou diferenças estatísticas entre os valores de $A R$ da FBV produzida de rodelas de banana verde pré-tratadas ou não e secas a $50{ }^{\circ} \mathrm{C}(p<0,05)$, como foi observado anteriormente (Tabela 5.14).

A solubilidade é outro bom parâmetro para avaliar a integridade do grânulo de amido, pois está relacionada com a quantidade de sólidos solúveis disponíveis que dependem da gelatinização, dextrinização e a consequente solubilização do amido (BEZERRA et al., 2013). São apresentados na Figura 5.32 os valores obtidos de solubilidade a $(25,40,50$ e 60$){ }^{\circ} \mathrm{C}$ para a FBV, produzida a partir de rodelas de banana verde não pré-tratadas e pré-tratadas com ultrassom de $P_{\text {us }}=9,38 \mathrm{~W} / \mathrm{L}$ por $20 \mathrm{~min}$, imersas em água (hidratadas) e embaladas a vácuo (não hidratadas) e secas a $50^{\circ} \mathrm{C}$. 
Figura 5.32 - Solubilidade a $(25,40,50$ e 60$){ }^{\circ} \mathrm{C}$ para farinha de banana verde produzida de rodelas de banana verde embaladas a vácuo ou não submetidas ao pré-tratamento com ultrassom por $20 \mathrm{~min}$ a $P_{\text {us }}=9,38 \mathrm{~W} / \mathrm{L}$ e secas a $50{ }^{\circ} \mathrm{C} \mathrm{em}$ relação a rodelas não pré-tratadas.

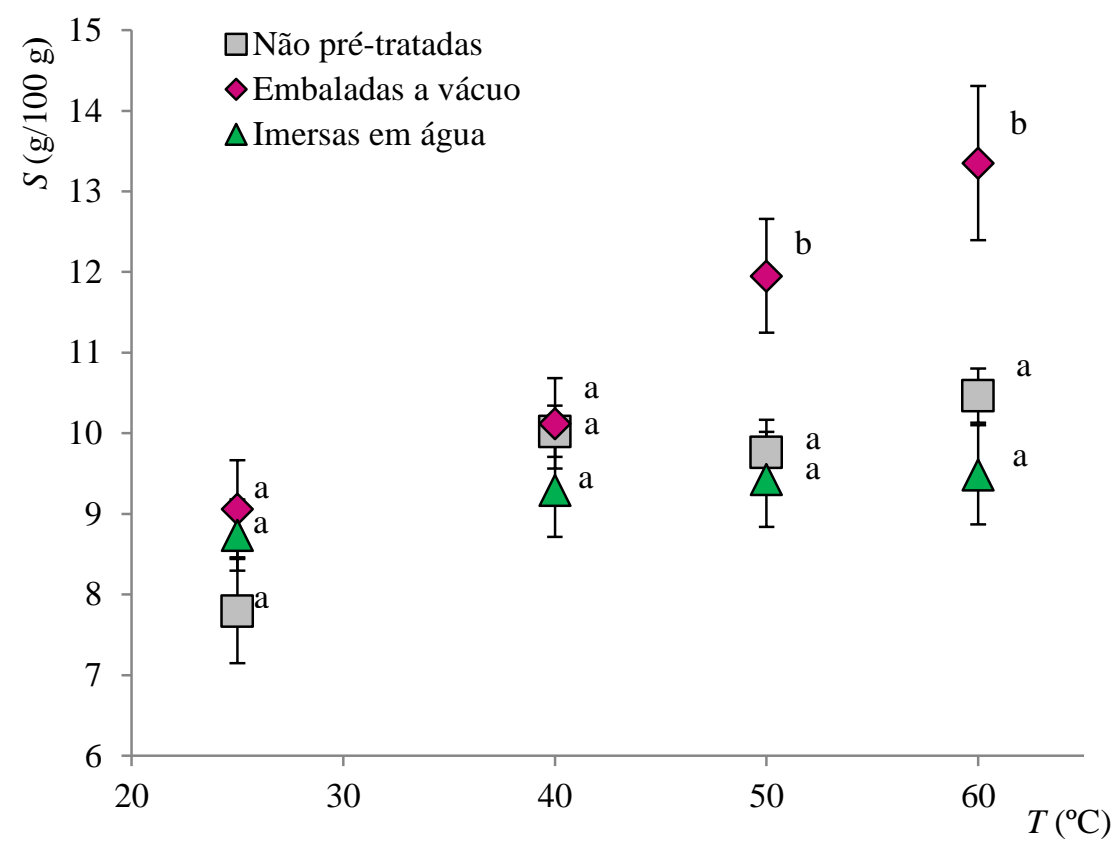

Fonte: O próprio autor. Letras diferentes na mesma coluna indicam diferença significativa entre os tratamentos $(p<0,05)$.

A FBV mostrou baixa solubilidade na faixa de temperatura estudada, embora o aumento desse parâmetro esteja diretamente relacionado à temperatura, comportamento semelhante para a farinha de banana verde foi relatado na literatura (BEZERRA et al., 2013). ANOVA não revelou diferença estatística entre as amostras a $(25$ e 40$){ }^{\circ} \mathrm{C}(p>0,05)$. Por outro lado, a (50 e 60) ${ }^{\circ} \mathrm{C}$, a farinha de banana verde, produzida a partir das rodelas de banana verde não hidratadas (embaladas a vácuo), apresentou os valores mais altos de solubilidade. As ligações de hidrogênio são rompidas pelo efeito da temperatura, consequentemente, as moléculas de água se ligam aos grupos de hidroxila liberados, e o grânulo se expande e a amilose é exsudada (BEZERRA et al., 2013). A disposição molecular, que depende da quantidade de amilose e amilopectina presentes, permite uma estimativa do tipo de organização que ocorre no interior do grânulo. Foi relatada na literatura maior facilidade para a entrada de água em amido de milho devido à ruptura do grânulo, pela aplicação do ultrassom, levando a uma maior absorção de água (JAMBRAK et al., 2010). O colapso súbito das bolhas de cavitação induz gradientes de alta pressão e velocidades locais elevadas, rompendo as cadeias de polímeros e quebrando as 
ligações covalentes. Assim, a estrutura molecular cristalina do amido de milho é quebrada, o que poderia causar um aumento na solubilidade (JAMBRAK et al., 2010).

Na Figura 5.33 as imagens obtidas no MEV a 2500x e 5000x para farinha de banana verde, produzida com rodelas não pré-tratadas e pré-tratadas com ultrassom de $P_{\text {us }}=9,38 \mathrm{~W} / \mathrm{L}$ por 20 min, imersas em água (hidratadas) e embaladas a vácuo (não hidratadas), e secas a 50 ${ }^{\circ} \mathrm{C}$, são apresentadas.

Uma média de 20 imagens foram adquiridas para cada FBV e o tamanho dos grânulos foi medido aleatoriamente. Os valores medidos ficaram na faixa dos valores relatados na literatura de (10,3 e 49,6) $\mu \mathrm{m}$ (PERONI et al., 2010). Consequentemente, o pré-tratamento com ultrassom não afetou o tamanho dos grânulos de amido. De maneira geral, os grânulos de amido das FBV produzidas a partir de rodelas de banana verde não pré-tratadas e pré-tratadas, apresentaram forma oval e alongada, tal como descrito na literatura (PERONI et al., 2010). No entanto, os grânulos de amido da farinha produzida com as rodelas de banana verde não prétratadas apresentaram superfícies mais lisas (Figuras 5.33A e 5.33B), em relação, aos grânulos de amido da FBV produzida com rodelas de banana verde pré-tratadas, nos quais, o amiloplasto que envolve os grânulos tem aparência quebradiça (Figuras 5.33C a 5.33F), indicando uma possível ruptura do gránulo pelo tratamento empregado, regiões indicadas pelas zetas em vermelho. Segundo Jambrak et al. (2010), as micrografias de grânulos de amido de milho ressaltaram claramente o efeito do pré-tratamento com ultrassom, na frequência fixa de $24 \mathrm{kHz}$, pré-tratados por (15 e 30) min, na potência nominal de (100 a 400) W, ocasionando a ruptura mecânica dos grânulos. Não foi ressaltada uma diferença visível entre as imagens das farinhas produzidas a partir de rodelas de banana verde submetidas ao ultrassom imersas em água (hidratadas) ou embaladas a vácuo (não hidratadas), tal como ocorreu nas imagens apresentadas nas Figuras (5.30 e 5.31). Assim, a eventual formação de micro-canais, por ação do ultrassom (que ocasionou danos nos grânulos do amido) foi visível independentemente da aplicação do pré-tratamento em rodelas imersas em água (hidratadas) ou embaladas a vácuo (não hidratadas). Da mesma forma a aplicação do pré-tratamento em rodelas imersas em água ou embaladas a vácuo não foi significativa nos valores de difusividade efetiva de água (Tabela 5.13), nem no conteúdo de $A R$ (Tabela 5.15), mostrando que os efeitos do ultrassom são evidente indepentemente do ganho de água. 
Figura 5.33 - Imagens obtidas dos grânulos de amido de FBV produzida a partir de rodelas de banana verde embaladas a vácuo ou não submetidas ao pré-tratamento com ultrassom por 20 min a $P_{\text {us }}=9,38 \mathrm{~W} / \mathrm{L}$ e secas a $50{ }^{\circ} \mathrm{C}$, em relação aos grânulos de amido de FBV produzida a partir de rodelas não pré-tratadas.
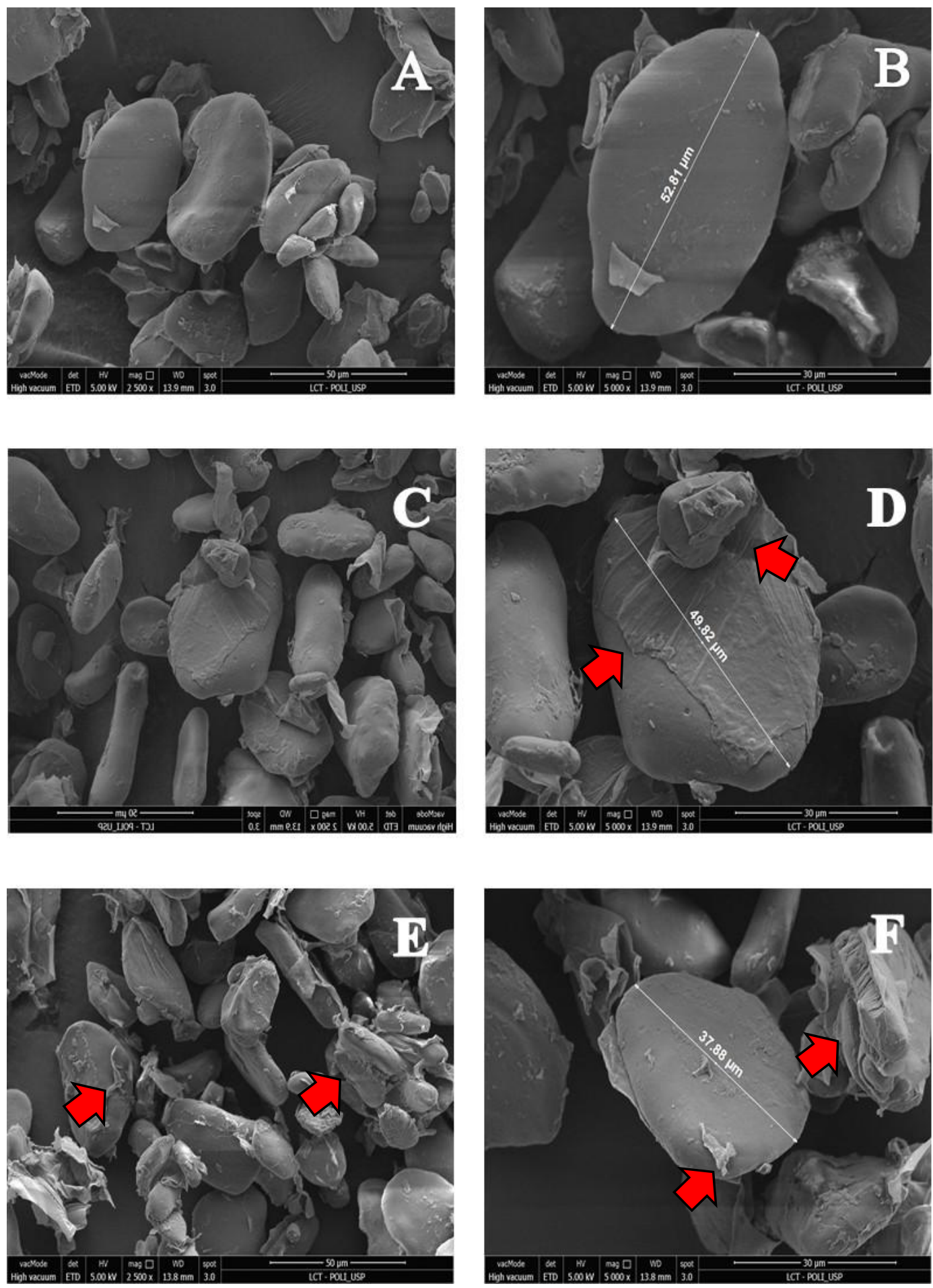

(A) e (B) grânulos de amido de farinha produzida de rodelas de banana verde não pré-tratadas (C) e (D) grânulos de amido da farinha produzida de rodelas de banana verde embaladas a vácuo submetidas ao ultrassom, (E) e (F) grânulos de amido da farinha produzida de rodelas de banana verde imersas em água submetidas ao ultrassom. Fonte: O próprio autor. 


\section{CONCLUSÕES}

\section{$1^{\circ}$ Etapa}

As rodelas de banana verde imersas no ultrassom de potência $(9,38 \pm 0,60) \mathrm{W} / \mathrm{L}$, apresentaram maior ganho de água $(G A)$ se comparadas com as rodelas imersas no ultrassom de potência volumétrica ultrassônica de $(25,63 \pm 1,24) \mathrm{W} / \mathrm{L}$. O GA foi diretamente proporcional ao tempo de imersão no banho ultrassônico, sendo o valor alcançado de $\left(6,39\right.$ e 7,53) g $\mathrm{H}_{2} \mathrm{O} / 100$ g para as rodelas de banana verde pré-tratadas por (20 e 25) min, respectivamente, no banho de potência volumétrica ultrassônica de $(9,38 \pm 0,60) \mathrm{W} / \mathrm{L}$.

A hipótese inicial - a de que micro-canais gerados pelo pré-tratamento de ultrassom, e o gradiente de pressão existente durante o pré-tratamento por pulso de vácuo promoveriam a migração de umidade - não foi comprovada. Possivelmente devido ao colapso da estrutura da fruta.

\section{$2^{\circ}$ Etapa}

Para os ensaios conduzidos na estufa convectiva, a análise estatística mostrou que, o tempo de imersão de $(0,10,15,20$ e 25$)$ no banho de ultrassom de $(9,38 \pm 0,60) \mathrm{W} / \mathrm{L}$ e temperatura de secagem (50 e 60) ${ }^{\circ} \mathrm{C}$ não influenciou significativamente a difusividade efetiva da água. No entanto, à temperatura de $50{ }^{\circ} \mathrm{C}$, a difusividade efetiva da água das rodelas de banana verde pré-tratadas com 20 min de ultrassom foi maior, e a $60{ }^{\circ} \mathrm{C}$ isso foi evidente para as rodelas que foram pré-tratadas com 25 min de ultrassom. Por outro lado, o pré-tratamento das rodelas de banana verde no ultrassom de potência de $(25,63 \pm 1,24)$ W/L não aumentou a eficiência da secagem, já que foram obtidos valores menores da difusividade efetiva da água se comparados com os das rodelas não pré-tratadas.

\section{$3^{\circ}$ Etapa}

Na secagem a $50{ }^{\circ} \mathrm{C}$, o aumento da difusividade efetiva da água, das rodelas pré-tratadas com 20 min de ultrassom, em relação as rodelas não pré-tratadas foi de $(72,1$ e 78,1$) \%$, na primeira e segunda fases de taxa decrescente, respectivamente. No caso das amostras prétratadas por $25 \mathrm{~min}$ e secas a $60{ }^{\circ} \mathrm{C}$, o aumento foi de $(25,8$ e 38,6$) \%$. Ainda, observou-se que, nas secagem a (50 e 60) ${ }^{\circ} \mathrm{C}$ não há sinergia dos pré-tratamentos: ultrassom e pulso de vácuo, e que o uso do ultrassom sozinho foi mais favorável para a remoção de água. 
Em imagens obtidas no MEV a 300x e 600x foi claramente visível a formação de microcanais após o pré-tratamento com ultrassom. Ainsa, as rodelas de banana verde pré-tratadas e secas apresentaram estruturas mais porosas e, consequentemente, maiores valores de difusividade efetiva da água foram obtidos. A formação de micro-canais e o aumento no valor da difusividade efetiva da água foi independentemente do pré-tratamento: rodelas imersas em água (hidratadas), ou embaladas a vácuo (não hidratadas).

\section{$4^{\circ}$ Etapa}

O conteúdo médio de amido resistente foi de (38 - 53) g/100 g b.s. para as farinhas de banana verde produzidas sob diferentes condições. A FBV produzida a partir de rodelas prétratadas com ultrassom apresentaram estruturas cristalinas menos estáveis e, por isso menor quantidade de energia foi necessária para a gelatinização. No estanto, a $50^{\circ} \mathrm{C}$, a redução do teor de amido resistente não foi significativa, no caso da secagem a $60{ }^{\circ} \mathrm{C}$, a redução no teor de $A R$ foi significativa.

\subsection{Considerações finais}

Comparando os dois pré-tratamentos: ultrassom e pulso de vácuo, o pré-tratamento mais favorável para a cinética de secagem da banana verde resultou ser o primeiro. O processo aplicando ultrassom por 20 min e secagem a $50{ }^{\circ} \mathrm{C}$ aumentou o valor da difusividade efetiva da água, em relação às outras condições estudadas. Este processo diminuiu em $30 \mathrm{~min}$ o tempo de secagem. Nessas condições, a economia no custo da energia é de $(1,12$ para 1,05$) \mathrm{R} \$ / \mathrm{kg}$ de matéria-prima. Ainda, na farinha obtida não houve redução significativa no teor de amido resistente, mostrando-se ser assim a melhor rota tecnológica para a produção de farinha de banana verde. 


\section{CONTINUIDADE DO TRABALHO}

- Tal como foi discutido no presente trabalho, dois banhos ultrassônicos foram empregados. No entanto, os dois banhos tem volume útil, potência nominal e frequência diferentes, o que dificulta a comparação. A utilização de um único banho ultrassônico que permita alterar os parâmetros facilitaria os estudos e a comparação dos efeitos.

- No presente trabalho, o ultrassom foi aplicado como pré-tratamento (tratamento em meio líquido). No entanto, na literatura, foram descritos processos de secagem assistidos com ultrassom (tratamento em meio gasoso). Embora estas aplicações sejam mais difíceis quando comparadas à aplicação em meio líquido, sistemas com estas características conseguiram uma redução do tempo da secagem entre (30 e 75) \% e aumento da difusividade efetiva da água de até $400 \%$, dependendo do produto. Seria interessante aprofundar neste tipo de aplicação.

- As vantagens da aplicação do ultrassom como pré-tratamento ao processo de secagem convectiva da banana verde foram comprovadas em escala laboratorial. No entanto, o objetivo principal da pesquisa é a aplicação em nível industrial. Nas seguintes etapas do trabalho poderiam realizar-se estudos em maior escala. O secador de bandejas (LABMAQ, modelo LM.ES-20, Brasil) tem uma capacidade de $4 \mathrm{~kg}$, sendo $1 \mathrm{~kg}$ por cada bandeja. No presente trabalho foi empregada apenas uma bandeja, dado o limite da capacidade do banho ultrassônico. Um banho que atenda a essa capacidade ainda é necessário.

- No caso da banana verde, foi comprovado que a aplicação de pulsos de vácuo prévia à secagem não aumentou a taxa de remoção de umidade. No entanto, cada fruta tem um estrutura diferente, e resultados divergentes podem ser obtidos empregando outras frutas ou hortaliças.

- A migração interna de água, no decorrer do período de taxa decrescente, foi fundamentada na teoria difusional. Dada a importância da teoria capilar, maiores estudos poderiam ser realizados considerando esta teoria também. 
- Embora a secagem seja uma das tecnologias mais amplamente estudadas e uma das mais antigas, a combinação desta tecnologia convencional com as novas tecnologias de processamento de alimentos ou 'emerging technologies', como o ultrassom, resultou em vantagens na eficiência de secagem e no tempo total da operação. Outro estudos podem ser conduzidos com a combinação da secagem com outras tecnologias emergentes como secagem em campos elétricos pulsados ou secagem assistida com radio-frequência, entre outros 


\section{REFERÊNCIAS}

AGÊNCIA NACIONAL DE ENERGIA ELÉTRICA - ANEEL. Resolução Homologatória N ${ }^{\circ}$ 2.103 de 28 de Junho de 2016. Disponível em: http://biblioteca.aneel.gov.br/ Acesso em: 16 de Fevereiro, 2016.

ANTONIO, G.C. Avaliação do efeito dos pré-tratamentos de desidratação osmótica e secagem HTST na obtenção de snacks de batata doce (Ipomoea Batatas Lam). Tese (Doutorado em Engenharia de Alimentos). Faculdade de Engenharia de Alimentos, Universidade Estadual de Campinas (UNICAMP), Campinas (SP), 2006.

ASHOKKUMAR, M.; SUNARTIO, D.; KENTISH, S.; MAWSON, R.; SIMONS, L. VILKHU, K. Modification of food ingredients by ultrasound to improve functionality: A preliminary study on a model system. Innovative Food Science and Emerging Technologies, v.9, p. 155-160, 2008.

AZOUBEL, P. M.; MELO, B. M.; ROCHA, A. M.; SORELLY, B. O. Effect of ultrasound on banana cv. Pacovan drying kinetics. Journal of Food Engineering, v. 97, p. 194-198, 2010.

BERMÚDEZ-AGUIRRE, D.; MOBBS, T.; BARBOSA-CÁNOVAS, G. Capítulo 3: Ultrasound Applications in Food Processing. In: Ultrasound Technologies for Food and Bioprocessing - Food engineering serie. Eds. Hao Feng, Gustavo Barbosa-Canovas, Jochen Weiss, p. 65-105, 2011.

BERRY, C. Resistant Starch: Formation and measurement of starch that survives exhaustive digestion with amylolytic enzymes during the determination of dietary fiber. Journal of Cereal Science, v. 4(4), p. 301-304, 1986.

BEZERRA, C.V., AMANTE, E.R., OLIVEIRA, D.C., RODRIGUES A.M.C., SILVA, L.H.M. Green banana (Musa cavendishii) flour obtained in spouted bed - effects of drying on physicchemical, functional and morphological characteristics of the starch. Industrial Crops and Products v.41, p.241-249, 2013. 
BROD, F. P. Avaliação de um secador vibro-fluidizado. Tese (Doutorado em Engenharia Agrícola). Faculdade de Engenharia Agrícola, Universidade Estadual de Campinas (UNICAMP), Campinas (SP), 2003.

BOIRA, J. B.; STRINGARI, G. B.; LAURINDO, J. B. Estudo da desidratação de pêssegos por tratamento osmótico e secagem. Boletim do Centro de Pesquisa de Processamento de Alimentos (Curitiba), v. 25, n. 1, p. 77-90, 2007.

CÁRCEL, J.A. Influencia de los ultrasónidos de potência em procesos de transferencia de materia. Disertação, Universitat Politèctica de Valencia, Valencia (SP), 2003.

CÁRCEL, J.A., GARCÍA-PEREZ, J.V., BENEDITO, J., MULET, A. Food Process innovation through new technologies: Use of Ultrasound. Journal of Food Engineering, v. 110, p.200207, 2012.

CÁRCEL, J. A., GARCIA-PÉREZ, J. V., RIERA, E., ROSELlÓ, C., MULET, A. Drying assisted by Power Ultrasound, In: E. Tsotsas and A. S. Mujundar (Eds,). Modern drying technology- Process Intensification, 237-277, 2014.

CÁRCEL, J.A.; BENEDITO, J.; ROSELLÓ, C.; MULET, A. Influence of ultrasound intensity on mass transfer in apple immersed in a sucrose solution. Journal of Food Engineering, v. 78, p. 472-479, 2007.

CAVALLI, D. Pós-colheita na cultura da Banana (Casa do Produtor Rural - ESALQ/USP). Disponível em: http://www.clubeamigosdocampo.com.br/artigo/pos-colheita-na-cultura-dabanana-1350. Acessado em: 26 Janeiro, 2017.

CRANK, J. (1975). Diffusion in a plate sheet, En: E. House \& W. London (Eds), The mathematics of diffusion, 2nd Ed. (pp. 51-75). Uxbridge: Oxford University Press.

CUMMING, H.; ENGLYST, H. N. Fermentation in the human large intestine and the available substrates. American Journal of Clinical Nutrition, v. 45, p. 1243-1255, 1987.

DEMIREL, D.; TURHAN, M. Air-drying behavior of Dwarf Cavendish and Gros Michel banana slices. Journal of Food Engineering, v. 59, p. 1-11, 2003. 
DITCHFIELD, C.; TADINI; C. Acompanhamento do processo de amadurecimento da banana nanicão (Musa cavendishii Lamb). In XVIII Congresso Brasileiro de Ciência e tecnologia de Alimentos, 2002. Disponível em: http://sites.poli.usp.br/pqi/lea/docs/cbcta2002h.pdf Acesso em: 25 Maio,2015.

FAO. Food and Agriculture Organization, FAOSTAT, statistic database (2014), Disponível em: http://faostat.fao.org/. Acesso em: 30 abril, 2015.

FAO/WHO. FOODS AND AGRICULTURAL ORGANIZATION/WORLD HEALTH ORGANIZATION. Report of the $\mathbf{2 7}^{\text {th }}$ session of the Codex Committee on Nutrition and Foods for Special Dietary Uses. Bonn, Germany, 2006.

FERNANDES, F. A. N.; GALLÃO, M.I.; RODRIGUES, S. Effect of osmosis and ultrasound on pineapple cell tissue structure during dehydration. Journal of Food Engineering, v. 90, p. 186-190, 2009.

FERNANDES, F. A. N.; RODRIGUES, S. Ultrasound as pre-treatment for drying of fruits: Dehydration of banana. Journal of Food Engineering, v. 82, p. 261-267, 2007.

FERNANDES, F. A. N.; RODRIGUES, S.; GASPARETO, O. C. P.; OLIVEIRA, E. L.; Optimization of osmotic dehydration of bananas followed by air-drying. Journal of Food Engineering, v. 77, p. 188-193, 2006.

FITO, P. Modelling of vacum osmotic dehydration fruit. Journal of Food Engineering, v. 22, p. 313-328, 1994.

FUENTES-BLANCO, S.; SARABIA, E. R. F.; ACOSTA-APARICIO, V. M.; BLANCOBLANCO, A.; GALLEGO-JUÁREZ, J. A. Food drying process by power ultrasound. Ultrasonics v. 44, e. 523-527, 2006.

FUENTES-ZARAGOZA, E.; RIQUELME-NAVARRETE, M. J.; SÁNCHEZ-ZAPATA, E.; PÉREZ-ÁLVAREZ, J. A.Resistant starch as functional ingredient: a review. Food Research International, v. 43, p. 931-942, 2010.

HENDERSON, S.M., \& PABIS, S. Grain drying theory I: temperature effect on drying coefficient. Journal of Agricultural Engineering Research, v.6 (3), p.169-174, 1961. 
HUGH, Y., FREEDMAN, R.A., Ondas mecânicas. Em: Física Universitária - SEARS ZEMANSKY. 12 Ed. (p. 510 -584). Addison-Wesley.

IGBE. Instituto Brasileiro de Geografia e Estatística. Banco de dados agregados. Disponível em: http://www.ibge.gov.br/home/estatistica/populacao/estimativa2013/ Acceso em: 14 de outubro, 2016

ITO, A.; CAVENAGHI, M.; BERTOLDO, C.; PARK, K. J.; HUBINGER, M. Efeito pro processo de desidratação osmótica a pulso de vácuo na transferência de massa e nas propriedades reológicas e de cor de fatias de manga. Ciência e tecnologia de alimentos (Campinas), supl. 27, p. 54-63, 2007.

IZIDORO, D.R., SIERAKOWSKI, M.R., HAMINIUK, C.W.I., SOUZA, C.F., SCHEER, A.P. Physical and chemical properties of ultrasonically, spray-dried green banana (Musa Cavendish) starch, Journal of Food Engineering, v.104, 639-648, 2011.

JAMBRAK, A.R., HERCEG, Z., SUBARIC, D., BABIC, J., BRNCIC, M., BRNCIC, S.R., TOMISLAV, B., CVEK, D., TRIPALO, B., GELO, J. Ultrasound effect on physical properties of corn starch, Carbohydrate Polymers, v. 79, p. 91-100, 2010.

JAYA, S.; DAS, H. A vacuum drying model for mango pulp. Drying Technology, v. 21, n. 4, p. 1215-1234, 2003.

KARATHANOS, V. T.; VILlalobOS, G.; SARAVACOS, G.D. Comparison of Two Methods of Estimation of the Effective Moisture Diffusivity from Drying Data. Journal of Food Science, v. 55(1), p. 218-231, 1990.

KARIM, M.A.; HAWLADER, M.N.A. Drying characteristics of banana: theoretichal modelling and experimental validation. Journal of Food Engineering, v. 70, p. 35-45, 2005.

KENTISH S.; FENG, H. Applications of Power Ultrasound in Food Processing. Annual Review of Food Science and Technology, v.5, p. 263-284, 2014.

KEK, S. P.; CHIN, N. L.; YUSOF, Y. A. Direct and indirect power ultrasound assisted preosmotic treatments in convective drying of guava slices. Food and bioproducts processing, v. 91, p. 495-506, 2013.

KIKUCHI, T., UCHIDA, T. Calorimetric method for measuring high ultrasonic power using water as a heating material. Journal of Physics. v.279, 1-5, 2011. 
KIM, M. H.; TOLEDO, R. T. Effect of osmotic dehydration and high temperature fluidized bed drying on properties of dehydrated rabbiteye blueberries. Journal of Food Science, v. 52, n. 4, p. 980-984, 1987.

KNORR, D.; FROEHLING, A.; JAEGER, H.; REINEKE, K.; SCHLUETER, O.; SCHOESSLER, K. Emerging technologies in food processing. Annual Review Food Science Technology, v.2, p. 203-235, 2011.

LII, C.Y.; CHANG, S. M.; YOUNG, Y.L.; Investigation of the physical and chemical properties of banana starches. Journal of Food Science, v. 47, p. 1493-1497, 1982.

LIMA, L.P., FERNANDES, F.A.N., Avaliação do uso de ultrassom na produção de ácidos graxos via reação de saponificação seguida de hidrólise ácida. XX Congresso de Engenharia Química (COBEQ 2014), Florianópolis(SC), Brasil.

LIMA, A. A; NEBRA, S. A.; QUEIROZ, Z. M. R. Aspectos técnicos: Aspecto científico e tecnológico da banana. Revista Brasileira de Produtos Agroindustriais (Campina Grande), v. 2, n. 1, p. 87-101, 2000.

LINS EMERY. Princípios de Ultrassom. Disponível em: http://ebm.ufabc.edu.br/wpcontent/uploads/2013/11/Aula-07_Ultrassonografia.pdf Acesso em: 14 de outubro, 2016.

MACHADO, N. O Espectro Sonoro, Aulas de física e química. Disponível em: http://www.aulas-fisica-quimica.com/8f_07.html Acesso em: 14 outubro, 2016.

MASON, T.; RIERA, E.; VERCET, A.; LOPEZ-BUESA. P. Application of Ultrasound. Emerging technologies for food processing. In: D.W. Sun (Ed), p. 323-350, 2005.

McCLEMENTS, J. Advances in the application of ultrasound in food analysis and processing Advances in the application of ultrasound in food analysis and processing - A review. Trends in Food, Science and Technology. v.6, p.293-299, 1995.

MEDINA, V.; PEREIRA, M. Banana:Pós-colheita. Em EMBRAPA. Disponível em: http://www.agencia.cnptia.embrapa.br/Agencia40/AG01/Abertura.html. Acesso em: 30 abril, 2015. 
MENEZES, E. W. Bases científicas e práticas para disseminar a utilização de carboidratos não-disponíveis na alimentação. Texto crítico (Concurso livre-docência). Departamento de Alimentos e Nutrição Experimental da Faculdade de Ciências Farmacêuticas, Universidade de São Paulo, São Paulo (SP), 2008.

MERLIN, K. B. Estudo comparativo da impregnação a vácuo de maçã (var. Fuji), Pêra (var. d'água e d'anjou) e manga (var. Tommy Atkins). Dissertação (mestrado). Centro Tecnológico, Universidade Federal de Santa Catarina, Florianópolis (SC), 2007.

MESQUITA, C.B., LEONEL, M., FRANCO, C.M.L. Characterization of banana starches obtained from cultivars grown in Brazil, International Journal of Biological Macromolecules $89,632-639,2016$.

MIANO, A.C., IBARZ, A., AUGUSTO, P.E.D. Mechanisms for improving mass transfer in food with ultrasound technology: Describing the phenomena in two model. Ultrasonics Sonochemistry, v. 29, 413-419, 2016.

MIDILLI, A.; KUCUK, H.; YAPAR, Z. A new model for single-layer drying. Drying Technology: An International Journal, v. 20 (7), p. 1503-1513, 2002.

MUJUNDAR, A. S. Principles, Classification, and Selection of Dryers. In: MUJUNDAR, A. S. Handbook of Industrial Drying. $3^{\text {th }}$ Edition, CRC Press, 2006, p. 4-5.

NASCIMENTO, E., MULET, A., ASCHERI, J., CARVALHO, C., CÁRCEL, J.A. Effects of high-intensity ultrasound in drying kinetics and antioxidant properties of passion fruit peel, Journal of Food Engineering, v.170, p.108-118, 2016.

O’CALLAGHAN, J.R.; MENZIES, D.J.; BAILEY, P.H. Digital simulation of agricultural drier performance. Journal of Agricultural Engineering Research, v.16 (3), p. 223-244, 1971.

ORMENENSE RITA DE CÁSSIA. Obtenção de farinha de banana verde por diferentes processos de secagem e aplicação em produtos alimentícios. Tese (doutorado em Tecnologia de Alimentos). Faculdade de Engenharia de Alimentos, Universidade Estadual de Campinas (SP), 2010. 
PARK, K. J. Estudo comparativo do coeficiente de difusão sem e com encolhimento durante a secagem. Tese (Livre Docência em Fenômenos de Transporte). Departamento de Engenharia de Alimentos, Faculdade de Engenharia de Alimentos, Universidade Estadual de Campinas. Campinas, 1987.

PARK, K. J.; ANTONIO, G. C.; OLIVEIRA, R. A.; PARK, K. J. B. Conceito de processo e equipamentos de secagem. Campinas (SP), 2007. Disponível em: http://www.feagri.unicamp.br/ctea/projpesq.html. Acesso em: 30 abril, 2015.

PARK, K. J.; YADO, M. K. M.; BROD, F. P. R. Estudo de secagem de Pera Bartlett (Pyrus sp.). Ciência e tecnologia de alimentos (Campinas), v. 21, n. 3, p. 288-292, 2001.

PATERO, T.; AUGUSTO, P.E.D. Ultrasound (US) enhaces the hydration of sorghum (Sorghum bicolor). Ultrasonics Sonochemistry, v.23, p.11-15, 2015.

PERONI-OKITA, F.H.G.; CARDOSO, M.B.; AGOPIAN, R.P.L.; NASCIMENTO, J.R.O.; PURGATTO, E.; TAVARES, M.I.B.; LAJOLO M.F.; CORDENUNSI, B.R. The cold storage of green bananas affects the starch degradation during ripening at higher temperatures. Carbohydrate Polymers. v. 96, p. 137-1147, 2013.

PERONI, F., SIMÃO, R., CARDOSO, M.; SOARES, C.; LAJOLO A, F.; CORDENUNSI, B. In vivo degradation of banana starch: Structural characterization of the degradation process. Carbohydrate Polymers. v. 81, p. 291-299, 2010.

POLESI, L. F. Amido Resistente: aplicações e métodos de produção. Boletim do Centro de Pesquisa de Processamento de Alimentos (Curitiba), v. 29, n. 2, p. 211-222, 2011.

PORCIUNCULA, B. D. Desenvolvimento de processo integrado de desidratação e modificação da textura de banana (var. Prata) por secagem convectiva e pulsos de vácuo. Dissertação (mestrado). Centro Tecnológico, Universidade Federal de Santa Catarina, Florianópolis (SC), 2010.

PORCIUNCULA, B. D. Controle da microestrutura e textura na desidratação de banana usando ciclos de aquecimento - pulso de vácuo. Tese (doutorado). Centro Tecnológico, Universidade Federal de Santa Catarina, Florianópolis (SC), 2014. 
PUHL, J.; NITZKE, J. A. Secagem a vácuo: Alimentus. Disponível em: http://www.ufrgs.br/alimentus1/objetos/veg_desidratados/b_vacuo.html Acesso em: 30 abril, 2015.

RAYO, L.M. Processo de aglomeração de farinha de banana verde com alto conteúdo de amido resistente em leito fluidizado pulsado. Dissertação (mestrado em Engenharia Química). Escola Politécnica, Universidade de São Paulo, São Paulo (SP), 2013.

RAYO, L. M., CHAGURI CARVALHO, L., SARD, F.A.H., DACANAL, G. C., MENEZES, E.W., TADINI, C.C. Production of instant green banana flour (Musa cavendishii, var. Nanicão) by a pulsed-fluidized bed agglomeration, LWT - Food Science and Technology, v.63, p. 461$469,2015$.

RICCE, C., ROJAS, M.L., MIANO, A.C., SICHE, R., AUGUSTO, P.E.D. Ultrasound Pretreatment enhances the carrot drying and rehydration, Food Research International, v. 89, p. 701-708, 2016.

RODRIGUES, S.; FERNANDES, F.A.N. Ultrasound in fruit processing. New Food Engineering Research Trends, p.103-135, 2008.

RODRÍGUES, O., SANTACATALINA, J.V., SIMAL, S., GARCIA-PEREZ, J.V., FEMENIA, A., ROSELLÓ. C. Influence of power ultrasound application on drying kinetics of apple and its antioxidant and microstructural properties, Journal of Food Engineering, v. 129, p.21-29, 2014.

SANTOS, J. Avaliação das propriedades nutricionais de barra de cereais elaboradas com farinha de banana verde. Dissertação (mestrado). Faculdade de Ciências Farmacêuticas, Universidade de São Paulo, São Paulo (SP), 2010.

SCHÖSSLER, K.; JÄGER, H.; KNORR, D. Effect of continuous and intermittent ultrasound on drying time and effective diffusivity during convective drying of apple and red bell pepper. Journal of Food Engineering, v.108, p.103-110, 2012a.

SCHÖSSLER, K., THOMAS, T., \& KNORR, D. Modification of cell structure and mass transfer in potato tissue by contact ultrasound. Food Research International, v.49, p. 425-431 2012b. 
SEBRAE. Serviço Brasileiro de Apoio às Micro e Pequenas Empresas. Estudos de Mercado: Banana. Disponível em:

http://www.bibliotecas.sebrae.com.br/chronus/ARQUIVOS_CHRONUS/bds/bds.nsf/8E2336 FF6093AD96832574DC0045023C/\$File/NT0003904A.pdf. Acessado em: 05 de outubro, 2016.

SESHADRI, R.; WEISS, J.; HULBERT, G. J.; MOUNT, J. Ultrasonic processing influences rheological and optical properties of high methoxyl pectin dispersions. Food Hydrocolloids, v.17, p. 191-197, 2003.

SILVA, S. P.; TASSARA, H. Frutas no Brasil: Banana. Dados internacionais da Catalogação na Publicação (CIP), 4 ed. Câmara Brasileira do Livro, São Paulo (SP), 2001, p. 41-43.

SILVA, L. C. Efeito da desidratação osmótica assistida por ultrassom no processo de secagem convectiva de abacaxi pérola. Dissertação (mestrado). Departamento de Engenharia Química, Universidade Federal do Ceará, Fortaleza (CE), 2012.

SILVA, S. O.; SANTOS-SEREJO, J.A., CORDEIRO, Z.J.M. Em agência de informação EMBRAPA. Banana: Variedades. Disponível em:

http://www.agencia.cnptia.embrapa.br/recursos/Livro_Banana_Cap_4ID-F7QzQ9c5WB.pdf. Acesso em:05 de outubro, 2016

SOKHANSANJ, S.; JAYAS, D.S. Drying of Foodstuffs. In: MUJUNDAR, A. S. Handbook of Industrial Drying. $3^{\text {th }}$ Edition, CRC Press, 2006, p. 522-545.

SORIA, A. C.; VILLAMIEL, M. Effect of ultrasound on the technological properties and bioactivity of food: a review. Trends in Food Science \& Technology, v. 21, p. 323-331, 2010.

SOUSA, P. H. Desidratação osmótica de banana com e sem vácuo com complemento de secagem em estufa de circulação de ar. Dissertação (mestrado). Departamento de Tecnologia de alimentos, Universidade Federal do Ceará, Fortaleza (CE), 2002.

SOUSA, P. H.; MAIA, G. A.; SOUZA FILHO, M.; FIGUEIREDO, R. W.; NASSU, R. T.; SOUZA NETO, M. A. Influência da concentração e da proporção fruto: xarope na desidratação osmótica de bananas processadas. Ciência e tecnologia de alimentos (Campinas), supl. 23, n. 3, p. 126-130, 2003. 
TRIBESS, T. Processo de obtenção de farinha de banana verde com alto conteúdo de amido resistente. Tese (doutorado em Engenharia Química). Escola Politécnica, Universidade de São Paulo, São Paulo (SP), 2009.

TRIBESS, T. B.; HERNANDÉZ-URIBE, J. P.; MÉNDEZ-MONTEALVO, M. G.; MENEZES, E. W.; BELLO-PEREZ, L. A.; TADINI, C. C. Thermal properties and resistant starch content of Green banana flour (Musa Cavendishii) produced at different conditions. LWT-Food Science and Technology, v. 42, p. 1022-1025, 2009.

VINATORU, M. Ultrasonically assisted extraction (UAE) of natural products some guidelines for good practice and reporting. Ultrasonics Sonochemistry. v. 25, p. 94-95, 2015.

WITROWA-RAJCHERT, D., WIKTOR, A., SLEDZ, M., NOWACKA, M. Selected emerging technologies to enhance the drying process: A review. Drying Technology, v. 32, p.13861396, 2014.

YALDIZ, O.; ERTEKIN, C.; UZUN, H.I. Mathematical modeling of thin layer solar drying of sultana grapes. Energy, v.26 (5), p. 457-465, 2001.

YILDIRIM, A., DURDU, O.M., BAYRAM, M. Fitting Fick's model to analyze water diffusion into chickpeas during soaking with ultrasound treatment. Journal of Food Engineering, v.104 (1), p.134-142, 2011.

ZABALAGA, R. Mathematical modeling of drying process of unripe banana slices. Tese (Doutorado em Engenharia Química). Escola Politécnica, Universidade de São Paulo, São Paulo (SP), 2016.

ZABALAGA, R. F., LA FUENTE, C. I. A., TADINI, C. C. Experimental determination of thermophysical properties of unripe banana slices (Musa cavendishii) during convective drying. Journal of Food Engineering, 187, 62-69, 2016.

ZENEBON, O.; PASCUET, N.S.; TIGLEA, P. Métodos fisico-químicos para análises de alimentos, $4^{\mathrm{a}}$ Ed., Instituto Adolfo Lutz, São Paulo, 2008.

ZHANG, Q.; LITCHFIELD, J.B. An optimization of intermittent corn drying in a laboratory scale thin layer dryer. Drying Technology: An International Journal, v.9 (2), p. 383-395, 1991. 
ZHENG, L.; SUN, D.W. Innovative applications of power ultrasound during foo freezing processes - A review. Trends in Food Science and Technology, v.17, p. 16-23, 2006. 


\section{ANEXO A}

Curvas de secagem a (50 e 60) ${ }^{\circ} \mathrm{C}$, obtidas no processo de secagem em estufa, para rodelas de banana verde, imersas por $10 \mathrm{~min}$ no banho ultrassônico de potência volumétrica 9,38 W/L

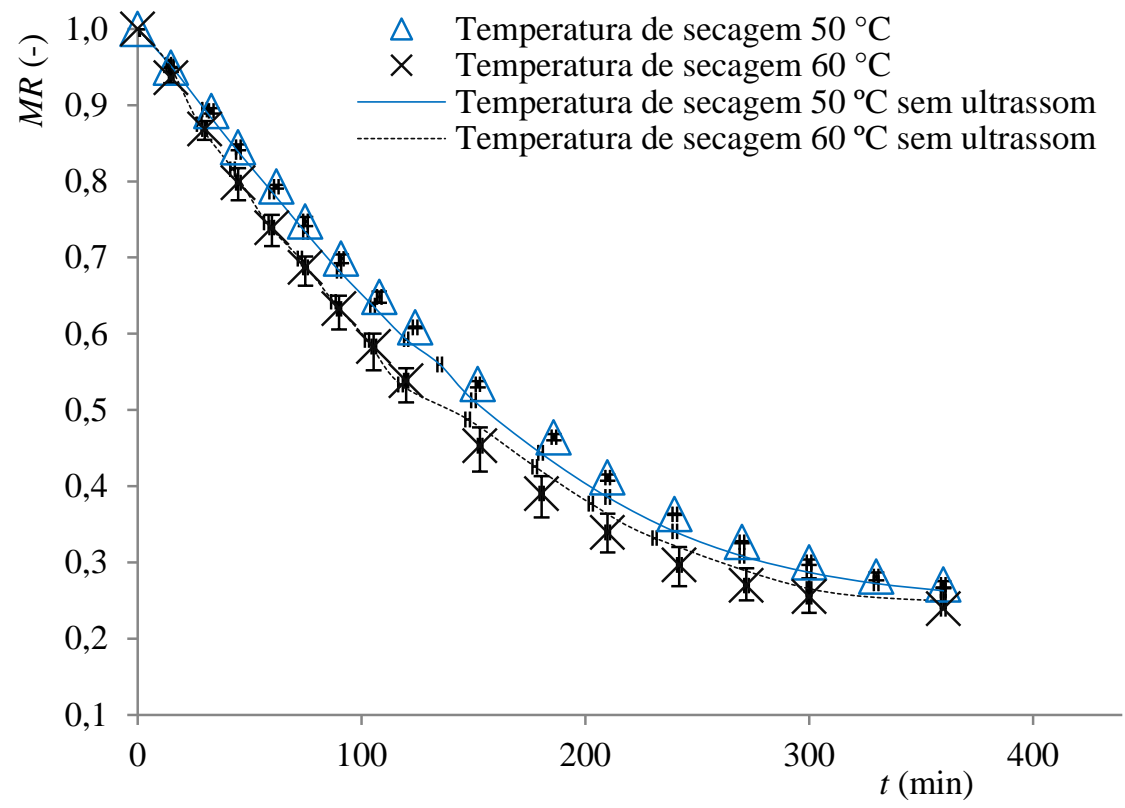

Fonte: O próprio autor.

Curvas de secagem a $(50$ e 60$){ }^{\circ} \mathrm{C}$, obtidas no processo de secagem em estufa, para rodelas de banana verde, imersas por $15 \mathrm{~min}$ no banho ultrassônico de potência volumétrica $9,38 \mathrm{~W} / \mathrm{L}$

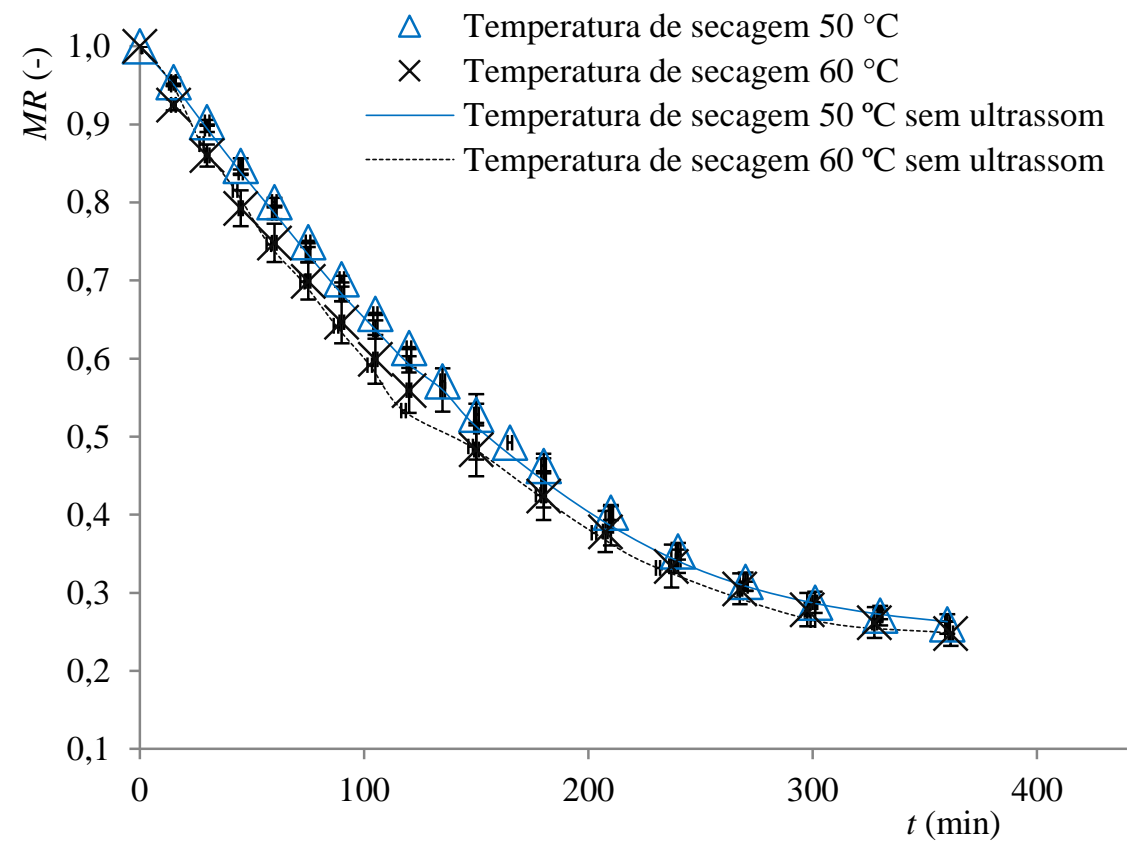

Fonte: O próprio autor. 
Curvas de secagem a $(50$ e 60$){ }^{\circ} \mathrm{C}$, obtidas no processo de secagem em estufa, para rodelas de banana verde, imersas por 20 min no banho ultrassônico de potência volumétrica $9,38 \mathrm{~W} / \mathrm{L}$

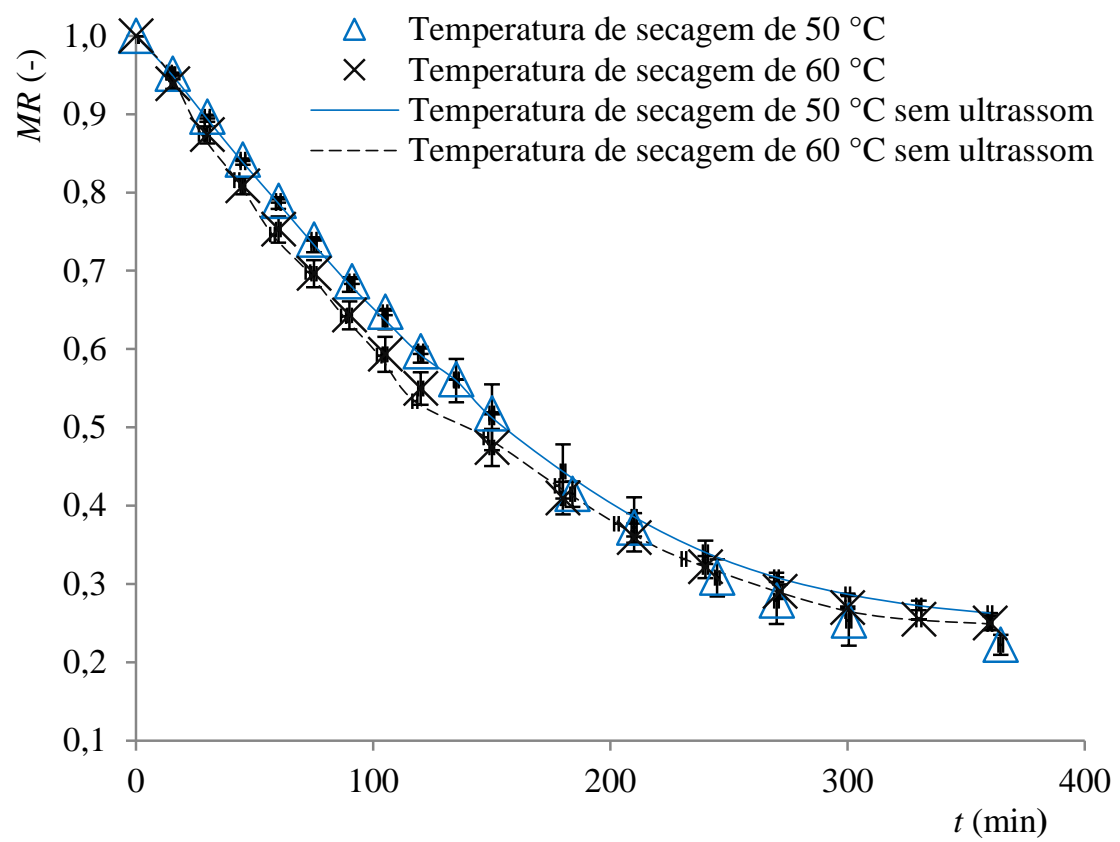

Fonte: O próprio autor.

Curvas de secagem a $(50 \text { e } 60)^{\circ} \mathrm{C}$, obtidas no processo de secagem em estufa, para rodelas de banana verde, imersas por 25 min no banho ultrassônico de potência volumétrica $9,38 \mathrm{~W} / \mathrm{L}$

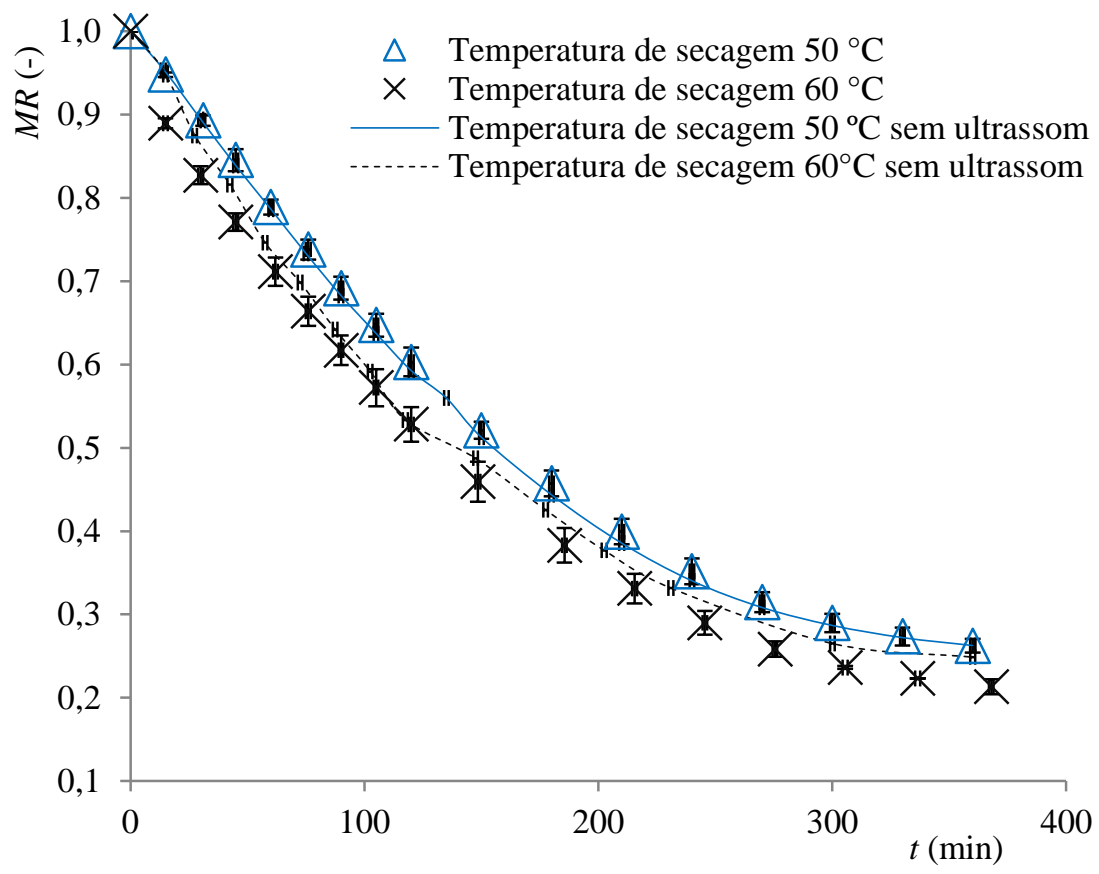

Fonte: O próprio autor. 


\section{ANEXO B}

Curvas de secagem a $50{ }^{\circ} \mathrm{C}$, obtidas no processo de secagem em estufa, para rodelas de banana verde, imersas por 20 min no banho ultrassônico de potência volumétrica $(9,38$ e 25,63$) \mathrm{W} / \mathrm{L}$

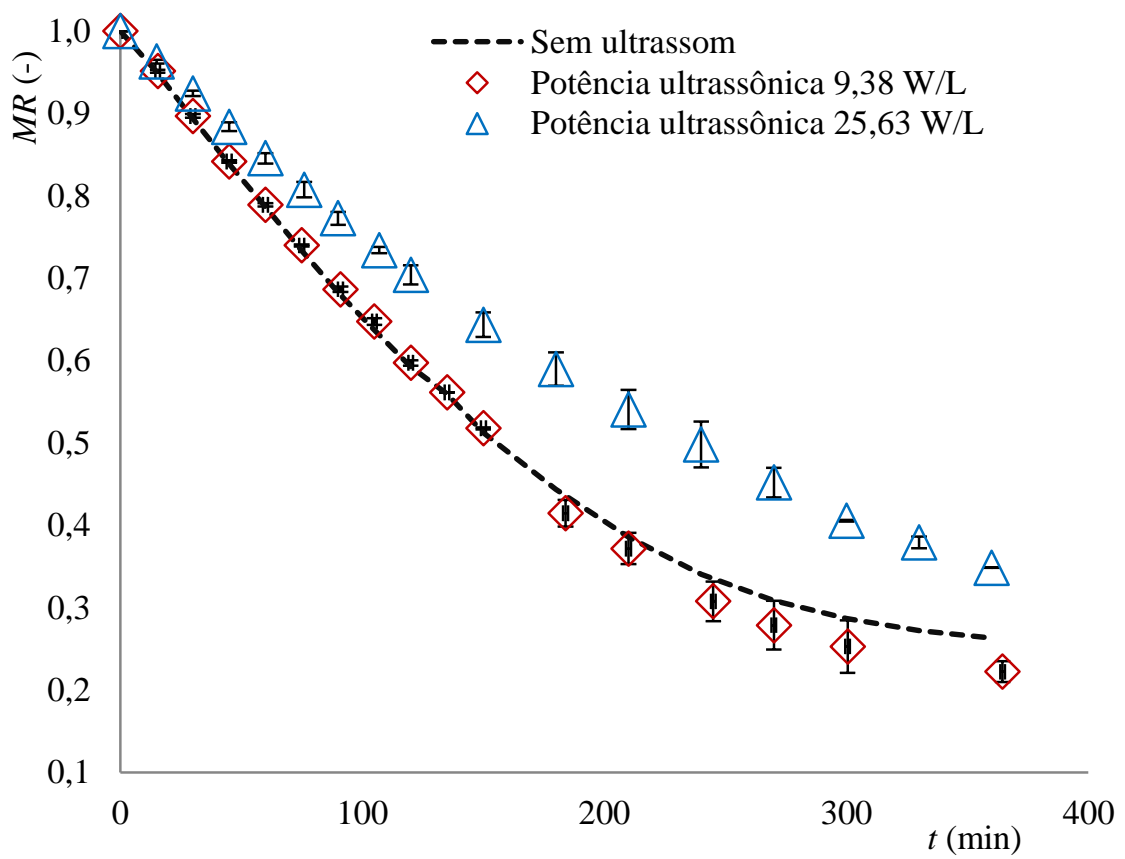

Fonte: O próprio autor.

Curvas de secagem a $60{ }^{\circ} \mathrm{C}$, obtidas no processo de secagem em estufa, para rodelas de banana verde, imersas por 20 min no banho ultrassônico de potência volumétrica $(9,38$ e 25,63$) \mathrm{W} / \mathrm{L}$

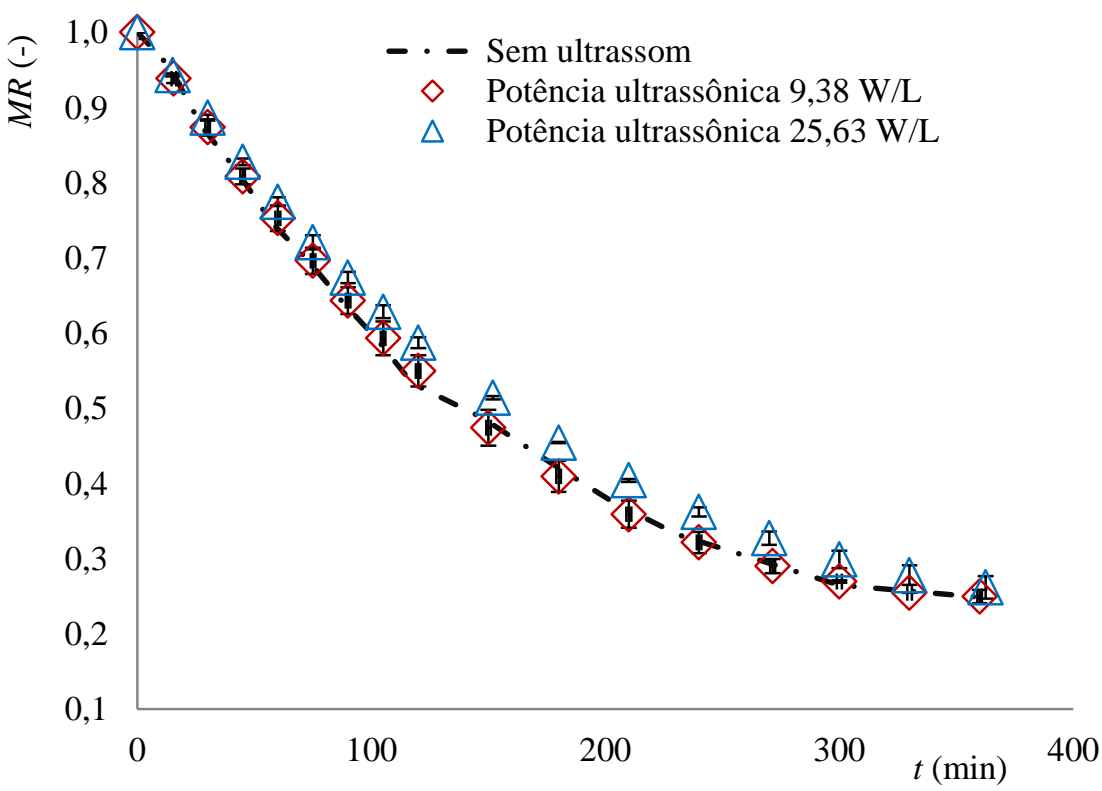

Fonte: O próprio autor. 
Curvas de secagem a $50{ }^{\circ} \mathrm{C}$, obtidas no processo de secagem em estufa, para rodelas de banana verde, imersas por 25 min no banho ultrassônico de potência volumétrica $(9,38$ e 25,63$) \mathrm{W} / \mathrm{L}$

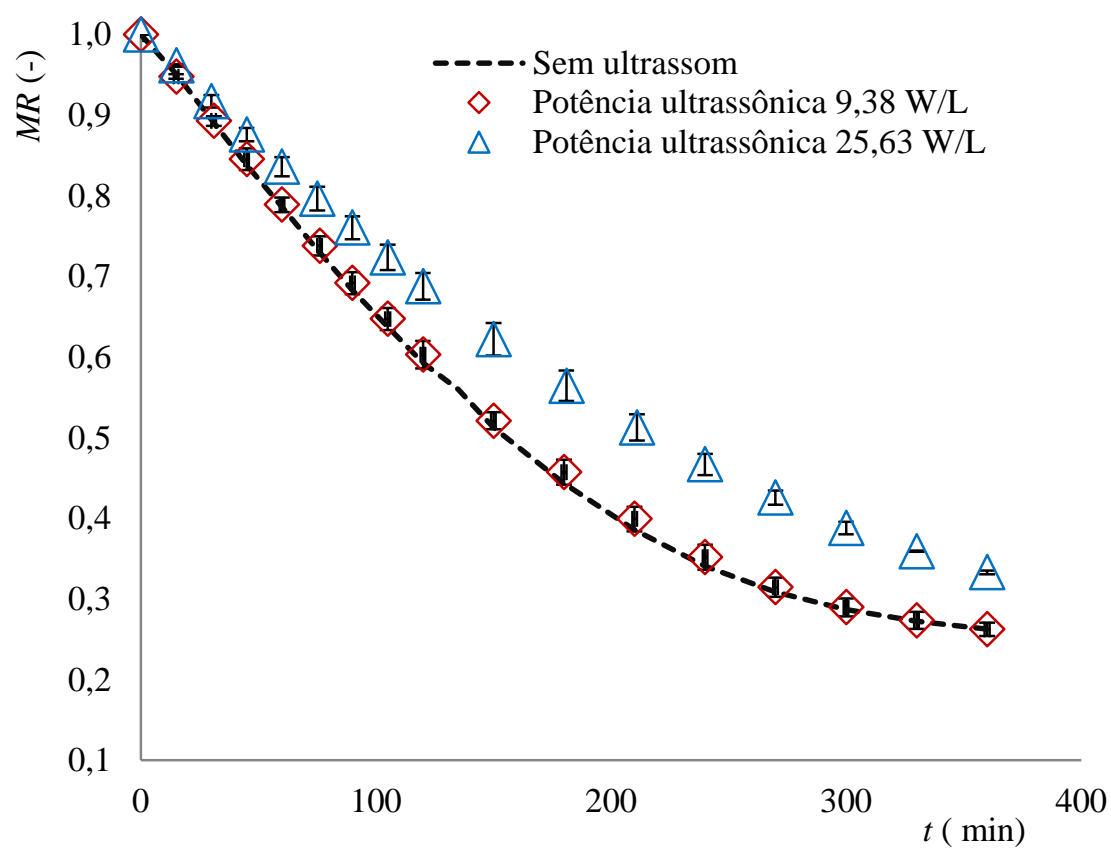

Fonte: O próprio autor.

Curvas de secagem a $60{ }^{\circ} \mathrm{C}$, obtidas no processo de secagem em estufa, para rodelas de banana verde, imersas por 25 min no banho ultrassônico de potência volumétrica $(9,38$ e 25,63$) \mathrm{W} / \mathrm{L}$

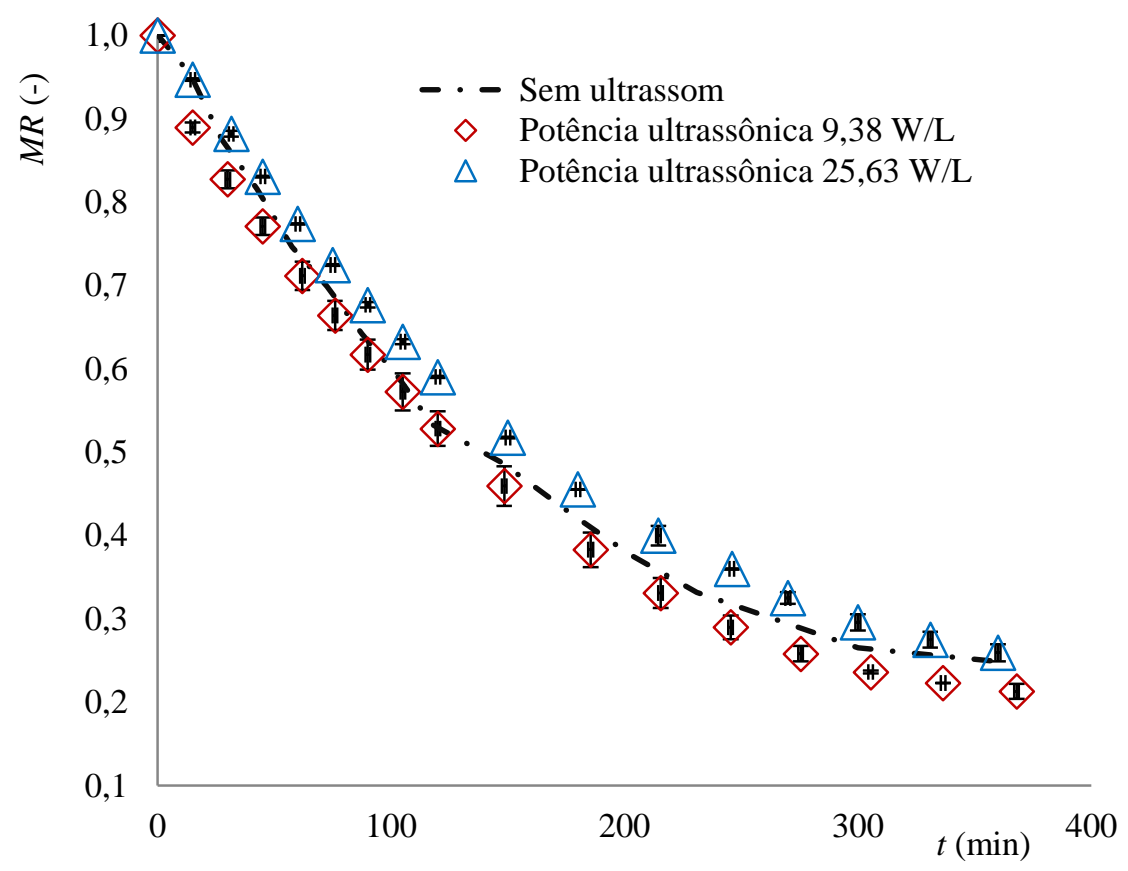

Fonte: O próprio autor. 